\title{
New postcranial bones of the extinct mammalian family Nyctitheriidae (Paleogene, UK): Primitive euarchontans with scansorial locomotion
}

\author{
Jerry J. Hooker
}

\begin{abstract}
New postcranial bones from the Late Eocene and earliest Oligocene of the Hampshire Basin, UK, are identified as belonging to the extinct family Nyctitheriidae. Previously, astragali and calcanea were the only elements apart from teeth and jaws to be unequivocally recognized. Now, humeri, radii, a metacarpal, femora, distal tibiae, naviculars, cuboids, an ectocuneiform, metatarsals and phalanges, together with additional astragali and calcanea, have been collected. These are shown to belong to a diversity of nyctithere taxa previously named from dental remains. Functional analysis shows that nyctitheres had mobile shoulder and hip joints, could pronate and supinate the radius, partially invert the foot at the astragalocalcaneal and upper ankle joints using powerful flexor muscles, all indicative of a scansorial lifestyle and allowing headfirst descent on vertical surfaces. Climbing appears to have been dominated by flexion of the forearms and feet. Cladistic analysis employing a range of primitive eutherian mammals shows that nyctitheres are stem euarchontans, rather than lipotyphlans, with which they had previously been classified based on dental characters. Earlier ideas of relationships with the extinct Adapisoriculidae, recently considered stem eutherians, are not upheld.
\end{abstract}

Jerry J. Hooker. Department of Earth Sciences, Natural History Museum, Cromwell Road, London SW7 5BD, UK. j.hooker@nhm.ac.uk

Keywords: Eutheria; Lipotyphla; placental; Scandentia; shrews; Soricidae

\section{INTRODUCTION}

Nyctitherium Marsh, 1872, the type genus of the eutherian family Nyctitheriidae Simpson, 1928a was first classified as a bat (Marsh, 1872). Matthew (1909) instead referred Nyctitherium to the Talpidae (moles), but later (Matthew, 1918), on the basis of some straight slender limb bone shafts, apparently associated with teeth (on which this genus was based), returned to Marsh's original idea that Nyctitherium was a chiropteran. Simpson (1937) considered the family Nyctitheriidae to belong to an undifferentiated group from which moles and shrews alone or moles, shrews and bats 
arose. The family was included in the lipotyphlan superfamily Soricoidea in his mammal classification (Simpson, 1945). A few years earlier, Stehlin (1941) had classified his new genus Saturninia as a primitive member of the family Soricidae (shrews). Robinson (1968) revised the family Nyctitheriidae and his nominate subfamily essentially corresponds to our current understanding of the scope of the family (McKenna and Bell, 1997), where Saturninia is included. Cray (1973) described the genus Scraeva from the British Late Eocene. Sigé (1976) revised mainly French nyctitheres and included the genera Amphidozotherium Filhol, 1876 and Darbonetus Crochet, 1974, which Crochet (1974) had placed in the superfamily Erinaceoidea incertae sedis; however, Sigé transferred the entire family to the Erinaceomorpha. Butler (1988), in his revision of the Lipotyphla, regarded the Nyctitheriidae as primitive soricomorphs, but McKenna and Bell (1997) returned the family to the Soricoidea. Genus-rank revision has taken place (Hooker and Weidmann, 2000) and additional European taxa have been described (Smith, 2004, 2006a, 2006b; Ziegler, 2007), although some issues remain (Hooker, 2010).

All these classificatory changes were based on dentitions, although indeterminate bones were sometimes found associated with them. However, Gingerich (1987) referred an isolated proximal metatarsal IV to his new nyctithere species Leptacodon rosei and suggested a saltatorial locomotor mode for it. The first characterful postcranial bones to be found were isolated astragali and calcanea from early Late Eocene strata of the Hampshire Basin, UK (Hooker, 2001). These showed no close resemblance to lipotyphlan ankle bones and that nyctitheres were capable of foot inversion at the astragalocalcaneal joint, thus likely to have been scansorial. Cladistic analysis placed them as stem members of Euarchonta. The correct attribution of these isolated tarsals to the Nyctitheriidae was confirmed (Manz et al., 2010) when associated skeletal remains of Leptacodon were found in Late Paleocene strata of Wyoming, USA (Bloch and Boyer, 2001; Manz and Bloch, 2011). More recently an isolated calcaneum from the earliest Eocene of Dormaal, Belgium, has been attributed to Leptacodon dormaalensis (Quinet) by Coillot et al. (2013).

Further collecting in particular Hampshire Basin Late Eocene and earliest Oligocene Solent Group localities, where bone preservation is best, has yielded more isolated skeletal elements attributable to nyctitheres, which are described here.
Familial attribution is accomplished either by direct articulation via the astragali and calcanea already described or by eliminating other candidates of similar size as in the original study (Hooker, 2001) or both. As the relevant strata have been intensively screenwashed through $0.5 \mathrm{~mm}$ sieves, collecting bias has been effectively eliminated, except for sub- $0.5 \mathrm{~mm}$ bones or fragments. The only nonnyctitheriid taxa in the Solent Group known from dentitions, which overlap in size with nyctitheres are: the pseudosciurid rodents Suevosciurus bosmae Hooker, 1991 and Treposciurus gardneri Hooker, 1991; glirid rodents; the talpid Eotalpa anglica Sigé et al., 1977; the apatemyid Heterohyus nanus Teilhard de Chardin, 1922; the omomyid primate Pseudoloris parvulus (Filhol, 1890); and herpetotheriid marsupials (Table 1). Only the glirids and herpetotheriids show taxonomic diversity for size comparable with nyctithere diversity, within nyctithere size constraints. Importantly, the only apatemyid found in the Mammal Bed, Hordle, is an unnamed species of Heterohyus much larger than any nyctithere (Cray, 1973). This site has provided some of the best preserved nyctithere material. Postcranial elements of some of these nonnyctitheriid taxa have been found in the Solent Group, although have yet to be described, whilst those of some close relatives have been described elsewhere, including from articulated skeletons at such sites as Messel and Green River (e.g., Koenigswald, 1990; Koenigswald et al., 2005). By these means of elimination, postcranials from particular sites and levels can be referred in many cases not just to the family Nyctitheriidae, but also to particular genera or species, where these are documented by dentitions (Table 1). Images are shown at a magnification of 20 times (except for the reconstructed ankle illustration) to demonstrate the taxonomic attributions based on size.

\section{Anatomical Abbreviations}

af, astragalar facet; aitfl, scar for attachment of anterior inferior tibiofibular ligament; ap, anterior projection; at, anterior tubercle; bg, bicipital groove; bt, bicipital tuberosity; caf, calcaneal facet; ce, capitular eminence; ct, capitular tail; cuf, cuboid facet; def, dorsoepitrochlear fossa; dpc, deltopectoral crest; dpt, distal plantar tubercle; dsuf, distal sustentacular facet; ect, ectocuneiform facet; ef, ectal facet; eomp, groove for extensor ossis metacarpi pollicis muscle; fdf, groove for flexor digitorum fibularis tendon; fdt, groove for flexor digitorum tibialis tendon; ff, fibular facet; fht, facet for humeral trochlea; ftl, fovea for teres ligament; gtr, greater 
TABLE 1. Occurrences of nyctitheriid and equivalent-sized non-nyctitheriid taxa, mostly known dentally, in the levels and localities from which postcranials are described herein. The Hamstead Member (earliest Oligocene) belongs to the Bouldnor Formation, the rest to the Headon Hill Formation (Late Eocene). The levels at Hordle and Headon Hill are in the Totland Bay Member. These records update Hooker $(1987,2010)$ and Hooker et al. (2005), where details of the stratigraphy can be found. 1, C. beata Crochet, 1974, previously recorded, is indistinguishable from C. woodi. 2, Based tentatively only on an ulna.

\begin{tabular}{|c|c|c|c|c|c|}
\hline & $\begin{array}{c}\text { Mammal Bed, } \\
\text { Hordle }\end{array}$ & $\begin{array}{l}\text { Rodent Bed, } \\
\text { Hordle }\end{array}$ & $\begin{array}{c}\text { How Ledge } \\
\text { Limestone, Headon } \\
\text { Hill }\end{array}$ & $\begin{array}{l}\text { Fishbourne } \\
\text { Member, } \\
\text { Woodside }\end{array}$ & $\begin{array}{l}\text { L. Hamstead } \\
\text { Member, } \\
\text { Bouldnor }\end{array}$ \\
\hline \multicolumn{6}{|l|}{ Nyctitheriidae } \\
\hline Cryptotopos woodi ${ }^{1}$ & $x$ & $x$ & $x$ & & \\
\hline Scraeva hatherwoodensis & $x$ & & & $x$ & \\
\hline Paradoxonycteris tobieni & & & & & $x$ \\
\hline Paradoxonycteris sp. 1 & & $x$ & $x$ & & \\
\hline Paradoxonycteris sp. 2 & & & & & $x$ \\
\hline Amphidozotherium spp. & & & & $x$ & $x$ \\
\hline Euronyctia grisollensis & $x$ & & $x$ & & \\
\hline Saturninia gracilis & $x$ & $x$ & $x$ & & $x$ \\
\hline \multicolumn{6}{|l|}{ Other nyctithere-sized taxa } \\
\hline Suevosciurus bosmae & $x$ & $x$ & $x$ & & \\
\hline Treposciurus gardneri & $x$ & & $x$ & & \\
\hline Glamys priscus & $x$ & $x$ & $x$ & & \\
\hline G. fordi & & & & & $x$ \\
\hline Gliravus daamsi and aff. & $x$ & & $x$ & & \\
\hline Bransatoglis bahloi & & & $x$ & & \\
\hline B. planus & & & & & $x$ \\
\hline Miniglis minor & & $x$ & $x$ & & \\
\hline Eotalpa anglica & $x$ & & $x$ & & $x^{2}$ \\
\hline Heterohyus nanus & & & $x$ & & \\
\hline Pseudoloris parvulus & $x$ & $x$ & $x$ & & \\
\hline Amphiperatherium spp. & $x$ & $x$ & $x$ & $x$ & $x$ \\
\hline Peratherium cuvieri & & & $x$ & & \\
\hline
\end{tabular}

trochanter; gtu, greater tuberosity; ig, intercondylar groove; III, facet for metatarsal III; itc, intertrochanteric crest; IV, facet for metatarsal IV; Itr, lesser trochanter; Itu, lesser tuberosity; me, medial epicondyle; mes, mesocuneiform facet; $\mathrm{mm}$, medial malleolus; mmt, facet for medial malleolus of tibia; navf, navicular facet; of, olecranon fossa; os, oblique shelf; pep, peroneal process; plp, plan- tar process; pop, posterior protuberance; sc, supinator crest; sf, syndesmosis with fibula; sqf, squatting facet; suf, sustentacular facet; tp, groove for tibialis posterior tendon; ttm, tubercle for teres major muscle; ttr, third trochanter; tu, tuber; uf, ulnar facet; $V$, facet for metatarsal V; vmt, ventral margin of trochlea. 


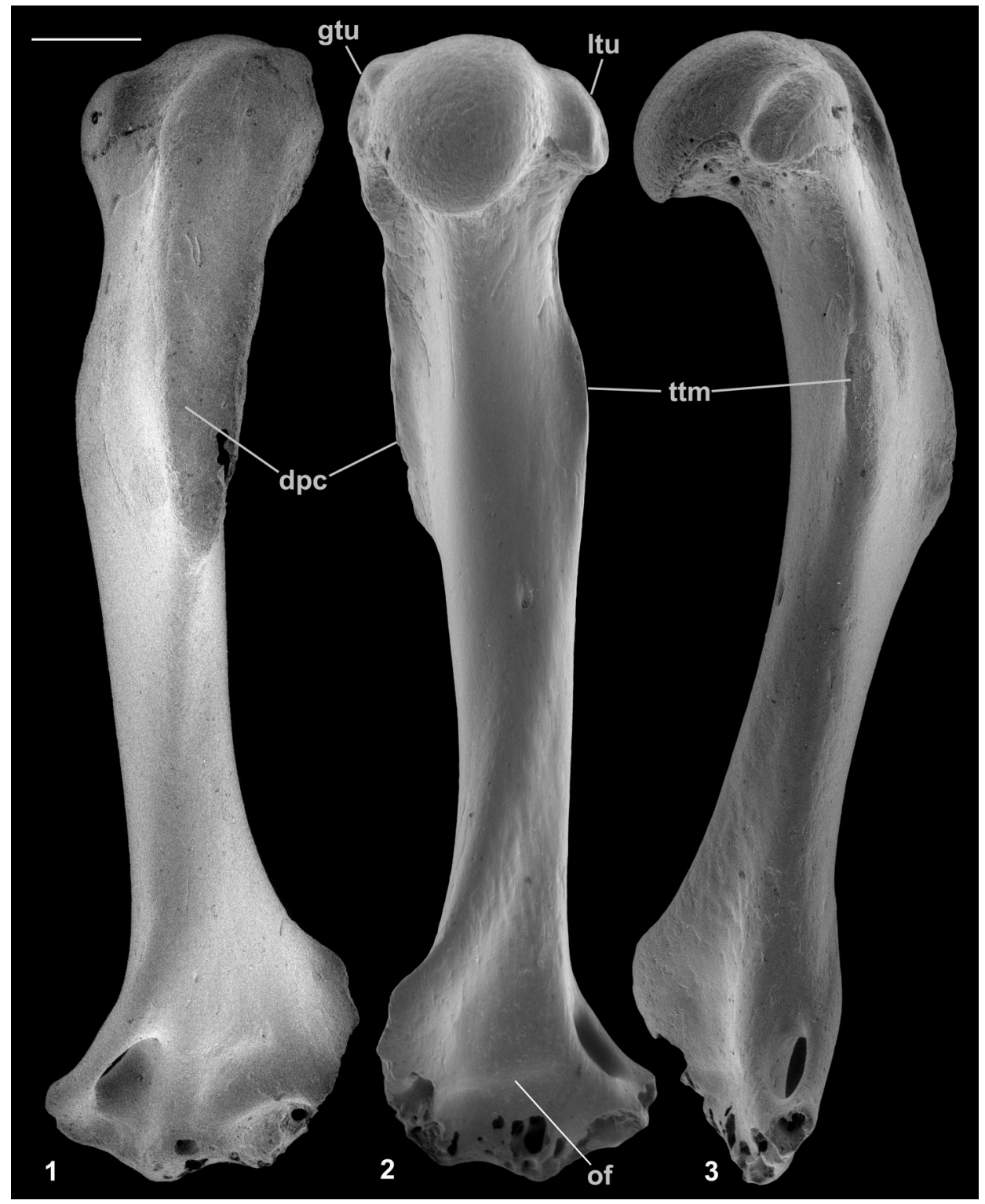

FIGURE 1. Scanning electron micrographs of right humerus (reversed) type 1 (Scraeva hatherwoodensis), M61009, Mammal Bed Hordle, Hampshire, in anterior (1), posterior (2) and medial (3) views. Scale bar equals $1 \mathrm{~mm}$.

\section{Institutional Abbreviations}

HZM, Harrison Institute, Sevenoaks, Kent; MNHN, Muséum National d'Histoire Naturelle, Paris; NHMUK, Natural History Museum, London. Specimens in the last are in the Earth Sciences Department, Vertebrates Division, which take the prefix $\mathrm{PV}$ and are further prefixed $\mathrm{M}$ or OR. Where Mprefixed numbers are quoted (the majority), the NHMUK.PV part of the prefix is omitted to save space.

\section{DESCRIPTIONS AND FUNCTIONAL INTERPRETATIONS}

\section{Humerus}

Material of humerus type 1. Right humerus, M61009; Mammal Bed, Hordle.

Description. An entire humerus with a damaged distal articulation is $10.38 \mathrm{~mm}$ long. It has a shaft whose proximal half is bowed anteriorly (Figure 1.3). The head articulation is nearly spherical, apart from a slightly angled medial edge, and spans nearly a hemisphere (Figures 1.2, 1.3, 2.1). It overhangs posteriorly and faces posteroproxi- 


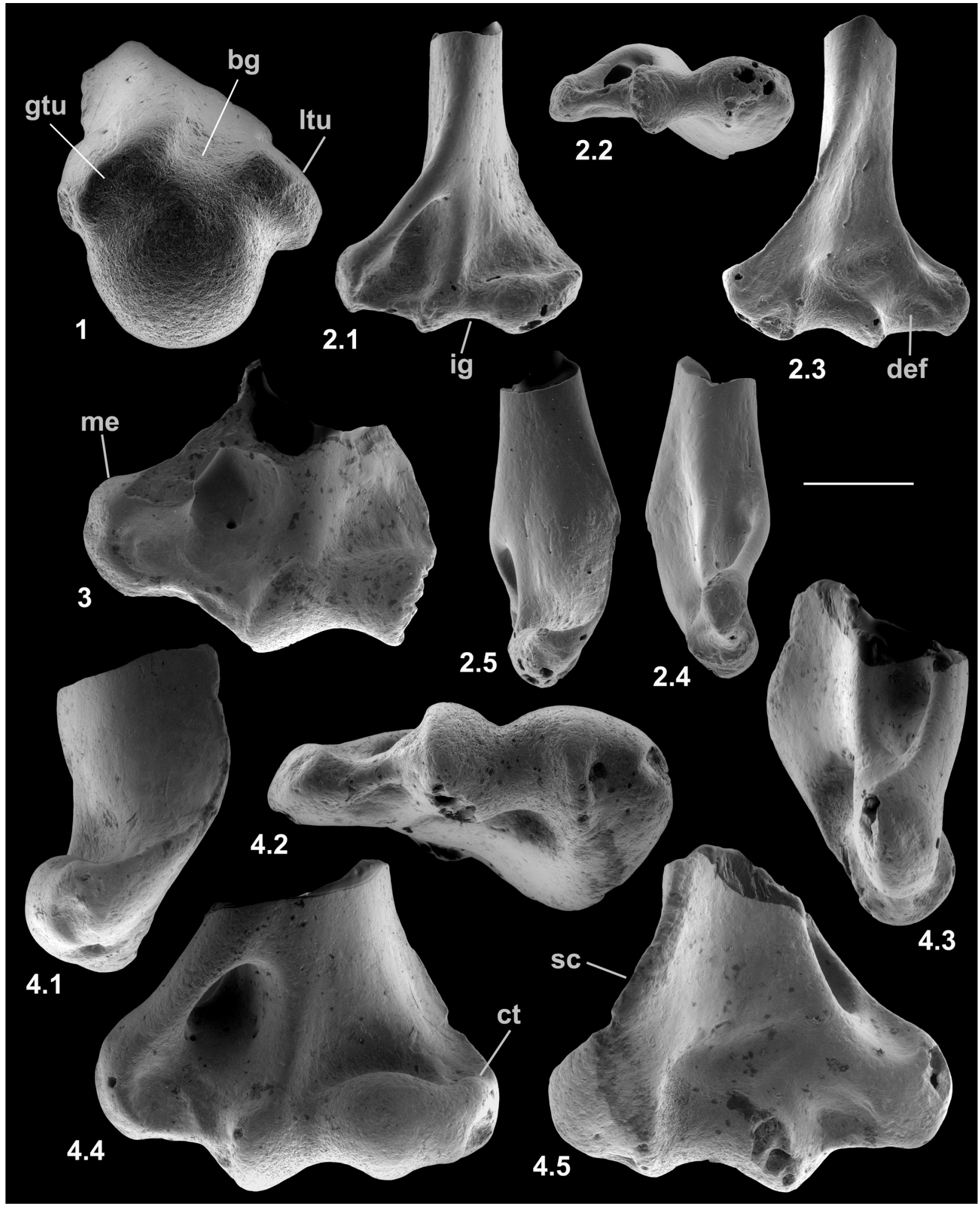

FIGURE 2. Scanning electron micrographs of humeri of Nyctitheriidae. 1, right humerus (reversed) type 1 (Scraeva hatherwoodensis), M61009; 2, distal left humerus type 2 (Euronyctia grisollensis), M60810; 3, distal right humerus (reversed) type 4 (Paradoxonycteris sp. 1?), M61422; 4, distal right humerus (reversed) type 3 (Cryptotopos woodi), M95898. 'Views are proximal (1), anterior $(2.1,3,4.4)$, distal $(2.2,4.2)$, posterior $(2.3,4.5)$, medial $(2.4,4.3)$ and lateral $(\mathbf{2 . 5}, \mathbf{4 . 1}) .3$ is from the How Ledge Limestone, Headon Hill, Isle of Wight, the rest are from the Mammal Bed, Hordle, Hampshire. Scale bar equals $1 \mathrm{~mm}$. 
mally with respect to the main axis of the shaft. The head extends slightly proximally of the greater and lesser tuberosities. The lesser tuberosity extends less proximally than the greater tuberosity and projects medially. The bicipital groove is shallow and wide with a slight overhang from the greater tuberosity. There is a broad, strong deltopectoral crest with an angular distal extremity (Figure 1.1, 1.3). It is situated on the lateral half of the anterior surface of the shaft, overhanging its lateral face, and extending nearly half the length of the shaft. The tuberosity for the teres major muscle is crestiform, situated about one third of the distance distally down the medial side of the shaft (Figure 1.2).

The supinator crest is damaged, although its proximal origin is seen to be far distal, scarcely proximal of the medial flaring towards the medial epicondyle (Figure 2.2). It is also deflected posteriorly. There is a large entepicondylar foramen. The medial extent of the medial epicondyle cannot be determined owing to breakage. The olecranon fossa is very shallow. Other aspects of the distal articulation are obscure because of damage and are best seen in the other humeral types.

Material of humerus type 2. Left distal humerus, M60810; Mammal Bed, Hordle.

Description. The distal articulation is complete. Part of the shaft is preserved but the edge of the supinator crest is damaged, although it had a proximal extent like that of type 1 (Figure 2.2). The distal width is $2.21 \mathrm{~mm}$ and shows a bone significantly smaller than type 1.The large entepicondylar foramen extends proximally slightly farther than in type 1.The medial epicondyle projects medially, its distal margin being proximal of the trochlea (Figure 2.2.1, 2.2.3). There is a faint mediolateral ridge on the posterior surface of the medial epicondyle, proximally delimiting a mediolaterally elongated dorsoepitrochlear fossa. Like type 1, the olecranon fossa is very shallow. The trochlea is rounded and blunt, has an oblique medial edge and does not project distally beyond the capitulum (Figure 2.2.1, 2.2.3). The radial fossa is well developed and there is a coronoid fossa that leads directly into the entepicondylar foramen. A prominent ridge separates the two fossae. There is a distinct intercondylar groove. The capitulum is subspherical and projects anteriorly, such that it has a proximally facing part in front of the radial fossa (Figure 2.2.2, 2.2.5). The capitulum has a confluent lateral tail and a weak posterior crest (Figure 2.2.1, 2.2.3). Posteriorly, the articular surface of the capitulum extends farther proximally than that of the trochlea.
Material of humerus type 3. Left distal humerus, M95897, three right distal humeri, M60713, M95896, M95898; Mammal Bed, Hordle.

Description. These distal fragments measure 3.64-3.85 $\mathrm{mm}$ in distal width (mean of three: 3.71 $\mathrm{mm}$ ). They have about twice the linear dimensions of type 2 and are about 1.5 times the size of type 1 . The most complete of the four in its distal articulation is similar to type 2 in the shape of the trochlea, capitulum, and presence of a capitular tail (Figure 2.4). It differs in having a relatively proximodistally longer, but medially less projecting medial epicondyle, a shallower coronoid fossa, a smaller entepicondylar foramen and a shorter, weaker supinator crest. There is variation in depth of the dorsoepitrochlear fossa.

Material of humerus type 4. Right distal humerus, M61422; How Ledge Limestone, Headon Hill.

Description. This specimen has lateral breakage, truncating the capitulum. It is approximately the same size as type 3 , but morphologically closer to type 2, except that the entepicondylar foramen is smaller like type 3 (Figure 2.3).

Reasons for identification as nyctithere. Herpetotheriid humeri differ in that they have a proximal spur on the supinator crest (Kurz, 2006), the capitulum is fusiform with a shallower intercondylar groove, the trochlea has a proximodistally orientated medial edge, and the medial epicondyle is shorter and, in Peratherium elegans (Aymard, 1846), more distally projecting (Crochet, 1980, figure 209). Glirid humeri occur in the Solent Group, and they are like modern Glis in having a fusiform capitulum without a tail and a cylindrical trochlea with a lateral keel (personal obs.). Talpid humeri have not yet been recognized in the Solent Group, but modern talpids and also soricids have a differently shaped head that does not project proximally of the greater and lesser tuberosities, a prominent teres tubercle, distinct pectoral and deltoid processes, a medial epicondyle with a proximal spur and no lateral capitular tail (Reed, 1951). No dentally recognized apatemyids small enough to belong to types 1-4 are present in the Hordle Mammal Bed, although there are in the How Ledge Limestone. In contrast, the humerus of Apatemys has a weaker deltopectoral crest, a deeper olecranon fossa and a supinator crest that extends farther proximally (Koenigswald et al., 2005). Although the humerus of Pseudoloris, a nyctitheresized omomyid has not yet been recognized, that of another larger European microchoerine omomyid has a longer less bowed shaft, a weaker deltopectoral crest, proximally more extensive 
supinator crest, a trochlea with a lateral keel, no lateral capitular tail, and the division between the coronoid and radial fossae is more laterally situated (Szalay and Dagosto, 1980, figure 20). By a process of elimination therefore, the humeri described here are attributed to the Nyctitheriidae. On size grounds, types 1-3 from the Hordle Mammal Bed belong respectively to Scraeva hatherwoodensis Cray, 1973, Euronyctia grisollensis (Sigé, 1976), and Cryptotopos woodi (Cray, 1973), nyctitheres in the fauna all known from teeth. Saturninia gracilis, also known from teeth, is intermediate in size between $S$. hatherwoodensis and $E$. grisollensis and is a less likely bearer of the type 2 humerus. The similarity of type 4 to type 2 suggests close relationship in the subfamily Amphidozotheriinae, following which size suggests Paradoxonycteris sp. 1.

Functional comparisons. The near spherical shape of the head and its projection above the greater and lesser tuberosities in type 1 are indications of shoulder mobility. This has particularly been noted for arboreal Ptilocercus in contrast to the more terrestrial tupaiine tree shrews, where a narrower head tends to restrict movement to a parasagittal plane, although tupaiines have a projecting head like Ptilocercus (Sargis, 2002a). Similarly, arboreal cercopithecid monkeys have spherical heads that project above the tuberosities, whereas their terrestrial relatives have narrower heads with more projecting tuberosities (Gebo and Sargis, 1994). The same head shapes differentiate climbing versus terrestrial tenrecs, but in contrast to the tupaiids, climbing Echinops has tuberosities that project beyond the head like its terrestrial relatives (Salton and Sargis, 2008). Regardless of these exceptions, the type 1 nyctithere shoulder joint is adapted in both ways, like Ptilocercus and arboreal cercopithecids, for mobility, likely associated with climbing. The lesser tuberosity of the type 1 nyctithere projects medially slightly more than in Tupaia tana and slightly less than in Ptilocercus, suggesting like the latter a relatively powerful subscapularis muscle, facilitating medial humeral rotation during vertical climbing (Sargis, 2002a).

The moderately long and strong, laterally displaced deltopectoral crest is found in arboreal cercopithecids (Gebo and Sargis, 1994) and in plesiadapiforms, also interpreted to have had important climbing ability (Szalay et al., 1975; Beard, 1993). A large projecting teres tubercle in soricids and especially talpids is associated with insertion of powerful teres major and latissimus dorsi muscles, which retract and rotate the humerus in digging (Reed, 1951). The insertion for the teres major muscle in the type 1 nyctithere is a relatively weak crest, similar in development to that in modern galagid primates and the extinct plesiadapiforms where climbing not digging is known or inferred (Simpson, 1935; Szalay et al., 1975; Gebo, 1989; Beard, 1993). In tree shrews it is missing (Tupaia) or reduced to a roughened surface (Ptilocercus) (personal obs.).

The distal restriction of the trochlea, whose curved surface is gently convex, rather than concave, and its distinct separation by a groove from the capitulum in the nyctitheres are like many modern arboreal primates and extinct primates and plesiadapiforms (Szalay and Dagosto, 1980; Gebo and Sargis, 1994), although it lacks the lateral trochlear crest found in many primates and some plesiadapiforms. The nyctithere capitulum is also less spherical than in many primates and plesiadapiforms such as Plesiadapis and Phenacolemur (Szalay et al., 1975; Beard, 1993), than in the arboreal tree shrew Ptilocercus (Sargis, 2002a) and than in adapisoriculids (Storch, 2008; Boyer et al., 2010; Goswami et al., 2011). The relatively bulbous and proximally facing capitulum and its clear separation from the trochlea in the nyctitheres implies that the radius rotated on it, allowing a degree of supination of the radius (see description below) and habitual flexion of the forearm. More terrestrial primates, tupaiine tree shrews and soricids with restricted radial rotation have a fusiform to cylindrical capitulum that is less well separated from the trochlea (Reed, 1951; Gebo and Sargis, 1994; Sargis, 2002a).

The relatively long medial epicondyle in the nyctitheres indicates powerful flexion of the wrist and digits, as it is here that the relevant flexor muscles originate (Sargis, 2002a). Such flexion is important for branch grasping in climbing mammals, but is also important in digging in terrestrial mammals (Sargis, 2002a). However, the medial epicondyle is much larger in specialized diggers (Rose and Emry, 1983; Salton and Sargis, 2008), and its size in the nyctitheres is more consistent with climbing adaptations. This latter contention is supported by the very shallow olecranon fossa in the nyctitheres, indicating that extension of the forearm, important in digging and terrestrial running (Reed, 1951; Sargis, 2002a), was restricted. Nyctitheres were therefore using a largely flexed forearm, which fits with a dominantly climbing locomotor mode.

The relatively short supinator crest in the nyctitheres suggests a weak brachioradialis muscle, 
an elbow flexor, and weak extensors of the hand, all of which originate on this crest. The supinator crest is typically large in many arboreal primates, the plesiadapiforms Plesiadapis and Phenacolemur (Szalay and Dagosto, 1980; Beard, 1993), the tree shrew Ptilocercus (Clark, 1926), and the arctocyonid Chriacus, interpreted to have been scansorial (Rose, 1987).

\section{Radius}

Material. Right, lacking distal end (M95899), right proximal fragment (M60817), Mammal Bed, Hordle; left proximal fragment (HZM.592.30489), and right proximal fragment (HZM.324.28063), Rodent Bed, Hordle.

Description. M95899 is nearly complete, although the distal articulation is lacking and the head is damaged (Figure 3.1). Its preserved length is 9.41 $\mathrm{mm}$. M60817 is preserved for about half its length but has a slightly damaged head (Figure 3.2), whereas HZM.324.28063, with less length of shaft, has a well-preserved articulation (Figure 3.3). The head is broad and funnel-shaped, asymmetrically orientated with respect to the shaft, tilted anteromedially and with a marked anterior overhang. HZM.324.28063 in proximal view shows a near oval head tapering slightly medially and evenly recessed for articulation with the humeral capitulum (Figure 3.3.1). There is a small anterior lip anterolaterally. There is a small capitular eminence anteromedially, posteriorly of which there is a tiny facet facing proximomedioposteriorly, for articulation with the lateral extremity of the humeral trochlea. The rest of the description of the proximal section refers to M60817. The ulnar facet is c.1.2 $\mathrm{mm}$ in circumferential length and curves around the posterior and lateral margins of the head in an arc of c.130 degrees. It is triangular in outline, tapering distally from the proximal margin. The bicipital tuberosity is extensive on the posterior surface, delimited proximally by an oblique ridge that almost extends to the proximal margin medially. The main area of the tuberosity is flat, rising gradually distolaterally to a sharp ledge that overhangs the shaft laterally, beneath which it is excavated.

In M95899, the proximal half of the shaft is sinuous in shape, bowing anteriorly after about one quarter of the length, then remaining straight for the the rest of the distal half (Figure 3.1.2). It is wider mediolaterally than anteroposteriorly in its proximal half. More distally, the cross section becomes essentially equidimensional. Near what would have been the distal extremity, the cross section becomes wedge shaped, the narrow end pointing anterolaterally. This is the distal continuation of a sharp lateral edge, which begins just distal of the bicipital tuberosity. At about the midpoint of the shaft, this edge is interrupted by an oblique groove that crosses the shaft in a distomedial direction, dying out anteromedially. A shallower groove in a similar position frequently occurs in modern carnivorans, especially the domestic cat (Felis catus L.) and red fox (Vulpes vulpes (L.)) (personal obs.) and some moles (Reed, 1951; personal obs.). This marks the trace of the extensor ossis metacarpi pollicis muscle (= extensor carpi obliquus, abductor pollicis longus), which originates from the lateral border and dorsal surface of the ulna and the proximal part of the lateral border of the radius (and in Canis also the interosseous ligament); it inserts into $\mathrm{M} / \mathrm{C}$ I and abducts the first digit (Jayne, 1898; Reed, 1951; Sisson and Grossman, 1953). It is likely that the groove on the nyctithere radius contained the same muscle, which from its depth suggests that it was powerful. Such a groove is lacking in tree shrews.

All three specimens with well-preserved heads are very similar morphologically, although the two specimens from the Hordle Rodent Bed are slightly larger (mediolateral width of head 1.24 and $1.32 \mathrm{~mm}$ ) than that from the Hordle Mammal Bed (mediolateral width of head of M60817, $1.15 \mathrm{~mm}$ ). The latter is of appropriate size to articulate with the type 1 humerus.

Reasons for identification as nyctithere. Although no radii attributable to Eotalpa have been found, modern soricoids have a flat ulnar facet, limiting movement at that joint. The radius of modern Glis has a straighter shaft, the bicipital tuberosity is weaker, the central cross section of the shaft tapers anteromedially, and the head is more symmetrical, with a more laterally positioned capitular eminence. Very similar proximal fragments from the Solent Group can be attributed to the Gliridae and be clearly distinguished from the putative nyctithere radii. The radius of the herpetotheriid Amphiperatherium cf. maximum Crochet, 1979 from the Lutetian of Messel (Koenigswald and Storch, 1988, figure 225) has a more massive bicipital tuberosity and a straighter shaft (personal obs. of cast of SMNK-PAL 983). Only the anterior surface of the proximal radius of Suevosciurus ehingensis Dehm, 1937 from the Oligocene of Armissan (Lavocat, 1955; Schmidt-Kittler, 1971) is exposed on its slab, but shows a mediolaterally more symmetrical head with an indentation in its anterior margin and no anterior overhang (personal obs.). The small Solent Group pseudosciurids can 


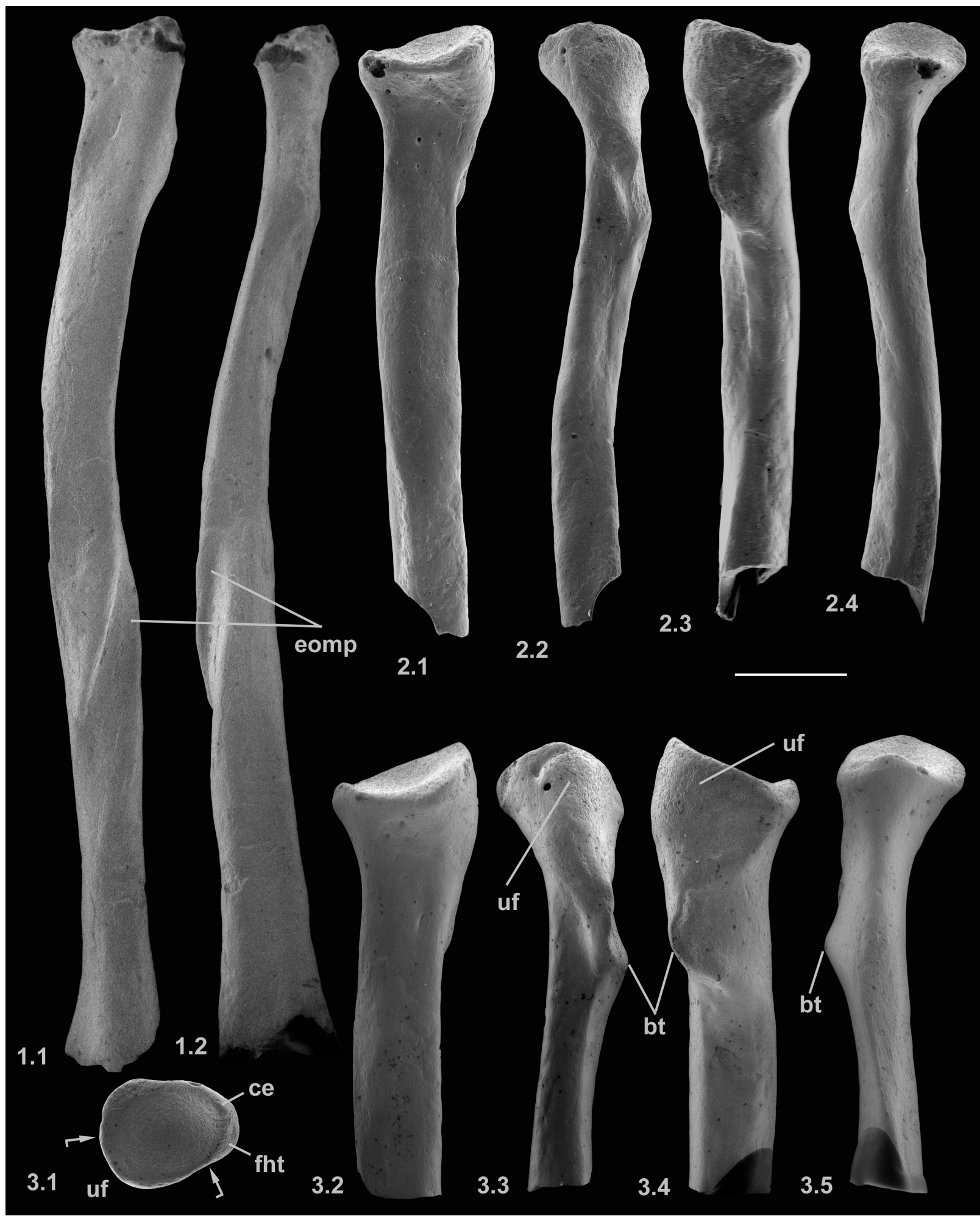

FIGURE 3. Scanning electron micrographs of right radii (reversed) of Nyctitheriidae. 1, Nearly complete radius lacking end, M95899; 2, proximal fragment, M60817; 3, proximal fragment, HZM.324.28063. 1-2 are attributed to Scraeva hatherwoodensis, 3 to Paradoxonycteris sp. 1? The extent of the ulnar facet (uf) in 3.1 is shown by arrows. Views are: anterior $(1.1,2.1,3.2)$, lateral $(1.2,2.2,3.3)$, posterior $(2.3,3.4)$, medial $(2.4,3.5)$ and proximal $(3.1)$. 1-2 are from the Mammal Bed, Hordle, Hampshire; 3 is from the Rodent Bed, Hordle. Scale bar equals $1 \mathrm{~mm}$. 
therefore be eliminated. No omomyid radii appear to have been reported, but they are likely to have had a near circular head like those of the primitive adapoids from the Early Eocene of Vastan, India (Rose et al., 2009, figure 17), a necessity for articulating with the spherical capitulum of the omomyid humerus (Szalay and Dagosto, 1980, figure 20). The radius of Heterohyus nanus from Messel is not well preserved, but appears to have a nearly straight shaft (Koenigswald, 1990). On size grounds, M60817 from the Hordle Mammal Bed should belong to Scraeva hatherwoodensis. As S. hatherwoodensis is absent from the Hordle Rodent Bed, the slightly larger radii from this stratum are likely to belong to its close relative Paradoxonycteris sp.1.

Functional comparisons. The length and rounded trajectory of the ulnar facet suggests substantial supination ability of the forearm, despite lack of knowledge of the nyctithere ulna. The evenly excavated head, articulating with the subspherical capitulum of the humerus, would have facilitated this. As the outline shape of the head is broadly oval, it is unlikely that the degree of supination was as great as in plesiadapiforms, arboreal primates or the arboreal tree shrew Ptilocercus, where the radial head is circular or nearly circular and the humeral capitulum spherical. However, it would have been greater than in the more terrestrial tree shrew Tupaia and the soricid Sorex, where the radial head is more mediolaterally elongate, with a near flat ulnar facet, and where the humeral capitulum is fusiform to cylindrical (Sargis, 2002a; personal obs.).

The implications of strong development of the extensor ossis metacarpi pollicis muscle in nyctitheres is uncertain given its widespread occurrence in mammals. However, the ability of the muscle to abduct the first digit suggests that it may have been partly responsible for spreading the entire hand. Combined with supination of the radius, this is likely to have been important in aiding gripping during climbing.

\section{Metacarpal}

Material. Left M/C II, HZM.266.27528, Mammal Bed, Hordle.

Description. Length is $3.37 \mathrm{~mm}$. The shaft is straight in dorsal and ventral views and very slightly bowed dorsally. The shaft flares only at the extreme distal end where the projection is slightly greater medially than laterally, indicating the digit number (Figure 4.3.1). The width of the distal articulation is c. $18 \%$ of the length of the bone. The dis- tal articulation is gently convex dorsally and distally, and the posteriorly restricted median ridge is relatively narrow. The proximal articulation is mainly flat, but slopes steeply distally at its dorsal end. In proximal view it is subrectangular, slightly constricted in the middle and tapers ventrally (Figure 4.3.2). The contact for $\mathrm{M} / \mathrm{C}$ III at the proximal end of the shaft is shallowly concave with a faint subterminal inverted $\mathrm{v}$-shaped ridge. That for $\mathrm{M} / \mathrm{C}$ I is in two parts, a large ventral medially facing facet and a smaller dorsal proximodorsomedial facing facet.

Reasons for identification as nyctithere. Identification is through exclusion of other small contenders, as no nyctithere carpals have yet been recognized to allow articulation tests. Herpetotheriid metacarpals, like modern Didelphis (personal obs.), have shafts that widen distally from near the proximal end, and their distal articulations are nearly twice as wide as the narrowest part of the shaft. The depressions at the distal end for the collateral ligaments are shallow, and the crested medial and lateral margins of the distal articulation project ventrally as far as the central keel. Glirid metacarpals have bulbous distal articulations (personal obs.). So do metapodials of omomyids (Szalay, 1976), eliminating Pseudoloris. Apatemyid metacarpals are greatly elongated (Bloch and Boyer, 2001) and in any case no small apatemyids occur in the Hordle Mammal Bed. Small metacarpals attributable to small pseudosciurids because of their similarity to the larger theridomyids (personal obs.) have more flared distal ends with blunter keels. Identification of HZM.266.27528 to a particular nyctithere taxon is difficult. However, if one assumes that width of the metacarpal distal articulation is similar to that of the equivalent metatarsal, this $\mathrm{M} / \mathrm{C} \mathrm{II}$ is c. $70 \%$ narrower and therefore is unlikely to belong to the large species represented by $M / T$ III in the How Ledge Limestone (M95970, q.v.), which is attributable to Paradoxonycteris sp. 1 or Cryptotopos woodi. HZM.266.27528 may therefore belong to the smaller Hordle Mammal Bed species Scraeva hatherwoodensis. If this is correct and if different nyctitheres are comparable in their metacarpalmetatarsal length proportions, M/C II should be $\mathrm{c}$. three quarters the length of $M / T$ III.

\section{Femur}

Material of femur type 1. Right, lacking distal end, M60701, proximal left, M60819; Mammal Bed, Hordle. 


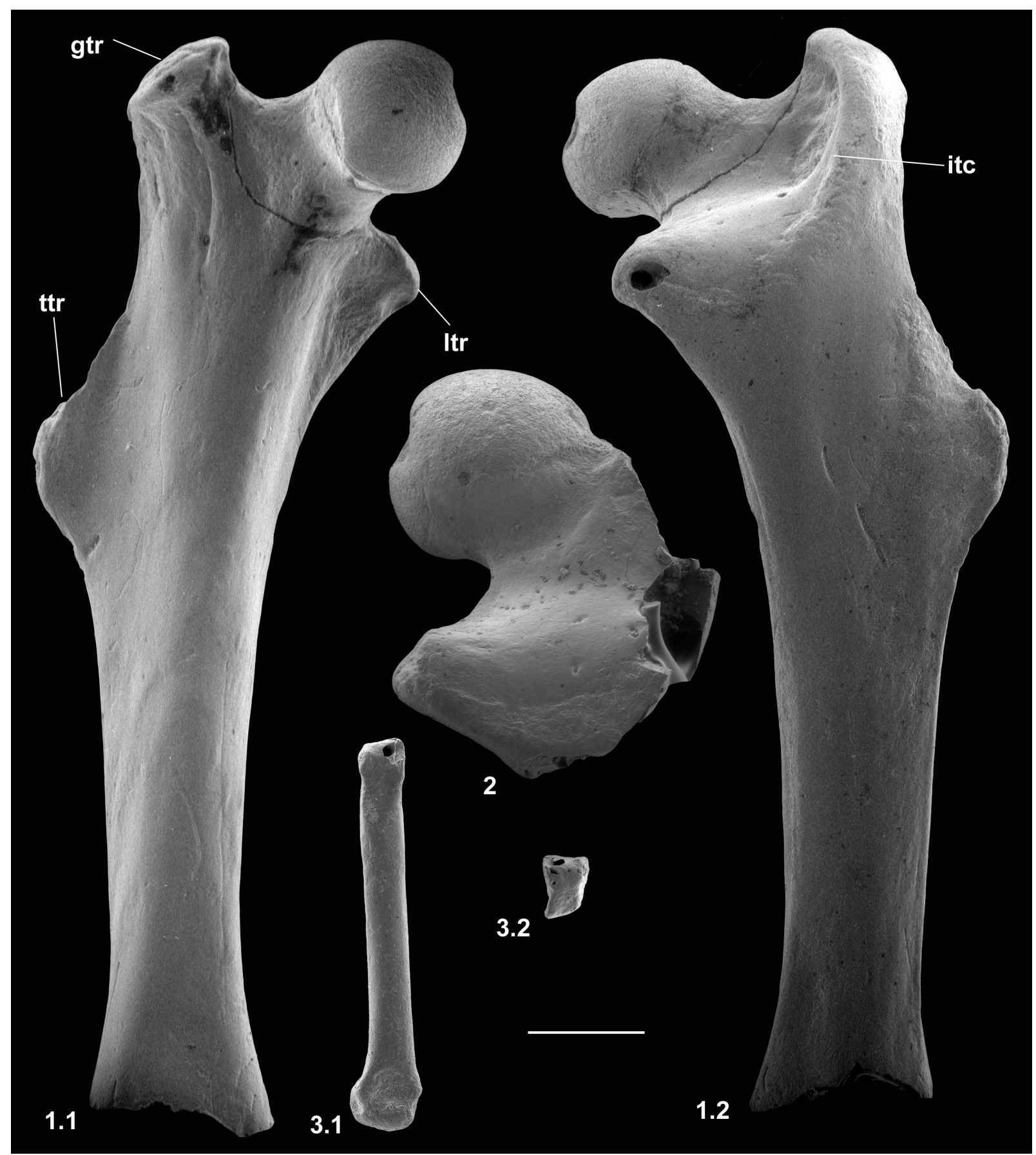

FIGURE 4. Scanning electron micrographs of right femora (reversed) of Nyctitheriidae. 1, nearly complete femur type 1 (Scraeva hatherwoodensis?), lacking distal end, M60701; 2, proximal fragment of femur type 2 (Cryptotopos woodi?), M95900; 3, left metacarpal II, HZM.266.27528. Views are: anterior (1.1, 3.1), posterior (1.2, 2) and proximal (3.2). All from the Mammal Bed, Hordle, Hampshire. Scale equals $1 \mathrm{~mm}$.

Description. M60701, although it lacks the distal end, mediolateral flaring and anterior flattening at the preserved distal end shows that the bone is nearly complete (Figure 4.1). Preserved length is $9.35 \mathrm{~mm}$ and head diameter is $1.47 \mathrm{~mm}$. The head is directed anteromedially (Figure 5.1). Its main articular surface is spherical and covers more than a hemisphere, both distally and proximally, with a tapering extension onto the neck posteroproximally about halfway to the greater trochanter. The head articulation is also extensive distally, especially on the anterior side. In both specimens there is a dis- 


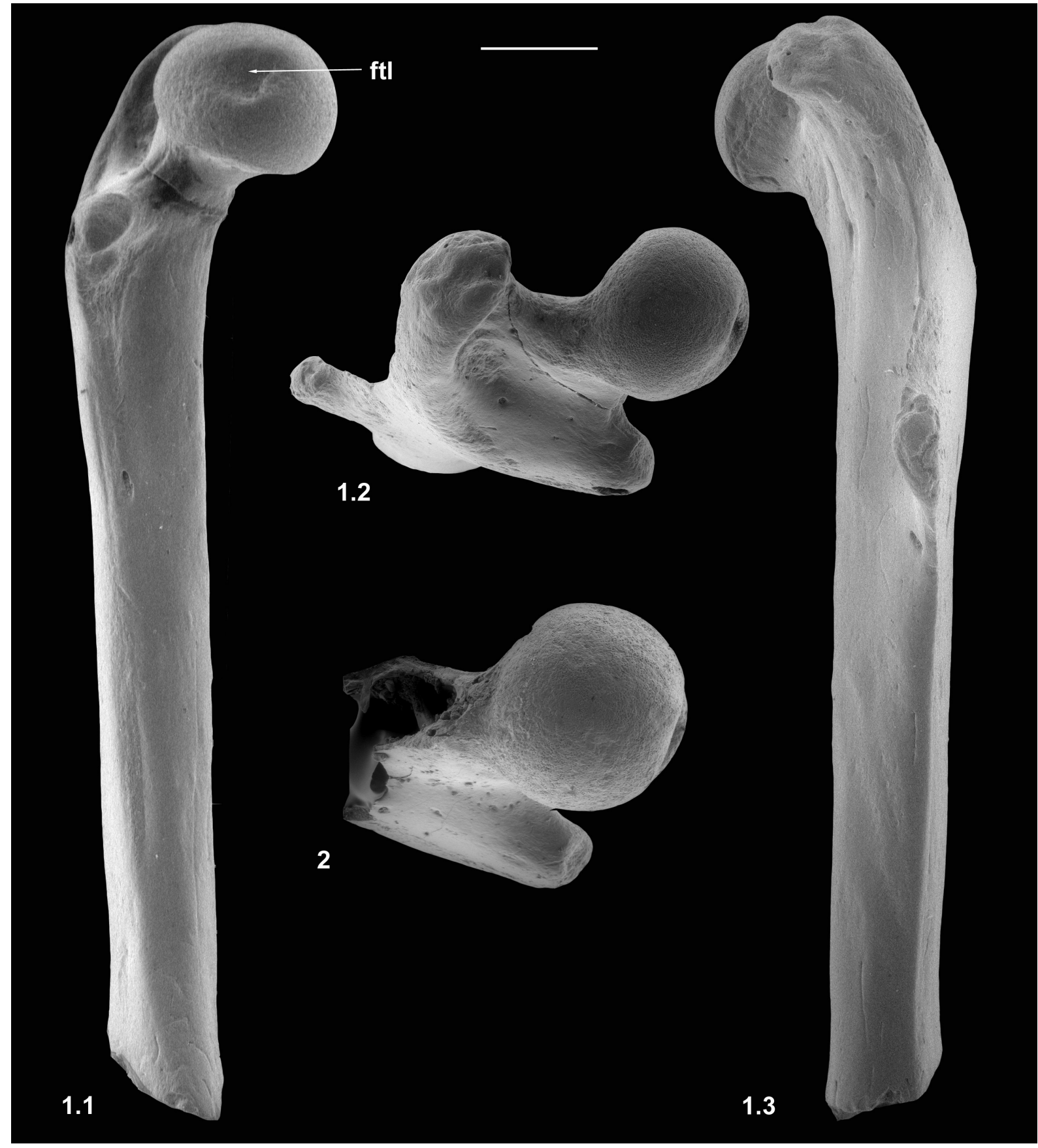

FIGURE 5. Scanning electron micrographs of right femora (reversed) of Nyctitheriidae. 1, nearly complete femur type 1 (Scraeva hatherwoodensis?), lacking distal end, M60701; 2, proximal fragment of femur type 2 (Cryptotopos woodi?), M95900. Views are: medial (1.1), proximal $(\mathbf{1 . 2}, \mathbf{2})$ and lateral (1.3). Both from the Mammal Bed, Hordle, Hampshire. Scale equals $1 \mathrm{~mm}$.

tinct fovea for the teres ligament, slightly posteriorly situated with respect to the head articulation, but approximately parallel with the proximodistal anteroposterior plane. The neck is relatively short but is fairly deeply emarginated proximally, so that it is constricted relative to the head. The constric- tion involves that part of the articulation that extends onto the neck (Figures 4.1.2, 5.1.2). The neck is orientated at c. 110 degrees to the long axis of the shaft. The greater trochanter projects very slightly proximally of the head and curves anteriorly towards its tip (damaged in M60819). It is 
expanded and rugose apically. The lesser trochanter is situated just distal of the head and projects essentially medially (Figure 5.1.1, 5.1.2), extending nearly as far as the head (broken in M60819). In M60701, the third trochanter is prominent and situated distal of the lesser trochanter about a third of the way down the shaft, but overlapping with the lesser trochanter in extent. The lateral border of the bone that extends in both directions from the third trochanter is sharp except near the distal end of the bone. There is a shallow trochanteric fossa bordered by an intertrochanteric crest that curves evenly and weakens only as it approaches the lesser trochanter (Figure 4.1.2). There is a weak crest within the trochanteric fossa emanating from beneath the greater trochanter and curving towards the level of the distal edge of the head, but dying out less than halfway across the fossa. M60819 differs in having a slightly angled intertrochanteric crest and in that the proximal side of the neck forms a posteriorly overhanging edge. Its head diameter is $1.53 \mathrm{~mm}$. The shaft of M60701 is slightly bowed laterally, but straight in medial or lateral view. Except distally, the anterior shaft wall is strongly convex mediolaterally. The distal half of the posterior surface is sharply convex mediolaterally, but more proximally it is flat. Similarity between the two specimens in size and morphology is suggestive of a single species.

Reasons for identification as nyctithere. Nonnyctithere taxa, which would have femora of comparable size in the Solent Group are the herpetotheriid marsupials Peratherium and Amphiperatherium, the apatemyid Heterohyus, the talpid lipotyphlan Eotalpa and glirid rodents. However, in the Hordle Mammal Bed, whence these two femora came, the only apatemyid is far too large to be a candidate. Although herpetotheriid femora are not recorded from the Solent Group, they are known from France (Peratherium: Crochet, 1980, p. 187, figure 212; Amphiperatherium: Kurz, 2006, text-figure 6) and North America (Herpetotherium: Sanchez-Villagra et al., 2007). They differ from M60701 in being relatively longer and straighter, having an unconstricted neck proximally, a weaker, more proximally situated third trochanter, a much deeper trochanteric fossa and a distolaterally trending crest from the lesser trochanter on the posterior face (Horovitz et al., 2008, plate 6, figures A-B). The femur of apatemyids is relatively poorly known, but that of Apatemys, like herpetotheriids, is relatively longer than M60701, has a weaker third trochanter and a much deeper trochanteric fossa (Koenigswald et al., 2005, p. 160, plate 4, fig- ure A). The femur of Eotalpa has not yet been found, but modern talpids and their closest relatives, soricids, lack a trochanteric fossa and the third trochanter is more proximally situated (Reed, 1951, figure 9). Undescribed glirid femora occur in the Solent Group and they closely resemble modern Glis. They differ from M60701 in having a deeper trochanteric fossa, a slightly more distal lesser trochanter, and a head articulation, which does not extend onto the neck and which has a slightly less posteriorly shifted teres fovea. Pseudosciurid femora have a greater trochanter that extends significantly above the head and a lesser trochanter that is orientated posteromedially (Lavocat, 1955). By a process of elimination, it is concluded that M60701 and M60819 belong to the family Nyctitheriidae. Minimum mediolateral shaft width of the tibia in mammals is commonly slightly less than that of the femur. The shaft as far as preserved in the type 2 tibia (M61087) attributed to Scraeva hatherwoodensis is slightly narrower than that of the type 1 femur (M60701), whereas that of the type 1 tibiae (M60822, M60823) attributed to Cryptotopos woodi is slightly wider. Both type 1 femora described here are therefore tentatively attributed to Scraeva hatherwoodensis.

Material of femur type 2. Proximal right, M95900, Mammal Bed, Hordle.

Description. This fragment shows only the head and lesser trochanter. What is preserved is larger (head diameter $1.77 \mathrm{~mm}$ ) than type 1 but very similar, except that there is only slight extension of the head articulation onto the neck (Figures 4.2, 5.2). It is likely to belong to Cryptotopos woodi.

Functional comparisons. This section refers mainly to type 1 , although that which concerns the head and lesser trochanter is also applicable to type 2 . The relatively large spherical head with extensive articulation, especially its extension onto the neck proximally, and the short, proximally angled neck suggest climbing ability when compared with the catarrhine Cercopithecus mitis (Gebo and Sargis, 1994) and, in terms of the extent of head articular surface, with the climbing tenrec Echinops (Salton and Sargis, 2009) and with the arboreal tree-shrew Ptilocercus (Sargis, 2002b). These modern taxa nevertheless have a relatively larger femoral head than does the nyctithere and Ptilocercus lacks a neck extension. The proximal extent of the greater trochanter being scarcely greater than that of the head, among treeshrews, is like arboreal Ptilocercus rather than like the more terrestrial Tupaia, whose greater trochanter projects proximally farther than the head (Sar- 
gis, 2002b). Similarly, the terrestrial tenrecs Microgale cowani and $M$. dobsoni also have a greater trochanter that projects proximally farther than the head, although so does M. talazaci, which has climbing ability (Salton and Sargis, 2009, figure 5). Correspondingly, terrestrial Tenrec and Hemicentetes have a head that projects more proximally than the greater trochanter like the climbers Echinops and Setifer (Salton and Sargis, 2009 , figure 5). Some of these differences in the tenrecs may be influenced slightly by differing angles of the neck to the long axis of the bone, but may also reflect ancestral character retentions in closely related taxa (Salton and Sargis, 2009). A similar argument has been used to explain the proximally projecting greater trochanter in arboreal Tupaia minor, like its more terrestrial relatives (Sargis, 2002b, p. 164). The angle of the neck may be more important in the case of the terrestrial carnivoran Vulpes. Here the greater trochanter extends proximally less than the head and the angle of the neck to the bone long axis is c.130 degrees (personal obs.). Despite these exceptions, a proximally projecting greater trochanter does restrict hip mobility and does provide more available insertion area for the gluteus medius muscle, which gives increased femoral extension, often for terrestrial running (Sargis, 2002b). This feature in T. minor presumably also powers running, but along branches. However, this muscle also provides abduction of the hip, which is important in climbing. The nyctithere in any case appears not to have suffered from restricted hip mobility at the hands of its greater trochanter.

The lesser trochanter is a somewhat clearer indicator of locomotor ability. Its essentially medial projection in the nyctithere is found in the climbing tenrec Echinops (Salton and Sargis, 2009), in arboreal monkeys (Gebo and Sargis, 1994), climbing aeluroid carnivorans (Taylor, 1976), the tree squirrel Sciurus, and the arboreal dormouse Glis (personal obs.), in contrast to their more terrestrial relatives. The muscles that insert on the lesser trochanter and adjacent intertrochanteric crest, the iliopsoas and quadratus femoris, are external rotators of the femur, associated with climbing ability (Taylor, 1976). However, Sorex also has a medial lesser trochanter, yet limited climbing ability. A more posteriorly directed lesser trochanter, found in terrestrial species is nevertheless associated with emphasis on parasagittal movement (Gebo and Sargis, 1994). However, orientation is not the only criterion involving function of this structure. A medially longer lesser trochanter more distally positioned on the shaft is associated with greater climbing ability, a state found in Ptilocercus (Sargis, 2002b) and Lemuriformes (Gebo, 1989). Although the intertrochanteric crest is strong in the nyctithere, its lesser trochanter is proximally positioned, just distal of the head, suggesting that its hip rotation capabilities were less than those of Ptilocercus. The implication is that these capabilities were also less than those of the extinct plesiadapiforms Plesiadapis and Tinimomys, where the lesser trochanter is longer and more distally positioned (Szalay et al., 1975; Beard, 1993).

The third trochanter has a complex pattern of occurrence in mammals. A large, relatively distally positioned one as in the nyctithere provides a long lever arm for the gluteus maximus muscle where it inserts. This can give powerful extension of the thigh (Sargis, 2002b), but also abduction and rotation (Reed, 1951). This is similar in position to that found in Tupaia, although it is a little smaller. In Tupaia, it allows rapid terrestrial running, but occurs also in arboreal T. minor (Sargis, 2002b). It has development similar to that of terrestrial tenrecs, such as Microgale and Oryzorictes and the terrestrial erinaceid Echinosorex (Salton and Sargis, 2009). However, in galagid primates, its presence is associated with arboreal leaping, although it is positioned more proximally than in the nyctithere, opposite the lesser trochanter (Gebo, 1989). In Sciurus and Glis, the third trochanter is at a position relative to the lesser trochanter similar to that of the nyctithere, but only about a quarter of the way down the shaft because of the relatively longer bone. It is weaker in Glis than in Sciurus, where size is similar to that of the nyctithere.

In summary, the nyctithere femur shows a number of features associated with, although not necessarily diagnostic of, considerable climbing ability. The evidence of the third trochanter is somewhat conflicting in terms of its distribution among different locomotor types, although its comparable development in climbing Tupaia minor and Sciurus is tentatively supportive of the other femoral features. The third trochanter of Sciurus is similar to that of primitive paramyid rodents (Wood, 1962) as well as of their nearest sister group within Glires, the mixodontian Rhombomylus (Meng et al., 2003). Therefore, Sciurus appears to have retained the third trochanter from an ancestral condition, like T. minor, and it is possible that the same phenomenon applies also to nyctitheres. 


\section{Tibia}

Material of distal tibia type 1. Right, M60823, M95901, left, M60822, Mammal Bed, Hordle.

Description. Distal width is $1.94-1.97 \mathrm{~mm}$, mean $1.95 \mathrm{~mm}$. These articulate well with astragali attributed to Cryptotopos woodi from the same bed and are thus similarly attributed. M60823 is limited largely to the distal articulation, whereas M60822 retains a considerable portion of the shaft. The former, however, shows a better preserved and thus more clearly demarcated astragalar articulation. In distal view, this is rhomboidal in outline emarginated on its anterior edge (Figure 6.1.1). Medially, it extends onto the lateral wall of the medial malleolus, which has a shallow groove at its tip. The anterior emargination borders a blunt anterior tubercle (Figures 6.1.1, 7), which fits into a concavity in the distal slope of the trochlear valley of the astragalus. In combination with the oblique shelf at the distal end of the lateral trochlea of the astragalus (Hooker, 2001), this structure appears to act as a stop for excessive dorsiflexion at the upper ankle joint. It also occurs in erinaceids, Tupaia (personal obs.), and apheliscid and macroscelidid elephant shrews (Penkrot et al., 2008). In distal view, the tibia has a prominent posterior protuberance, which on M60822 can be seen to form the distal end of a median posterior ridge that quickly weakens proximally. Such a posterior protuberance is present in Ptilocercus, although not in Tupaia or lipotyphlans. On the nyctithere specimens, the anterolateral corner projects anteriorly as a blunt tubercle (anterior projection) with a scar probably for the anterior inferior tibiofibular ligament (Figure 7.1).

Anterior and posterior views show a prominent medial malleolus (Figures 6.1.2, 7). On M60822, features of the shaft can be observed. This is straight in medial and lateral views and very gently bowed laterally in anterior and posterior views. There is a gentle elongated fluted depression on the anterior face. The medial face is broadly rounded in cross section. The lateral face is flattened from anterior to posterior more proximally, but the flattening narrows distally between anterior and posterior depressions although appears to continue as far as the distal extremity, where there is no sign of a synovial joint (Figure 7.3). The flattened area indicates contact, implying syndesmosis, although not co-ossification (synostosis), with the fibula along an undetermined but significant extent of the distal shaft. This is similar to the situation in some primates, where tibio-fibular syndesmosis (Microcebus) or synostosis (Tar- sius) occurs between the distal shafts (Fleagle and Simons, 1983; Dagosto, 1985).

On the posterior face, the median ridge is demarcated laterally by a weak groove that soon dies out proximally (Figures 6.1.2, 7.3). Medially, there is a much stronger, longer groove that extends proximally for at least $3 \mathrm{~mm}$. This groove is demarcated medially by a sharp ridge, beyond which is another shorter groove on the posterior side of the medial malleolus. In most placentals, a broad shallow groove, which is essentially median on the posterior face, carries the tendon of the flexor digitorum fibularis (= flexor hallucis longus). The homologous groove in the nyctithere appears to be that which is lateral of the median ridge and thus unusually laterally situated. In this respect it is like Ptilocercus and unlike Tupaia. In the nyctithere, its position matches the strong obliquity, albeit weak development, of the groove for this tendon on the proximoventral region of the astragalus (Hooker, 2001). Normally in placentals, there is only one, more medial groove on the posterior face of the tibia, situated behind the medial malleolus, carrying both the flexor digitorum tibialis (= flexor digitorum longus) and tibialis posterior (= tibialis posticus) tendons. In Cryptotopos, there are two grooves medial of the median ridge (Figures 6.1.1, $6.1 .2,7.2)$. The more lateral is here interpreted to have carried the flexor digitorum tibialis, whilst the more medial is interpreted to have carried the tibialis posterior.

Material of distal tibia type 2. Left, M61087, Mammal Bed, Hordle.

Description. This bone is slightly smaller than type 1. Distal width is $1.63 \mathrm{~mm}$. It retains a portion of the shaft, but less than in M60822. In distal view it is similar in outline, but slightly deeper anteroposteriorly, with a more rounded lateral margin and with a shallower anterior emargination. The articulatory surface narrows from the posterior side in a lateral direction. The articulation on the anterior tubercle extends onto the anterior face (Figure 6.2.1). Posteriorly, the median ridge is slightly wider mediolaterally at its distal end and there is only one depression in the outline medial of this ridge behind the medial malleolus. In posterior view, it can be seen that this depression marks a single, wide longitudinal groove, where there are two narrower ones in type 1 (Figure 6.2.2). In having only a single groove interpreted as being for transmission of both the flexor digitorum tibialis and tibialis posterior tendons, it is more like other mammals, but the groove is significantly wider, so that these tendons could each have been as well developed 


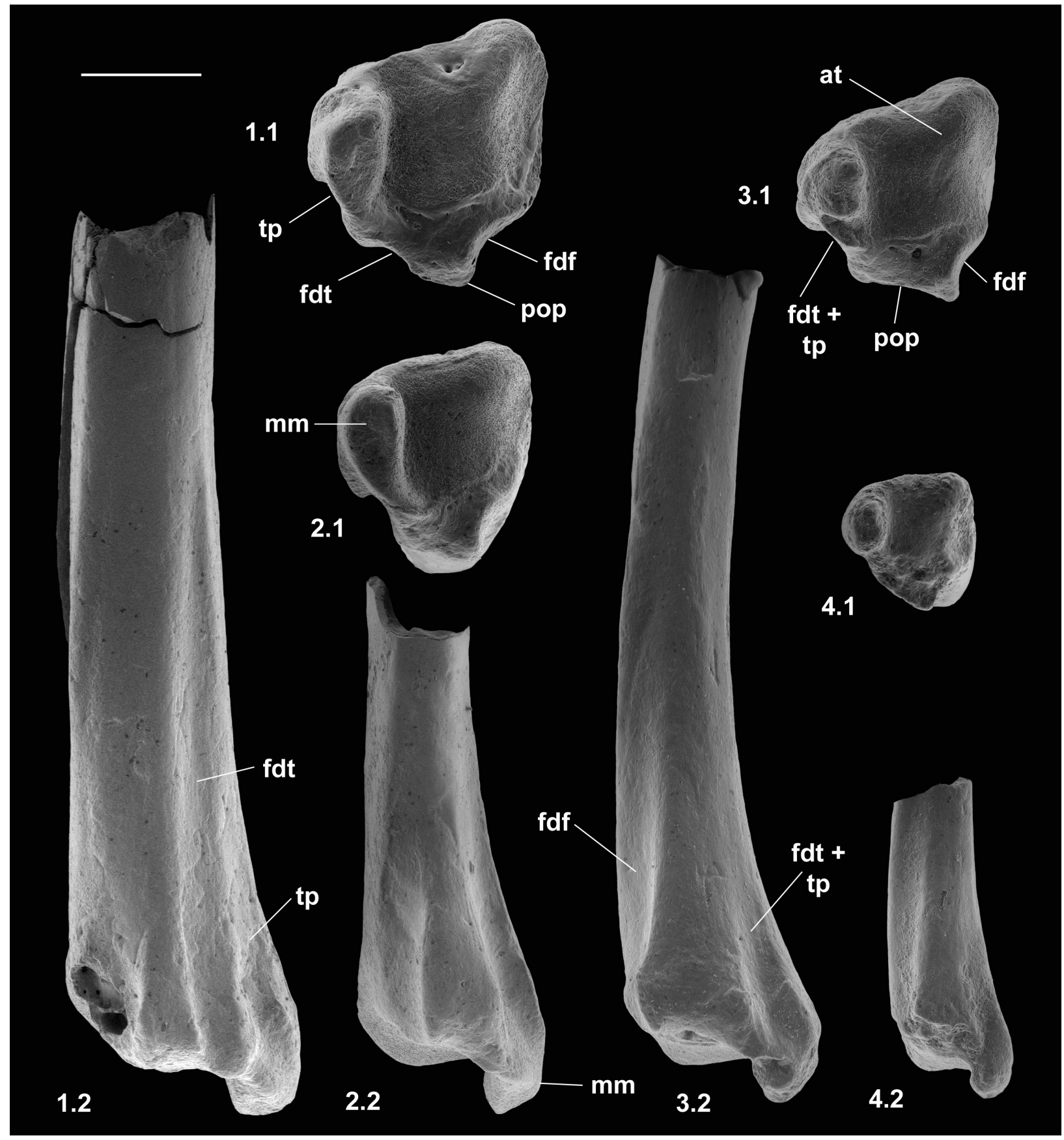

FIGURE 6. Scanning electron micrographs of distal tibiae, shown as from left side, of Nyctitheriidae. 1.1, right tibia (reversed) type 1 (Cryptotopos woodi), M60823; 1.2, left tibia type 1 (Cryptotopos woodi), M60822; 2, left tibia type 2 (Scraeva hatherwoodensis), M61087; 3, right tibia (reversed) type 3 (Paradoxonycteris sp. 1), M95949; 4, left tibia type 4 (Euronyctia grisollensis), M95951. Views are: distal (1.1, 2.1, 3.1, 4.1) and posterior (1.2, 2.2, 3.2, 4.2). 1-2 from the Mammal Bed, Hordle, Hampshire; 3-4 from the How Ledge Limestone, Headon Hill, Isle of Wight. Scale equals 1 $\mathrm{mm}$. 


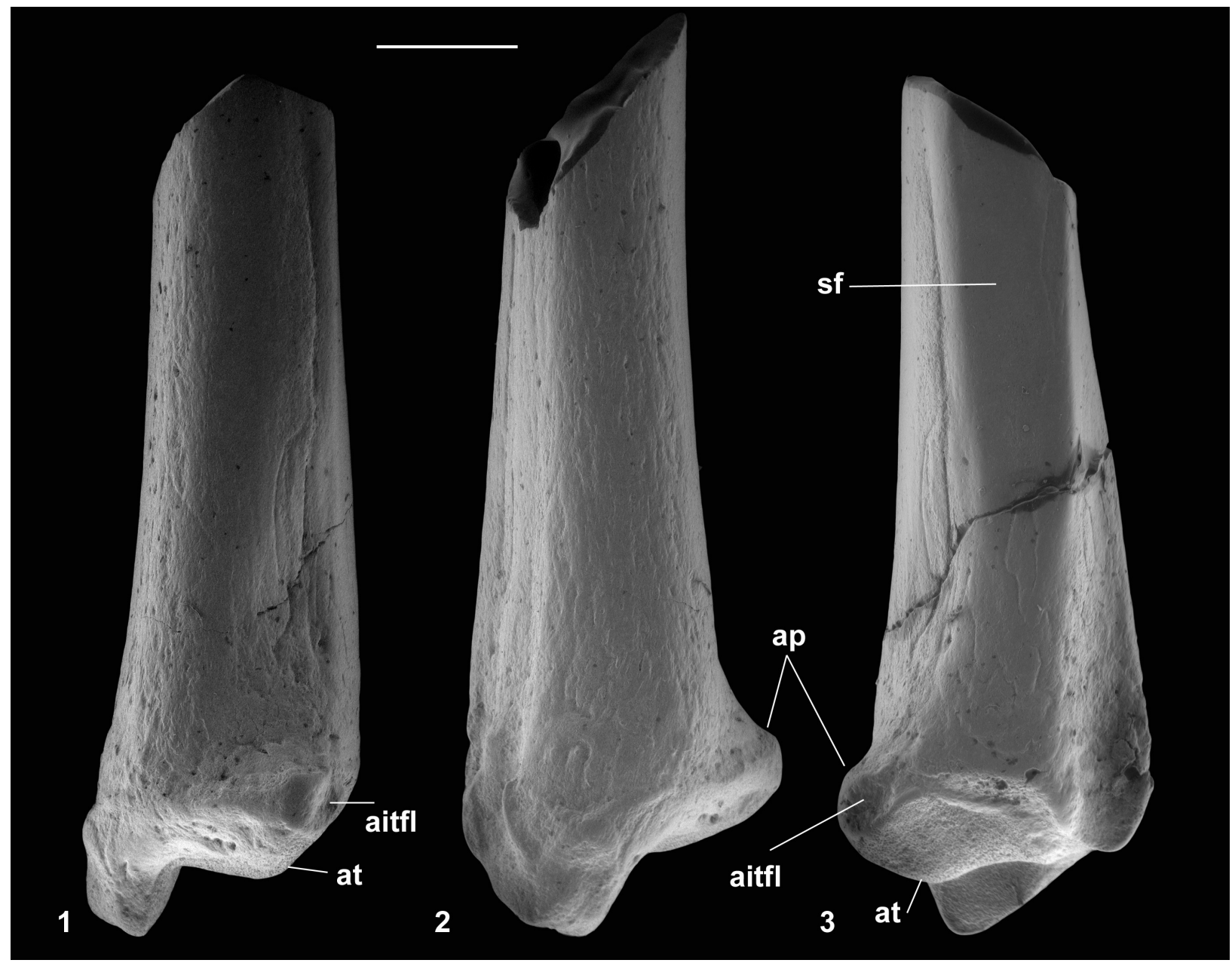

FIGURE 7. Scanning electron micrographs of right distal tibia (reversed) type 1 (Cryptotopos woodi), M95901, Mammal Bed, Hordle, Hampshire. Views are: anterior (1), medial (2) and lateral (3). Scale equals $1 \mathrm{~mm}$.

as in type 1. On the lateral edge of the anterior face there is a small depression lateral to the more central shallow depression as seen in type 1. Apart from subtle differences in shape of the distal articulatory area, the bone is very similar to that of Cryptotopos. On size grounds, this tibia is judged to belong to Scraeva hatherwoodensis.

Material of distal tibia type 3. Left, M61426; right, M95949, M95950; How Ledge Limestone, Headon Hill.

Description. This type is very slightly larger than type 2. Distal width is $1.71-1.77 \mathrm{~mm}$, mean 1.74 $\mathrm{mm}$. It is most like the latter in having only a single groove medial of the median ridge (Figure 6.3). It differs from it, however, in that the median ridge is wider distally (Figure 6.3). There is a longer section of shaft preserved than in any of the other nyctithere distal tibiae (Figures 6.3.2, 8). In lateral view, this shows that the flat area interpreted to represent contact with the fibula extends for much of its length, only narrowing and dying out as the distal extremity is approached (Figure 8.3). A second less complete distal tibia from the same site indicates intraspecific variation in width of the median ridge. On size grounds these tibiae could belong to C. woodi or Paradoxonycteris sp. 1, both of which are represented in the fauna by teeth. However, morphological similarities to $S$. hatherwoodensis, which is dentally similar to Paradoxonycteris, point to identification as Paradoxonycteris.

Material of distal tibia type 4. Left, M95951, How Ledge Limestone, Headon Hill.

Description. Type 4 is about half the linear dimensions of type 1 in distal view (distal width $1.11 \mathrm{~mm}$ ). It is like types 2 and 3 in having only one groove for both the flexor digitorum tibialis and tibialis posterior tendons (Figure 6.4.1, 6.4.2). It differs from types 1 and 3 in that the outline in distal view is relatively more extensive anteroposteriorly. The median ridge on the posterior face is wider like one 


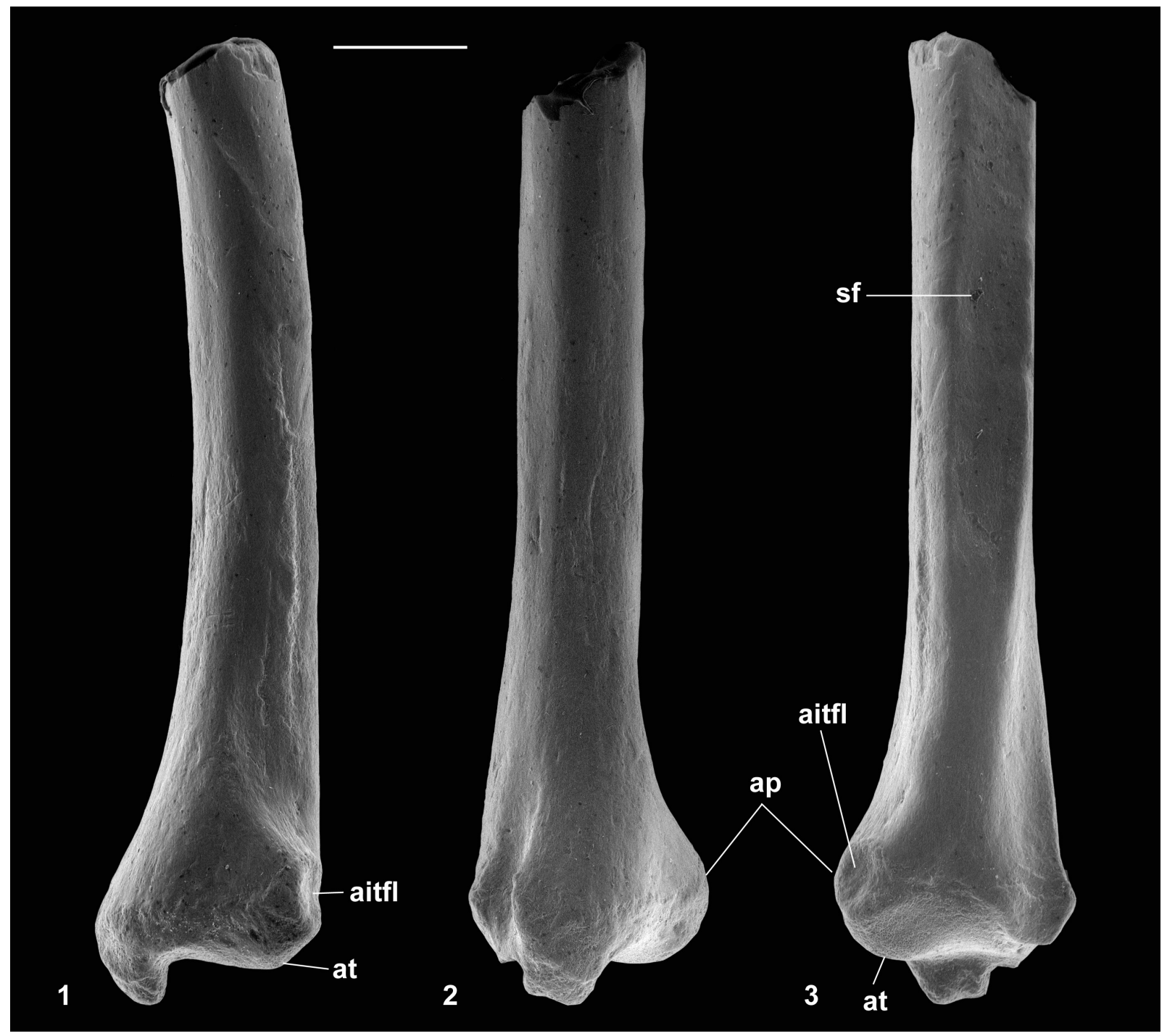

FIGURE 8. Scanning electron micrographs of right distal tibia (reversed) type 3 (Paradoxonycteris sp. 1), M95949, How Ledge Limestone, Headon Hill, Isle of Wight. Views are: anterior (1), medial (2) and lateral (3). Scale equals 1 $\mathrm{mm}$.

specimen of type 3 . It differs from types 1,2 , and 3 in having a relatively stouter shaft and a less prominent anterodistal projection. On size grounds and its ability to articulate with astragalus type 4, which in turn articulates with calcaneum type 4, attributable to Euronyctia grisollensis, tibia type 4 is judged also to belong to Euronyctia grisollensis.

Functional comparisons. The implication of the depths of the grooves on either side of the posterior protuberance is that the flexor digitorum fibularis, flexor digitorum tibialis and tibialis posterior tendons were well developed. The last two are important in flexing the plantar foot muscles. Their exact action, however, is difficult to establish, without knowing their insertion sites. For instance in the moles Scapanus and Neurotrichus, the flexor digitorum tibialis abducts the hallux, whereas in the shrew Sorex it flexes digits I-IV (Reed, 1951). In primates and Ptilocercus, both muscles participate in inverting the foot and the flexor digitorum tibialis, together with the flexor digitorum fibularis, is also involved in hallucal grasping (Grand, 1967; Dagosto, 1983; Gebo, 1993; Sargis, 2002b). Given the articular evidence that nyctitheres could invert the foot (Hooker, 2001), it is reasonable to infer at least an inversion function for these muscles. In the nyctithere, the tendinal grooves are deep and arranged on either side of the posterior protuberance, as in Ptilocercus, and unlike Tupaia, where the grooves are shallow and that for the flexor digi- 


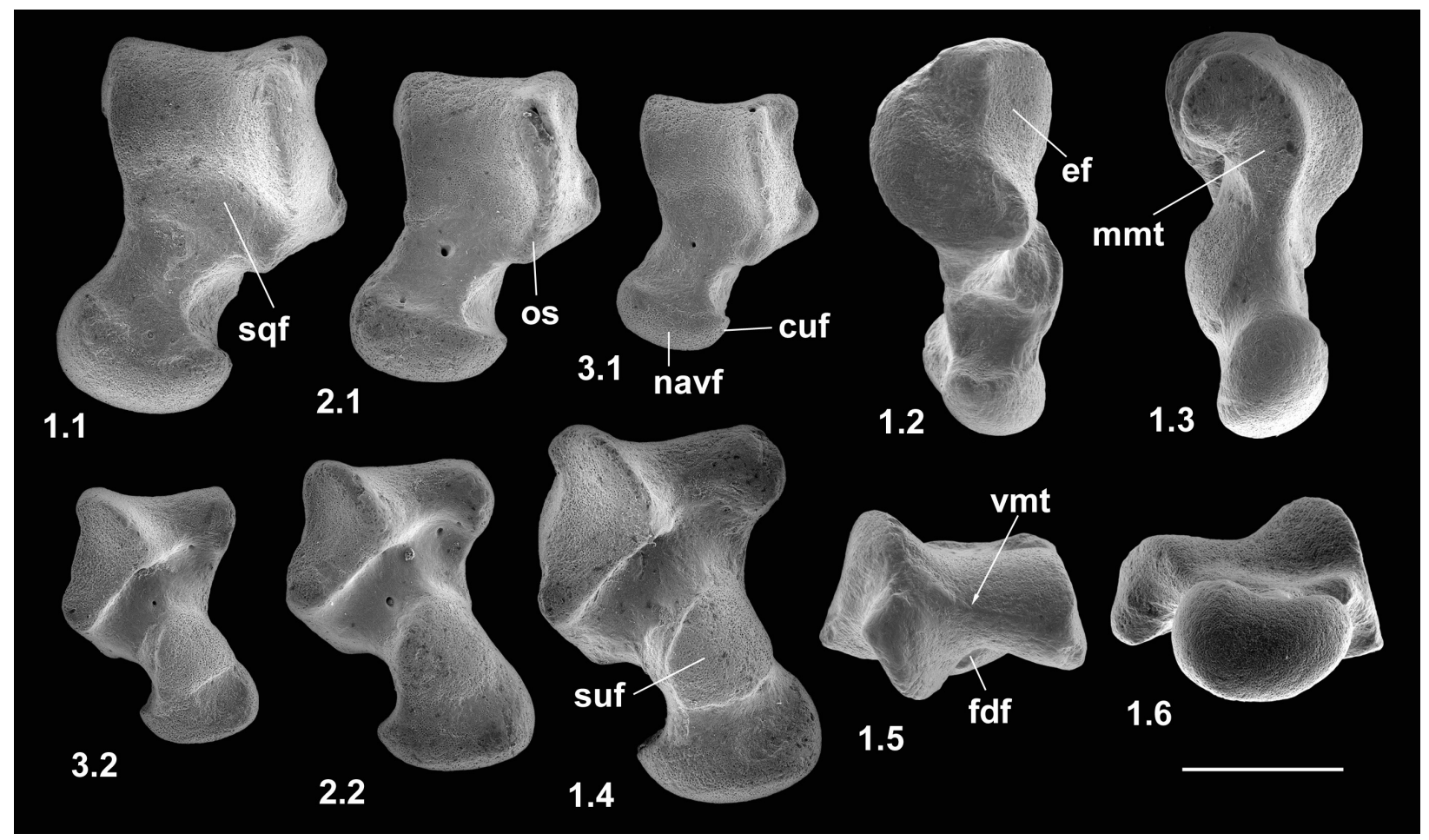

FIGURE 9. Scanning electron micrographs of left astragali of Nyctitheriidae. 1, type 2 (Paradoxonycteris sp. 1), M95952; 2, type 3 (Scraeva hatherwoodensis), M60101; 3, type 4 (Euronyctia grisollensis), HZM.108.25595. Views are: dorsal $(1.1,2.1,3.1)$, ventral $(1.4,2.2,3.2)$, lateral $(1.2)$, medial $(1.3)$, proximal $(1.5)$ and distal $(1.6)$. 3 is from the Rodent Bed, Hordle, Hampshire; the others from the Mammal Bed, Hordle. Scale equals $1 \mathrm{~mm}$.

torum fibularis is posterior. This suggests also a hallucal grasping function for nyctitheres, although the hallux and entocuneiform are currently unknown.

\section{Astragalus}

Material of astragalus type 2. Left, M95952M95954, M95956, right, M95955, M95957; How Ledge Limestone, Headon Hill.

Description. The astragalus attributed tentatively to Cryptotopos has already been described (Hooker, 2001). It is referred to here as type 1 and attributed more precisely to $C$. woodi. Astragalus type 2 from the How Ledge Limestone is slightly shorter than type 1. Medial length is $2.27-2.49 \mathrm{~mm}$, mean of five $2.41 \mathrm{~mm}$. Proximal width is $1.43-1.60$ $\mathrm{mm}$, mean of five $1.51 \mathrm{~mm}$. In contrast, type 1 is 2.68-2.74 $\mathrm{mm}$ in medial length, mean of six 2.70 $\mathrm{mm}$, but of similar proximal width: $1.47-1.59 \mathrm{~mm}$, mean of seven $1.53 \mathrm{~mm}$. Type 2 differs in having: a relatively longer body; a relatively shorter neck; a protruding proximolateral corner; a less projecting distolateral corner of the fibular facet; a dorsoventrally deeper oblique shelf at the distal end of the lateral trochlear ridge; a squatting facet that is less sharply demarcated laterally; a smaller more iso- lated sustentacular facet; a weak proximomedial plantar process; and a more ventrally projecting proximomedial edge of the ectal facet (Figure 9.1). These last two features produce a deeper intervening plantar groove for transmission of the flexor digitorum fibularis tendon (Figure 9.1.5). The trochlea is also slightly shallower. The medial side of the body is also dorsoventrally shallower, the facet for articulation with the medial malleolus of the tibia extending the full depth distal of the ligamental area (Figure 9.1.3, 9.1.6). In contrast, in type 1 this facet extends only half way down the medial wall. In distal view, the head of type 2 can be seen to have a different shape. Its long axis dips gently laterally rather than being horizontal with respect to the body as in type 1 (Figure 9.1.6). It is also dorsoventrally deeper at its medial end and has a dorsal concavity. According to size, this astragalar type is referable to Paradoxonycteris sp. 1 (Figure 10 , Tables 2-3), whose distal tibia is also recognized.

Material of astragalus type 3. Left, M60101, M95906, right, M95907, Mammal Bed, Hordle.

Description. This is a slightly smaller astragalus than type 2. Medial length is $1.95-2.12 \mathrm{~mm}$, mean $2.04 \mathrm{~mm}$. Proximal width is $1.19-1.29 \mathrm{~mm}$, mean 

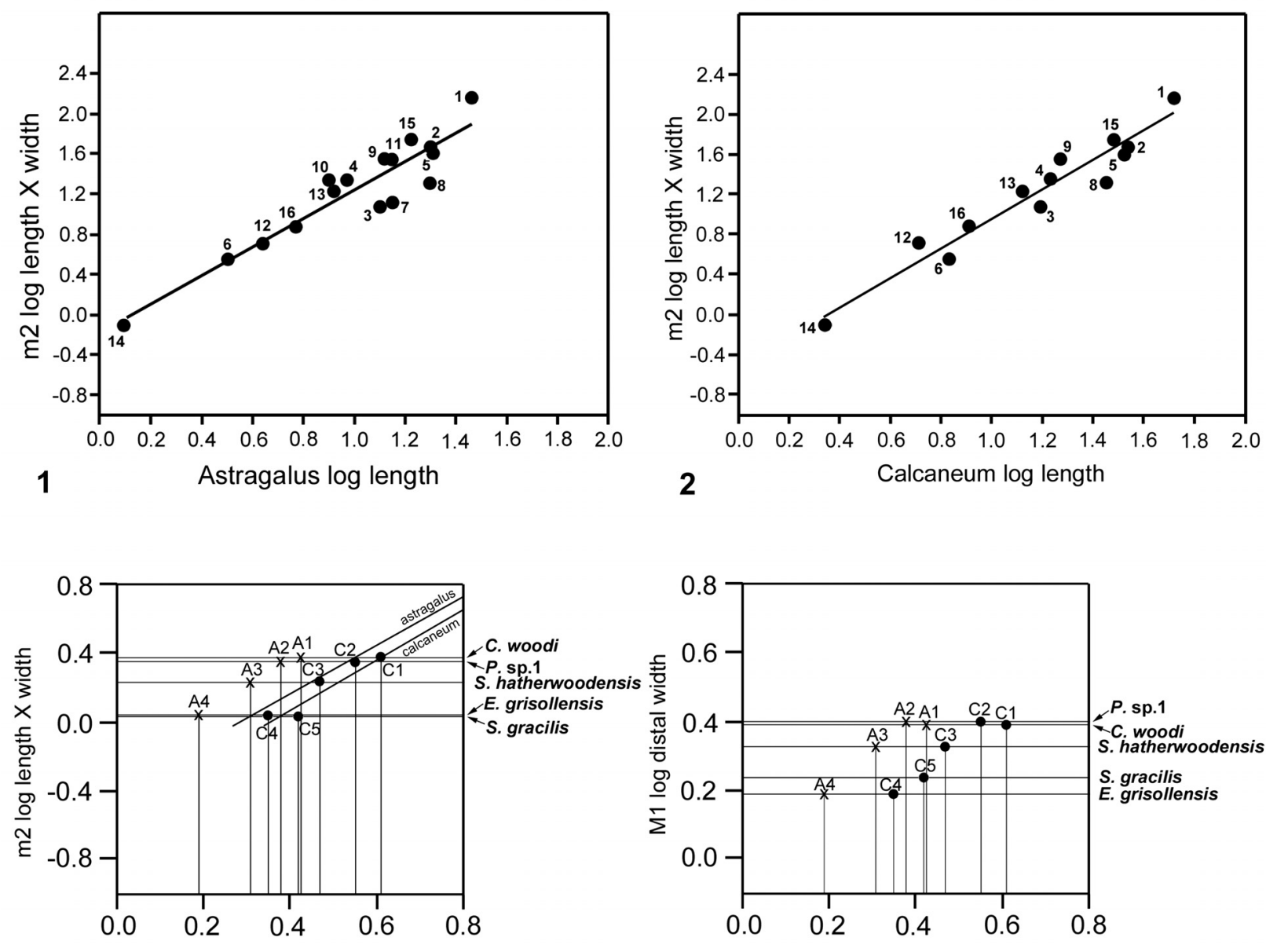

3 Astragalus \& Calcaneum log length

4 Astragalus \& Calcaneum log length

FIGURE 10. Logarithmic linear regressions of tooth versus astragalar and calcaneal dimensions in millimetres, following the methodology of Cifelli (1983) and Coillot et al. (2013). 1, $\mathrm{M}_{\mathbf{2}}$ area versus astragalar length of a range of mammals of known tooth and tarsal association; measurements of the numbered taxa are from Table 2; regression slope 1.4264, intercept $-0.18646 .2, M_{2}$ area versus calcaneal length as for 1; regression slope1.4686, intercept $0.52107 .3, M_{2}$ area of named nyctitheres versus lengths of astragalar $(A)$ and calcaneal $(C)$ numbered types, using the regression lines from 10.1 and 10.2; $\mathrm{M}_{\mathbf{2}}$ areas of Saturninia gracilis and Euronyctia grisollensis (How Ledge Limestone, Headon Hill) are nearly identical; those of Cryptotopos woodi and Paradoxonycteris sp. 1, although similar, are from the Mammal Bed, Hordle, and How Ledge Limestone, Headon Hill, respectively, removing doubt of attribution of type 1 and 2 tarsals from the same locations; calcaneal plots are closer to the regression line than are those of the astragali. 4, $M^{1}$ distal width versus lengths of astragalar $(A)$ and calcaneal $(C)$ numbered types; here the substantial difference in $\mathrm{M}^{1}$ distal width between $E$. grisollensis and $S$. gracilis supports the referral of calcaneum type 5 to the latter; Scraeva hatherwoodensis is from the Mammal Bed, Hordle. Measurements in 10.3 and 10.4 are derived from Table 3.

$1.24 \mathrm{~mm}$. It is very similar morphologically (Figure 9.2). It is thus referred to Scraeva hatherwoodensis on size grounds (Figure 10, Tables 2-3). It articulates well with calcaneum type 3 .

Material of astragalus type 4. Left, HZM.108.25595, right, HZM.107.25594, Rodent
Bed, Hordle; right, M95958, How Ledge Limestone, Headon Hill.

Description. This type is two-thirds the linear dimensions of type 2. Medial length is 1.52$1.54 \mathrm{~mm}$, mean $1.53 \mathrm{~mm}$. Proximal width is $0.85-$ $0.96 \mathrm{~mm}$, mean $0.92 \mathrm{~mm}$. However, types 2 and 4 are morphologically very similar (Figure 9.3). The 
TABLE 2. Tooth and tarsal measurements in millimetres of taxa numbered in Figure 10.1 and 10.2. All are means or single measurements. Sorex minutus, Ptilocercus lowii, Tupaia, Cynocephalus variegatus and Echinosorex gymnura are modern. Numbered sources: 1, Coillot et al. (2013); 2, Tobien (1962), Storch (1993); 3, Kondrashov and Lucas (2012).

\begin{tabular}{lcccc}
\hline & $\begin{array}{c}\text { Length } \mathbf{X} \text { width } \\
\mathbf{M}_{\mathbf{2}}\end{array}$ & $\begin{array}{c}\text { Length } \\
\text { Astragalus }\end{array}$ & $\begin{array}{c}\text { Length } \\
\text { Calcaneum }\end{array}$ & Source \\
\hline 1.Arctocyon primaevus & 144.64 & 28.5 & 52.5 & 1 \\
2.Arfia shoshoniensis & 47.24 & 19.95 & 34.95 & 1 \\
3.Cynocephalus variegatus & 11.75 & 12.6 & 15.5 & herein \\
4.Echinosorex gymnura & 22.46 & 9.28 & 17.14 & herein \\
5.Gazinocyon vulpeculus & 39.4 & 20.33 & 32.9 & 1 \\
6.Macrocranion tenerum & 3.52 & 3.14 & 6.71 & 2 \\
7.Miacis exiguus & 12.76 & 14.2 & - & 1 \\
8.Notoparamys costilloi & 20.52 & 20 & 28.4 & 1 \\
9.Plesiadapis cookei & 35.14 & 13.02 & 18.8 & 1 \\
10. Plesiadapis rex & 22.3 & 7.94 & - & 1 \\
11. Prototomus martis & 34.78 & 14.1 & - & 1 \\
12. Ptilocercus lowii & 5.15 & 4.35 & 5.15 & herein \\
13. Rhombomylus turpanensis & 16.85 & 8.38 & 13.07 & 1 \\
14. Sorex minutus & 0.77 & 1.27 & 2.18 & herein \\
15. Tetraclaenodon puercensis & 54.27 & 16.4 & 30.4 & 3 \\
16.Tupaia sp. & 7.54 & 5.9 & 8.15 & herein \\
\hline
\end{tabular}

two Rodent Bed specimens are well preserved. That from the contemporaneous How Ledge Limestone is somewhat abraded, which probably accounts for its slenderer proportions, despite similar length. Size fits contemporaneous calcaneum type 4, which suggests referral to Euronyctia grisollensis (Figure 10, Tables 2-3).

\section{Calcaneum}

Material of calcaneum type 2. Left, M95960M95962, M95978, right, M95963, M95964; How Ledge Limestone, Headon Hill.

Description. Calcanea from the Hordle Mammal Bed have already been described and attributed tentatively to the genus Cryptotopos (Hooker, 2001). They are referred to here as type 1 and attributed more precisely to $C$. woodi.

Type 2 is slightly shorter than type 1 , but broadly similar in overall size (Figures 11.1, 12.1). Length is $3.37-3.74 \mathrm{~mm}$, mean $3.51 \mathrm{~mm}$. Width is 2.41-2.47 mm, mean of two $2.44 \mathrm{~mm}$. In contrast, type 1 is $3.89-4.27 \mathrm{~mm}$ in length, mean of seven $4.09 \mathrm{~mm}$, and $2.65 \mathrm{~mm}$ in width (single value). From its size it should belong to Paradoxonycteris sp. 1, the commonest large nyctithere represented by teeth in the How Ledge Limestone (Figure 10, Tables 2-3). It articulates well with co-occurring astragalus type 2 with the same attribution. There are six type 2 calcanea, showing the consistency of differences from type 1 . The ectal facet is orientated at c. 35 degrees to the tuber long axis (Figure 11.1.1), whereas this angle is c. 25 degrees in type 1. The tuber is more cylindrical, less laterally compressed than in type 1 . The depression on its lateral wall proximal of the fibular facet, which is probably for attachment of the calcaneofibular ligament, is deeper (Figure 11.1.3). The ectal facet overlaps slightly with the sustentaculum as in type 1. The lateral wall of the tuber curves evenly into the base of the peroneal process (Figure 11.1.2), whereas in type 1 there is a slight 'shoulder' opposite the proximal base of the sustentaculum (Hooker, 2001, figure 11B). The groove for transmission of the flexor digitorum fibularis tendon begins slightly more distally than in type 1 , the ridge delimiting it curving dorsally at its proximal end (Figure 12.1.1). The ectal facet is more extensive ventrally and projects dorsally more than in 
TABLE 3. Tooth (named) and tarsal (numbered types) measurements in millimetres of nyctitheriid taxa used in Figure 10.3 and 10.4. All are means or single measurements.

\begin{tabular}{lccccc}
\hline & $\begin{array}{c}\text { Length } \mathbf{X} \text { width } \\
\mathbf{M}_{\mathbf{2}}\end{array}$ & $\begin{array}{c}\text { Distal width } \\
\mathbf{M} \mathbf{1}\end{array}$ & Type & $\begin{array}{c}\text { Length } \\
\text { Astragalus }\end{array}$ & $\begin{array}{c}\text { Length } \\
\text { Calcaneum }\end{array}$ \\
\hline Cryptotopos woodi & 2.36 & 2.46 & 1 & 2.7 & 4.09 \\
Paradoxonycteris sp. 1 & 2.22 & 2.48 & 2 & 2.41 & 3.51 \\
Scraeva hatherwoodensis & 1.71 & 2.15 & 3 & 2.04 & 2.97 \\
Euronyctia grisollensis & 1.09 & 1.54 & 4 & 1.53 & 2.24 \\
Saturninia gracilis & 1.07 & 1.73 & 5 & - & 2.65 \\
\hline
\end{tabular}

type 1. The distal margins of both sustentaculum and peroneal process are nearly terminal, flush with the cuboid facet (Figure 11.1.1, 11.1.2), whereas they are subterminal in type 1 . The sustentaculum has a rounded rather than angular profile and is orientated transversely, rather than angled slightly proximomedially as occurs in type 1 . The peroneal process is longer proximodistally and recurves proximally at its tip. The outline of the cuboid facet in distal view has a straight rather than concave dorsomedial edge (Figure 12.1.2). The distal sustentacular facet is as on type 1 (Hooker, 2001), separate from the main sustentacular facet (Figure 11.1.1).

Material of calcaneum type 3. Right, M95911, M95912, Hordle Mammal Bed.

Description. M95911 is the more complete, but has much of the peroneal process broken away (Figures 11.2, 12.2). M95912 has both this and the sustentaculum truncated. Both have a weathered surface. They are intermediate in size between type 1 (Cryptotopos woodi) and type 4 (Euronyctia grisollensis) (length 2.82-3.12 mm). Preservation limits detailed observations of structure, but the tuber is relatively longer than that of types 2 and 4 . Size indicates attribution to Scraeva hatherwoodensis (Figure 10, Tables 2-3).

Material of calcaneum type 4. Left, M95959, M95966; How Ledge Limestone, Headon Hill.

Description. This type is about two-thirds the linear dimensions of type 2 (Figures 11.3, 12.3). Length is $2.15-2.32 \mathrm{~mm}$. Width of M95959 is 1.62 $\mathrm{mm}$. It articulates well with astragalus type 4 . In most morphological features, calcaneum type 4 resembles type 2 . It differs in having a relatively narrower tuber like type 1, a slightly more proximally positioned ectal facet, making the more proximal part of the tuber shorter than that of either type 1 or type 2 (Figure 11.3.1). The ectal facet of calcaneum type 4 also extends medially more than it does in types 1 or 2 , although this may be partly influenced by the narrower tuber. The peroneal process is slightly smaller and subterminal like type 1. The cuboid facet is relatively more elongate dorsomedially-ventrolaterally than in the other types of calcaneum (Figure 12.3.2). Unlike types 1 and 2, the distal sustentacular facet is confluent with the main sustentacular facet (Figure 11.3.1). The fact that type 5 is intermediate in size between types 4 and 3 shows that type 4 should belong to the smallest species of nyctithere, E. grisollensis (Figure 10, Tables 2-3). This is supported by the strong morphological similarity to its closest relative $S$. hatherwoodensis.

Material of calcaneum type 5. Left, M95965; How Ledge Limestone, Headon Hill.

Description. The single specimen is somewhat rolled and has most of the sustentaculum and peroneal process broken away, so information is limited (Figures 11.4, 12.4). It differs from the other nyctithere calcanea in appearing to have an ectal facet nearly parallel to the long axis, although this might be influenced by poor preservation (Figure $11.4 .1,11.4 .2$ ). It is intermediate in size (length $2.65 \mathrm{~mm}$ ) between types 3 and 4 and may therefore belong to Saturninia gracilis Stehlin, 1941 (Figure 10.4, Table 3).

\section{Navicular}

Material of navicular type 1. Left, HZM.204.27205, right, M95913; Mammal Bed, Hordle; left, M95968; How Ledge Limestone, Headon Hill.

Description. Dorsoventral length is $1.32-1.56 \mathrm{~mm}$, mean $1.43 \mathrm{~mm}$. Mediolateral width is $1.28-1.35$ $\mathrm{mm}$, mean $1.31 \mathrm{~mm}$. HZM.204.27205 is the best preserved (Figure 13.1). The bone is about half as long proximodistally as it is mediolaterally or dorsoventrally. Proximally, the astragalar facet is evenly concave and rounded-triangular in outline (Figure 13.1.3). The dorsal surface is obliquely orientated with respect to the mediolateral plane (Figure 


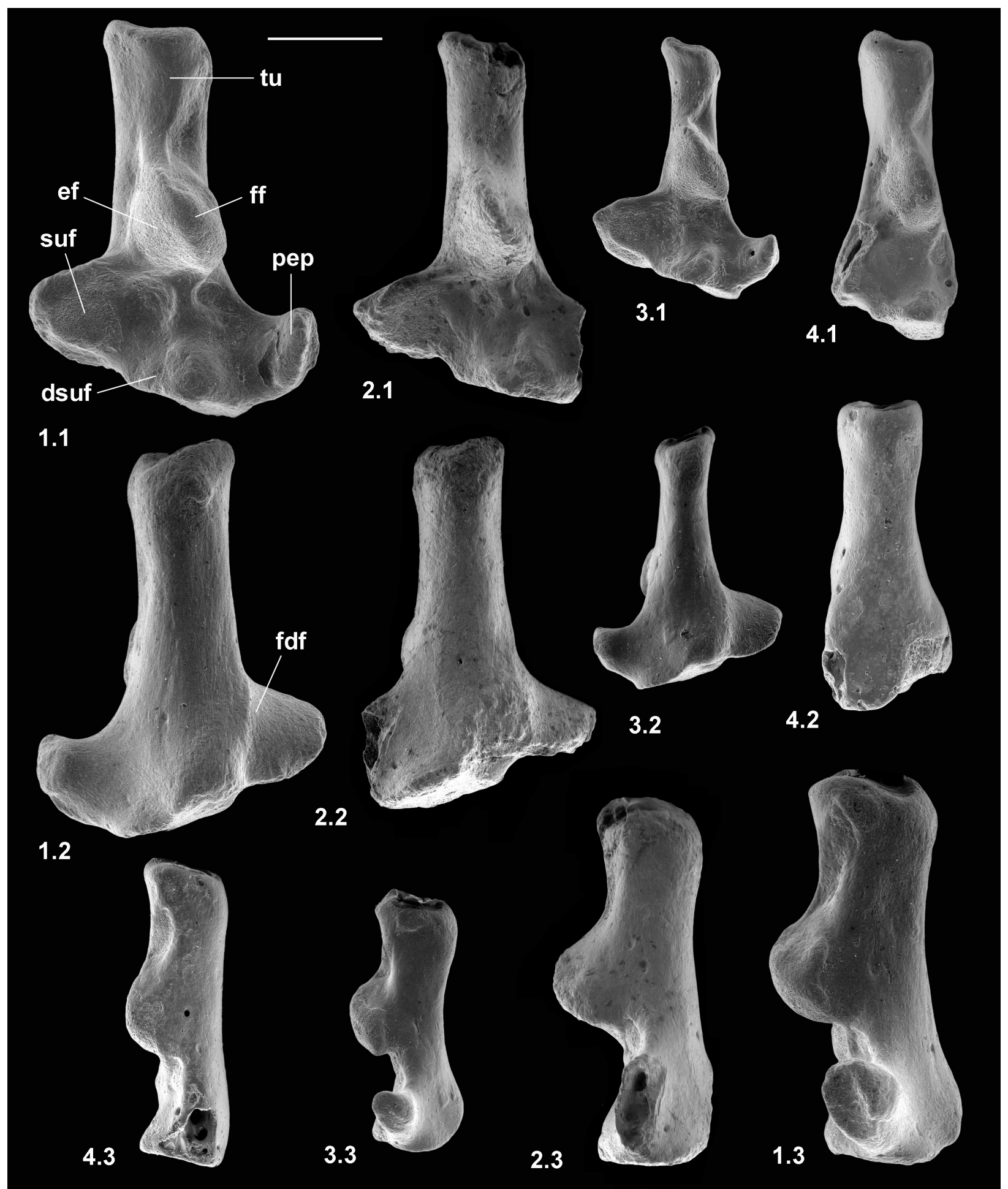

FIGURE 11. Scanning electron micrographs of calcanea, shown as left, of Nyctitheriidae. 1, left calcaneum type 2 (Paradoxonycteris sp. 1), M95960; 2, right calcaneum (reversed) type 3 (Scraeva hatherwoodensis), M95911; 3, left calcaneum type 4 (Euronyctia grisollensis), M95959; 4, left calcaneum type 5 (Saturninia gracilis?), M95965. Views are: dorsal $(1.1,2.1,3.1,4.1)$, ventral $(1.2,2.2,3.2,4.2)$ and lateral $(1.3,2.3,3.3,4.3)$. 1-2 are from the Mammal Bed, Hordle, Hampshire; 3-4 are from the How Ledge Limestone, Headon Hill, Isle of Wight. Scale equals $1 \mathrm{~mm}$. 


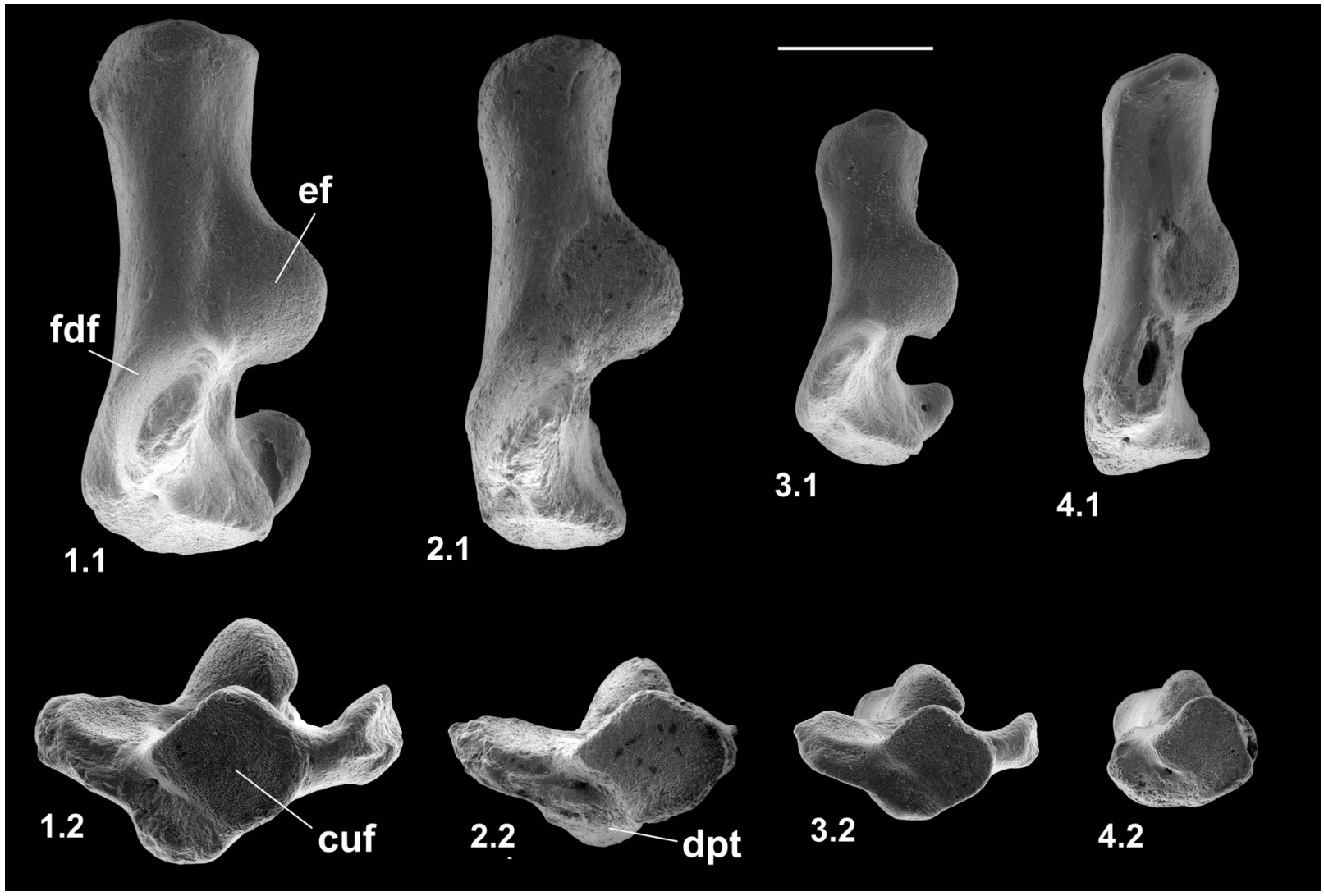

FIGURE 12. Scanning electron micrographs of calcanea, shown as left, of Nyctitheriidae. 1, left calcaneum type 2 (Paradoxonycteris sp. 1), M95960; 2, right calcaneum (reversed) type 3 (Scraeva hatherwoodensis), M95911; 3, left calcaneum type 4 (Euronyctia grisollensis), M95959; 4, left calcaneum type 5 (Saturninia gracilis?), M95965. Views are: medial $(1.1,2.1,3.1,4.1)$ and distal $(1.2,2.2,3.2,4.2)$. 1-2 are from the Mammal Bed, Hordle, Hampshire; 3-4 are from the How Ledge Limestone, Headon Hill, Isle of Wight. Scale equals $1 \mathrm{~mm}$.

13.1.1). There is a plantar process that projects slightly distoventrally, with a long ventral slope, but without a major distal process (see medial and lateral views: Figure 13.1.5, 13.1.6). In distal view, the plantar process is a major feature, the facets for the mesocuneiform and ectocuneiform being restricted dorsally, that for the ectocuneiform more than for the mesocuneiform (Figure 13.1.2), although the difference is less for M95968. This distribution of these facets is comparable to that in tree shrews and the dermopteran Cynocephalus. Laterally, the concave ectocuneiform facet is visible, its oblique plane scalloping the distal margin and invading the lateral face for at least half of its proximodistal extent (Figure 13.1.6). In contrast, the mesocuneiform facet is approximately aligned with the distal face. It is mainly gently concave but curves away proximally at its ventrolateral extremity. On the lateral face there is a small cuboid facet dorsally. The dorsal face of HZM.204.27205 and M95913 bears a neurovascular foramen, which lies in a shallow sulcus trending proximomedially to distolaterally. Both are lacking in M95968, but this could be due to poor preservation. All three have a neurovascular foramen on the lateral flank of the plantar process around the proximodistal midpoint. The proximal margin of the dorsal face is gently concave proximally. The only appropriately sized nyctithere represented dentally in both the Hordle Mammal Bed and How Ledge Limestone is Cryptotopos woodi. Teeth from the latter unit are very slightly larger than those from the former, matching the size differences in the two naviculars. They also articulate well with the type 1 astragalus (Figure 14.6, 14.7). Navicular type 1 is therefore identified as $C$. woodi.

Material of navicular type 2. Right. M95967, How Ledge Limestone, Headon Hill.

Description. This is similar to type 1, but relatively narrower mediolaterally (Figure 13.2). Dorsoventral length is $1.32 \mathrm{~mm}$ and mediolateral width is 1.09 $\mathrm{mm}$. The ectocuneiform facet has a shallower angle and is flat rather than concave (Figure 13.2.3); the plantar process extends less ventrally 


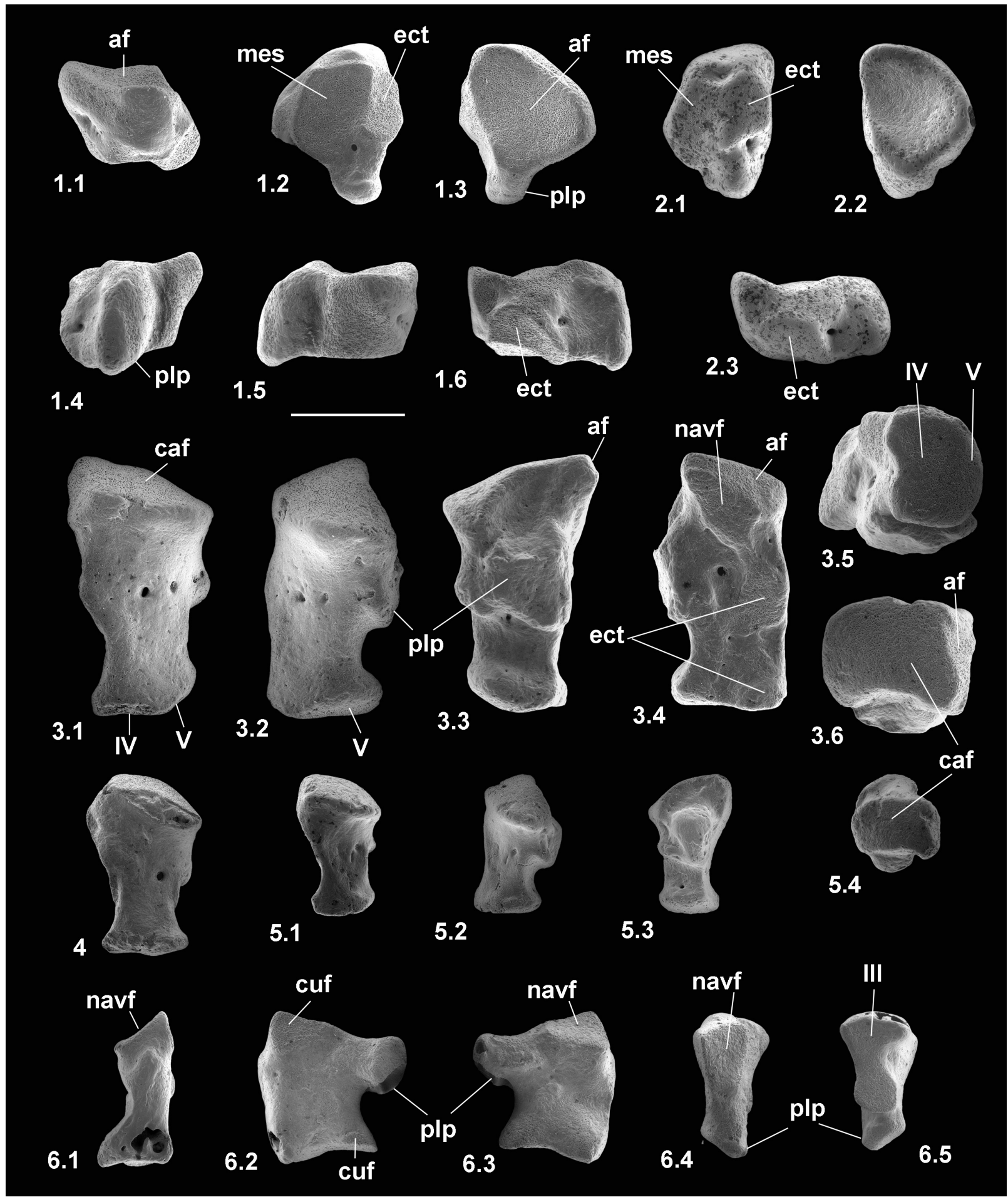

FIGURE 13. Scanning electron micrographs of naviculars, cuboids and ectocuneiform, shown as left, of Nyctitheriidae. 1, left navicular type 1 (Cryptotopos woodi), HZM.204.27205; 2, right navicular (reversed) type 2 (Paradoxonycteris sp.1?), M95967; 3, right cuboid (reversed) type 1 (Cryptotopos woodi), M60970; 4, right cuboid (reversed) type 2 (Scraeva hatherwoodensis), M95918; 5, right cuboid (reversed) type 3 (Euronyctia grisollensis), M95969; 6, left ectocuneiform (Scraeva hatherwoodensis?), M95919. Views are: dorsal (1.1, 3.1, 4, 5.1, 6.1), distal (1.2, 2.1, 3.5, 6.5), proximal $(1.3,2.2,3.6,5.4,6.4)$, ventral $(1.4,3.3,5.3)$, medial $(1.5,3.4,6.3)$, lateral $(1.6,2.3,3.2,5.2,6.2) .1,3,4,6$ are from the Mammal Bed, Hordle, Hampshire; 2, 5 are from the How Ledge Limestone, Headon Hill, Isle of Wight. Scale equals $1 \mathrm{~mm}$. 


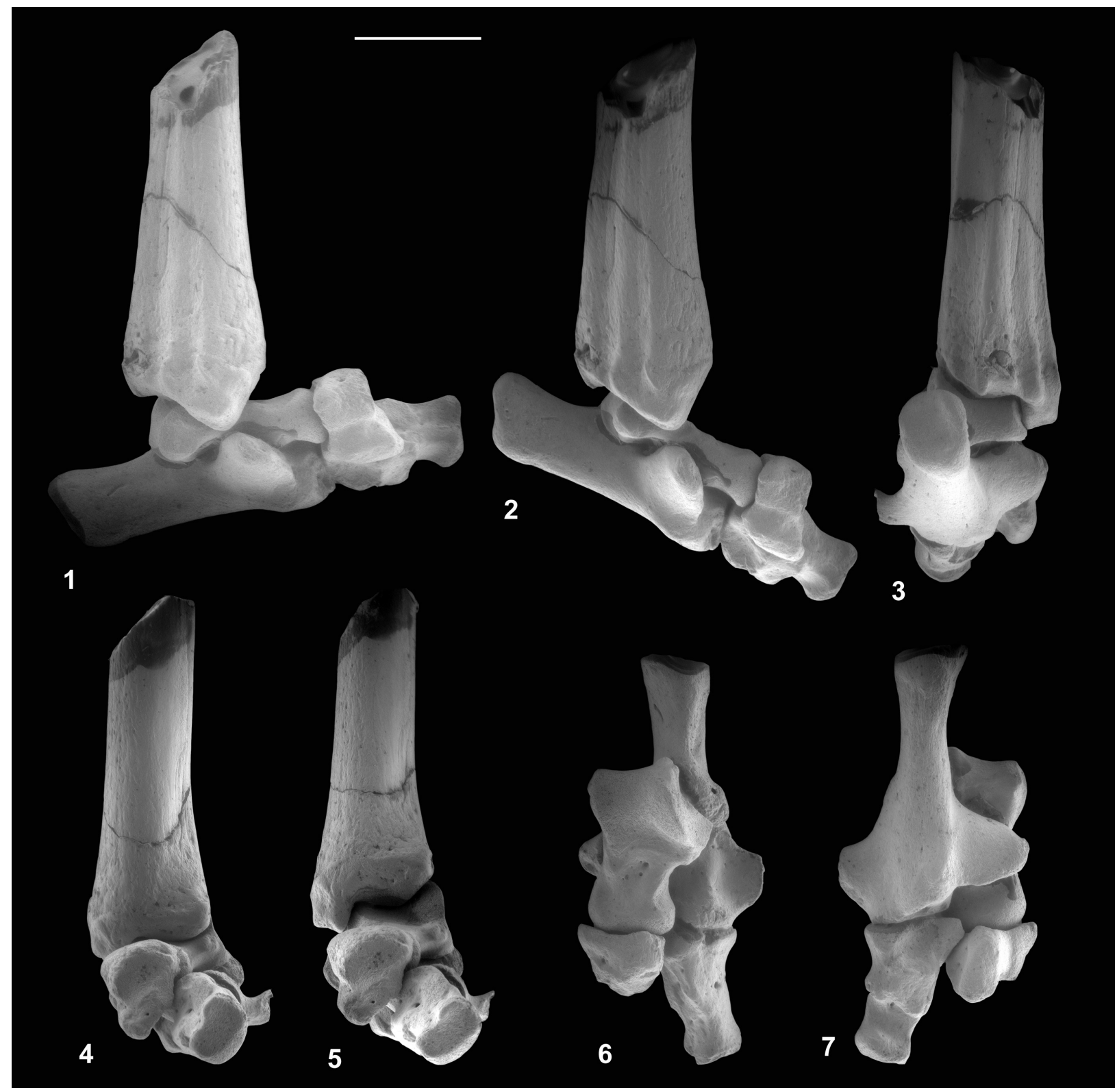

FIGURE 14. Scanning electron micrographs of composite reconstructed right ankle region (reversed), inverted at astragalo-calcaneal joint, of Cryptotopos woodi (type 1), Mammal Bed, Hordle, Hampshire. Distal tibia, M95901; astragalus, M95905; calcaneum, M95910; navicular, M95913; cuboid, M60970. Tibia is omitted from 6-7. Ankle dorsiflexed $(1,4)$, plantarflexed $(2,3,5)$. Views are: medial (1-2), posterior (3), anterior (4-5), dorsal (6), ventral (7). Scale equals $2 \mathrm{~mm}$.

and distally; and the neurovascular foramen on the lateral flank of the plantar process is more distally positioned. The lesser extent of the plantar process might be influenced by poor preservation, but less so the other two differences. Size suggests that navicular type 2 may belong to Paradoxonycteris sp 1.

Reasons for identification as nyctithere. Comparably sized taxa other than nyctitheres occurring in the Solent Group can be excluded. Glirid navicu- lars occur, although not yet described, and are proximodistally relatively longer, have nearly equalsized facets for ectocuneiform and mesocuneiform, which are both more extensive dorsoventrally, the plantar process is weaker and less projecting and the lateral wall bulges proximoventrally. In these ways they are similar to modern Glis (personal obs.). Undescribed herpetotheriid naviculars also occur and are like modern Didelphis in having a long tuber tibialis (Szalay, 1994; personal obs.). 
Although talpid naviculars are yet to be found in the Solent Group, modern talpid and indeed other lipotyphlan (soricid and erinaceid) naviculars also have a tuber tibialis, unlike the putative nyctitheres. Likewise, the unknown navicular of the microchoerine Pseudoloris should be greatly elongated proximodistally as in other omomyids (e.g., Szalay, 1976). The best preserved apatemyid navicular is that of Apatemys chardini from the Early Eocene Green River Formation, Wyoming (Koenigswald et al., 2005, figure 5, plate 4, figure A). The line drawing (Koenigswald et al. 2005, figure 5) shows the left navicular in dorsal view, with a short tuber tibialis, unlike the putative nyctitheres. The navicular of the apatemyid Heterohyus nanus from the Middle Eocene of Messel, Germany, is similar (Koenigswald, 1990, figure 18a (left)).

\section{Cuboid}

Material of cuboid type 1. Right, M60788, M60970, M95914-M95917, Mammal Bed, Hordle.

Description. These bones are about twice as long as wide in medial or lateral views. Proximodistal length is $2.29-2.48 \mathrm{~mm}$, mean $2.40 \mathrm{~mm}$. In dorsal or ventral view they are wider proximally than distally (Figure 13.3.1, 13.3.3). The calcaneal facet is very gently convex, sloping at c. 20 degrees dorsolaterally to the transverse plane. The distal articulation is kidney-shaped in outline with a main gently concave area for articulation with M/T IV more medially and a narrow proximally tilted facet at the lateral edge for articulation with $\mathrm{M} / \mathrm{T} \mathrm{V}$ (Figure 13.3.1, 13.3.2, 13.3.5). The medial face shows facets for articulation with the astragalar head, navicular and ectocuneiform (Figure 13.3.4).

The navicular facet appears to be slightly undercut distally, and its elongate outline is tilted dorsally. A large facet immediately distal of the navicular facet on the dorsal half of the medial face and a small facet on the dorsal half of the distal rim are apparently for the ectocuneiform. The remaining facet on the medial face, which is proximal to the navicular facet, dips dorsomedially and must contact the lateral side of the astragalar head (Figures 13.3.3, 13.3.4, 13.3.6, 14.7). This facetted part of the astragalar head is only faintly demarcated from the rounded navicular facet (Figure 9.1.1, 9.2.1, 9.3.1) and was originally thought to contact the distal sustentacular facet of the calcaneum (Hooker, 2001). However, when the astragalus is articulated with the calcaneum (admittedly likely different individuals) the astragalar head projects distally of the calcaneum, and the only available tarsal for contact with the lateral side of the astragalar head is the proximal facet of the medial face of the cuboid. As the calcaneum inverts under the astragalus, the cuboid moves with it and the latter's astragalar facet slides around the lateral side of the astragalar head.

The plantar tubercle projects distally over the distal third of the ventral face of the bone (Figure 13.3.2, 13.3.3, 13.3.4). This part of the face is rendered concave by a large ventral lip to the distal articulation. The plantar tubercle is transversely elongate, projecting slightly medially and laterally beyond the main profile in dorsal view. Its distal margin dips at c.10 degrees medially to the transverse plane. Although the concavity distal of the plantar tubercle is deep for transmitting the peroneus longus tendon, its course on the lateral face is relatively poorly marked. It is nevertheless demarcated proximally and dorsally by a blunt edge. This weakness is perhaps because the peroneal tubercle on the calcaneum is sufficiently distal and projects far enough laterally for the tendon to be angled such that it has relatively little contact with the cuboid before its strictly medial course distal of the plantar tubercle.

The angle and outline shape of the calcaneal facet match those of the cuboid facet of the type 1 calcanea attributed to Cryptotopos woodi (Hooker, 2001). The sizes of these facets also match well, indicating that type 1 cuboids belong to $C$. woodi, the largest nyctithere in the fauna.

Material of cuboid type 2. Right, M95918, Mammal Bed, Hordle.

Description. Type 2 is intermediate in size between types 1 and 3 (proximodistal length 1.63 $\mathrm{mm}$ ). The single specimen is damaged along the dorsal edge of the proximal articulation and on the plantar process (Figure 13.4). Morphologically it is more like type 3 than type 1. It articulates well with the type 3 calcaneum and is of appropriate size to belong to Scraeva hatherwoodensis.

Material of cuboid type 3. Right, M95969, How Ledge Limestone, Headon Hill.

Description. This cuboid is similar morphologically to type 1 from Hordle, but is much smaller, being $1.22 \mathrm{~mm}$ long. On size grounds and ability to articulate with the type 4 calcaneum, it should belong to Euronyctia grisollensis. Compared to type 1 cuboids, M95969 shows: in dorsal view a medial edge that trends distolaterally smoothly without being interrupted by an intermediate projection (Figure 13.5.1); a plantar tubercle that projects slightly further ventrally (Figure 13.5.2); a more convex calcaneal facet (Figure 13.5.1, 13.5.3); and virtually no facet contact for $M / T \mathrm{~V}$. Its calcaneal 
facet matches well the cuboid facets of the small nyctithere calcaneum type 4 from the same bed in being more elongate dorsomedially-ventrolaterally and of appropriate size (Figure 13.5.4).

Reasons for identification as nyctithere. These three cuboid types are unlike other small cuboids from the Solent Group (personal obs.). Glirid cuboids from the Solent Group, like modern Glis, are relatively shorter with a near transverse, not sloping calcaneal facet, a more extensive navicular facet and a more oblique groove for the peroneus longus tendon. Cuboids of small pseudosciurids are so far unknown, but are likely to be similar to the closely related, larger theridomyids. These share features with the glirid cuboids, but differ in having a dorsally sloping calcaneal facet and a parallel undercut M/T IV facet, giving a rhombic outline in side view. Those of herpetotheriids have a strongly convex and oblique calcaneal facet, a more distally situated groove for the peroneus longus tendon and proportions that are wider distally than proximally. Apatemyid cuboids are known only in dorsal view. They are relatively shorter and have a more transverse calcaneal facet (Koenigswald, 1990; Koenigswald et al., 2005). Cuboids of Eotalpa have not yet been found in the Solent Group, but are likely to be similar to those of modern shrews or primitive moles. That of Sorex has a more extensive navicular facet, the proximal articulation overhangs the dorsal surface, the groove for the peroneus longus tendon is more extensive, and there is no astragalar facet. Talpids are similar, but may also have a proximal process and a plantar process with a distal spur (Reed, 1951).

However, the most compelling evidence for types 1-3 belonging to the Nyctitheriidae is that their calcaneal facets closely match the cuboid facets of nyctithere calcanea and that they show taxonomic diversity especially in size.

\section{Ectocuneiform}

Material. Left, M95919, Mammal Bed, Hordle.

Description. The bone is narrow mediolaterally with a deeply concave medial face and a medially flaring distal articulation in dorsal view (Figure 13.6.1). The dorsal face is $1.28 \mathrm{~mm}$ long proximodistally. The proximal (navicular) facet is flat, dipping medially at c. 45 degrees. Its outline tapers slightly ventrally (Figure 13.6.4). The distal facet for $\mathrm{M} / \mathrm{T}$ III is gently concave and its outline is somewhat hourglass-shaped, flaring sharply mediolaterally at its dorsal end (Figure 13.6.2, 13.6.3, 13.6.5). There is a large plantar process, which projects from the proximal end of the ventral face. The dis- tal facet matches that of the $\mathrm{M} / \mathrm{T}$ III proximal facet of M95970 from the How Ledge Limestone, in outline and profile, although it is slightly smaller (Figure 15.2). The proximal facet matches the ectocuneiform facet of the type 2 navicular (M95967), also from the How Ledge Limestone, in outline and profile, but again is slightly smaller. This justifies identification of this ectocuneiform as a nyctithere. It should therefore belong to Scraeva hatherwoodensis, on size grounds and as this is the nyctithere from the Hordle Mammal Bed that on dental characters is most closely related to Paradoxonycteris sp. 1, the taxon in the How Ledge Limestone to which the M/T III and type 2 navicular are tentatively referred, but slightly smaller. Ptilocercus has a similar shaped ectocuneiform, but with a weaker distal flare, shallower medial concavity, less projecting plantar process and a proximal facet whose plane is normal to the long axis.

\section{Ankle Function}

Manipulation of the articulation of the type 1 astragalus and type 1 distal tibia of Cryptotopos woodi indicates that the long axis of the astragalus makes an angle of 120 degrees to the long axis of the tibia when plantarflexed and 80 degrees when dorsiflexed, giving a range of movement of 40 degrees (Figure 14.1, 14.2). Before the tibia was known, it was thought that the significant difference in dimensions of the radii of the lateral and medial trochleae of the astragalus would have conferred some degree of pedal inversion at the upper ankle joint (Hooker, 2001). It can be seen now that there appears to be slight change in the vertical plane of motion of the astragalus with respect to the tibia between dorsiflexion (Figure 14.4) and plantarflexion (Figure 14.5), leading to an increase in inversion of c. 20 degrees. This would have to have been accommodated by the distal shaft syndesmosis between the tibia and fibula, which should have restricted mediolateral movements at the upper ankle joint. However, the lateral movements here are likely to have been small.

In full inversion of the foot at the calcaneoastragalar joint, the lateral plane of the foot, according to a line drawn across the dorsal surface of the navicular and cuboid in distal view, is c.50 degrees short of being parallel with the longitudinal anteroposterior plane of the tibia (Figure 14.4). This is judged with the astragalus fully dorsiflexed. With the slight shift at the upper ankle joint with plantarflexion, inversion should have been shifted another c.20 degrees (Figure 14.5). Abduction and external rotation of the femur as envisaged (see 


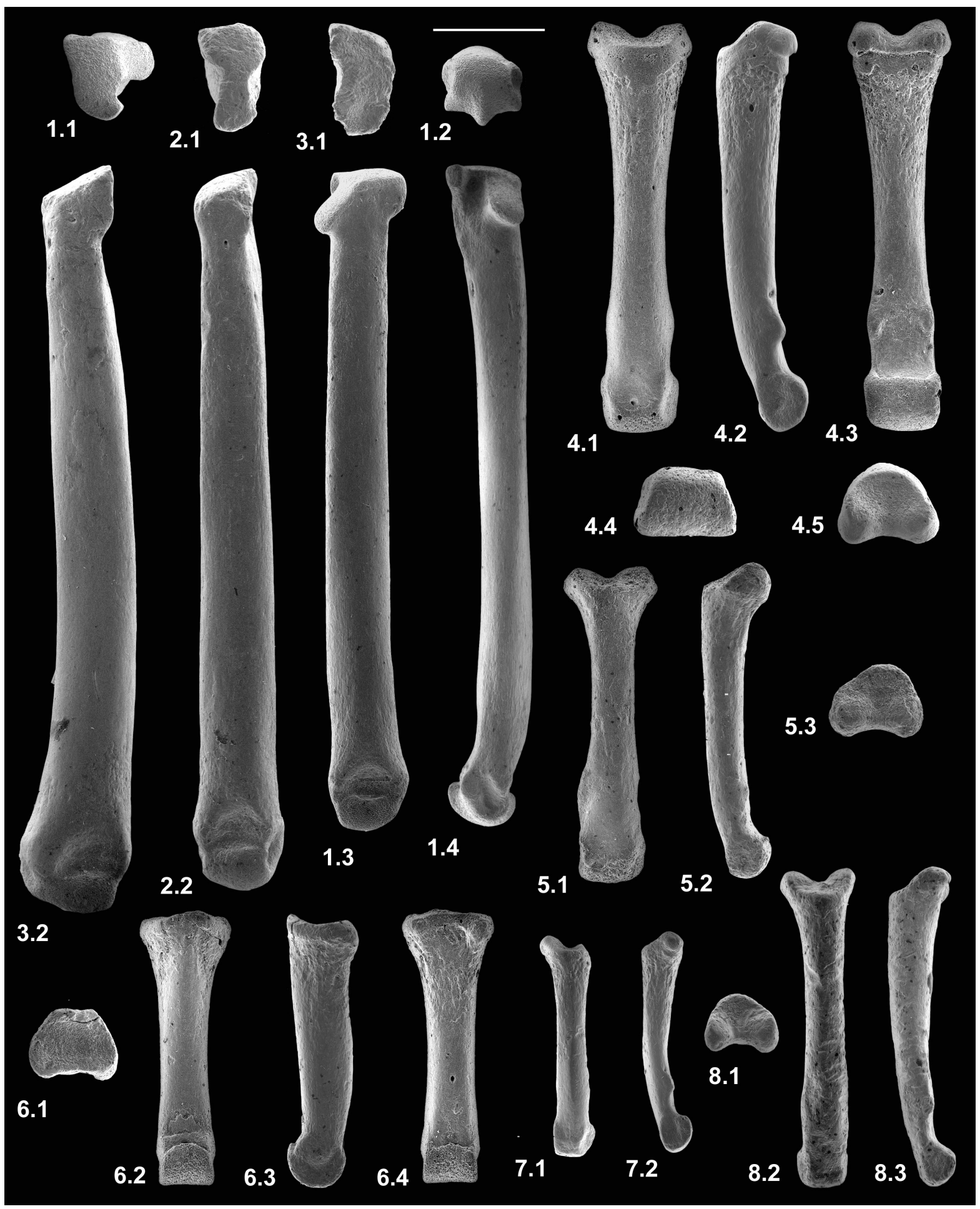

FIGURE 15. Scanning electron micrographs of metatarsals and phalanges of Nyctitheriidae. 1, right metatarsal IV (reversed), M95976; 2, left metatarsal III, M95970; 3, right metatarsal II (reversed), M95975; 4-5, 7-8, first phalanges; 6, second phalanx. 5 is manual?, 4, 7-8 are pedal?. 4, M60843; 5, M61114; 6, M60989; 7, HZM.588.30474; 8, M60790. Views are: proximal $(1.1,2.1,3.1,4.5,5.3,6.1,8.1)$, distal $(1.2,4.4)$, dorsal $(1.3,2.2,3.2,4.1,5.1,6.2,7.1$, 8.2), medial (1.4), ventral $(4.3,6.4)$ and side $(4.2,5.2,6.3,7.2,8.3)$. 2, Paradoxonycteris sp. 1?; 4-6, Cryptotopos woodi?; 7, Euronyctia grisollensis or Saturninia gracilis; 8, Scraeva hatherwoodensis? 1, lower Hamstead Member, Bouldnor, Isle of Wight; 2, How Ledge Limestone, Headon Hill, Isle of Wight; 3, Fishbourne Member, Woodside, Isle of Wight; 7, Rodent Bed, Hordle, Hampshire; 4-6, 8, Mammal Bed, Hordle. Scale equals $1 \mathrm{~mm}$. 
above) could have effected limited further invertion of the entire foot. In Scraeva hatherwoodensis, the plantarflexed angle of the type 3 astragalus to the type 2 tibia long axis is 130 degrees and the angle in dorsiflexion is 100 degrees, thus a range of 30 degrees, less than in Cryptotopos woodi.

In all nyctitheres examined, there is a depression on the distal side of the astragalar trochlea, into which the blunt anterior process of the tibia fitted when the foot was fully dorsiflexed. This has been identified as a squatting facet by Rose et al. (2013). However, it is uncertain if it is strictly homologous with the squatting facet of humans, which is a variable accessory feature (Aiello and Dean, 1990) not associated with an anterior tibial process. The structure in nyctitheres suggests that dorsiflexion was a habitual posture for the foot during locomotion. Such a structure occurs in modern and extinct macroscelideans (Penkrot et al., 2008) and to a lesser extent in modern lipotyphlans and Tupaia (personal obs.).

It appears that the medial malleolus of the tibia did not obstruct the sustentaculum in the inverted position of the calcaneum, when the foot was dorsiflexed as in Sciurus, but unlike in the kinkajou, Potos (Jenkins and McClearn, 1984). In Cryptotopos, these two structures appear to have been a short distance apart as the medial malleolus contacted the medial wall of the astragalar body only as far down as the halfway point (Figure 14.1). However, in Paradoxonycteris, and probably also in Euronyctia and Scraeva, the medial malleolus contacted the entire height of the medial astragalar body wall, almost certainly making contact with the tip of the sustentaculum in full inversion when dorsiflexed. This relationship had the effect of creating slight rotation of the foot from the lateral plane when fully everted. Thus, even though the amount of astragalocalcaneal inversion was slightly less than in Cryptotopos, the inverted foot position would have been the same. In Tupaia, there is also no distal shift of the calcaneum with astragalocalcaneal inversion. However, there is an articulatory facet between the anterodistal tip of the medial malleolus of the tibia and the proximomedial surface of the sustentaculum, allowing sliding movements between the two bones during flexionextension and inversion-eversion.

Manipulating in articulation astragalus type 2 with calcaneum type 2, attributed to Paradoxonycteris sp. 1, produces a pattern of inversion at the astragalocalcaneal joint similar to that described for Cryptotopos (Hooker, 2001; herein). However, it appears to have had a slightly lesser degree of inversion. The difference may be within error, given the difficulty of manipulating such small objects and the unlikelihood of them belonging to a single individual. However, the ectal and sustentacular facets in Paradoxonycteris appear less curved. Also, the sustentacular facet of the astragalus is slightly less extensive, although this might be compensated for by the more extensive ectal facet of the calcaneum. The deeper ventral sulcus on the astragalus for the tendon of the flexor digitorum fibularis would have allowed a steeper trajectory for this tendon to the underside of the sustentaculum. This explains the dorsal curvature of the proximal end of the ridge demarcating the tendon on the ventromedial surface of the calcaneum. The course of the tendon in Cryptotopos via grooves on the tibia, astragalus and calcaneum can be envisaged from the reconstructed ankle (Figure 14.1-14.3). The morphological similarity of the type 4 astragalus and type 4 calcaneum, attributed to Euronyctia, to those attributed to Paradoxonycteris, suggests similar inversion characteristics at the astragalocalcaneal joint.

In Cryptotopos, the similar squarish rather than circular configurations of the cuboid facet of the calcaneum and of the calcaneal facet of the cuboid show that, during inversion at the astragalocalcaneal joint, the cuboid inverted along with the calcaneum, not moving independently of it. Unlike Ptilocercus (and Tupaia, where it is limited), primates or tree squirrels, there was therefore no inversion at the transverse tarsal joint and maximum rotation of the foot at the ankle joints was less than 90 degrees. As noted above, as the astragalus projects distally of the calcaneum, a facet on the lateral side of its head slid along a facet near the proximal margin of the medial face of the cuboid during inversion at the astragalocalcaneal joint (Figure 14.6-14.7). The even concavity of the astragalar facet of the type 1 navicular would accommodate the differing positions of the oval outline astragalar head. It is expected that a similar pattern of movement during inversion would have taken place in Paradoxonycteris. Although no cuboid is yet known, the astragalar facet of navicular type 2 is similar to that of type 1 . However, The kidney shape of the astragalar head and its greater dorsoventral depth medially suggests a greater curvature in the trajectory of the navicular against the head in eversion-inversion than in Cryptotopos.

\section{Metatarsals}

Material. Right M/T II, M95975 (length $6.78 \mathrm{~mm}$ ), Fishbourne Member, Woodside; left M/T III, 
M95970 (length $6.38 \mathrm{~mm}$ ), How Ledge Limestone, Headon Hill; right M/T IV, M95976 (5.91 mm), lower Hamstead Member, Bouldnor.

Description. The distal articulation of these metatarsals is, like the metacarpal, gently convex dorsally and distally, with a weak plantar keel restricted posteriorly (Figure 15.1.2- 4, 15.2.2, 15.3.2). In this way, it is more like that of a soricid than of a tree shrew (Tupaia or Ptilocercus), which is more strongly convex, thus bulbous. The shafts of M/T III and IV are nearly straight, and the distal articulations scarcely project medially or laterally from the shaft. In M/T II there is a slight medial curvature, with a slight medial projection of the distal articulation. The proximal articulation of $M / T$ II is kidney-shaped, sloping medially (Figure 15.3.1), whilst that of $M / T$ III is constricted mediolaterally, the ventral section being narrower than the dorsal section (Figure 15.2.1). The proximal articulation of $M / T$ IV is quite similar to that of a large glirid from the same bed. It differs subtly from the latter (personal obs.) in having a transverse, not anteromedially sloping, proximal facet, a more evenly sloping facet for M/T III, a shorter step from articulation to shaft laterally and, in proximal view, a medially curved ventral extremity to the proximal facet and a dorsolateral process that wraps around the corner of adjacent $\mathrm{M} / \mathrm{T} \vee$ (Figure 15.1.1, 15.1.3, 15.1.4). The shape of the nyctithere distal metatarsal articulations suggests relatively restricted mediolateral movement at the metatarsal-phalangeal joint, at least compared to glirids and tree shrews.

Reasons for identification as nyctithere. Unbroken metatarsals attributable to nyctitheres are rare. Because distinctiveness of the proximal and distal articulations independently is subtle, it is necessary to have complete bones with both articulations to be sure of the correct identification. Herpetotheriid metatarsals, like modern Didelphis (personal obs.), differ in being relatively short with distally widening shafts, wide distal ends with more bulbous articulations, and very different proximal articulations. Mole-like metatarsals attributable to Eotalpa are even shorter with strictly cylindrical distal articulations (personal obs.). Omomyids have expanded bulbous distal articulations (e.g., Szalay, 1976), thus excluding Pseudoloris. Small pseudosciurids should differ in similar ways to the metacarpals (q.v.). Glirids show only small differences in the proximal articulations, but the distal articulation is extremely bulbous in modern Glis and Muscardinus, whilst fossil Glamys is no different, as shown by Cuvier's "loir des platrières" (personal obs. of MNHN.F.GY673b).
Attributing any of these nyctithere metatarsals to particular genera is difficult. For M/T II, lack of knowledge of nyctithere mesocuneiforms means that articulation tests cannot be done. However, good articulation with the ectocuneiform attributed to Scraeva hatherwoodensis, despite slightly smaller size of the latter (see above) suggests that the M/T III may be attributable to Paradoxonycteris sp. 1. The M/T IV has a proximal articulation too small to match the type 1 cuboid attributed to Cryptotopos woodi and too large to match the type 2 cuboid attributed to Euronyctia. The M/T IV is likewise too small to belong to the same taxon/taxa as the other metatarsals.

\section{First Phalanges}

Material. M60476, M60479, M60790, M60842, M60843, M61113, M61114, M61116, M95920M95939, HZM.201.27202, HZM.229.27354; Mammal Bed, Hordle; HZM.126.26361, HZM.190.27114, HZM.465.29402, HZM.588.30474, Rodent Bed, Hordle; M95971M95973, HZM.350.28413, HZM.506.29665, How Ledge Limestone, Headon Hill; M95974, Fishbourne Member, Woodside.

Description. All the specimens exhibit gentle curvature and have prominent paired ventral tubercles for attachment of annular ligaments (Figure 15.4.2, 15.5.2, 15.7.2, 15.8.3). The shafts flare proximally, approaching the articulation, and the distal articulation projects medially and laterally beyond the shaft (Figure 15.4.1, 15.5.1, 15.7.1, 15.8.2). The distal articulation is nearly circular in medial or lateral view. In ventral view it is slightly wider than long (Figure 15.4.3). In distal view it tapers slightly dorsally (Figure 15.4.4). Its articular surface is strictly cylindrical, with no concavity. The proximal articular surface is partly visible in dorsal view and bordered by blunt medial and lateral processes. This structure produces a proximal extremity that is oblique to the long axis in medial or lateral view. In proximal view, the sides converge more strongly dorsally in the putative manual than in the putative pedal (Figure 15.4.5, 15.5.3, 15.8.1).

There is much variation in size and proportions, indicating different taxa and probably manual versus pedal. It is not known how much variation there may be between different manual or pedal digits, although length versus proximal width plots show some distinct groupings especially for the Hordle Mammal Bed assemblage (Figure 16). This shows a cluster of large values, which, apart from one intermediate plot, is distinctly separated from a more diffuse cluster of smaller values. Within this 


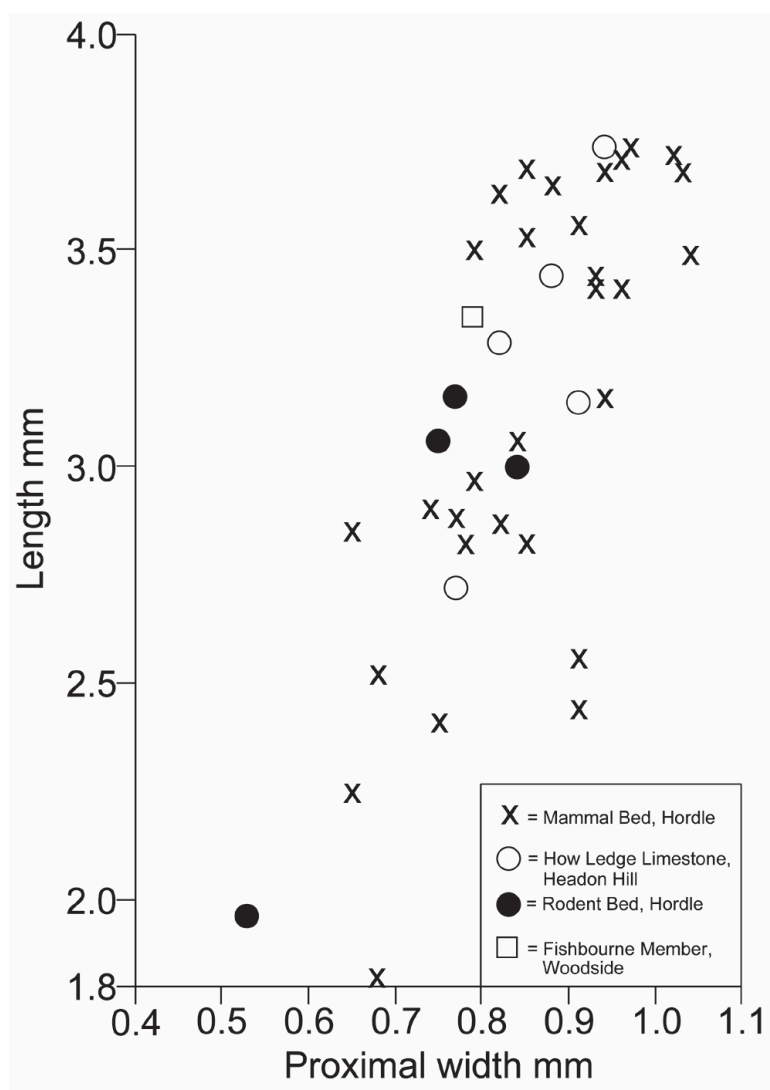

FIGURE 16. Scattergram of length against proximal width of first phalanges of Nyctitheriidae.

cluster of smaller values, four plots vary little in their proximal widths, which are less than $0.74 \mathrm{~mm}$. The cluster of largest values is likely to belong to pedal phalanges of Cryptotopos woodi (e.g., Figure 15.4), the smaller values of widths of $0.74 \mathrm{~mm}$ or greater to manual phalanges of the same species (e.g., Figure 15.5). Those with smaller proximal widths are overall rather slender and probably belong to both manuals and pedals of Scraeva hatherwoodensis (e.g., Figure 15.8). The latter attribution is further supported by appropriate articulation of manual examples with the metacarpal II (see above).

The Hordle Rodent Bed and How Ledge Limestone assemblages can be treated together as they are from identical levels a few $\mathrm{km}$ apart and have a very similar fauna. Here, a cluster with shorter values, but overlapping with that of the larger values from the Hordle Mammal Bed is likely to represent pedal phalanges of Paradoxonycteris sp. 1. The single much shorter value probably represents a manual of the same species. The longest value from the How Ledge Limestone plots with the longest values from the Hordle Mammal Bed and probably likewise belongs to Cryptotopos woodi. A single specimen (HZM.588.30474) from the Hordle Rodent Bed with very short and narrow dimensions may belong to Euronyctia grisollensis or Saturninia gracilis (Figure 15.7). The single specimen from Woodside plots with the longer Hordle Rodent Bed and How Ledge Limestone cluster and on size grounds may belong to a species of Amphidozotherium.

It is noteworthy that there is very little difference in width between first phalanges attributed to Paradoxonycteris sp. 1 and those attributed to $C$. woodi. The probable pedal ones of the former are, however, relatively shorter.

Reasons for identification as nyctithere. Suevosciurus, like its theridomyid relatives, has relatively short straight first phalanges, with narrow distal articulations (Lavocat, 1955), eliminating the small pseudosciurids from consideration. Apatemyids can be eliminated because their manual first phalanges are relatively much longer and their pedal ones shorter, both being apparently straight (Koenigswald, 1990; Bloch and Boyer, 2001; Koenigswald et al., 2005). Pseudoloris can be eliminated as omomyids, like other primates, have long paired ridges ventrally for attachment of the annular ligaments. No Eotalpa phalanges have yet been identified, but modern derived moles lack or have only very weak tubercles for annular ligament attachment (personal obs.). Moreover, the proximal hollow for articulation with the cylindrical distal articulations of metapodials identified as Eotalpa, would need to be similarly cylindrical, unlike the putative nyctitheres. Herpetotheriid marsupials like modern Didelphis and Monodelphis have mediolaterally flared proximal ends with shallow articulations (personal obs.). Glirid first phalanges can be identified by their similarity to modern Glis and Muscardinus and especially to Glamys priscus (Cuvier's "loir des plâtrières"), where that of pedal ray II is partially exposed dorsally and laterally, showing curvature and a slightly elongate ventral tubercle for annular ligament attachment (personal obs.). Although glirids larger than G. priscus do occur in the Solent Group, those contemporaneous with most nyctitheres in the Headon Hill Formation (Bosma and de Bruijn, 1979, 1982) are comparatively rare, especially in the Hordle Mammal Bed. Moreover, the first phalanx attributed to E. grisollensis or $S$. gracilis is significantly smaller than those of $G$. priscus. Pedal first phalanges identifiable as G. priscus on size grounds have a stronger curvature than the slightly straighter putative nyctithere first phalanges that are identified as pedal. 
Their annular ligament attachments are slightly more elongate than the strictly tubercular nyctithere ones. Their shafts are also waisted in the middle, and their distal articulations are more dorsoventrally compressed. In medial or lateral view, the proximal extremity is transverse to the long axis, instead of being oblique and sloping anteriorly. More subtle are the differences in the proximal articulations. In G. priscus, these appear shallower with an insignificant ventral notch. Nyctithere manual first phalanges, which are like the pedal ones in the shapes of their proximal articulations and of their annular ligament attachments, in which ways they differ from those of G. priscus, also differ from those of $G$. priscus in lesser shaft curvature.

Functional comparisons. The presence of bony processes for attachment of annular ligaments is typical of climbing mammals. This may be at the least specialized level of semiterrestrial types like shrews (Sorex), where they are minor tubercles, or that of specialized arborealists like primates, where the long ridge-shaped attachments support ligaments that extend along much of the shaft. In modern Glis, the slightly elongate tubercles support ligaments that represent c.13\% of bone length (personal obs.). Those of G. priscus would have been similar, but those of nyctitheres would have been slightly shorter, given the more tubercular shape of their processes. Nevertheless, although proximodistally short, they are prominent, more so for instance than in modern Sorex (personal obs.). The curvature of the nyctithere first phalanges is like that of a scansorial mammal like a tree squirrel or Tupaia. Ptilocercus has slightly greater curvature and a relatively larger distal articulation. It is essentially straight in a semiterrestrial mammal like a rat or a soricid shrew. Articulation at the metacarpal-phalangeal or metatarsal-phalangeal joint, however, because of the fusiform shape, would have been more restricted to parasagittal movement than in e.g., a tree shrew.

\section{Second Phalanges}

Material. M60989, M60994, M61128, M95940M95948, Mammal Bed, Hordle.

Description. In medial or lateral view, the dorsal shaft surface is straight whereas the ventral shaft surface is proximally gently concave and distally gently convex (Figure 15.6.3). In dorsal or ventral view, the shaft is mainly straight sided, but flares somewhat as the proximal end is approached, whereas distally it is confluent with the distal articulation (Figure 15.6.2, 15.6.4). The distal articulation is evenly cylindrical, projects dorsally and ventrally from the shaft and describes c.180 degrees of arc. In distal view, it is equidimensional and parallelsided. The proximal articulation is gently concave, slightly mediolaterally elongate and lacking a median ridge. In proximal view, the outline is concave ventrally and tapers dorsally (Figure 15.6.1). These second phalanges are of appropriate size (length 1.74-2.47 mm, proximal width 0.63-0.87 $\mathrm{mm}$ ) to match the largest first pedal phalanges, with which they articulate well, suggesting that they belong to Cryptotopos woodi. Length varies more than width, but how much this reflects which digit or how much pedal versus manual is unclear.

Reasons for identification as nyctithere. Pseudosciurids can be eliminated as second phalanges of Suevosciurus are robust, relatively short and their shafts taper gradually distally, without a proximal flare (Lavocat, 1955). Pedal second phalanges of apatemyids are poorly known, but appear slightly bowed (Koenigswald et al., 2005), whilst manual second phalanges can be eliminated because of their great length (Bloch and Boyer, 2001). Pseudoloris can be eliminated as omomyid second phalanges are bowed and bear ventral ridges for annular ligament attachment like first phalanges (Vasileiadou et al., 2009, figure 30). No Eotalpa second phalanges have yet been recognized, but in modern moles these are short and robust, even the less modified pedal elements (Reed, 1951). Solent Group herpetotheriid second phalanges, identified by comparison with modern Monodelphis, are generally stouter with mediolateral shaft walls more gradually distally tapering and a shaft that is dorsoventrally shallower, especially at the proximal end. There is also a tendency for there to be either a ventral emargination of the proximal articulation or a faint median ridge for articulation with a slightly concave phalanx 1 distal articulation. As for the first phalanges, glirid second phalanges, likely to belong to Glamys priscus, can be identified in the Solent Group by their similarity to modern Glis and Muscardinus. Compared to the putative nyctithere, they are smaller and more slender and the shaft flares more at the proximal and distal ends to create more extensive articulations. However, the differences apart from size are subtle.

Functional comparisons. Given the ventrally extensive distal articulation of the first phalanges, it is probable that the second phalanges could flex up to 90 degrees to the long axis of the first phalanges, giving a similar level of grip to that of a modern Glis or Muscardinus. The 180 degree arc of the 
distal articulation of the second phalanges would have given the as yet unknown unguals extensive flexion and extension movements.

\section{OVERVIEW OF FUNCTION}

What is known of the nyctithere skeleton is pervaded by features that indicate joint mobility associated with climbing ability. Thus, a range of movements at the shoulder and hip joints are unhindered by projecting tuberosities or trochanters; supination of the hand and rotation of the foot are particular adaptations; and curved first phalanges facilitate gripping. However, none of these adaptations are extreme. Thus, the humeroradial joint is subspherical/oval, not spherical/circular like arboreal primates and some of the extinct plesiadapiforms, (Szalay et al., 1975; Beard, 1993; Macleod and Rose, 1993; Gebo and Sargis, 1994; Sargis, 2002a). It is, however, only slightly less spherical/oval than in modern Ptilocercus. This suggests a maximum of 90 degrees rotation, probably less. Likewise, foot inversion is restricted to the astragalocalcaneal and (to a small extent) upper ankle joints, there being no rotation at the transverse tarsal joint. This is similar to the modern raccoon, Procyon lotor, (McClearn, 1977), where rotation is limited to c.140 degrees to the long axis of the tibia, therefore c.50 degrees from the horizontal plane. Extension of the forearm at the elbow was apparently restricted, according to the shallowness of the olecranon fossa of the humerus; and extension of the foot was restricted to c.120 degrees from the long axis of the tibia. Therefore, nyctitheres were not adapted for vertical suspension like e.g., tree squirrels or the kinkajou, Potos flavus (Jenkins and McClearn, 1984). Their climbing therefore appears to have been dominated by flexion of the forearms and feet, with the ability to descend tree trunks head-first with at least partially inverted hind feet. The analogy with $P$. lotor (McClearn, 1992) is a likely one, despite the difference in body mass. The ability of nyctitheres to negociate narrow branches was probably limited to squirrel-like gripping, by virtue of the curved first phalanges, unless they had a grasping ability suggested by the implied strength of the flexor digitorum fibularis and flexor digitorum tibialis tendons. Their fusiform distal metapodial articulations would have limited abduction and adduction at the metapodial-first phalangeal joint.

The function of the syndesmosis between tibia and fibula along parts of their shafts is difficult to interpret. Full tibia-fibula fusion (synostosis) of much of the shaft and distal extremity, plus, as in nyctitheres, an anterodistal tibial process with corresponding socket on the astragalus (squatting facet) is present in some arboreal primates (e.g., Tarsius) and terrestrial macroscelideans, where it is associated with leaping (Carleton, 1941; Evans, 1942; Godinot and Dagosto, 1983; Fleagle and Simons, 1983; Dagosto, 1985; Penkrot et al., 2008). However, similar structures in lipotyphlans are not associated with leaping. Moreover, leaping galagids have a more conventional primate distal synovial tibio-fibular joint (Dagosto, 1985). The lemuroid Microcebus has, like nyctitheres, a syndesmosis between tibial and fibular shafts (Fleagle and Simons, 1983; Dagosto, 1985). It is recorded as having "extremely versatile locomotion" in the "fine branch niche" and exhibiting "a frog-like hopping gait" when on the ground (Martin, 1973). However, the hindlimb-dominated locomotion of lemuroids and tarsiers, connected with limb proportions and tarsal elongation (e.g., Martin, 1990), is more important than syndesmosis in their hopping or leaping gaits. Syndesmosis, together with a distinctly grooved astragalar trochlea, in nyctitheres may simply have provided stability for the upper ankle joint, while most foot mobility was concentrated at the astragalocalcaneal joint.

The totality of their adaptations points to a scansorial locomotor mode, therefore with an extensive range of tree- and ground-based microhabitats for foraging for insect prey. According to tooth morphology, this diet persisted for their entire history of $37 \mathrm{Ma}$ from the early Paleocene to the middle Oligocene (Gunnell et al., 2008; Vandenberghe et al., 2012). Competition with the rapidly diversifying insectivorous bats must have been a factor in their extinction (Hooker, 2001), but their survival substantially after the climate crisis of the earliest Oligocene only in southern Europe (Crochet, 1995; Ziegler, 2007; Hooker et al., 2009) suggests also a climatic factor in their demise.

\section{PHYLOGENETIC ANALYSIS}

On the basis of cladistic analysis of a combination of cranial, dental and tarsal characters, Nyctitheriidae were concluded to be primitive euarchontans, one branch crownward of Deccanolestes (Hooker, 2001). More recently, Deccanolestes has been placed in the family Adapisoriculidae and included in analyses that point to it being a stem eutherian with characters convergent with Euarchonta (Wible et al., 2009; Goswami et al., 2011) rather than being an euarchontan (Storch, 2008; Boyer et al., 2010; Smith et al., 2010; De Bast et al., 2012). Now that more 
postcranials belonging to nyctitheres are known and described herein, it is important to revisit the phylogeny of the family to test whether it too is an euarchontan or a stem eutherian. The analysis therefore needs to include more basal eutherian taxa and employ only the most basal eutherians and stem therians to polarize a greater diversity of characters than in the earlier analysis (Hooker, 2001). The composition of the character-taxon matrix reflects this, although key groups like Scandentia, Dermoptera, Lipotyphla and Macroscelidea lack unequivocal extinct members with significant postcranial information and need to be included too. Morphological information for the ingroup has been gleaned from original specimens, casts and the following references: Archibald (1982), Archibald and Averianov (2003, 2012), Archibald et al. (2011), Argot (2013), Asher et al. (2005), Averianov and Archibald (2005), Beard and Houde (1989), Bloch and Silcox (2001), Bloch et al. (2007, 2009), Boyer and Bloch $(2003,2008)$, Boyer and Georgi (2007), Boyer et al. (2010), Butler (1948, 1956, 1980), Cartmill and MacPhee (1980), Chester et al. (2010, 2012b), Clark (1926), Clemens (1973, 2004), De Bast et al. (2012), Ekdale et al. (2004), Evans (1942), Frey et al. (1993), Frost et al. (1991), Gheerbrant and Russell (1989, 1991), Gingerich (1976), Gingerich et al. (1983), Godinot et al. (1996), Goswami et al. (2011), Gregory (1920), Heinrich and Houde (2006), Heinrich and Rose (1997), Hooker (2001, 2013), Horovitz (2000, 2003), Hunt and Korth (1980), Jepsen (1930, 1966), Kay et al. (1992), Kielan-Jaworowska (1977, 1978, 1981), Kielan-Jaworowska and Dashzeveg (1989), Kielan-Jaworowska et al. (1979, 2004), Krebs (1991), Lillegraven (1969), McDowell (1958), McKenna (1968), MacPhee and Novacek (1993), MacPhee et al. (1988, 1989), Maier (1979), Matthew (1909, 1918, 1937), Meng et al. (2003, 2004), Muller (1935), Nessov et al. (1998), Novacek (1977, 1980a, 1980b, 1986, 1987, 1991), Novacek and Wyss (1986), Novacek et al. (1997), Osborn (1902), Parker (1885), Penkrot et al. (2008), Polly et al. (2006), Prasad et al. (1994, 2010), Rose (1981, 1999, 2006), Rose and Gingerich (1976), Rose and Koenigswald (2005), Rose and Lucas (2000), Rose and Simons (1977), Rose and Walker (1985), Rose et al. (1993), Rougier (1993), Rougier et al. (1992), Russell (1964), Russell et al. (1973), Saban (1963), Sargis (2002a, 2002b), Secord (2008), Sigé (1976), Silcox (2003), Simmons et al. (2008), Simpson (1936, 1937), Sitt (1943), Sloan and Van Valen (1965), Smith et al. (2010, 2012), Stafford and Szalay (2000), Stafford and Thorington (1998), Stanĕk (1933), Storch (1993, 2008), Storch and Lister (1985), Storer (1991), Sulimski (1968), Szalay (1966, 1969), Szalay and Decker (1974), Szalay and Delson (1979), Szalay and Drawhorn (1980), Szalay and Lucas (1996), Szalay and Sargis (2006), Teilhard de Chardin (1927), Tobien (1962), Wesley-Hunt and Flynn (2005), Wible (1987, 1993, 2009, 2011), Wible and Davis (2000), Wible and Martin (1993), Wible and Novacek (1988), Wible et al. (2001, 2004, 2009), Wood and Clemens (2001). New as well as previously published characters with various modifications have been used and are noted as appropriate in the character list (Appendix 1). Where relevant, characters have been combined to create branching compound characters (Lipscomb, 1992), coded with stepmatrices (Forey and Kitching, 2000) to reflect natural complexity and to avoid inapplicable states, which increase the amount of missing data.

Choosing an appropriate outgroup taxon has been difficult. Stem therians such as Eomaia and Juramaia (O'Leary et al., 2013), formerly regarded as stem Eutheria (Ji et al., 2002; Luo et al., 2003, 2011), preserve a range of postcranial characters, but teeth in the former are of limited use. Prokennalestes has well-preserved dental material (Kielan-Jaworowska and Dashzeveg, 1989) and a petrosal (Wible et al., 2001), but no postcranials. Vincelestes preserves much of the skeleton, but is more primitive within Theria in a number of respects (Rougier, 1993). Henkelotherium (Krebs, 1991 ) is even more primitive (stem Cladotheria). All these are used in combination as outgroup for different characters as available, supplemented by certain isolated femora from the UK Berriasian, attributable to the Dryolestidae (Simpson, 1928b, figure 49; NHMUK.PV.OR48250, M13126). Details are discussed under each character regarding polarity, including cases of conflict.

\section{Results}

The analysis of 52 taxa and 310 characters (Appendices 1, 2) using PAUP 4.0b10 (Swofford, 2002) found four maximum parsimony trees of 2704 steps, with a consistency index of 0.2204 and a retention index of 0.4528 . The four trees differ only in two ways: Purgatorius is sister taxon to either Nyctitheriidae or to all the other euarchontans analyzed; and Gypsonictops is sister taxon to either Fordonia or to a clade containing Leptictidium, Macroscelidea and Anagalida. The strict consensus is shown in Figure 17. Adapisoriculidae are within stem group Eutheria, as found by Goswami 


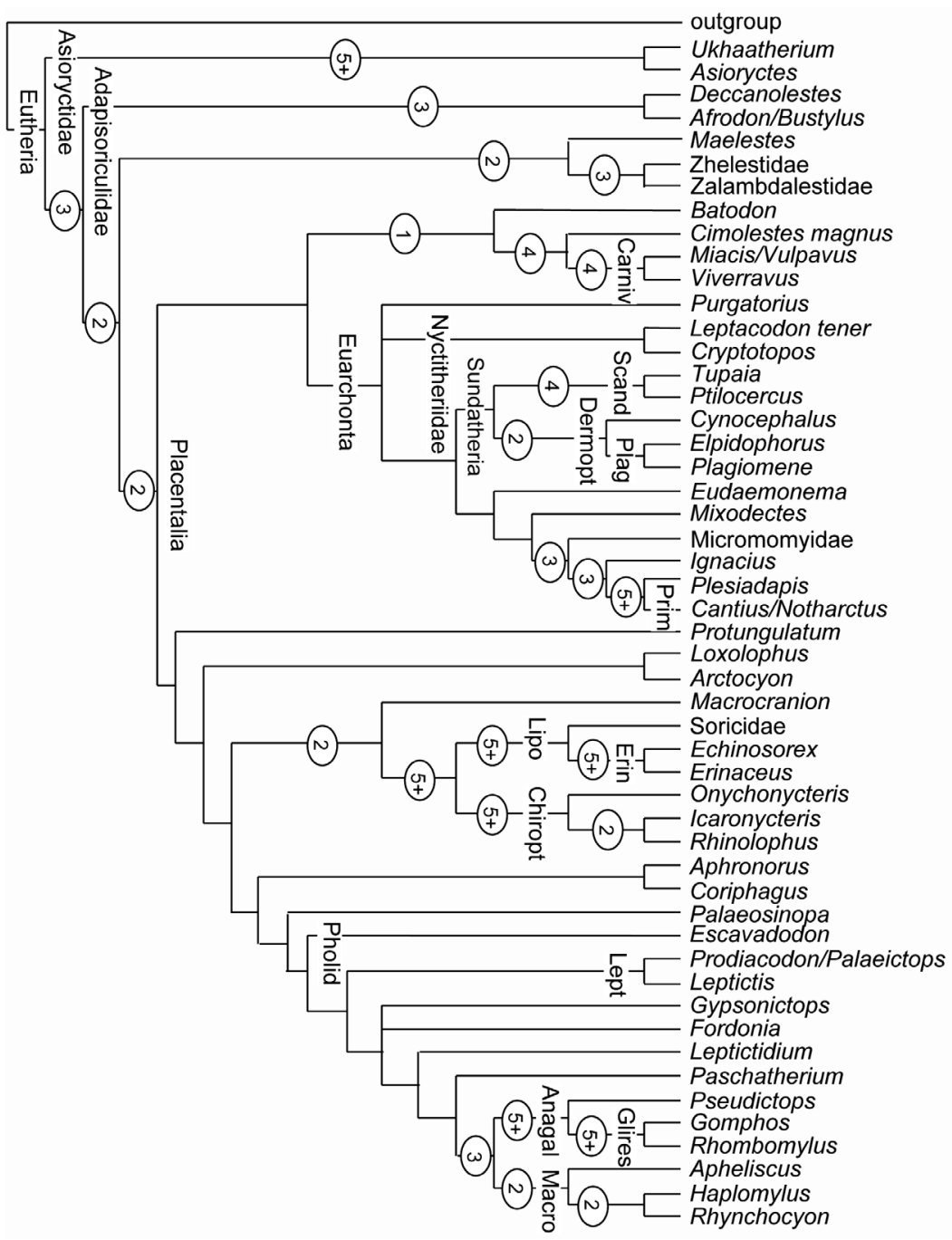

FIGURE 17. Strict consensus of four maximum parsimony trees generated by PAUP $4.0 \mathrm{~b} 10$ from the character-taxon matrix in Appendix 2. Node numbers are Bremer decay indices. Groups shown as monophyletic are labelled. Abbreviations: Anagal, Anagalida; Carniv, Carnivora; Chiropt, Chiroptera; Dermopt, Dermoptera; Erin, Erinaceidae; Lept, Leptictidae; Lipo, Lipotyphla; Macro, Macroscelidea; Pholid, Pholidota; Plag, Plagiomenidae; Prim, Primates; Scand, Scandentia;

et al. (2011), whereas Nyctitheriidae are stem members of the Euarchonta as found by Hooker (2001) and remote from both Lipotyphla and Adapisoriculidae. The instability of Purgatorius is likely to be because of its primitive dentition and lack of described postcranials. Future full description of its tarsals (Chester et al., 2012a) will likely improve knowledge of its relationships. The instability of Gypsonictops is likely to be because of the derived nature of parts of its dentition, together with lack of knowledge of its postcranials. Missing data generally are likely to be influencing relationships, where primitive members of groups, currently known only from teeth, have been included. Unsurprisingly, the higher Bremer decay indices (Bremer, 1994) sup- port nodes with the best represented taxa (Figure 17).

Characters supporting nodes in one of the trees (Figure 18) are listed in Appendix 3. Euarchonta (node 13) are supported by a large number of characters, which are discussed here in terms of how they relate to nyctithere evolution. None of the states of these characters are individually unique in the tree. The first upper incisor (of three) is primitively enlarged without a posterocone (1.4); Nyctitheriidae are more derived in having a posterocone (1.6), like plesiadapiforms, but with only one terminal cusp (Stehlin, 1941, figure 4c; Tobien, 1971, plate 2, figure 7). The first lower incisor (of three) is simple but enlarged (3.4) according 


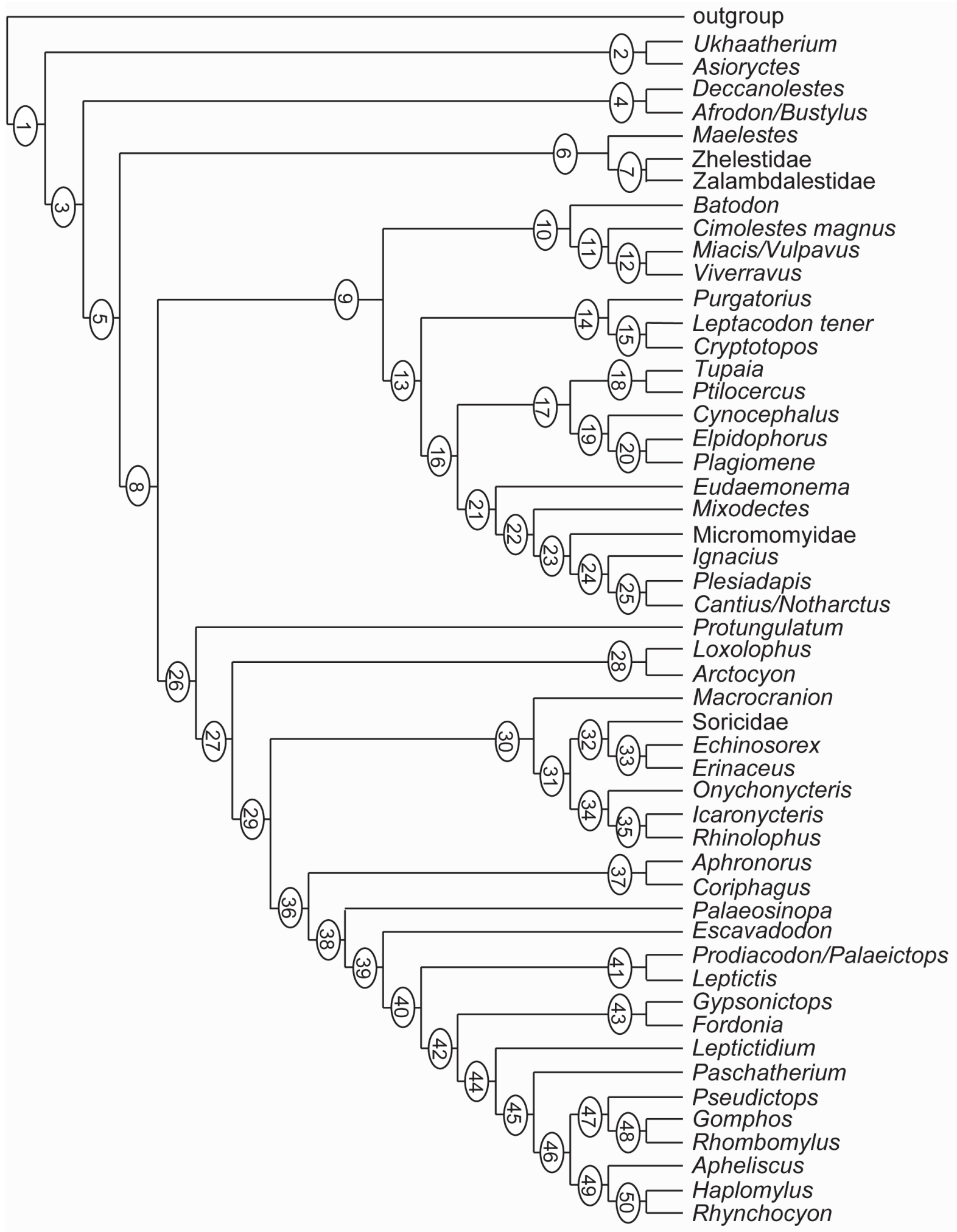

FIGURE 18. One of four maximum parsimony trees of 2704 steps generated by PAUP $4.0 b 10$ from the charactertaxon matrix in Appendix 2. Character states at numbered nodes are listed in Appendix 3. 
to ACCTRAN optimization, the serrated state of enlarged $I_{1}$ in Nyctitheriidae (3.6) developing one step on. The upper canine is small, single-rooted, without a talonid cusp (5.2); the nyctithere Cryptotopos retains this state and thus represents the primitive condition for Euarchonta. The lower canine is small and single-rooted with (6.3: ACCTRAN) or without (6.2: DELTRAN) a talonid cusp; the former state is present in Nyctitheriidae and might be primitive, but other states are present within the euarchontan clade. A degree of molarization of P5 is primitive for Euarchonta and typifies Nyctitheriidae, although it is paralleled widely within Placentalia. This involves a prominent $\mathrm{P}^{5}$ metacone that is smaller than the paracone (15.1), a $\mathrm{P}_{5}$ paraconid that is about half the height of the protoconid (33.2) and a basined $\mathrm{P}_{5}$ talonid either with hypoconid, hypoconulid and entoconid (36.3: ACCTRAN, the nyctithere state) or with only hypoconid and entoconid (36.4: DELTRAN). Shift of the lower molar hypoconulid to lingual of the midline (64.2) is present in the primitive nyctithere Leptacodon, although with reversed trend to the midline (64.1: Cryptotopos) or more buccally (64.0: primates and some plesiadapiforms). It is also widely paralleled outside the Euarchonta, so not a distinctive defining character. Several molar characters are shown by the DELTRAN optimization to support Euarchonta, whereas ACCTRAN shows them at lower nodes (50.1, 63.1, 67.2, 71.1 and 74.1). They are also widely paralleled, so of little help in definition, although the DELTRAN options appear the more likely. A number of cranial characters are recorded at the Euarchonta node only by ACCTRAN $(79.0,104.0,106.0,108.0,140.3$, $150.1,153.1,158.1,164.1,165.1,170.1,173.1$, $174.1,179.1,182.0)$. They are known in relatively few members of the clade and this does not include nyctitheres; they are therefore difficult to evaluate.

Postcranial character states at the Euarchonta node appear generally more meaningful, despite being paralleled at other points on the tree. The greater and lesser tuberosities of the humerus lower than or at same level as head (212.0) and ectal facet at midpoint along length of calcaneum (286.1) represent reversals to the primitive state. Humeral trochlea convex, without lateral crest and not projecting distally of capitulum (224.2) leads on to addition of a lateral crest (224.3) in derived plesiadapiforms and to a cylindrical shape (224.4) in primates and Ptilocercus; and reversed to concave with sharp medial keel (224.0) in Tupaia. Extension of the medial astragalar trochlear ridge onto the neck (267.1) is an important euarchontan character, being consistent where known (although Cynocephalus has the more derived state of both trochlear ridges extending onto the neck) and with limited parallelisms in the tree (Fordonia, Arctocyon, Echinosorex). Other characters are: calcaneal ectal facet at an angle of 5-15 degrees to the long axis (284.2) and groove for flexor digitorum fibularis tendon on calcaneum shallow (300.1, deepening to state 2 in Plesiadapis and primates). All these character states are either evolved from the respective primitive states or reversed from a more derived state in stem Eutheria. As scansorial adaptations, they are therefore newly evolved within Eutheria, not primitive retentions.

The nyctithere Cryptotopos has the states of all these characters the same as for the Euarchonta node. The positions on the tree of other postcranial characters differ between the ACCTRAN and DELTRAN optimizations. At the Euarchonta node, laterally displaced deltopectoral crest (215.0) and tuberosity for teres major muscle crestiform or tubercular (217.0) are reversals (ACCTRAN) or, more likely, primitive retentions (DELTRAN), but are of interest as being present in Cryptotopos. A narrow pubic symphysis (238.1) is known in too few taxa to be meaningful at this level. A similar problem affects the anteromedial projection of the femoral head (243.1: independently evolved in Cryptotopos and Scandentia + Dermoptera in DELTRAN) and shallow femoral trochanteric fossa (250.1: independently evolved in Cryptotopos and Ptilocercus in DELTRAN). The proximal foramen of the astragalar canal is lost basally (268.1: ACCTRAN) or independently in Cryptotopos, Scandentia + Dermoptera and Primates (DELTRAN). The lateral projection of the peroneal process of the calcaneum (289) and the overlap of the calcaneal ectal and sustentacular facets (291) are characters particularly variable in pattern between the ACCTRAN and DELTRAN optimizations. The mesocuneiform facet being longer than the ectocuneiform facet of the navicular (302.3) is more interesting as it is uniquely shared between Cryptotopos and Scandentia + Dermoptera, but is either treated as primitive for Euarchonta (ACCTRAN: reversed to more primitive states at higher nodes) or independently acquired in the two groups that share it (DELTRAN). Its limited knowledge in other fossil euarchontans make it of interest for future investigation. The presence of a distal sustentacular facet on the calcaneum, either separate from (292.1) or confluent with the main one on the sustentaculum (292.0) has been 
considered to be an archontan character (e.g., Szalay and Drawhorn, 1980; Hooker, 2001). However, state 0 is primitive for Eutheria, whilst the other states have a patchy distribution in crown Placentalia and even within Euarchonta, so it is no longer a key character.

\section{Discussion}

This analysis was performed with the aim of establishing the position of Nyctitheriidae within Eutheria. However, some novel or resurrected clades in the tree as a whole deserve comment and comparison with recent comprehensive morphological analyses. As in Wible et al. (2009, figure 29 ) and O'Leary et al. (2013, figure S2A: phenomic data), many Cretaceous eutherians were found to be stem members rather than crown placentals. However, there are exceptions. Thus closely related Leptictidae and Gypsonictops (e.g., KielanJaworowska et al., 2004) are shown to have relationships with Pholidota, Glires, and Macroscelidea and thus are crown placentals (contra Wible et al., 2009). O'Leary et al. (2013) found a sister relationship between Leptictis and Rhynchocyon, but did not include Cretaceous Gypsonictops in their analysis. The relationship between some cimolestids and Carnivora found herein, in common with earlier studies (e.g., Hunt and Tedford, 1993), places Cimolestidae within crown Placentalia too. This differs from the analysis of Wible et al. (2009), who included Maelestes in Cimolestidae, which placed Cimolestidae within stem Eutheria. O'Leary et al. (2013) excluded cimolestids except Maelestes from their analysis. In the present analysis, Maelestes is separated from Cimolestidae as sister taxon to Zhelestidae plus Zalambdalestidae. Inclusion of Gypsonictops and Cimolestidae s.s. in the analysis herein produces relationships within crown Placentalia, which imply that roots of the latter extend into the latest Cretaceous.

Anagalida (including Glires) are shown herein as sister taxon to Macroscelidea (Macroscelididae + Apheliscidae). These are nested successively with the louisinid Paschatherium, pseudorhyncocyonids, Gypsonictops, Leptictidae, Pholidota and Pantolestidae. This accords broadly with similarities and relationships previously recognized between different members of these groups (Rose, 1999; Rose and Lucas, 2000; Penkrot et al., 2008; Hooker and Russell, 2012; Hooker, 2013).

Lipotyphla plus Chiroptera is a novel morphology-based clade, although it has been found by some molecular analyses (Arnason et al., 2002). Here, it is supported uniquely by absence of a pubic symphysis (238.2) and numerous characters paralleled elsewhere on the tree. A better understanding of the homologies of bat ankle structure through early fossils would be an important aim to test this and other placements of Chiroptera within Placentalia.

The sister relationship between Cimolestidae + Carnivora and Euarchonta also seems to be novel. All the taxa with known humerus, except Tupaia and Cynocephalus, have coronoid fossae (228.1). Other characters are paralleled elsewhere on the tree. A number of the postcranial characters represent scansorial adaptations. Given that the only postcranials known for Cimolestidae (the rather derived Procerberus, not analyzed here) suggest more terrestrial adaptations (Szalay and Decker, 1974; Szalay and Drawhorn, 1980), these characters could be convergent between Carnivora and Euarchonta.

The Sundatheria clade (Scandentia + Dermoptera) is in common with both the morphological and molecular results given in O'Leary et al. (2013), but differ from $\mathrm{Ni}$ et al. (2013), who, in a combined morphological and molecular analysis, instead found Dermoptera, independent of Plagiomenidae, to be sister group to Primates.

The results of the present analysis, like other morphology-based analyses, differ considerably from those using molecular evidence. For instance, it did not find a Euarchontoglires clade. Euarchonta has even been shown to be paraphyletic within Euarchontoglires in a number of molecular analyses (O'Leary et al., 2013). A molecule-based Euarchonta has, however, now been resolved as monophyletic (Lin et al., 2014), and so this is another case where morphology and molecules do find the same clade.

Some of the differences between recent morphological analyses might be attributable to methodological factors. Thus, some groups (e.g., Xenarthra, Tubulidentata), with problematic dental homologies, which have never been implicated in nyctithere relationships, were omitted from the analysis herein. Dermoptera were omitted from Wible et al.'s (2009) analysis and Gypsonictops and Cimolestes were omitted from that of O'Leary et al. (2013) and both included non-eutherian taxa. Also, more modern compared to fossil (stem) taxa were analyzed by O'Leary et al. (2013: 53.5\%) than herein $(15 \%)$, which is comparable to Wible et al. (2009: 16\%). The somewhat different taxonomic composition of the matrices may have influenced the results. Different results could also be achieved by categorizing multistate characters as mainly 
ordered, often including stepmatrices, as herein, versus all unordered (Wible et al., 2009; O'Leary et al., 2013). There are $39.2 \%$ missing data in the present matrix, of which none represent inapplicable states. There are $44.4 \%$ missing data in Wible et al.'s (2009) matrix, of which $4.6 \%$ represent inapplicable states. In O'Leary et al.'s (2013) matrix, there is a total of $51.6 \%$ missing data, understandable given the large number of soft tissue characters used. However, $23 \%$ represent inapplicable states. Given the evidence for rapid evolution of crown placental groups at the beginning of the Cenozoic (O'Leary et al., 2013), regardless of whether any origins reach down into the Cretaceous, relationships of many placental groups are likely to be close and are likely to require much greater anatomical knowledge of early Paleocene and late Cretaceous fossils to resolve them. Differences in current phylogenetic hypotheses with slightly different methodologies and taxa analyzed are to be expected.

The analysis herein highlights the problems associated with missing data that affect many primitive placentals, which are still mainly known from dentitions. Lagerstätten like Messel and the freshwater limestones in the Bighorn Basin Paleocene (Bloch and Boyer, 2001) provide wonderful illuminating articulated skeletons, but many taxa are only known from sites with disarticulated material. Careful screenwashing of strata in the latter can yield an abundance of isolated bones capable of being identified with tooth taxa, thus helping to fill gaps in our knowledge of these key animals, as demonstrated here.

\section{ACKNOWLEDGEMENTS}

I thank B. Gasson and M. Jurd for making specimens available; A.G. Lawson and S.T. Grimes for sorting residues; M.E. Collinson, A.P. Currant, the late R. Estes, B. McCord, A.C. Milner, H. Pain, N.P. Sille, and R.L. Singer for help with field work; the National Trust and J. and M. Smith for site access; A. Prieur (Faculté des Sciences, Université de Lyon), D.L. Harrison, P.J.J. Bates, M. Pearch (HZM), C. Sagne, P. Tassy (MNHN), and R. Portela-Miguel (Life Sciences Department, NHMUK) for access to collections; M. Sánchez-Villagra for loan of a Monodelphis skeleton; A. Ball and T. Goral (EMMA Unit, NHMUK) for SEM facility support; and G.W. Rougier and P. Brewer for helpful discussion. Comments by T. Smith and an anonymous reviewer have improved the paper.

\section{REFERENCES}

Aiello, L. and Dean, C. 1990. An Introduction to Human Evolutionary Anatomy. Academic Press, London.

Archibald, J.D. 1982. A study of Mammalia and geology across the Cretaceous-Tertiary boundary in Garfield County, Montana. University of California Publications in Geological Sciences, 122: i-xvi, 1-286.

Archibald, J.D. and Averianov, A.O. 2003. The Late Cretaceous placental mammal Kulbeckia. Journal of Vertebrate Paleontology, 23:404-419.

Archibald, J.D. and Averianov, A.O. 2012. Phylogenetic analysis, taxonomic revision, and dental ontogeny of the Cretaceous Zhelestidae (Mammalia: Eutheria). Zoological Journal of the Linnean Society, 164:361426.

Archibald, J.D., Zhang, Y., Harper, T., and Cifelli, R.L. 2011. Protungulatum, confirmed Cretaceous occurrence of an otherwise Paleocene Eutherian (placental?) mammal. Journal of Mammalian Evolution, 18:153-161.

Argot, C. 2013. Postcranial analysis of a carnivoran-like archaic ungulate: the case of Arctocyon primaevus (Arctocyonidae, Mammalia) from the Late Paleocene of France. Journal of Mammalian Evolution, 20:83114.

Arnason, U., Adegoke, J.A., Bodin, K., Born, E.W., Esa, Y.B., Gullberg, A., Nilsson, M., Short, R.V., Xu, X.F., and Janke, A. 2002. Mammalian mitogenomic relationships and the root of the eutherian tree. PNAS, 99:8151-8156.

Asher, R.J., Meng, J., Wible, J.R., McKenna, M.C., Rougier, G.W., Dashzeveg, D., and Novacek, M.J. 2005. Stem Lagomorpha and the antiquity of Glires. Science, 307:1091-1094.

Averianov, A.O. and Archibald, J.D. 2005. Mammals from the mid-Cretaceous Khodzhakul Formation, Kyzylkum Desert, Uzbekistan. Cretaceous Research, 26:593-608.

Aymard, A. 1846. Essai monographique sur un genre nouveau de mammifère fossile trouvé dans la HauteLoire et nommé Entelodon. Annales de la Société d'Agriculture, Sciences, Arts et Commerce du Puy, 12:227-267.

Beard, K.C. 1993. Phylogenetic systematics of the Primatomorpha, with special reference to Dermoptera, p. 129-150. In Szalay, F.S., Novacek, M.J., and McKenna, M.C. (eds.), Mammal Phylogeny. Placentals. Springer, New York.

Beard, K.C. and Houde, P. 1989. An unusual assemblage of diminutive plesiadapiforms (Mammalia, ?Primates) from the Early Eocene of the Clark's Fork Basin, Wyoming. Journal of Vertebrate Paleontology, 9:388-399. 
Bloch, J.I. and Boyer, D.M. 2001. Taphonomy of small mammals in freshwater limestones from the Paleocene of the Clarks Fork Basin, p. 185-198. In Gingerich, P.D. (ed.), Paleocene-Eocene stratigraphy and biotic change in the Bighorn and Clarks Fork Basins, Wyoming. University of Michigan Papers on Paleontology, 33.

Bloch, J.I. and Silcox, M.T. 2001. New basicrania of Paleocene-Eocene Ignacius: re-evaluation of the plesiadapiform-dermopteran link. American Journal of Physical Anthropology, 116:184-198.

Bloch, J.I., Silcox, M.T., Boyer, D.M., and Sargis, E.J. 2007. New Paleocene skeletons and the relationship of plesiadapiforms to crown-clade primates. PNAS, 104:1159-1164.

Bloch, J., Silcox, M., Chester, S., and Gunnell, G. 2009. New observations on the cranial anatomy of Paleogene Micromomyidae (Mammalia, Primates) from the Clarks Fork Basin, Wyoming. Journal of Vertebrate Paleontology, 29(supplement to no.3):66A.

Bosma, A.A. and de Bruijn, H. 1979. Eocene and Oligocene Gliridae (Rodentia, Mammalia) from the Isle of Wight, England. Part 1. The Gliravus priscus - Gliravus fordi lineage. Proceedings of the Koninklijke Nederlandse Akademie van Wetenschappen, 82:367-384.

Bosma, A.A. and de Bruijn, H. 1982. Eocene and Oligocene Gliridae (Rodentia, Mammalia) from the Isle of Wight, England. Part 2. Gliravus minor n. sp., Gliravus daamsi n. sp., and Bransatoglis bahloi n. sp. Proceedings of the Koninklijke Nederlandse Akademie van Wetenschappen, 85:365-380.

Boyer, D. and Bloch J.I. 2003. Comparative anatomy of the pentacodontid Aphronorus orieli (Mammalia, Pantolesta) from the Paleocene of the western Crazy Mountains Basin, Montana. Journal of Vertebrate Paleontology, 23(Supplement to no.3):36A.

Boyer, D. and Bloch, J.I. 2008. Evaluating the mittengliding hypothesis for Paromomyidae and Micromomyidae (Mammalia, "Plesiadapiformes") using comparative functional morphology of new Paleogene skeletons, p. 233-284. In Sargis, E.J. and Dagosto, M. (eds.), Mammalian Evolutionary Morphology: a Tribute to Frederick S. Szalay. Springer, Dordrecht.

Boyer, D.M. and Georgi, J.A. 2007. Cranial morphology of a pantolestid eutherian mammal from the Eocene Bridger Formation, Wyoming, USA: implications for relationships and habitat. Journal of Mammalian Evolution, 14:239-280.

Boyer, D.M., Prasad, G.V.R., Krause, D.W., Godinot, M., Goswami, A., Verma, O., and Flynn, J.J. 2010. New postcrania of Deccanolestes from the Late Cretaceous of India and their bearing on the evolutionary and biogeographic history of euarchontan mammals. Naturwissenschaften, 97:365-377.

Bremer, K. 1994. Branch support and tree stability. Cladistics, 10:295-304.
Butler, P.M. 1948. On the evolution of the skull and teeth in the Erinaceidae, with special reference to fossil material in the British Museum. Proceedings of the Zoological Society of London, 118:446-500.

Butler, P.M. 1956. The skull of Ictops and the classification of the Insectivora. Proceedings of the Zoological Society of London, 126:453-481.

Butler, P.M. 1980. The tupaiid dentition, p. 171-204. In Luckett, W.P. (ed.), Comparative Biology and Evolutionary Relationships of Tree Shrews. Plenum, New York.

Butler, P.M. 1988. Phylogeny of the insectivores, p. 117141. In Benton, M.J. (ed.), The Phylogeny and Classification of the Tetrapods 2: Mammals. Clarendon Press, Oxford.

Carleton, A. 1941. A comparative study of the inferior tibio-fibular joint. Journal of Anatomy, 76:45-55.

Cartmill, M. and MacPhee, R.D.E. 1980. Tupaiid affinities: the evidence of the carotid arteries and cranial skeleton, p. 95-132. In Luckett, W.P. (ed.), Comparative Biology and Evolutionary Relationships of Tree Shrews. Plenum, New York.

Chester, G.B., Bloch, J.I., and Clemens, W.A. 2012a. Tarsal morphology of the oldest plesiadapiform Purgatorius indicates arboreality in the earliest primates. Journal of Vertebrate Paleontology Program and Abstracts, 2012:77.

Chester, G.B., Sargis, E.J., Szalay, F.S., Archibald, J.D., and Averianov, A.O. 2010. Mammalian distal humeri from the Late Cretaceous of Uzbekistan. Acta Palaeontologica Polonica, 55:199-211.

Chester, G.B., Sargis, E.J., Szalay, F.S., Archibald, J.D., and Averianov, A.O. 2012b. Therian femora from the Late Cretaceous of Uzbekistan. Acta Palaeontologica Polonica, 57:53-64.

Cifelli, R.L. 1983. Eutherian tarsals from the Late Paleocene of Brazil. American Museum Novitates, 2761:131.

Clark, W.E. Le Gros 1926. On the anatomy of the pentailed tree-shrew (Ptilocercus lowii). Proceedings of the Zoological Society of London, 1926:1179-1309.

Clemens, W.A. 1973. Fossil mammals of the type Lance Formation Wyoming. Part 3. Eutheria and summary. University of California Publications in Geological Sciences, 94:1-102.

Clemens, W.A. 2004. Purgatorius (Plesiadapiformes, Primates?, Mammalia), a Paleocene immigrant into northeastern Montana: stratigraphic occurrences and incisor proportions. Bulletin of Carnegie Museum of Natural History, 36:3-13.

Coillot, T., Smith, R., Gigase, P., and Smith, T. 2013. Tarsal diversity in the earliest Eocene mammal fauna of Dormaal, Belgium. Geologica Belgica, 16:274-283.

Cray, P.E. 1973. Marsupialia, Insectivora, Primates, Creodonta and Carnivora from the Headon Beds (Upper Eocene) of southern England. Bulletin of the British Museum (Natural History), Geology, 23:1-102.

Crochet, J.-Y. 1974. Les insectivores des Phosphorites du Quercy. Palaeovertebrata, 6:109-159. 
Crochet, J.-Y. 1979. Diversité systématique des Didelphidae (Marsupialia) Européens Tertiaires. Geobios, 12:365-378.

Crochet, J.-Y. 1980. Les Marsupiaux du Tertiaire d'Europe. Fondation Singer-Polignac éditions, Paris.

Crochet, J.-Y. 1995. Le Garouillas et les sites contemporains (Oligocène, MP25) des Phosphorites du Quercy (Lot, Tarn-et-Garonne, France) et leurs faunes de vertébrés. 4. Marsupiaux et insectivores. Palaeontographica A, 236:39-75.

Dagosto, M. 1983. Postcranium of Adapis parisiensis and Leptadapis magnus (Adapiformes, Primates). Adaptational and phylogenetic significance. Folia Primatologica, 41:49-101.

Dagosto, M. 1985. The distal tibia of primates with special reference to the Omomyidae. International Journal of Primatology, 6:45-75.

De Bast, E., Sigé, B., and Smith, T. 2012. Diversity of the adapisoriculid mammals from the early Paleocene of Hainin, Belgium. Acta Palaeontologica Polonica, $57: 35-52$.

Dehm, R. 1937. Über die alttertiäre Nager Familie Pseudosciuridae und ihr Entwicklung. Neues Jahrbuch für Mineralogie, Geologie und Paläontologie, BeilBand B, 77:268-290.

Ekdale, E.G., Archibald, J.D., and Averianov, A.O. 2004. Petrosal bones of placental mammals from the Late Cretaceous of Uzbekistan. Acta Palaeontologica Polonica, 49:161-176.

Evans, F.G. 1942. The osteology and relationships of the elephant shrews (Macroscelididae). Bulletin of the American Museum of Natural History, 80:85-125.

Filhol, H. 1876. Recherches sur les phosphorites du Quercy. Etude des fossiles qu'on y rencontre et spécialement des mammifères. Annales des Sciences Géologiques, 7:1-220.

Filhol, H. 1890. Description d'une nouvelle espèce de lémurien fossile. Bulletin de la Société Philomathique de Paris, 8, 2:39-40.

Fleagle, J.G. and Simons, E.L. 1983. The tibio-fibular articulation in Apidium phiomense, an Oligocene anthropoid. Nature, 301:238-239.

Forey, P. and Kitching, I. 2000. Experiments in coding multistate characters, p. 54-80. In Scotland, R.W. and Pennington, R.T. (eds.), Homology and Systematics: Coding Characters for Phylogenetic Analysis. Taylor and Francis, London.

Frey, E., Herkner, B., Schrenk, F., and Seiffert, C. 1993. Reconstructing organismic constructions and the problem of Leptictidium's locomotion. Kaupia, 3:8995.

Frost, D.R., Wozencraft, W.C., and Hoffmann, R.S. 1991. Phylogenetic relationships of hedgehogs and gymnures (Mammalia: Insectivora: Erinaceidae). Smithsonian Contributions to Zoology, 518:1-69.

Gebo, D.L. 1989. Postcranial adaptation and evolution in Lorisidae. Primates, 30:347-367.
Gebo, D.L. 1993. Functional morphology of the foot in primates, p. 175-196. In Gebo, D.L. (ed.), Postcranial Adaptation in Nonhuman Primates. Northern Illinois University Press, DeKalb.

Gebo, D.L. and Sargis, E.J. 1994. Terrestrial adaptations in the postcranial skeletons of guenons. American Journal of Physical Anthropology, 93:341-371.

Gheerbrant, E. and Russell, D.E. 1989. Presence of the genus Afrodon [Mammalia, Lipotyphla (?), Adapisoriculidae] in Europe: new data for the problem of trans-Tethyan relations between Africa and Europe around the K/T boundary. Palaeogeography Palaeoclimatology Palaeoecology, 76:1-15.

Gheerbrant, E. and Russell, D.E. 1991. Bustylus cernaysi nov. gen., nov. sp., nouvel adapisoriculidé (Mammalia, Eutheria) Paléocène d'Europe. Geobios, 24:467-481.

Gingerich, P.D. 1976. Cranial anatomy and evolution of early Tertiary Plesiadapidae (Mammalia, Primates). University of Michigan Papers on Paleontology, 15:1141.

Gingerich, P.D. 1987. Early Eocene bats (Mammalia, Chiroptera) and other vertebrates in freshwater limestones of the Willwood Formation, Clark's Fork Basin, Wyoming. Contributions from the Museum of Paleontology, The University of Michigan, 27:275320.

Gingerich, P.D., Houde, P., and Krause, D.W. 1983. A new earliest Tiffanian (Late Paleocene) mammalian fauna from Bangtail Plateau, western Crazy Mountain Basin, Montana. Journal of Paleontology, 57:957-970.

Godinot, M. and Dagosto, M. 1983. The astragalus of Necrolemur (Primates, Microchoerinae). Journal of Paleontology, 57:1321-1324.

Godinot, M., Smith, T., and Smith, R. 1996. Mode de vie et affinités de Paschatherium (Condylarthra, Hyopsodontidae) d'après ses os du tarse. Palaeovertebrata, 25:225-242.

Goswami, A., Prasad, G.V.R., Upchurch, P., Boyer, D.M., Seiffert, E.R., Verma, O., Gheerbrant, E., and Flynn, J.J. 2011. A radiation of arboreal basal eutherian mammals beginning in the Late Cretaceous of India. PNAS, 108:16333-16338.

Grand, T.I. 1967. The functional anatomy of the ankle and foot of the slow loris (Nycticebus coucang). American Journal of Physical Anthropology, NS, 26:207-218.

Gregory, W.K. 1920. On the structure and relations of Notharctus, an American Eocene primate. Memoirs of the American Museum of Natural History, 3:49243.

Gunnell, G.F., Bown, T.M., Hutchison, J.H., and Bloch, J.I. 2008. Lipotyphla, p. 89-125. In Janis, C.M., Gunnell, G.F., and Uhen, M.D. (eds.), Evolution of Tertiary Mammals of North America. Volume 2: Small mammals, Xenarthrans, and Marine Mammals. Cambridge University Press, Cambridge. 
Heinrich, R.E. and Houde, P. 2006. Postcranial anatomy of Viverravus (Mammalia, Carnivora) and implications for substrate use in basal Carnivora. Journal of Vertebrate Paleontology, 26:422-435.

Heinrich, R.E. and Rose, K.D. 1997. Postcranial morphology and locomotor behaviour of two Early Eocene miacoid carnivorans, Vulpavus and Didymictis. Palaeontology, 40:279-305.

Hooker, J.J. 1987. Mammalian faunal events in the English Hampshire Basin (late Eocene - early Oligocene) and their application to European biostratigraphy. Münchner Geowissenschaftliche Abhandlungen, A, 10:109-116.

Hooker, J.J. 1991. Two new pseudosciurids (Rodentia, Mammalia) from the English Late Eocene, and their implications for phylogeny and speciation. Bulletin of the British Museum (Natural History), Geology, 47:35-50.

Hooker, J.J. 2001. Tarsals of the extinct insectivoran family Nyctitheriidae (Mammalia): evidence for archontan relationships. Zoological Journal of the Linnean Society, 132:501-529.

Hooker, J.J. 2010. The 'Grande Coupure' in the Hampshire Basin, UK: taxonomy and stratigraphy of the mammals on either side of this major Palaeogene faunal turnover, p. 147-215. In Whittaker, J.E. and Hart, M.B. (eds.), Micropalaeontology, Sedimentary Environments and Stratigraphy: a Tribute to Dennis Curry (1912-2001). The Micropalaeontological Society, Special Publications, The Geological Society, London.

Hooker, J.J. 2013. Origin and evolution of the Pseudorhyncocyonidae, a European Paleogene family of insectivorous placental mammals. Palaeontology, 56:807-835.

Hooker, J.J. and Russell, D.E. 2012. Early Palaeogene Louisinidae (Macroscelidea, Mammalia), their relationships and north European diversity. Zoological Journal of the Linnean Society, 164:856-936.

Hooker, J.J. and Weidmann, M. 2000. The Eocene mammal faunas of Mormont, Switzerland. Systematic revision and resolution of dating problems. Schweizerische Paläontologische Abhandlungen, 120:1-141.

Hooker, J.J., Cook, E., and Benton, M.J. 2005. British Tertiary fossil mammal GCR sites, p. 67-124. In Benton, M.J., Cook, E., and Hooker, J.J. (eds.), Mesozoic and Tertiary Fossil Mammals and Birds of Great Britain. Geological Conservation Review Series, no. 32, Joint Nature Conservation Committee, Peterborough.

Hooker, J.J., Grimes, S.T., Mattey, D.P., Collinson, M.E., and Sheldon, N.D. 2009. Refined correlation of the UK Late Eocene-Early Oligocene Solent Group and timing of its climate history. In Koeberl, C. and Montanari, A. (eds.), The Late Eocene Earth-hothouse, icehouse, and impacts. Geological Society of America Special Paper, 452: 179-195.
Horovitz, I. 2000. The tarsus of Ukhaatherium nessovi (Eutheria, Mammalia) from the Late Cretaceous of Mongolia. Journal of Vertebrate Paleontology, 20:547-560.

Horovitz, I. 2003. Postcranial skeleton of Ukhaatherium nessovi (Eutheria, Mammalia) from the Late Cretaceous of Mongolia. Journal of Vertebrate Paleontology, 23:857-868.

Horovitz, I., Ladevèze, S., Argot, C., Macrini, T.E., Martin, T., Hooker, J.J., Kurz, C., de Muizon, C., and Sánchez-Villagra, M.R. 2008. The anatomy of Herpetotherium cf. fugax Cope, 1873, a metatherian from the Oligocene of North America. Palaeontographica A, 284:109-141.

Hunt, R.M. and Korth, W.W. 1980. The auditory region of Dermoptera: morphology and function relative to other living mammals. Journal of Morphology, 164:167-211.

Hunt, R.M. and Tedford, R.H. 1993. Phylogenetic relationships within the aeluroid Carnivora and implications of their temporal and geographic distribution, $p$. 53-73. In Szalay, F.S., Novacek, M.J., and McKenna, M.C. (eds.), Mammal Phylogeny. Placentals. Springer, New York.

Jayne, H. 1898. Mammalian Anatomy, part 1, the Skeleton of the Cat. J.B. Lippincott Co., London.

Jenkins, F.A. and McClearn, D. 1984. Mechanisms of hind foot reversal in climbing mammals. Journal of Morphology, 182:197-219.

Jepsen, G.L. 1930. New vertebrate fossils from the Lower Eocene of the Bighorn Basin, Wyoming. Proceedings of the American Philosophical Society, 69:117-131.

Jepsen, G.L. 1966. Early Eocene bat from Wyoming. Science, 154:1333-1339.

Ji, Q., Luo, Z.X., Yuan, C.X., Wible, J.R., Zhang, J.P., and Georgi, J.A. 2002. The earliest eutherian mammal. Nature, 416:816-822.

Kay, R.F., Thewissen, J.G.M., and Yoder, A.D. 1992. Cranial anatomy of Ignacius graybullianus and the affinities of the Plesiadapiformes. American Journal of Physical Anthropology, 89:477-498.

Kielan-Jaworowska, Z. 1977. Evolution of the therian mammals in the Late Cretaceous of Asia. Part 2. Postcranial skeleton in Kennalestes and Asioryctes. Palaeontologia Polonica, 37:65-83.

Kielan-Jaworowska, Z. 1978. Evolution of the therian mammals in the Late Cretaceous of Asia. Part 3. Postcranial skeleton in Zalambdalestidae. Palaeontologia Polonica, 38:3-41.

Kielan-Jaworowska, Z. 1981. Evolution of the therian mammals in the Late Cretaceous of Asia. Part 4. Skull structure in Kennalestes and Asioryctes. Palaeontologia Polonica, 42:25-78.

Kielan-Jaworowska, Z. and Dashzeveg, D. 1989. Eutherian mammals from the Early Cretaceous of Mongolia. Zoologica Scripta, 18:347-355. 
Kielan-Jaworowska, Z., Bown, T.M., and Lillegraven, J.A. 1979. Eutheria, p. 221-258. In Lillegraven, J.A., Kielan-Jaworowska, Z., and Clemens, W.A. (eds.), Mesozoic Mammals: the First Two-Thirds of Mammalian History. California University Press, Berkeley.

Kielan-Jaworowska, Z., Cifelli, R.L., and Luo, Z.X. 2004. Mammals from the Age of Dinosaurs. Origins, Evolution, and Structure. Columbia University Press, New York.

Koenigswald, W.v. 1990. Die Paläobiologie der Apatemyiden (Insectivora s.I.) und die Ausdeutung der Skelettfunde von Heterohyus nanus aus dem Mitteleozän von Messel bei Darmstadt. Palaeontographica $A$, 210:41-77.

Koenigswald, W.v. and Storch, G. 1988. Messeler BeuteItiere - unauffällige Beutelratten, p. 155-159. In Schaal, S. and Ziegler, W. (eds.), Messel - ein Schaufenster in die Geschichte der Erde und des Lebens. Waldemar Kramer, Frankfurt am Main.

Koenigswald, W.v., Rose, K.D., Grande, L. and Martin, R.D. 2005. First apatemyid skeleton from the Lower Eocene Fossil Butte Member, Wyoming (USA), compared to the European apatemyid from Messel, Germany. Palaeontographica A, 272:149-169.

Kondrashov, P.E. and Lucas, S.G. 2012. Nearly complete skeleton of Tetraclaenodon (Mammalia, Phenacodontidae) from the Early Paleocene of New Mexico: morphofunctional analysis. Journal of Paleontology, 86:25-43.

Krebs, B. 1991. Das Skelett von Henkelotherium guimarotae gen. et sp. nov. (Eupantotheria, Mammalia) aus dem Oberen Jura von Portugal. Berliner Geowissenschaftliche Abhandlungen, A, 133:1-121.

Kurz, C. 2006. Preservation and frequency of occurrence of cranial and skeletal remains of European Tertiary marsupials. Palaeontographica A, 278:6986.

Lavocat, R. 1955. Sur un squelette de Pseudosciurus provenant du gisement d'Armissan (Aude). Annales de Paléontologie, 41:75-89.

Lillegraven, J.A. 1969. Latest Cretaceous mammals of upper part of Edmonton Formation of Alberta, Canada, and review of marsupial-placental dichotomy in mammalian evolution. The University of Kansas Paleontological Contributions, 50:1-122.

Lin, J.N., Chen, G.F., Gu, L., Shen, Y.F., Zheng, M.Z., Zheng, W.S., Hu, X.J., Zhang, X.B., Qiu, Y., and Jiang, C.Z. 2014. Phylogenetic affinity of tree shrews to Glires is attributed to fast evolution rate. Molecular Phylogenetics and Evolution, 71:193-200.

Lipscomb, D.L. 1992. Parsimony, homology and the analysis of multistate characters. Cladistics, 8:45-65.

Luo, Z.X., Ji, Q., Wible, J.R., and Yuan, C.X. 2003. An Early Cretaceous tribosphenic mammal and metatherian evolution. Science, 302:1934-1940.

Luo, Z.X., Yuan, C.X., Meng, Q.J., and Ji, Q. 2011. A Jurassic eutherian mammal and divergence of marsupials and placentals. Nature, 476:442-445.
Macleod, N. and Rose, K.D. 1993. Inferring locomotor behavior in Paleogene mammals via eigenshape analysis. American Journal of Science, 293A:300355.

MacPhee, R.D.E. and Novacek, M.J. 1993. Definition and relationships of Lipotyphla, p. 13-31. In Szalay, F.S., Novacek, M.J., and McKenna, M.C. (eds.), Mammal Phylogeny. Placentals. Springer, New York.

MacPhee, R.D.E., Cartmill, M., and Rose, K.D. 1989. Craniodental morphology and relationships of the supposed Eocene dermopteran Plagiomene (Mammalia). Journal of Vertebrate Paleontology, 9:329349.

MacPhee, R.D.E., Novacek, M.J., and Storch, G. 1988. Basicranial morphology of early Tertiary erinaceomorphs and the origin of primates. American Museum Novitates, 2921:1-42.

McClearn, D. 1977. Morphological and behavioral adaptations for arboreality in the raccoon family, Procyonidae. American Zoologist, 17:975.

McClearn, D. 1992. Locomotion, posture, and feeding behavior of kinkajous, coatis, and raccoons. Journal of Mammalogy, 73:245-261.

McDowell, S.B. 1958. The Greater Antillean insectivores. Bulletin of the American Museum of Natural History, 115:113-214.

McKenna, M.C. 1968. Leptacodon, an American Paleocene nyctithere (Mammalia, Insectivora). American Museum Novitates, 2317:1-12.

McKenna, M.C. and Bell, S.K. 1997. Classification of Mammals above the Species Level. Columbia University Press, New York.

Maier, W. 1979. Macrocranion tupaiodon, an adapisoricid (?) insectivore from the Eocene of 'Grube Messel' (Western Germany). Paläontologische Zeitschrift, 53:38-62.

Manz, C. and Bloch, J. 2011. Evidence for scansoriality in the forelimb of North American Paleocene insectivores (Mammalia, Eulipotyphla). Journal of Vertebrate Paleontology Program and Abstracts, 2011:151A.

Manz, C., Bloch, J., and Boyer, D. 2010. Tarsal bones of North American Paleocene Leptacodon (Mammalia, Eulipotyphla?) and evidence for scansoriality in Nyctitheriidae. Journal of Vertebrate Paleontology Program and Abstracts, 2010:128A-129A.

Marsh, O.C. 1872. Preliminary description of new Tertiary mammals. American Journal of Science, 104:122-128, 202-224.

Martin, R.D. 1973. A review of the behaviour and ecology of the lesser mouse lemur (Microcebus murinus J.F. Miller 1777), p. 1-68. In Michael, R.P. and Crook, J.H. (eds.), Comparative Ecology and Behaviour of Primates. Academic Press, London.

Martin, R.D. 1990. Primate Origins and Evolution. A Phylogenetic Reconstruction. Princeton University Press, Princeton. 
Matthew, W.D. 1909. Part 6. - The Carnivora and Insectivora of the Bridger Basin, Middle Eocene. Memoirs of the American Museum of Natural History, 9:289567.

Matthew, W.D. 1918. Part 5. - Insectivora (continued), Glires, Edentata. In Matthew, W.D. and Granger, W.A. Revision of the Lower Eocene Wasatch and Wind River faunas. Bulletin of the American Museum of Natural History, 38:565-657.

Matthew, W.D. 1937. Paleocene faunas of the San Juan Basin, New Mexico. Transactions of the American Philosophical Society, NS, 30:i-viii,1-510.

Meng, J., Hu, Y.M., and Li, C.K. 2003. The osteology of Rhombomylus (Mammalia, Glires): implications for phylogeny and evolution of Glires. Bulletin of the American Museum of Natural History, 275:1-247.

Meng, J., Bowen, G., Ye, J., Koch, P.L., Ting, S.Y., Li, Q., and Jin, X. 2004. Gomphos elkema (Glires, Mammalia) from the Erlian basin: evidence for the early Tertiary Bumbanian Land Mammal Age in Nei-Mongol, China. American Museum Novitates, 3425:1-24.

Muller, J. 1935. The orbitotemporal region of the skull of the Mammalia. Archives Néerlandaises de Zoologie, 1:118-259.

Nessov, L.A., Archibald, J.D., and Kielan-Jaworowska, Z. 1998. Ungulate-like mammals from the Late Cretaceous of Uzbekistan and a phylogenetic analysis of Ungulatomorpha, p. 40-88. In Beard, K.C. and Dawson, M.R. (eds.), Dawn of the Age of Mammals in Asia. Bulletin of Carnegie Museum of Natural History, 34.

Ni, X.J., Gebo, D.L., Dagosto, M., Meng, J., Tafforeau, P., Flynn, J.J., and Beard, K.C. 2013. The oldest known primate skeleton and early haplorhine evolution. Nature, 498:60-64.

Novacek, M.J. 1977. A review of Paleocene and Eocene Leptictidae (Eutheria: Mammalia) from North America. PaleoBios, 24:1-42.

Novacek, M.J. 1980a. Cranioskeletal features in tupaiids and selected Eutheria as phylogenetic evidence, $p$. 35-93. In Luckett, W.P. (ed.), Comparative Biology and Evolutionary Relationships of Tree Shrews. Plenum, New York.

Novacek, M.J. 1980b. Phylogenetic analysis of the chiropteran auditory region, p. 317-330. In Wilson, D.E. and Gardner, A.L. (eds.), Proceedings of the Fifth International Bat Research Conference. Texas Tech Press, Lubbock.

Novacek, M.J. 1986. The skull of leptictid insectivorans and the higher level classification of eutherian mammals. Bulletin of the American Museum of Natural History, 183:1-111.

Novacek, M.J. 1987. Auditory features and affinities of the Eocene bats Icaronycteris and Palaeochiropteryx (Microchiroptera, incertae sedis). American Museum Novitates, 2877:1-18.
Novacek, M.J. 1991. Aspects of the morphology of the cochlea in microchiropteran bats: an investigation of character transformation. Bulletin of the American Museum of Natural History, 206:84-100.

Novacek, M.J. and Wyss, A. 1986. Higher-level relationships of the Recent eutherian orders: morphological evidence. Cladistics, 2:257-287.

Novacek, M.J., Rougier, G.W., Wible, J.R., McKenna, M.C., Dashzeveg, D., and Horovitz, I. 1997. Epipubic bones in eutherian mammals from the Late Cretaceous of Mongolia. Nature, 389:483-486.

O'Leary, M.A., Bloch, J.I., Flynn, J.J., Gaudin, T.J., Giallombardo, A., Giannini, N.P., Goldberg, S.L., Kraatz, B.P., Luo, Z.X., Meng, J., Ni, X.J., Novacek, M.J., Perini, F.A., Randall, Z.S., Rougier, G.W., Sargis, E.J., Silcox, M.T., Simmons, N.B., Spaulding, M., Velazco, P.M., Weksler, M., Wible, J.R., and Cirranello, A.L. 2013. The placental mammal ancestor and the post-K-Pg radiation of placentals. Science, 339:662-667.

Osborn, H.F. 1902. American Eocene primates, and the supposed rodent family Mixodectidae. Bulletin of the American Museum of Natural History, 16:169-214.

Parker, W.K. 1885. On the structure and development of the skull in the Mammalia. Part 3. Insectivora. Philosophical Transactions of the Royal Society, 176:121275.

Penkrot, T.A., Zack, S.P., Rose, K.D., and Bloch, J.I. 2008. Postcranial morphology of Apheliscus and Haplomylus (Condylarthra, Apheliscidae): evidence for a Paleocene Holarctic origin of Macroscelidea, $p$. 73-106. In Sargis, E.J. and Dagosto, M. (eds.), Mammalian Evolutionary Morphology: a Tribute to Frederick S. Szalay. Springer, Dordrecht.

Polly, P.D., Wesley-Hunt, G.D., Heinrich, R.E., Davis, G., Houde, P. 2006. Earliest known carnivoran auditory bulla and support for a recent origin of crown-group Carnivora (Eutheria, Mammalia). Palaeontology, 49:1019-1027.

Prasad, G.V.R. and Godinot, M. 1994. Eutherian tarsal bones from the late Cretaceous of India. Journal of Paleontology, 68:892-902.

Prasad, G.V.R., Jaeger, J.J., Sahni, A., Gheerbrant, E., and Khajuria, C.K. 1994. Eutherian mammals from the Upper Cretaceous (Maastrichtian) Intertrappean Beds of Naskal, Andhra Pradesh, India. Journal of Vertebrate Paleontology, 14:260-277.

Prasad, G.V.R., Verma, O., Gheerbrant, E., Goswami, A., Khosla, A., Parmar, V., and Sahni, A. 2010. First mammal evidence from the Late Cretaceous of India for biotic dispersal between India and Africa at the KT transition. Comptes Rendus Palevol, 9:63-71.

Reed, C.A. 1951. Locomotion and appendicular anatomy in three soricoid insectivores. American Midland Naturalist, 45:513-671.

Robinson, P. 1968. Nyctitheriidae (Mammalia, Insectivora) from the Bridger Formation of Wyoming. Contributions to Geology, University of Wyoming, 7:129138. 
Rose, K.D. 1981. The Clarkforkian Land-Mammal Age and mammalian faunal composition across the Paleocene-Eocene boundary. University of Michigan Papers on Paleontology, 26:i-x,1-195.

Rose, K.D. 1987. Climbing adaptations in the Early Eocene mammal Chriacus and the origin of Artiodactyla. Science, 236:314-316.

Rose, K.D. 1999. Postcranial skeleton of Eocene Leptictidae (Mammalia) and its implications for behavior and relationships. Journal of Vertebrate Paleontology, 19:355-372.

Rose, K.D. 2006. The postcranial skeleton of early Oligocene Leptictis (Mammalia: Leptictida), with a preliminary comparison to Leptictidium from the middle Eocene of Messel. Palaeontographica A, 278:37-56.

Rose, K.D. and Emry, R.J. 1983. Extraordinary fossorial adaptations in the Oligocene palaeanodonts Epoicotherium and Xenocranium (Mammalia). Journal of Morphology, 175:33-56.

Rose, K.D. and Gingerich, P.D. 1976. Partial skull of the plesiadapiform primate Ignacius from the Early Eocene of Wyoming. Contributions from the Museum of Paleontology, The University of Michigan, 24:181189.

Rose, K.D. and Koenigswald, W.v. 2005. An exceptionally complete skeleton of Palaeosinopa (Mammalia, Cimolesta, Pantolestidae) from the Green River Formation, and other postcranial elements of the Pantolestidae from the Eocene of Wyoming (USA). Palaeontographica A, 273:55-96.

Rose, K.D. and Lucas, S.G. 2000. An early Paleocene palaeanodont (Mammalia, ?Pholidota) from New Mexico, and the origin of Palaeanodonta. Journal of Vertebrate Paleontology, 20:139-156.

Rose, K.D. and Simons, E.L. 1977. Dental function in the Plagiomenidae: origin and relationships of the mammalian order Dermoptera. Contributions from the Museum of Paleontology, The University of Michigan, 24:221-236.

Rose, K.D. and Walker, A. 1985. The skeleton of Early Eocene Cantius, oldest lemuriform primate. American Journal of Physical Anthropology, 66:73-89.

Rose, K.D., Beard, K.C., and Houde, P. 1993. Exceptional new dentitions of the diminutive plesiadapiforms Tinimomys and Niptomomys (Mammalia), with comments on the upper incisors of Plesiadapiformes. Annals of Carnegie Museum, 62:351-361.

Rose, K.D., Storch, G., and Krohmann, K. 2013. Smallmammal postcrania from the middle Paleocene of Walbeck, Germany. Paläontologische Zeitschrift, doi:10.1007/s12542-013-0211-3.

Rose, K.D., Rana, R.S., Sahni, A., Kumar, K., Missiaen, P., Singh, L., and Smith, T. 2009. Early Eocene primates from Gujarat, India. Journal of Human Evolution, 56:366-404.
Rougier, G.W. 1993. Vincelestes neuquenianus Bonaparte (Mammalia, Theria), un primitivo mammífero del Cretácico Inferior de la Cuenca Neuquina. Unpublished $\mathrm{PhD}$ thesis, Universidad Nacional de Buenos Aires, Argentina.

Rougier, G.W., Wible, J.R., and Hopson, J.A. 1992. Reconstruction of the cranial vessels in the Early Cretaceous mammal Vincelestes neuquenianus: implications for the evolution of the mammalian cranial vascular system. Journal of Vertebrate Paleontology, 12:188-216.

Russell, D.E. 1964. Les Mammifères paléocènes d'Europe. Mémoires du Muséum National d'Histoire Naturelle, NS, C, 13:1-324.

Russell, D.E., Louis, P., and Savage, D.E. 1973. Chiroptera and Dermoptera of the French Early Eocene. University of California Publications in Geological Sciences, 95:1-57.

Saban, R. 1963. Contribution à l'étude de l'os temporal des primates. Description chez l'homme et les prosimiens. Anatomie comparée et phylogénie. Mémoires du Museeum National d'Histoire Naturelle, NS, A, Zoologie, 29:1-378.

Salton, J.A. and Sargis, E.J. 2008. Evolutionary morphology of the Tenrecoidea (Mammalia) forelimb skeleton, p. 51-71. In Salton, J.A. and Sargis, E.J. (eds.), Mammalian Evolutionary Morphology: a Tribute to Frederick S. Szalay. Vertebrate Paleobiology and Palaeoanthropology Series. Springer, Dordrecht.

Salton, J.A. and Sargis, E.J. 2009. Evolutionary morphology of the Tenrecoidea (Mammalia) hindlimb skeleton. Journal of Morphology, 270:367-387.

Sánchez-Villagra, M., Ladevèze, S., Horovitz, I., Argot, C., Hooker, J.J., Macrini, T.E., Martin, T., Moore-Fay, S., de Muizon, C., Schmelzle, T., and Asher, R.J. 2007. Exceptionally preserved North American Paleogene metatherians: adaptations and discovery of a major gap in the opossum fossil record. Biology Letters, 3:318-322.

Sargis, E.J. 2002a. Functional morphology of the forelimb of tupaiids (Mammalia, Scandentia) and its phylogenetic implications. Journal of Morphology, 253:10-42.

Sargis, E.J. 2002b. Functional morphology of the hindlimb of tupaiids (Mammalia, Scandentia) and its phylogenetic implications. Journal of Morphology, 254:149-185.

Schmidt-Kittler, N. 1971. Odontologische Untersuchungen an Pseudosciuriden (Rodentia, Mammalia) des Alttertiärs. Bayerischen Akademie der Wissenschaften, Mathematisch-Naturwissenschaftliche Klasse Abhandlungen, NF, 150:1-133.

Secord, R. 2008. The Tiffanian Land-Mammal Age (Middle and Late Paleocene) in the northern Bighorn Basin, Wyoming. University of Michigan Papers on Paleontology, 35:i-xi,1-192. 
Sigé, B. 1976. Insectivores primitifs de l'Eocène supérieur et Oligocène inférieur d'Europe occidentale. Nyctithériidés. Mémoires du Muséum National d'Histoire Naturelle, NS, C, Sciences de la Terre, 34:1140.

Sigé, B., Crochet, J.-Y., and Insole, A. 1977. Les plus vieilles taupes. Géobios Mémoire Spécial, 1:141157.

Silcox, M.T. 2003. New discoveries on the middle ear anatomy of Ignacius graybullianus (Paromomyidae, Primates) from ultra high resolution X-ray computed tomography. Journal of Human Evolution, 44:73-86.

Simmons, N.B., Seymour, K.L., Habersetzer, J., and Gunnell, G. 2008. Primitive Early Eocene bat from Wyoming and the evolution of flight and echolocation. Nature, 451:818-821.

Simpson, G.G. 1928a. A new mammalian fauna from the Fort Union of southern Montana. American Museum Novitates, 297:1-15.

Simpson, G.G. 1928b. A Catalogue of the Mesozoic Mammalia in the Geological Department of the British Museum. British Museum, London.

Simpson, G.G. 1935. The Tiffany fauna, upper Paleocene. 2. - Structure and relationships of Plesiadapis. American Museum Novitates, 816:1-30.

Simpson, G.G. 1936. A new fauna from the Fort Union of Montana. American Museum Novitates, 873:1-27.

Simpson, G.G. 1937. The Fort Union of the Crazy Mountain Field, Montana and its mammalian faunas. Bulletin of the United States National Museum, 169:1-287.

Simpson, G.G. 1945. The principles of classification and a classification of mammals. Bulletin of the American Museum of Natural History, 85:1-350.

Sisson, S. and Grossman, J.D. 1953. The anatomy of the domestic animals, $4^{\text {th }}$ edition revised. WB Saunders Company, Philadelphia.

Sitt, W. 1943. Zur Morphologie des Primaordialcraniums und des Osteocraniums eines Embryos von Rhinolophus rouxii von $15 \mathrm{~mm}$ Scheitel-Steiss-Länge. Gegenbaurs Morphologisches Jahrbuch, 88:268-342

Sloan, R.E. and Van Valen, L. 1965. Cretaceous mammals from Montana. Science, 148:220-227.

Smith, R. 2004. Nouveau nyctithère (Mammalia, Lipotyphla) de l'Oligocène inférieur de Belgique (Formation de Borgloon, MP21). Bulletin de I'Institut Royal des Sciences Naturelles de Belgique, Sciences de la Terre, 74(Supplement):197-204.

Smith, R. 2006a. Sigenyctia oligocaena n. gen. n. sp., nyctithère (Mammalia, Lipotyphla) de l'Oligocène inférieur de Belgique (Formation de Borgloon, MP21). Bulletin de l'Institut Royal des Sciences Naturelles de Belgique, Sciences de la Terre, 76:131136.

Smith, R. 2006b. Le genre Euronyctia (Nyctitheriidae, Mammalia) en Europe occidentale. Strata, 1, 13:229241.
Smith, T., De Bast, E., and Sigé, B. 2010. Euarchontan affinity of Paleocene Afro-European adapisoriculid mammals and their origin in the late Cretaceous Deccan Traps of India. Naturwissenschaften, 97:417422.

Smith, T., Habersetzer, J., Simmons, N.B., and Gunnell, G.F. 2012. Systematics and paleobiogeography of early bats, p. 23-66. In Gunnell, G.F. and Simmons, N.B. (eds.), Evolutionary History of Bats: Fossils, Molecules and Morphology. Cambridge University Press, Cambridge.

Stafford, B.J. and Szalay, F.S. 2000. Craniodental functional morphology and taxonomy of dermopterans. Journal of Mammalogy, 81:360-385.

Stafford, B.J. and Thorington, R.W. jr. 1998. Carpal development and morphology in archontan mammals. Journal of Morphology, 235:135-155.

Stanĕk, V.J. 1933. K topografické a srovnávaci anatomii sluchového orgánu našich chiropter. Nákladem České Akademie Věd a Umění, Prague.

Stehlin, H.G. 1941. Zur Stammesgeschichte der Soriciden. Eclogae Geologicae Helvetiae, 33:298-306.

Storch, G. 1993. Morphologie und Paläobiologie von Macrocranion tenerum, einem Erinaceomorphen aus dem Mittel-Eozän von Messel bei Darmstadt (Mammalia, Lipotyphla). Senckenbergiana Lethaea, 73:6181.

Storch, G. 2008. Skeletal remains of a diminutive primate from the Paleocene of Germany. Naturwissenschaften, 95:927-930.

Storch, G. and Lister, A.M. 1985. Leptictidium nasutum, ein Pseudorhyncocyonide aus dem Eozän der "Grube Messel" bei Darmstadt (Mammalia, Proteutheria). Senckenbergiana Lethaea, 66:1-37.

Storer, J.E. 1991. The mammals of the Gryde Local Fauna, Frenchman Formation (Maastrichtian, Lancian), Saskatchewan. Journal of Vertebrate Paleontology, 11:350-369.

Sulimski, A. 1968. Paleocene genus Pseudictops Matthew, Granger and Simpson 1929 (Mammalia) and its revision. Palaeontologia Polonica, 19:101-129.

Swofford, D.L. 2002. PAUP*. Phylogenetic Analysis Using Parsimony ("and other methods). Version 4. Sinauer, Sunderland, Massachusetts.

Szalay, F.S. 1966. The tarsus of the Paleocene leptictid Prodiacodon (Insectivora, Mammalia). American Museum Novitates, 2267:1-13.

Szalay, F.S. 1969. Mixodectidae, Microsyopidae, and the insectivore-primate transition. Bulletin of the American Museum of Natural History, 140:193-330.

Szalay, F.S. 1976. Systematics of the Omomyidae (Tarsiiformes, Primates) taxonomy, phylogeny, and adaptations. Bulletin of the American Museum of Natural History, 156:157-450.

Szalay, F.S. 1994. Evolutionary History of the Marsupials and an Analysis of Osteological Characters. Cambridge University Press, Cambridge. 
Szalay, F.S. and Dagosto, M. 1980. Locomotor adaptations as reflected on the humerus of Paleogene primates. Folia Primatologica, 34:1-45.

Szalay, F.S. and Decker, R.L. 1974. Origins, evolution, and function of the tarsus in Late Cretaceous Eutheria and Paleocene primates, p. 223-259. In Jenkins, F.A. (ed.), Primate Locomotion. Academic Press, New York.

Szalay, F.S. and Delson, E. 1979. Evolutionary History of the Primates. Academic Press, New York.

Szalay, F.S. and Drawhorn, G. 1980. Evolution and diversification of the Archonta in an arboreal milieu., $p$. 133-169. In Luckett, W.P. (ed.), Comparative Biology and Evolutionary Relationships of Tree Shrews. Plenum, New York.

Szalay, F.S. and Lucas, S.G. 1996. The postcranial morphology of Paleocene Chriacus and Mixodectes and the phylogenetic relationships of archontan mammals. Bulletin of the New Mexico Museum of Natural History and Science, 7:1-47.

Szalay, F.S. and Sargis, E.J. 2006. Cretaceous therian tarsals and the metatherian-eutherian dichotomy. Journal of Mammalian Evolution, 13:171-210.

Szalay, F.S., Tattersall, I., and Decker, R.L. 1975. Phylogenetic relationships of Plesiadapis - postcranial evidence, p.136-166. In Szalay, F.S. (ed.), Approaches to primate paleobiology. Contributions to Primatology, 5.

Taylor, M.E. 1976. The functional anatomy of the hindlimb of some African Viverridae (Carnivora). Journal of Morphology, 148:227-254.

Teilhard de Chardin, P. 1922. Les mammifères de l'Eocène inférieur français et leurs gisements. Annales de Paléontologie, 11:1-116.

Teilhard de Chardin, P. 1927. Les mammifères de l'Eocène inférieur de la Belgique. Mémoires $d u$ Musée Royal d'Histoire Naturelle de Belgique, 36:133.

Tobien, H. 1962. Insectivoren (Mamm.) aus dem Mitteleozän (Lutetium) von Messel bei Darmstadt. Notizblatt des Hessischen Landesamtes für Bodenforschung zu Wiesbaden, 90:7-47.

Tobien, H. 1971. Mikromammalier aus dem alttertiären Melanienton von Nordhessen. Teil 1: Marsupialia, Insectivora, Primates. Notizbatt des Hessischen Landesamtes für Bodenforschung zu Wiesbaden, 99:9-29.

Vandenberghe, N., Hilgen, F.J., Speijer, R.P., Ogg, J.G., Gradstein, F.M., Hammer, O., Hollis, C.J., and Hooker, J.J. 2012. The Paleogene Period, p. 855-921. In Gradstein, F.M., Ogg, J.G., Schmitz, M., and Ogg, G. (eds.), The Geologic Time Scale 2012. Elsevier, Oxford.

Vasileiadou, K., Hooker, J.J., and Collinson, M.E. 2009. Paleocommunity reconstruction and accumulation of micromammalian remains (Late Eocene, southern England). Palaios, 24:553-567.
Wesley-Hunt, G.D. and Flynn, J.J. 2005. Phylogeny of the carnivora: basal relationships among the carnivoramorphans, and assessment of the position of 'Miacoidea' relative to Carnivora. Journal of Systematic Palaeontology, 3:1-28.

Wible, J.R. 1987. The eutherian stapedial artery: character analysis and implications for superordinal relationships. Zoological Journal of the Linnean Society, 91:107-135.

Wible, J.R. 1993. Cranial circulation and relationships of the colugo Cynocephalus (Dermoptera, Mammalia). American Museum Novitates, 3072:1-27.

Wible, J.R. 2009. The ear region of the pen-tailed treeshrew, Ptilocercus lowii Gray, 1848 (Placentalia, Scandentia, Ptilocercidae). Journal of Mammalian Evolution, 16:199-233.

Wible, J.R. 2011. On the treeshrew skull (Mammalia, Placentalia, Scandentia). Annals of Carnegie Museum, 79:149-230.

Wible, J.R. and Davis, D.L. 2000. Ontogeny of the chiropteran basicranium, with reference to the Indian false vampire bat, Megaderma lyra, p. 214-246. In Adams, R.A. and Pedersen, S.C. (eds.), Ontogeny, Functional Ecology, and Evolution of Bats. Cambridge University Press, Cambridge.

Wible, J.R. and Martin, J.R. 1993. Ontogeny of the tympanic floor and roof in archontans, p. 111-148. In MacPhee, R.D.E. (ed.), Primates and their Relatives in Phylogenetic Perspective. Plenum Press, New York.

Wible, J.R. and Novacek, M.J. 1988. Cranial evidence for the monophyletic origin of bats. American Museum Novitates, 2911:1-19.

Wible, J.R., Novacek, M.J., and Rougier, G.W. 2004. New data on the skull and dentition in the Mongolian Late Cretaceous eutherian mammal Zalambdalestes. Bulletin of the American Museum of Natural History, 281:1-144.

Wible, J.R., Rougier, G.W., Novacek, M.J., and Asher, R.J. 2009. The eutherian mammal Maelestes gobiensis from the Late Cretaceous of Mongolia and the phylogeny of Cretaceous Eutheria. Bulletin of the American Museum of Natural History, 327:1-123.

Wible, J.R., Rougier, G.W., Novacek, M.J., and McKenna, M.C. 2001. Earliest eutherian ear region: a petrosal referred to Prokennalestes from the Early Cretaceous of Mongolia. American Museum Novitates, 3322:1-44.

Wood, A.E. 1962. The early Tertiary rodents of the family Paramyidae. Transactions of the American Philosophical Society, 52:1-261.

Wood, C.B. and Clemens, W.A. 2001. A new specimen and a functional reassociation of the molar dentition of Batodon tenuis (Placentalia, incertae sedis), latest Cretaceous (Lancian), North America. Bulletin of the Museum of Comparative Zoology, 156:99-118. 
Ziegler, R. 2007. The nyctitheriids (Lipotyphla, Mammalia) from the Early Oligocene fissure fillings in south Germany. Neues Jahrbuch für Geologie und Paläontologie Abhandlungen, 246:183-203. 


\section{APPENDIX 1. LIST OF CHARACTERS}

Note that the zero state is primitive unless otherwise stated. Multistate characters are ordered unless stated to be unordered or a stepmatrix.

\section{Teeth}

1. Upper incisors: more than 3, simple structure, similar-sized (0); 3, simple structure, similar sized (1); 2, simple structure, similar-sized (2); 3 or 2 , similar-sized, spatulate (3); 3 or 2 , the first enlarged without heel (posterocone) (4); 2, both enlarged, simple (5); 3 , the first enlarged with heel (posterocone) but only one terminal cusp (6); 3 or 2 , the first enlarged, with heel (posterocone) and 2 or 3 terminal cusps (7); 3 or 2 , similar-sized, serrated/denticulate (8); 1 or none (9). Primitive state based on Eomaia and Vincelestes. STEPMATRIX.

\begin{tabular}{ccccccccccc} 
& 0 & 1 & 2 & 3 & 4 & 5 & 6 & 7 & 8 & 9 \\
\hline 0 & - & 1 & 2 & 2 & 2 & 3 & 3 & 4 & 2 & 3 \\
1 & 1 & - & 1 & 1 & 1 & 2 & 2 & 3 & 1 & 2 \\
2 & 2 & 1 & - & 2 & 2 & 1 & 3 & 4 & 2 & 1 \\
3 & 2 & 1 & 2 & - & 2 & 3 & 3 & 4 & 2 & 1 \\
4 & 2 & 1 & 2 & 2 & - & 1 & 1 & 2 & 2 & 3 \\
5 & 3 & 2 & 1 & 3 & 1 & - & 2 & 3 & 3 & 2 \\
6 & 3 & 2 & 3 & 3 & 1 & 2 & - & 1 & 3 & 4 \\
7 & 4 & 3 & 4 & 4 & 2 & 3 & 1 & - & 4 & 5 \\
8 & 2 & 1 & 2 & 2 & 2 & 3 & 3 & 4 & - & 1 \\
9 & 3 & 2 & 1 & 1 & 3 & 2 & 4 & 5 & 1 & -
\end{tabular}

2. Mesial gap between mesialmost upper teeth: absent (0); present (1). Primitive state based on Eomaia and Vincelestes. Modified from Wible et al. (2009) character 9.

3. Lower incisors: 4 , simple structure, similar-sized (0); 4, first enlarged (1); 3 , simple structure, similar-sized (2); 3 or 2 , similar-sized, spatulate (3); 3 or 2, first enlarged, simple (4); 3 , first two enlarged, simple (5); first incisor of 3 or 2 , or sole if one, enlarged and serrated (6); 3 or 2 , similarsized, serrated/denticulate (7); absent (8). Primitive state based on Eomaia and Prokennalestes. STEPMATRIX.

\begin{tabular}{cccccccccc} 
& 0 & 1 & 2 & 3 & 4 & 5 & 6 & 7 & 8 \\
\hline 0 & - & 1 & 1 & 2 & 2 & 2 & 3 & 2 & 3 \\
1 & 1 & - & 2 & 3 & 1 & 2 & 2 & 3 & 4 \\
2 & 1 & 2 & - & 1 & 1 & 1 & 2 & 1 & 2 \\
3 & 2 & 3 & 1 & - & 2 & 2 & 3 & 2 & 1 \\
4 & 2 & 1 & 1 & 2 & - & 1 & 1 & 2 & 3 \\
5 & 2 & 2 & 1 & 2 & 1 & - & 2 & 2 & 3 \\
6 & 3 & 2 & 2 & 3 & 1 & 2 & - & 1 & 2 \\
7 & 2 & 3 & 1 & 2 & 2 & 2 & 1 & - & 1
\end{tabular}

4. $\mathrm{DI} 2 / 2$ simple, small, fully enamelled, rooted (if unknown, inferred from state of $12 / 2$ or form of the dentary), or absent (0); hypselodont, chiselshaped with buccally restricted enamel (1). Primitive state based on ingroup commonality.

5. Upper canine: large, two-rooted (0); large, singlerooted (1); small, single rooted (2); small, tworooted (3); absent (4). Primitive state based on Vincelestes. Modified from Wible et al. (2009) characters 23-24. STEPMATRIX.

\begin{tabular}{cccccc} 
& 0 & 1 & 2 & 3 & 4 \\
\hline 0 & - & 1 & 2 & 1 & 2 \\
1 & 1 & - & 1 & 2 & 2 \\
2 & 2 & 1 & - & 1 & 1 \\
3 & 1 & 2 & 1 & - & 1 \\
4 & 2 & 2 & 1 & 1 & -
\end{tabular}

6. Lower canine: large, two-rooted (0); large, singlerooted (1); small, single rooted, without talonid cusp (2); small, single rooted, with talonid cusp (3); small, two-rooted (4); absent (5). Primitive state based on Prokennalestes. Modified from Wible et al. (2009) characters 25-26. STEPMATRIX.

\begin{tabular}{ccccccc} 
& 0 & 1 & 2 & 3 & 4 & 5 \\
\hline 0 & - & 1 & 2 & 2 & 1 & 2 \\
1 & 1 & - & 1 & 2 & 2 & 2 \\
2 & 2 & 1 & - & 1 & 1 & 1 \\
3 & 2 & 2 & 1 & - & 1 & 1 \\
4 & 1 & 2 & 1 & 1 & - & 1 \\
5 & 2 & 2 & 1 & 1 & 1 & -
\end{tabular}

7. $\quad \mathrm{P} 3 / 3$ present (0); absent (1). Primitive state based on Prokennalestes.

8. $\quad \mathrm{P}^{1}$ root number: $2(0) ; 1$ (1); tooth absent (2). Primitive state based on Juramaia. Modified from Wible et al. (2009) character 33.

9. $\quad P_{1}$ root number: $2(0) ; 1(1)$; tooth absent (2). Primitive state based on Juramaia. Modified from Wible et al. (2009) character 48.

10. P2 root number: 2 or more (0); 2 upper, one lower (1); 1 (2); 2 or one upper, $P_{2}$ absent (3); P2 absent (4). Primitive state based on Juramaia. Those only known from $\mathrm{P}_{\mathbf{2}}$ are assumed to have same $\mathrm{P}^{2}$ root number.

11. P4 root number: 1 (0); 2 (1) PRIMITIVE; 3 (2). Primitive state based on Juramaia. 
12. $\mathrm{P}^{4}$ metacone absent (0); small, close to paracone (1); large, distant from paracone (2); no cusp structure (3). Primitive state based on Juramaia and Prokennalestes. Modified from Hooker and Russell (2012) character 2. STEPMATRIX

\begin{tabular}{ccccc} 
& 0 & 1 & 2 & 3 \\
\hline 0 & - & 1 & 2 & 1 \\
1 & 1 & - & 1 & 1 \\
2 & 2 & 1 & - & 1 \\
3 & 1 & 1 & 1 & -
\end{tabular}

13. $\mathrm{P}^{4}$ protocone lobe essentially absent (0); small, short with small protocone (1); relatively long with small protocone (2); relatively long with large protocone (3). Primitive state based on Juramaia and Prokennalestes. Modified from Hooker and Russell (2012) character 3. STEPMATRIX

\begin{tabular}{ccccc} 
& 0 & 1 & 2 & 3 \\
\hline 0 & - & 1 & 2 & 3 \\
1 & 1 & - & 1 & 2 \\
2 & 2 & 1 & - & 1 \\
3 & 3 & 2 & 1 & -
\end{tabular}

14. $\quad P^{4}$ parastyle mesially projecting (0); poorly developed (1). Primitive state based on Juramaia and Prokennalestes. Modified from Hooker and Russell (2012) character 4.

15. P5 metacone small to absent (0); prominent but smaller than paracone (1); as large as paracone (2). Primitive state based on Juramaia and Prokennalestes. Modified from Hooker and Russell (2012) character 5.

16. P5 preparacrista: strong (0); weak (1); absent (2). Primitive state based on Juramaia and Prokennalestes. Modified from Hooker and Russell (2012) character 6.

17. $P^{5}$ parastyle large, mesially projecting (0); medium (1); small (2). Primitive state based on Prokennalestes. Modified from Hooker and Russell (2012) character 7.

18. $\mathrm{P}^{5}$ metastylar wing (homologue of postmetacrista or, when metacone is absent, of postparacrista): continuous (0); cleft (1) PRIMITIVE; deeply notched, short (2); deeply notched, long (3). Primitive state based on Prokennalestes.

19. P5 preprotocrista-paracingulum complex without paraconule (0); paraconule present on preprotocrista-paracingulum complex (1); paraconule present with postparaconule crista (2); preprotocrista not linked to parastyle and without paraconule or postparaconule crista, precingulum (if present) joining paracingulum (3); preprotocrista linked to paracone and without paraconule or postparaconule crista, precingulum joining paracingulum (4). Primitive state based on Prokennalestes and Juramaia. Modified from Hooker and Russell (2012) character 9. STEPMATRIX.

\begin{tabular}{cccccc} 
& 0 & 1 & 2 & 3 & 4 \\
\hline 0 & - & 1 & 2 & 1 & 1 \\
1 & 1 & - & 1 & 2 & 2 \\
2 & 2 & 1 & - & 3 & 3 \\
3 & 1 & 2 & 3 & - & 1 \\
4 & 1 & 2 & 3 & 1 & -
\end{tabular}

20. (see Appendix Figure 1). $\mathrm{P}^{5}$ with: undifferentiated postprotocrista + metacingulum from protocone to metastyle (0); undifferentiated postprotocrista + metacingulum, with weak, short postcingulum (1); confluent postprotocrista + metacingulum, orientated distobuccally, postcingulum strong, long, with incipient to small hypocone (2); postprotocrista orientated nearly distally, joining long distal cingulum (3); postprotocrista short, distally orientated, joining prehypocrista, with hypocone (4); postprotocrista orientated buccally to distobuccally towards metacone or (where metacone absent) towards postparacrista, independent of distal cingulum (composed of postcingulum + metacingulum), with postflexus (5); as (5), but with no postflexus (6); as (6), but with lingual end of distal cingulum joind to protocone as postprotocingulum (7); postprotocrista deflected distally with buccal part weak to absent, distal cingulum present or absent (8). Primitive state based on Prokennalestes and Juramaia. Modified from Hooker and Russell (2012) character 10. STEPMATRIX.

\begin{tabular}{cccccccccc} 
& 0 & 1 & 2 & 3 & 4 & 5 & 6 & 7 & 8 \\
\hline 0 & - & 1 & 2 & 2 & 3 & 3 & 4 & 5 & 4 \\
1 & 1 & - & 1 & 1 & 2 & 2 & 3 & 4 & 3 \\
2 & 2 & 1 & - & 2 & 3 & 1 & 2 & 3 & 2 \\
3 & 2 & 1 & 2 & - & 1 & 3 & 4 & 5 & 4 \\
4 & 3 & 2 & 3 & 1 & - & 4 & 5 & 6 & 5 \\
5 & 3 & 2 & 1 & 3 & 4 & - & 1 & 2 & 1 \\
6 & 4 & 3 & 2 & 4 & 5 & 1 & - & 1 & 2 \\
7 & 5 & 4 & 3 & 5 & 6 & 2 & 1 & - & 3 \\
8 & 4 & 3 & 2 & 4 & 5 & 1 & 2 & 3 & -
\end{tabular}

21. $P^{5}$ metaconule +/- premetaconule crista: absent (0); present (1). Primitive state based on Prokennalestes.

22. $P^{5}$ : without talon shelf (0); with talon shelf (1). Primitive state based on Prokennalestes and Juramaia.

23. P5: without precingulum (0); with precingulum (1). Primitive state based on Prokennalestes and Juramaia. Wible et al. (2009) character 43.

24. P5 distinct ectoflexus: present (0); absent (1). Primitive state based on Prokennalestes. 


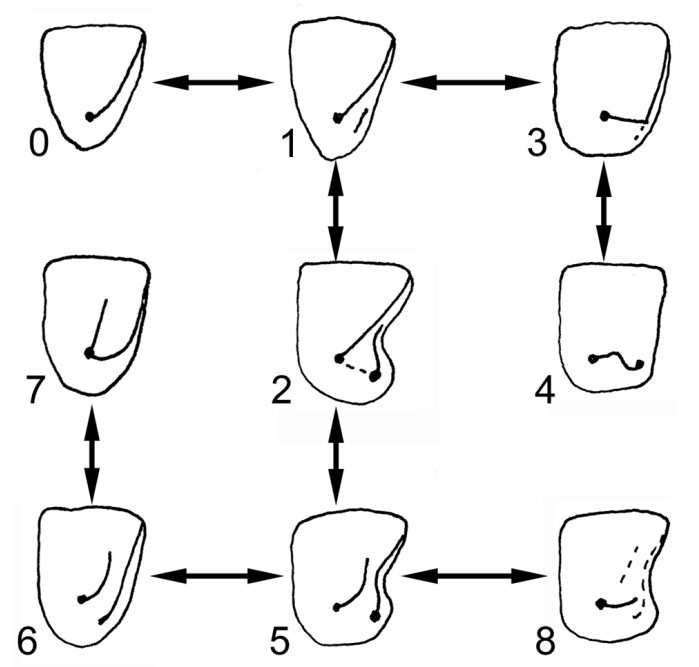

APPENDIX FIGURE 1. Illustrations of left $\mathrm{P}^{5}$ in crown view for character 20 states $0-8$ and their parsimonious transformations.

25. $\quad P^{5}$ buccal protocone crest (central crista of Archibald et al., 2011) absent (0); present (1). Primitive state based on Prokennalestes.

26. $\quad P^{5}$ protocone lobe transversely orientated (0); twisted mesially, making protocone tilt distally (1). Primitive state based on Prokennalestes.

27. $\mathrm{P} 4 / 4$ subequal in size to $\mathrm{P} 5 / 5(0)$; much smaller (1). Primitive state based on Prokennalestes and Juramaia.

28. $\quad \mathrm{P}_{4}$ paraconid height: low (0); nearly half the height of the protoconid (1); more than half the height of the protoconid (2). Primitive state based on Prokennalestes.

29. $\quad P_{4}$ paraconid strength: weak (0); medium (1); strong (2). Primitive state based on Prokennalestes.

30. $\mathrm{P}_{\mathbf{4}}$ metaconid: absent (0); about half the height of the protoconid, lingually placed (1); of subequal height to the protoconid, part of widely open trigonid (2); about half the height of the protoconid, distally placed (3). Primitive state based on Prokennalestes. STEPMATRIX.

\begin{tabular}{ccccc} 
& 0 & 1 & 2 & 3 \\
\hline 0 & - & 1 & 2 & 1 \\
1 & 1 & - & 1 & 1 \\
2 & 2 & 1 & - & 2 \\
3 & 1 & 1 & 2 & -
\end{tabular}

31. $\quad \mathrm{P}_{\mathbf{4}}$ talonid: single-cusped, no basin (0); singlecusped, tiny basin (1) PRIMITIVE; prominent hypoconid (the single cusp), small basin (2); basined with hypoconid and hypoconulid (3); basined with hypoconid, hypoconulid and entoconid (4); basined with hypoconid and entoconid (5). Primitive state based on Prokennalestes. STEPMATRIX.

\begin{tabular}{ccccccc} 
& 0 & 1 & 2 & 3 & 4 & 5 \\
\hline 0 & - & 1 & 2 & 3 & 4 & 3 \\
1 & 1 & - & 1 & 2 & 3 & 2 \\
2 & 2 & 1 & - & 1 & 2 & 1 \\
3 & 3 & 2 & 1 & - & 1 & 2 \\
4 & 4 & 3 & 2 & 1 & - & 1 \\
5 & 3 & 2 & 1 & 2 & 1 & -
\end{tabular}

32. $\quad P_{5}$ : not exodaenodont (0); exodaenodont (1) Primitive state based on Prokennalestes.

33. $\mathrm{P}_{5}$ paraconid height: low (0); about a third of the height of the protoconid (1) PRIMITIVE; about half the height of the protoconid (2); more than half the height of the protoconid (3). Primitive state based on Prokennalestes.

34. $\quad P_{5}$ paraconid strength: weak (0); medium (1) PRIMITIVE; strong (2). Primitive state based on Prokennalestes.

35. $\quad \mathrm{P}_{5}$ metaconid: absent or negligeably developed $(0)$; about half the height of the protoconid, lingually placed (1); of subequal height to the protoconid, part of widely open trigonid (2); of subequal height to the protoconid, part of fully formed short trigonid (3). Primitive state based on Prokennalestes.

36. $\quad P_{5}$ talonid: single-cusped, basin tiny or absent (0); prominent hypoconid (the single cusp), small basin (1); basined with hypoconid and hypoconulid (2); basined with hypoconid, hypoconulid and entoconid (3); basined with hypoconid and entoconid (4); basined with hypoconid, entoconid and doubled entoconid (also lower molars) (5). Primitive state based on Prokennalestes. STEPMATRIX.

\begin{tabular}{ccccccc} 
& 0 & 1 & 2 & 3 & 4 & 5 \\
\hline 0 & - & 1 & 2 & 3 & 2 & 4 \\
1 & 1 & - & 1 & 2 & 1 & 3 \\
2 & 2 & 1 & - & 1 & 2 & 2 \\
3 & 3 & 2 & 1 & - & 1 & 1 \\
4 & 2 & 1 & 2 & 1 & - & 2 \\
5 & 4 & 3 & 2 & 1 & 2 & -
\end{tabular}

37. $\mathrm{M}^{1}$ transverse axis: buccolingual (0); slightly distobuccal-mesiolingual (1). Primitive state based on Prokennalestes. Hooker and Russell (2012) character 28

38. $M^{1}$ metacone: smaller than paracone (0); equal sized or slightly larger (1). Primitive state based on Prokennalestes. Hooker and Russell (2012) character 29 
39. $M^{1}$ preparacrista: nearly transverse, joining stylocone (0); directed mesiobuccally, joining parastyle (possibly including a reduced, mesially shifted stylocone) (1); distinct, directed mesially (2); indistinct, directed mesially (3). Primitive state based on Prokennalestes. Modified from Hooker and Russell (2012) character 30.

40. $\mathrm{M}^{1}$ parastyle: massive and shelf-like (0); large, cuspate (1); small (2). Primitive state based on Prokennalestes. Modified from Hooker and Russell (2012) character 31.

41. Preultimate upper molar centrocrista: straight or slightly lingually deflected (0); buccally deflected, but not reaching buccal margin (1); buccally deflected, meeting buccal margin at single mesostyle (2); buccally deflected, meeting buccal margin at double mesostyle (3). Primitive state based on Prokennalestes. Modified from Hooker and Russell (2012) character 33.

42. Preultimate upper molar postmetacrista: strong, cleft or notched (0); strong, continuous (1); weak, cleft (2). Primitive state based on Prokennalestes. UNORDERED.

43. $M^{1}$ postmetacrista: distinct, long, nearly buccally directed (0); distinct, long, curved or angled distobuccally then buccally (1) PRIMITIVE; distinct, short distobuccally directed (2); distinct, short, distally directed (3); indistinct, short, distally directed (4). Primitive state based on Prokennalestes. Modified from Hooker and Russell (2012) character 34.

44. $\mathrm{M}^{1}$ : paraconule and metaconule situated close to protocone (0); paraconule closer to protocone than is metacone (1); paraconule and metaconule equally more distant from protocone (2); paraconule close to protocone, metaconule absent (3). Primitive state based on Prokennalestes. Modified from Hooker and Russell (2012) character 35. STEPMATRIX.

\begin{tabular}{ccccc} 
& 0 & 1 & 2 & 3 \\
\hline 0 & - & 1 & 2 & 1 \\
1 & 1 & - & 1 & 1 \\
2 & 2 & 1 & - & 2 \\
3 & 1 & 1 & 2 & -
\end{tabular}

45. Preultimate upper molar(s): preprotocrista +/paracingulum (incorporating preparaconule crista) without precingulum (0); Preultimate upper molar(s): preprotocrista + paracingulum with precingulum (1); precingulum and paracingulum joined, from which preprotocrista (including preparaconule crista) is isolated and which may join paracone (2). Primitive state based on Prokennalestes.

46. Preultimate upper molar paraconule and postparaconule crista absent (0); paraconule present, postparaconule crista absent (1) PRIMITIVE;

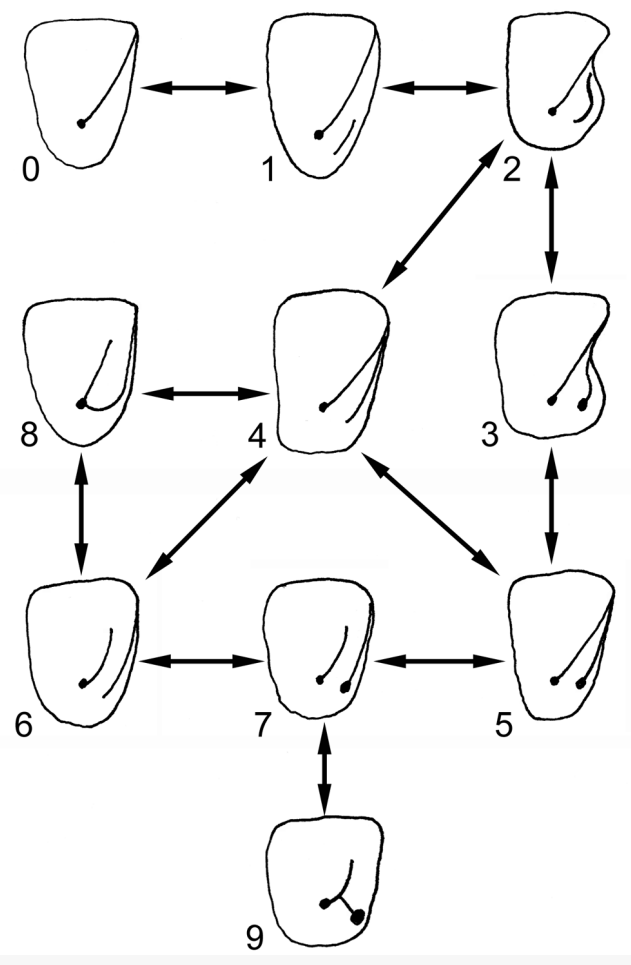

APPENDIX FIGURE 2. Illustrations of left preultimate upper molars in crown view for character 47 states 0-9 and their parsimonious transformations.

paraconule and postparaconule crista present (2). Primitive state based on Prokennalestes.

47. (see Appendix Figure 2). Preultimate upper molar: postprotocrista +/- metacingulum present, postcingulum absent (0); postprotocrista + metacingulum present, postcingulum present (1); postprotocrista + metacingulum present, postcingulum expanded into a short hypocone shelf (2); postprotocrista +/- metacingulum present, short hypocone shelf bearing hypocone (3); postprotocrista + metacingulum present, postcingulum expanded into a long hypocone shelf (4); postprotocrista + metacingulum present, long hypocone shelf bearing hypocone (5); postcingulum confluent with metacingulum, bypassing postprotocrista (6); postcingulum confluent with metacingulum, bypassing postprotocrista and bearing hypocone (7); as (6) but with postprotocingulum (Nannopithex fold) joining or nearly joining hypocone shelf (8); as (7) but with prehypocrista (erinaceid crest) (9). Primitive state based on Prokennalestes. STEPMATRIX.

\begin{tabular}{lllllllllll} 
& 0 & 1 & 2 & 3 & 4 & 5 & 6 & 7 & 8 & 9 \\
\hline 0 & - & 1 & 2 & 3 & 3 & 4 & 4 & 5 & 4 & 6 \\
1 & 1 & - & 1 & 2 & 2 & 3 & 3 & 4 & 3 & 5
\end{tabular}




$\begin{array}{lllllllllll}2 & 2 & 1 & - & 1 & 1 & 2 & 2 & 3 & 2 & 4 \\ 3 & 3 & 2 & 1 & - & 2 & 1 & 3 & 2 & 3 & 3 \\ 4 & 3 & 2 & 1 & 2 & - & 1 & 1 & 2 & 1 & 3 \\ 5 & 4 & 3 & 2 & 1 & 1 & - & 2 & 1 & 2 & 2 \\ 6 & 4 & 3 & 2 & 3 & 1 & 2 & - & 1 & 1 & 2 \\ 7 & 5 & 4 & 3 & 2 & 2 & 1 & 1 & - & 2 & 1 \\ 8 & 4 & 3 & 2 & 3 & 1 & 2 & 1 & 2 & - & 3 \\ 9 & 6 & 5 & 4 & 3 & 3 & 2 & 2 & 1 & 3 & -\end{array}$

48. Preultimate upper molar: metaconule and premetaconule crista absent (0); metaconule present, premetaconule crista absent (1) PRIMITIVE; metaconule and premetaconule crista present (2). Primitive state based on Prokennalestes.

49. Preultimate upper molar inflated talon shelf: absent (0); present, restricted lingually (1); present, extending buccally (2). Primitive state based on Prokennalestes.

50. Preultimate upper molar ectoflexus: deep on $\mathrm{M}^{2}$, shallow on $\mathrm{M}^{1}(0)$; shallow on $\mathrm{M}^{2}$ and shallow or absent on M1 (1); absent (2). Primitive state based on Prokennalestes.

51. Upper molar buccal margin with: stylar shelf nearly a third of the tooth width (0); stylar shelf narrow (1); no stylar shelf, strong ectocingulum (2); no stylar shelf, ectocingulum weak or incomplete (3); stylar shelf and ectocingulum absent (4). Primitive state based on Prokennalestes.

52. Preultimate upper molar stylar cusp D present (0); absent (1). Primitive state based on Prokennalestes.

53. Upper molar protocone tilt: lingual (0); more or less vertically orientated from crown base (1); buccal (2). Primitive state based on Prokennalestes.

54. $M_{1}$ paraconid height from lingual side: about a third the height of the protoconid (0); about half the height of the protoconid (1) PRIMITIVE; about two thirds the height of the protoconid (2); nearly as tall as protoconid (3). Primitive state based on Prokennalestes.

55. Transverse position of $\mathrm{M}_{1}$ paraconid tip with respect to that of metaconid: lingual (0); sublingual (1) PRIMITIVE; median (2). Primitive state based on Prokennalestes.

56. $\quad M_{1}$ paraconid strength: weak (0); medium (1) PRIMITIVE; strong (2). Primitive state based on Prokennalestes.

57. $\quad M_{1}$ paraconid shape: cuspate (0); crestiform (1). Primitive state based on Prokennalestes.

58. Lower molar paracristid notch: absent (0); present as cleft or angle (1) PRIMITIVE; present as deep (carnassial) notch (2). Primitive state based on Prokennalestes.
59. Shape of $\mathrm{M}_{\mathbf{1}}$ trigonid: very narrow mesiodistally (0); approximately an equilateral triangle (1) PRIMITIVE; elongate mesially (2). Primitive state based on Prokennalestes.

60. $\quad M_{2}$ paraconid: cuspate (0); crestiform (1). Primitive state based on Prokennalestes.

61. $M_{2}$ paraconid: separate from metaconid (0); the two cusps connate (1). Primitive state based on Prokennalestes.

62. $M_{1}$ hypoconid height: half or less than half height of protoconid (0); about two thirds the height of protoconid (1); subequal (2). Primitive state based on Prokennalestes.

63. $M_{1}$ entoconid: less than half height of metaconid (0); about half height of metaconid (1); about two thirds height of metaconid (2); the two cusps subequal (3). Primitive state based on Prokennalestes.

64. Lower molar hypoconulid buccal of midline (0); central (1) PRIMITIVE; lingual of midline (2); at or near lingual margin, nyctalodont condition (3). Primitive state based on Prokennalestes.

65. Lower molar cristid obliqua meets trigonid: lingually, rising up distolingual edge of metaconid (0); at about midpoint, rising obliquely up the back of the metaconid (1); at about midpoint, not or scarcely rising up back of trigonid (2); slightly buccal of midpoint, not or scarcely rising up back of trigonid (3); nearly at buccal margin, not or scarcely rising up back of trigonid (4); from a buccally convex trajectory, rising up the buccal side of the metaconid (5). Primitive state based on Prokennalestes.

66. Lower molar cristid obliqua: unnotched (0); notched (1). Primitive state based on Prokennalestes.

67. $M_{1}$ talonid: narrower than trigonid (0); equal in width to trigonid (1); wider than trigonid (2). Primitive state based on Prokennalestes.

68. Lower molar posthypocristid: complete or only narrowly notched (0); broken (1). Primitive state based on Prokennalestes.

69. Lower molar protocristid: fissured with carnassial notch (0); angled/cleft (1) PRIMITIVE; a smooth continuous crest (2). Primitive state based on Prokennalestes.

70. Lower molar precingulid: strong (0); weak (1); absent (2). Primitive state based on Prokennalestes.

71. Preultimate lower molar postcingulid: absent (0); present basally (1); rising to join hypoconulid (2); present basally, extended mesially to join precingulid, i.e., forming ectocingulid (3). Primitive state based on Prokennalestes. STEPMATRIX.

$\begin{array}{llll}0 & 1 & 2 & 3\end{array}$ 


\begin{tabular}{lllll}
\hline 0 & - & 1 & 2 & 2 \\
1 & 1 & - & 1 & 1 \\
2 & 2 & 1 & - & 2 \\
3 & 2 & 1 & 2 & -
\end{tabular}

72. $M_{3}$ hypoconulid: distally protruding, inflated to enclose a basin (0); distally protruding, a distinct cusp (1) PRIMITIVE; contracted, not protruding significantly from talonid, entoconid present (2); contracted, not protruding significantly from talonid, entoconid absent (3); absent together with talonid or entire tooth (4). Primitive state based on Prokennalestes.

73. $\mathrm{M}_{3}$ hypoconulid: overhangs distal tooth margin (0); distally extensive basally beyond tip (1); absent together with talonid or entire tooth (2). Primitive state based on Prokennalestes.

74. Relative height of molar cusps judged from height of $\mathrm{M}_{1 / 2}$ protoconid as $\%$ of tooth length: more than $95 \%$ (0); between 75 and $95 \%$ (1); less than $75 \%$ (2). Primitive state based on Prokennalestes.

\section{Dentary}

75. Anterior mental foramen below $P_{2}(0)$; between $P_{1}$ and $P_{2}(1)$; below $P_{1}(2)$; between $P_{4}$ and $P_{5}(3)$; at extreme anterior position (4); absent (5). Primitive state based on Juramaia. Modified from Wible et al. (2009) character 129. STEPMATRIX.

\begin{tabular}{ccccccc} 
& 0 & 1 & 2 & 3 & 4 & 5 \\
\hline 0 & - & 1 & 2 & 1 & 1 & 1 \\
1 & 1 & - & 1 & 2 & 2 & 1 \\
2 & 2 & 1 & - & 2 & 1 & 1 \\
3 & 1 & 2 & 2 & - & 2 & 1 \\
4 & 1 & 2 & 1 & 2 & - & 1 \\
5 & 1 & 1 & 1 & 1 & 1 & -
\end{tabular}

76. Posterior mental foramen: below $P_{2}(0)$; between $\mathrm{P}_{2}$ and $\mathrm{P}_{4}$ (1); below $\mathrm{P}_{4}(2)$; between $\mathrm{P}_{4}$ and $\mathrm{P}_{5}$ (3) PRIMITIVE; below $\mathrm{P}_{5}(4)$; between $\mathrm{P}_{5}$ and $\mathrm{M}_{1}$ or below $M_{1}$ (5). Primitive state based on Juramaia. Modified from Wible et al. (2009) character 130.

77. Height of condyle above alveolar line: one molar length (0); two molar lengths (1); three molar lengths (2); four molar lengths or more (3). Primitive state based on Juramaia. Modified from Wible et al. (2009) character 150.

78. Tilting of coronoid process; angle of anterior border to alveolar line: 120-130 degrees (0); 110 degrees (1); 100 degrees (2); 90 degrees (3). Primitive state based on Juramaia and Prokennalestes. Modified from Wible et al. (2009) character 135.

79. Height of coronoid process above alveolar line: two to three molar lengths (0); four molar lengths
(1); five molar lengths or more (2). Primitive state based on Juramaia and Prokennalestes. Modified from Wible et al. (2009) character 133.

80. Lateral mandibular foramen present (0); absent (1). Primitive state based on Eomaia, Juramaia and Prokennalestes. Modified from Wible et al. (2009) character 139: polarity reversed.

81. Angular process directed posteroventrally (0); posteroventromedially (1); posteroventrolaterally (2); posteriorly (3); dorsally to dorsomedially inflected (4); in the form of a rounded posteroventral corner (5); rounded with dorsal hook (6). Primitive state based on Eomaia, Juramaia and Prokennalestes. Modified from Wible et al. (2009) character 143. STEPMATRIX.

\begin{tabular}{cccccccc} 
& 0 & 1 & 2 & 3 & 4 & 5 & 6 \\
\hline 0 & - & 1 & 1 & 1 & 2 & 2 & 3 \\
1 & 1 & - & 2 & 1 & 2 & 2 & 3 \\
2 & 1 & 2 & - & 1 & 2 & 2 & 3 \\
3 & 1 & 1 & 1 & - & 1 & 1 & 2 \\
4 & 2 & 2 & 2 & 1 & - & 2 & 1 \\
5 & 2 & 2 & 2 & 1 & 2 & - & 1 \\
6 & 3 & 3 & 3 & 2 & 1 & 1 & -
\end{tabular}

82. Depression in ventral dentary margin anterior to angle present (0); absent (1). Primitive state based on Eomaia, Juramaia and Prokennalestes.

83. Angular process projects posteriorly less than dentary condyle (0); about equal (1); farther (2). Primitive state based on Eomaia, Juramaia and Prokennalestes. Wible et al. (2009) character 147.

84. Angular process vertical position: at posteroventral border (0); posterodorsal, at or near alveolar border (1). Primitive state based on Eomaia, Juramaia and Prokennalestes. Wible et al. (2009) character 146.

85. Dentary condyle with posteriorly directed peduncle (0); without (1). Primitive state based on Eomaia, Juramaia and Prokennalestes. Wible et al. (2009) character 148. Cimolestes magnus recoded 1 (Lillegraven 1969, figure 37.3); Erinaceus recoded 0 (personal obs.).

86. Vertical position of mandibular foramen: near ventral margin at root of angle (0); recessed dorsally from ventral margin, but below alveolar plane (1); recessed dorsally from ventral margin, at or above alveolar plane (2). Primitive state based on Eomaia and Prokennalestes. Wible et al. (2009) character 157.

\section{Rostrum}

87. Premaxilla-maxilla suture on face: vertically orientated, contacting nasals (0); projecting posterodorsally no further than canine, but without contacting frontal (1) PRIMITIVE; projecting pos- 
terodorsally further than canine, but without contacting frontal (2); projecting posterodorsally and contacting frontal (3); premaxilla lacking facial process (4). Primitive state based on Vincelestes. Modified from Wible et al. (2009) characters 160162. STEPMATRIX.

\begin{tabular}{cccccc} 
& 0 & 1 & 2 & 3 & 4 \\
\hline 0 & - & 1 & 2 & 2 & 1 \\
1 & 1 & - & 1 & 2 & 1 \\
2 & 2 & 1 & - & 1 & 1 \\
3 & 2 & 2 & 1 & - & 1 \\
4 & 1 & 1 & 1 & 1 & -
\end{tabular}

88. Infraorbital foramen dorsal to: $\mathrm{P}^{4}$ or more anterior (0); dorsal to $\mathrm{P}^{5}$ (1); Dorsal to $\mathrm{M}^{1}$ or more posterior (2). Primitive state based on Eomaia and Prokennalestes. Wible et al. (2009) character 165, with changed state numbering.

89. Vertical position of anterior margin of orbit with respect to tooth loci. Above $\mathrm{P}^{5}$ or more anterior (0); M1 (1) PRIMITIVE; M² or more posterior (2). Primitive state based on Eomaia. This, together with character 15, approximates length of infraorbital canal (Wible et al., 2009, character 166).

90. Nasal widest posteriorly (0); with sides subparallel (1); widest anteriorly (2). Primitive state based on Eomaia. Wible et al. (2009) character 168.

91. Nasal overhangs external nasal aperture (0); does not overhang (1). Primitive state based on Vincelestes. Wible et al. (2009) character 169.

92. Nasofrontal suture with medial process of frontals wedged between nasals (0); not wedged between nasals (1). Primitive state based on Eomaia. Wible et al. (2009) character 170.

93. Posterior margin of nasals posterior to or even with anterior orbital rim (0); anterior to anterior orbital rim (1). Primitive state based on Eomaia. Modified from Wible et al. (2009) character 171.

94. Anterior process of frontal weak/absent (0); elongate/thin (1). Primitive state based on Eomaia. Modified from Wible et al. (2009) character 174.

95. No frontal maxillary contact on rostrum (0); contact (1). Primitive state based on Eomaia. Wible et al. (2009) character 173.

96. Facial process of lacrymal large, triangular and pointed anteriorly (0); small and rectangular or crescentic (1). Primitive state based on Eomaia. Wible et al. (2009) character 177 . Erinaceus rescored 1 as, although fused to maxilla in adult, its extent can be judged from juveniles (Butler, 1948).

97. Lacrymal tubercle present (0); absent (1). Primitive state based on Vincelestes. Wible et al. (2009) character 178.
98. Lacrymal foramen not exposed on face (0); exposed on face (1). Primitive state based on Eomaia. Wible et al. (2009) character 179, but with reversed state numbering.

99. Number of lacrymal foramina: two (0); one (1). Primitive state based on Vincelestes. Wible et al. (2009) character 180.

100. Lacrymal foramen within lacrymal (0); with maxillary contribution (1); with jugal contribution (2). UNORDERED. Primitive state based on Vincelestes. Wible et al. (2009) character 181.

\section{Palate}

101. Premaxillary-maxillary suture on palate wedgeshaped, pointing anteriorly (0); transverse (1) PRIMITIVE; wedge-shaped, pointing posteriorly (2). Primitive state based on Vincelestes. Wible et al. (2009) character 184, with states 0 and 1 reversed.

102. Incisive foramina small, length of one or two incisors (0); length of three or four incisors (1). Primitive state based on Vincelestes. Wible et al. (2009) character 185.

103. Palatal vacuities absent (0); present (1). Primitive state based on Vincelestes. Wible et al. (2009) character 187.

104. Major (anterior) palatal foramen single within palatine (0); single between palatine and maxilla (1); single within maxilla (2). Primitive state based on Vincelestes. Wible et al. (2009) character 188.

105. Palatal expansion posterior to last molar (0); even with last molar (1) PRIMITIVE; anterior to last molar (2). Primitive state based on Vincelestes. Wible et al. (2009) character 190, with states 0 and 1 reversed.

106. Postpalatine torus absent (0); present (1). Primitive state based on Vincelestes. Wible et al. (2009) character 191.

107. Posterior nasal spine weak or absent (0); prominent (1). Primitive state based on Vincelestes. Wible et al. (2009) character 192. Ptilocercus rescored as 0 (pers. obs.).

108. Minor (posterior) palatal foramen small, single or multiple within palatine or between maxilla and palatine (0); large with thin posterior bony bridge, within palatine or between maxilla and palatine (1); large, with thin posterior bony bridge between palatine and pterygoid (2); absent (3). Primitive state based on Vincelestes. Combined from Wible et al. (2009) characters 193 and 194. Ptilocercus rescored as 0 (personal obs.). STEPMATRIX.

\begin{tabular}{ccccc} 
& 0 & 1 & 2 & 3 \\
\hline 0 & - & 1 & 2 & 1 \\
1 & 1 & - & 1 & 1 \\
2 & 2 & 1 & - & 1
\end{tabular}


$\begin{array}{lllll}3 & 1 & 1 & 1 & -\end{array}$

109. Maxilla without large shelf-like expansion posterior to last molar (0); with (1). Primitive state based on Vincelestes. Wible et al. (2009) character 195.

\section{Zygoma}

110. Posterior edge of anterior zygomatic root aligned with last molar (0); with anterior molars (1). Primitive state based on Eomaia. Wible et al. (2009) character 196.

111. Zygomatic process of maxilla: not bifurcated, jugal contribution to anteroventral orbit and zygoma, and jugal-lacrymal contact (0); bifurcated, jugal contribution to anteroventral orbit and zygoma, and jugal-lacrymal contact (1); bifurcated, jugal contribution to anteroventral orbit and zygoma, but no jugal-lacrymal contact (2); absent/vestigial, jugal contribution to anteroventral orbit and zygoma, and jugal-lacrymal contact (3); not bifurcated, jugal contribution to anteroventral orbit and zygoma, but no jugal-lacrymal contact (4); not bifurcated, jugal contribution only to zygoma and no jugal-lacrymal contact (5); present but no jugal (6). Primitive state based on Vincelestes. Wible et al. (2009) characters 197-201. STEPMATRIX.

\begin{tabular}{cccccccc} 
& 0 & 1 & 2 & 3 & 4 & 5 & 6 \\
\hline 0 & - & 1 & 2 & 1 & 1 & 2 & 3 \\
1 & 1 & - & 1 & 2 & 2 & 3 & 4 \\
2 & 2 & 1 & - & 3 & 1 & 2 & 3 \\
3 & 1 & 2 & 3 & - & 2 & 3 & 4 \\
4 & 1 & 2 & 1 & 2 & - & 1 & 2 \\
5 & 2 & 3 & 2 & 3 & 1 & - & 1 \\
6 & 3 & 4 & 3 & 4 & 2 & 1 & -
\end{tabular}

112. Zygomatic arch: stout, without malar foramen (0); delicate, without malar foramen (1) PRIMITIVE; delicate, with malar foramen (2); absent (3). Primitive state based on Eomaia. Modified from Wible et al. (2009) character 202. STEPMATRIX.

\begin{tabular}{ccccc} 
& 0 & 1 & 2 & 3 \\
\hline 0 & - & 1 & 2 & 1 \\
1 & 1 & - & 1 & 1 \\
2 & 2 & 1 & - & 1 \\
3 & 1 & 1 & 1 & -
\end{tabular}

\section{Orbit}

113. Palatine reaches infraorbital canal (0); does not reach (1). Primitive state based on Vincelestes. Wible et al. (2009) character 204.

114. Lacrymal contributes to maxillary foramen (0); does not contribute (1). Primitive state based on Vincelestes. Wible et al. (2009) character 205.
115. No groove connecting maxillary and sphenopalatine foramina (0); groove present (1). Primitive state based on Vincelestes. Wible et al. (2009) character 206.

116. Sphenopalatine (orbitonasal) foramen within palatine (0); between palatine and maxilla (1); between palatine, maxilla and frontal (2); within maxilla (3). Primitive state based on Vincelestes. Wible et al. (2009) character 207. STEPMATRIX.

\begin{tabular}{ccccc} 
& 0 & 1 & 2 & 3 \\
\hline 0 & - & 1 & 1 & 2 \\
1 & 1 & - & 1 & 1 \\
2 & 1 & 1 & - & 1 \\
3 & 2 & 1 & 1 & -
\end{tabular}

117. Sphenopalatine (orbitonasal) foramen not proximal to maxillary foramen (0); proximal (1). Primitive state based on Vincelestes. Wible et al. (2009) character 208.

118. Maxilla excluded from medial orbital wall (0); not excluded (1). Primitive state based on Vincelestes. Wible et al. (2009) character 209.

119. No frontal-maxilla contact in medial orbital wall (0); contact (1). Primitive state based on Vincelestes. Wible et al. (2009) character 210.

120. Orbital process of palatine present (0); absent or with thin sliver in ventromedial wall (1). Primitive state based on Vincelestes. Wible et al. (2009) character 211.

121. Ethmoidal foramen between frontal and orbitosphenoid (0); within frontal (1); absent (2). Primitive state based on Vincelestes. Modified from Wible et al. (2009) character 213. UNORDERED.

122. Foramen for frontal diploic vein absent (0); present (1). Primitive state based on Vincelestes. Wible et al. (2009) character 214.

123. Frontal foramen on cranial roof absent (0); present (1). Primitive state based on Vincelestes. Wible et al. (2009) character 215.

124. Postorbital process and dorsal process of jugal absent (0); postorbital process weak, dorsal process of jugal absent (1); postorbital process strong, dorsal process of jugal absent (2) PRIMITIVE; postorbital process strong, dorsal process of jugal present (3); postorbital bar composed of postorbital process and dorsal process of jugal (4). Primitive state based on Vincelestes. Wible et al. (2009) characters 216, 218, 219.

125. Optic foramen narrowly separated from sphenorbital fissure (0); broadly separated (1); not visible in lateral view (2). Polarity problematic as optic foramen absent or its state unknown in potential outgroups. Wible et al. (2009) character 221. UNORDERED.

126. Orbitosphenoid expanded anteriorly from optic foramen (or with anterior process) (0); expanded 
dorsally from optic foramen (or with dorsal process) (1). Primitive state based on Vincelestes. Wible et al. (2009) character 222, with changed state numbering.

127. Suboptic foramen absent (0); present (1). Primitive state based on Vincelestes. Wible et al. (2009) character 223. N.B., presence in Leptictis shown by Butler (1956) but stated by Novacek (1986), quoting Butler (1956, p. 473) to be absent anterior to the sphenorbital fissure, but not necessarily absent per se (see Butler 1956, figure 7), thus contra Wible et al. (2009). N.B., absence in Erinaceus is shown by Butler (1948, figure 7) contra Wible et al. (2009).

128. Orbitotemporal canal (sinus canal, cranio-orbital foramen) present (0); absent (1). Primitive state based on Vincelestes. Wible et al. (2009) character 224.

\section{Braincase}

129. Frontal length on midline more than $50 \%$ longer than parietal (0); subequal to slightly shorter than parietal (1) PRIMITIVE; less than half length of parietal (2). Primitive state based on Eomaia. Wible et al. (2009) character 226, with state numbering changed.

130. Fronto-parietal suture: with anterior process of parietal off the midline (0); transverse (1) PRIMITIVE; with anterior process on the midline (2). Primitive state based on Vincelestes. Wible et al. (2009) character 227.

131. Temporal lines (crista frontalis externa) meet on midline to form sagittal crest (0); do not meet (1). Primitive state based on Eomaia. Wible et al. (2009) character 228.

132. Interparietal absent (0); present (1). Primitive state based on Vincelestes. Wible et al. (2009) character 229.

133. Nuchal crest level with or anterior to foramen magnum (0); posterior to foramen magnum (1). Primitive state based on Eomaia. Wible et al. (2009) character 230.

\section{Mesocranium}

134. Choanae as wide as posterior palate (0); narrower (1). Primitive state based on Vincelestes. Wible et al. (2009) character 234.

135. Vomer does not contact pterygoid (0); contacts pterygoid (1). Primitive state based on Vincelestes. Wible et al. (2009) character 235.

136. Pterygoids contact on midline (0); do not contact (1). Primitive state based on Vincelestes. Wible et al. (2009) character 236.

137. Midline crest in basipharyngeal canal present (0); absent (1). Primitive state based on Vincelestes. Wible et al. (2009) character 238, with state numbering reversed.
138. Entopterygoid process ends at anterior basisphenoid (0); approaches ear region (1). Modified from Wible et al. (2009) character 239.

139. Midline rod-shaped eminence on basisphenoid absent (0); present (1). Primitive state based on Vincelestes. Wible et al. (2009) character 240.

140. Ectopterygoid process of alisphenoid: approaches ear region as long crest (0); ends at anterior basisphenoid as long crest (1) PRIMITIVE; ends at anterior basisphenoid as narrow process (2); approaches ear region as narrow process (3); absent (4). Wible et al. (2009) characters 241242. STEPMATRIX.

\begin{tabular}{ccccc} 
& 0 & 1 & 2 & 3 \\
\hline 0 & - & 1 & 2 & 1 \\
1 & 1 & - & 1 & 2 \\
2 & 2 & 1 & - & 1 \\
3 & 1 & 2 & 1 & -
\end{tabular}

141. Exit for maxillary nerve (cranial nerve V2) relative to alisphenoid: behind (0); within (1); in front (2). Primitive state based on Vincelestes. Wible et al. (2009) character 244.

142. Foramen ovale in petrosal (anterior lamina) (0); in alisphenoid (1); between alisphenoid and squamosal (2). Primitive state based on Vincelestes. Wible et al. (2009) character 246, with changed states.

143. Alisphenoid canal absent (0); present, posterior opening separate from foramen ovale (1); present, posterior opening in common depression with foramen ovale (2). Primitive state based on Vincelestes. Wible et al. (2009) characters 248-249. UNORDERED.

\section{Basicranium}

144. Glenoid fossa on zygoma (0); partly on braincase (1). Primitive state based on Vincelestes. Wible et al. (2009) character 251.

145. Glenoid fossa even dorsoventrally with sphenoid on midline cranial base (0); higher (1). Primitive state based on Vincelestes. Wible et al. (2009) character 253.

146. Jugal contributes to glenoid with articular facet (0); contributes to glenoid without articular facet (1); does not contribute to glenoid (2). Primitive state based on Vincelestes. Modified from Wible et al. (2009) character 254. State 2 for Ptilocercus (Wible, 2011) contra Wible et al. (2009) (0).

147. Postglenoid process present (0); absent (1). Primitive state based on Eomaia. Wible et al. (2009) character 256.

148. Postglenoid foramen within squamosal, behind postglenoid process (0); within squamosal, medial or anterior to postglenoid process or on lateral aspect of braincase (1); behind squamosal, 
behind postglenoid process (2); absent (3) PRIMITIVE. Primitive state based on Vincelestes. Wible et al. (2009) characters 257-259. UNORDERED.

149. Suprameatal foramen absent (0); present (1). Primitive state based on Vincelestes. Wible et al. (2009) character 260.

150. Entoglenoid process of squamosal absent (0); present, separated from postglenoid process (1); present, continuous with postglenoid process (2). Primitive state based on Eomaia. Wible et al. (2009) character 261. UNORDERED.

151. Posttympanic crest of squamosal absent (0); present (1). Primitive state based on Vincelestes. Wible et al. (2009) character 262.

152. Carotid foramen within basisphenoid (0); between basisphenoid and petrosal (1); absent (2). Primitive state based on Vincelestes. Wible et al. (2009) character 263. UNORDERED.

153. Cavum epiptericum floor composition: petrosal (0); petrosal and alisphenoid (1); primarily open as pyriform (piriform) fenestra (2). Primitive state based on Vincelestes. Wible et al. (2009) character 264. UNORDERED.

154. Alisphenoid tympanic process absent (0); present (1). Primitive state based on Vincelestes. Wible et al. (2009) character 265. Recoded 1 in Ptilocercus as shown present by Cartmill and MacPhee (1980) and Wible (2011), contra Wible et al. (2009), where coded 0.

155. Basisphenoid tympanic process absent (0); present (1). Primitive state based on Vincelestes. Wible et al. (2009) character 266.

156. Medial flange of petrosal absent (0); present (1). Polarity is equivocal as it is absent in Vincelestes, but present in Prokennalestes. 1 treated here as PRIMITIVE. Wible et al. (2009) character 268.

157. Rostral tympanic process of petrosal on posteromedial aspect of promontorium: absent or low ridge (0); moderate ridge, contributing to posterodorsomedial bulla (1); tall ridge, contributing to ventral bulla (2). Primitive state based on Vincelestes and Prokennalestes. Wible et al. (2009) character 269. UNORDERED.

158. Course of internal carotid artery (ICA) and of stapedial artery: ICA lateral (transpromontorial), both in sulcus (0); ICA lateral (transpromontorial), both in intratympanic vascular canal (1); medial (perbullar or extrabullar), both in sulcus (2); course indication absent (3). Primitive state based on Vincelestes and Prokennalestes. Modified from Wible et al. (2009) characters 270-271, 273-274 and Bloch et al. (2007) character 87. STEPMATRIX.

\begin{tabular}{lllll} 
& 0 & 1 & 2 & 3 \\
\hline 0 & - & 1 & 1 & 1 \\
1 & 1 & - & 2 & 2
\end{tabular}

$\begin{array}{lllll}2 & 1 & 2 & - & 1 \\ 4 & 1 & 2 & 1 & -\end{array}$

159. Promontorium shape: flat (0); globose (1). Polarity is equivocal as it is flat in Vincelestes, but globose in Prokennalestes. 1 treated here as PRIMITIVE. Wible et al. (2009) character 278.

160. Intratympanic course of facial nerve: open in sulcus (0); open anteriorly, canal posteriorly (1); in canal (2). Primitive state based on Vincelestes and Prokennalestes. Wible et al. (2009) character 280.

161. Aperture of hiatus Fallopii: in tympanic roof through petrosal (0); at anterior edge of petrosal (1); through cerebral surface, via fenestra semilunaris if present (2); absent (3). Primitive state based on Vincelestes and Prokennalestes. Modified from Wible et al. (2009) character 281. STEPMATRIX.

\begin{tabular}{ccccc} 
& 0 & 1 & 2 & 3 \\
\hline 0 & - & 1 & 2 & 1 \\
1 & 1 & - & 1 & 1 \\
2 & 2 & 1 & - & 1 \\
3 & 1 & 1 & 1 & -
\end{tabular}

162. Prootic canal present (0); absent (1). Primitive state based on Vincelestes and Prokennalestes. Wible et al. (2009) character 282.

163. Length of bony shelf lateral to promontorium (lateral trough or tegmen tympani): extended anteriorly as far as promontorium (0); confined posterolaterally (1) PRIMITIVE; prolonged anterior to promontorium (2). Polarity is equivocal as Vincelestes is 0, but Prokennalestes is 1.1 treated here as PRIMITIVE. Wible et al. (2009) character 285.

164. Width of bony shelf lateral to promontorium (lateral trough or tegmen tympani): uniform (0); expanded anteriorly (1). Primitive state based on Vincelestes and Prokennalestes. Wible et al. (2009) character 286.

165. Stapedial canal on bony shelf lateral to promontorium (lateral trough or tegmen tympani): absent (0); present (1). Primitive state based on Vincelestes and Prokennalestes. Wible et al. (2009) character 288.

166. Tensor tympani fossa on petrosal: shallow to absent (0); deep circular pit (1). Primitive state based on Vincelestes and Prokennalestes. Wible et al. (2009) character 289.

167. Cochlear width less than $20 \%$ of skull length (0); greater than $20 \%$. Primitive state based on Vincelestes. Novacek (1987).

168. Epitympanic recess to fossa incudis relative size: subequal (0); epitympanic recess larger (1); no visible depression for epitympanic recess (2). 
Polarity is equivocal as Vincelestes is 0 , but Prokennalestes is 1.1 treated here as PRIMITIVE. Wible et al. (2009) character 292.

169. Epitympanic recess lateral wall: with extensive contribution to lateral wall by squamosal (0); with small contribution to posterolateral wall by squamosal (1) PRIMITIVE; no squamosal contribution (2). Polarity is equivocal as Vincelestes is 1 , but Prokennalestes is 0.1 treated here as PRIMITIVE. Wible et al. (2009) character 293, with states 0 and 1 reversed.

170. Fossa incudis continuous with epitympanic recess (0); separated from it (1). Primitive state based on Vincelestes and Prokennalestes. Wible et al. (2009) character 294.

171. Foramen for ramus superior of stapedial artery: posterior or lateral to fenestra vestibuli (ovalis) (0); anterior to fenestra vestibuli (1); absent (2). Polarity is equivocal as Vincelestes is 0 , but Prokennalestes is 1.1 treated here as PRIMITIVE. Wible et al. (2009) character 298. UNORDERED.

172. Ascending canal (for arteria diploëtica magna): intramural (0); intracranial (1); absent (2). Primitive state based on Vincelestes and Prokennalestes. Wible et al. (2009) character 299. UNORDERED.

173. Stapedius fossa twice the size of fenestra vestibuli (ovalis) (0); small and shallow (1). Primitive state based on Vincelestes and Prokennalestes. Wible et al. (2009) character 300.

174. Cochlear canaliculus not visible in middle ear space (0); visible (1). Primitive state based on Vincelestes and Prokennalestes. Wible et al. (2009) character 301.

175. Postpromontorial tympanic sinus: dorsal to cochlear fossula (0); at same level as cochlear fossula (1). Primitive state based on Vincelestes and Prokennalestes. Wible et al. (2009) character 302.

176. Fenestra cochleae (rotunda) position to fenestra vestibuli (ovalis): posteromedial (0); posterior (1). Primitive state based on Vincelestes and Prokennalestes. Wible et al. (2009) character 303.

177. Posterior septum shielding fenestra cochleae (rotunda) absent (0); present (1). Primitive state based on Vincelestes and Prokennalestes. Wible et al. (2009) character 304.

178. Paroccipital process of petrosal: vertical (0); slanted, projecting as flange towards back of promontorium (1); indistinct to absent (2). Primitive state based on Vincelestes and Prokennalestes. Wible et al. (2009) character 305. UNORDERED.

179. Caudal tympanic process of petrosal: not notched (0); notched (1); absent (2). Primitive state based on Vincelestes. Modified from Wible et al. (2009) character 306. UNORDERED.
180. Crista interfenestralis and caudal tympanic process: not connected by curved ridge (0); connected by curved ridge (1). Primitive state based on Vincelestes and Prokennalestes. Wible et al. (2009) character 307.

181. 'Tympanic process' of Kielan-Jaworowska: absent (0); present, low, composed of petrosal (1); present, low, composed of petrosal and exoccipital (2); present, high, composed of petrosal (3). Primitive state based on Vincelestes and Prokennalestes. Wible et al. (2009) characters 308-309. STEPMATRIX.

\begin{tabular}{ccccc} 
& 0 & 1 & 2 & 3 \\
\hline 0 & - & 1 & 1 & 2 \\
1 & 1 & - & 1 & 1 \\
2 & 1 & 1 & - & 2 \\
3 & 2 & 1 & 2 & -
\end{tabular}

182. Jugular (posterior lacerate) foramen size relative to fenestra cochleae (rotunda): subequal (0); larger (1). Primitive state based on Vincelestes and Prokennalestes. Wible et al. (2009) character 312.

183. Jugular (posterior lacerate) foramen: confluent with opening for inferior petrosal sinus (0); separated from inferior petrosal sinus (1). Primitive state based on Vincelestes. Wible et al. (2009) character 313.

184. Hypoglossal foramen number: two or more (0); one (1); variable (2). Primitive state based on Vincelestes. Modified from Wible et al. (2009) character 314. UNORDERED.

185. Hypoglossal foramen not housed in opening larger than jugular (posterior lacerate) foramen (0); housed in opening larger than jugular foramen (1). Primitive state based on Vincelestes. Wible et al. (2009) character 315.

186. Paracondylar (paroccipital) process of exoccipital: weak or absent (0); prominent, vertical (1); prominent, posteriorly directed (2). Primitive state based on Vincelestes. Wible et al. (2009) character 316. UNORDERED.

187. Ectotympanic: phaneric or visible in ventral view (0); aphaneric or hidden by auditory bulla (1). Wible et al. (2009) character 317.

188. Ectotympanic: ring-like (0); fusiform (1) PRIMITIVE; expanded (2). Wible et al. (2009) character 318, but recoded (0) for Plesiadapis (Bloch and Silcox 2001, figure 7).

189. Anterior crus of ectotympanic: does not broadly contact facet on squamosal (0); does broadly contact facet on squamosal (1). Primitive state based on Vincelestes. Wible et al. (2009) character 319.

190. Elongate ossified external acoustic canal: absent (0); present (1). Primitive state based on ingroup commonality. Wible et al. (2009) character 320. 
191. Roof of external acoustic meatus: petrosal (0); petrosal and squamosal (1); squamosal (2). Polarity equivocal, as Vincelestes is 0, Prokennalestes is 1.0 treated here as PRIMITIVE. Modified from Wible et al. (2009) character 321. UNORDERED.

192. Entotympanic absent (0); present (1). Primitive state based on Vincelestes Wible et al. (2009) character 322.

193. Hyoid arch does not contribute to bulla (0); does contribute (1). Primitive state based on Vincelestes and Prokennalestes. Wible et al. (2009) character 324.

194. Dorsum sellae tall (0); low (1). Primitive state based on Vincelestes. Wible et al. (2009) character 325.

195. Wall separating cavum supracochleare from cavum epiptericum: incomplete, with fenestra semilunaris (0); complete (1). Polarity equivocal, as Vincelestes is 0, Prokennalestes is 1.0 treated here as PRIMITIVE. Modified from Wible et al. (2009) character 328.

196. Crista petrosa: vestigial or absent (0); a tall, thin crest (1). Primitive state based on Vincelestes. Wible et al. (2009) character 329.

197. Anterior (superior) semicircular canal: forms lateral wall of unconstricted subarcuate fossa aperture (0); forms lateral wall of constricted subarcuate fossa aperture (1); does not form lateral wall of constricted subarcuate fossa aperture (2). Primitive state based on Vincelestes. Wible et al. (2009) characters 330-331. UNORDERED.

198. Posttemporal canal on occiput: large, between petrosal and squamosal (0); small, between petrosal and squamosal (1); small, within petrosal (2); absent (3). Primitive state based on Vincelestes. Wible et al. (2009) characters 333-335. STEPMATRIX.

\begin{tabular}{ccccc} 
& 0 & 1 & 2 & 3 \\
\hline 0 & - & 1 & 2 & 2 \\
1 & 1 & - & 1 & 1 \\
2 & 2 & 1 & - & 1 \\
3 & 2 & 1 & 1 & -
\end{tabular}

\section{Vertebrae}

199. Atlantal foramen present (0); absent (1). Primitive state based on Vincelestes. Wible et al. (2009) character 339.

200. Atlas neural hemiarches unfused (0); fused (1). Primitive state based on Vincelestes. Wible et al. (2009) character 340.

201. Atlas neural arch and intercentrum unfused (0); fused (1). Primitive state based on Vincelestes. Wible et al. (2009) character 341.
202. Axis with suture between atlantal and axial parts (0); without (1). Wible et al. (2009) character 342.

203. Axis with extra pair of transverse processes on ventral surface (0); without (1). Primitive state based on Vincelestes. Wible et al. (2009) character 343.

204. Axis prezygapophyses extend ventral to dens (0); linked (1); not linked to dens (2). Primitive state based on Vincelestes. Wible et al. (2009) character 344.

205. Inferior lamellae present on posterior cervical vertebrae (0); absent (1). Primitive state based on Vincelestes. Wible et al. (2009) character 345.

206. Number of thoracic vertebrae 14 or fewer (0); 15 or more (1). Primitive state based on Eomaia. Modified from Wible et al. (2009) character 347.

207. Number of sacral vertebrae $2(0) ; 3(1) ; 4$ or more (2). Primitive state based on Vincelestes. Wible et al. (2009) character 350.

\section{Scapula}

208. Infraspinous fossa position with respect to supraspinous fossa: different planes (in part, medial to) (0); coplanar (1). Primitive state based on Vincelestes. Wible et al. (2009) character 352.

209. Suprascapular incisure absent (0); present (1). Primitive state based on Vincelestes. Wible et al. (2009) character 353.

210. Acromion reaches distal to glenoid articulation (0); is proximal (1). Primitive state based on Vincelestes. Wible et al. (2009) character 354.

211. Metacromion weak or absent (0); a well developed process (1). Primitive state based on Eomaia. Wible et al. (2009) character 355.

\section{Humerus}

212. Greater and lesser tuberosities lower than or at same level as head (0); Greater tuberosity higher than head (1). Primitive state based on Vincelestes. Wible et al. (2009) character 356.

213. Proximal third of shaft curved posteriorly (0); straight (1). Primitive state based on Vincelestes.

214. Deltopectoral crest extending less than one third the length from the proximal end $(0)$; between one third and one half (1) PRIMITIVE; more than a half (2). Primitive state based on Vincelestes.

215. Deltopectoral crest laterally displaced (0); median (1). Primitive state based on Vincelestes.

216. Deltopectoral crest strong (0); weak (1). Primitive state based on Vincelestes.

217. Tuberosity for teres major muscle a crestiform or tubercular structure (0); absent or represented only by rugose surface (1). Primitive state based on Vincelestes.

218. Entepicondylar foramen present (0); absent (1). Primitive state based on Vincelestes, Henkelothe- 
rium and Juramaia. Wible et al. (2009) character 360).

219. Supinator crest weak and short (0); weak and long (1); strong, short, extending scarcely proximal of the flaring of the medial epicondyle (2); strong extending more proximally (3). Primitive state based on Vincelestes. STEPMATRIX

\begin{tabular}{ccccc} 
& 0 & 1 & 2 & 3 \\
\hline 0 & - & 1 & 1 & 2 \\
1 & 1 & - & 2 & 1 \\
2 & 1 & 2 & - & 1 \\
3 & 2 & 1 & 1 & -
\end{tabular}

220. Medial epicondyle extends from medial trochlear ridge more than shaft width (0); less (1). Primitive state based on Vincelestes.

221. Medial epicondyle projects slightly distomedially (0); medially to slightly proximomedially (1). Primitive state based on Vincelestes and Juramaia.

222. Olecranon fossa very deep (0); moderately deep (1) (PRIMITIVE); shallow (2). Primitive state based on Vincelestes. Modified from Goswami et al. (2011) character 413 .

223. Olecranon fossa imperforate (0); perforate (1). Primitive state based on Vincelestes. Reworded from Wible et al. (2009) character 361.

224. Trochlea concave with sharp medial keel, projecting further distally than capitulum (0); convex, without clear lateral crest, projecting farther distally than capitulum (1) PRIMITIVE; convex, without lateral crest, not projecting further distally than capitulum (2); convex, narrow, with lateral crest (3); semicylindrical, wide, with lateral crest (4). Primitive state based on Vincelestes.

225. Capitulum semi-cylindrical, confluent with trochlea (0); semi-spherical, separated from trochlea by intercondylar groove (1) PRIMITIVE; spherical, separated from trochlea by intercondylar groove (2). Primitive state based on Vincelestes.

226. Capitulum with no distinct lateral flange (0); with distinct lateral flange confluent with rest of capitulum (1) PRIMITIVE; lateral flange separated from rest of capitulum by groove (2). Primitive state based on Vincelestes.

227. Dorsoepitrochlear fossa absent (0); present (1). Primitive state based on Vincelestes.

228. Radial fossa present, but coronoid fossa absent (0); both radial and coronoid fossae present (1). Primitive state based on Vincelestes.

\section{Radius}

229. Capitular eminence: weak to absent (0); strong (1). Primitive state based on Vincelestes.

230. Ulnar facet proximodistally shallow (0); deep (1). Primitive state based on Vincelestes.
231. Facet for humeral trochlea absent (0); present (1) PRIMITIVE. Primitive state based on Vincelestes. Modified from Wible et al. (2009) character 364.

232. Shaft strongly curved proximally with asymmetrical head (0); weakly curved with asymmetrical head (1); gently curved to straight with symmetrical head (2). Primitive state based on Vincelestes.

233. Bicipital tuberosity weak to absent (0); present, simple, confluent with proximal articulation, without lateral crest (1) PRIMITIVE; confluent with proximal articulation, with lateral crest (2); separate from proximal articulation, without lateral crest (3); separate from proximal articulation, with lateral crest (4). Primitive state based on Vincelestes.STEPMATRIX.

\begin{tabular}{cccccc} 
& 0 & 1 & 2 & 3 & 4 \\
\hline 0 & - & 1 & 1 & 2 & 2 \\
1 & 1 & - & 1 & 1 & 2 \\
2 & 1 & 1 & - & 2 & 1 \\
3 & 2 & 1 & 2 & - & 1 \\
4 & 2 & 2 & 1 & 1 & -
\end{tabular}

234. Ulnar facet strongly rounded (0); gently rounded (1) PRIMITIVE; flat or nearly so (2). Primitive state based on Vincelestes.

235. Radial articulation with carpals: a single fossa (0); two fossae (1). Primitive state based on Vincelestes. Wible et al. (2009) character 367.

\section{Carpals}

236. Scaphoid and lunar separate (0); partially fused, retaining surface division between the bones (1); fully fused (2). Primitive state based on Vincelestes. Modified from Wible et al. (2009) character 368.

237. Centrale separate (0); fused or lost (1). Primitive state based on Vincelestes. Modified from Wible et al. (2009) character 369.

\section{Pelvis}

238. Pubic symphysis extensive (0); narrow (1); separate (2). Primitive state based on Vincelestes. Modified from Wible et al. (2009) character 370.

239. Epipubic bones present (0); absent (1). Primitive state based on Vincelestes and Eomaia. Wible et al. (2009) character 371.

\section{Femur}

240. Head spherical, not extending onto neck (0); head spherical, extending onto neck proximally (1); head more cylindrical (2). Primitive state based on Henkelotherium, Eomaia and Purbeck cladotherian femur NHMUK.PV.OR48250.

241. Head extending far round neck distally (0); not extending far round distally (1). Primitive state 
based on stem cladotherian

NHMUK.PV.OR48250.

242. Neck distinct (0); poorly indented proximally (1). Primitive state based on Eomaia and stem cladotherian NHMUK.PV.OR48250.

243. Head and neck project medially (0); anteromedially (1); proximomedially (2); anteroproximomedially (3); UNORDERED. Primitive state based on stem cladotherian NHMUK.PV.OR48250.

244. Teres fovea central (0); posterior (1); absent (2). UNORDERED. Primitive state based on Henkelotherium. Modified from Wible et al. (2009) character 373.

245. Greater trochanter extends proximally less than head (0); to about level of head (1); farther (2). Primitive state based on Vincelestes. Modified from Wible et al. (2009) character 374.

246. Lesser trochanter posteromedial (0); medial (1). Primitive state based on Henkelotherium and stem cladotherian M13126.

247. Lesser trochanter projects as far as head or beyond (0); less than head (1). Primitive state based on Henkelotherium and stem cladotherians NHMUK.PV.OR48250, M13126. Modified from Wible et al. (2009) character 375.

248. Lesser trochanter near head (0); more distal (1). Primitive state based on Vincelestes and stem cladotherian M13126.

249. Third trochanter absent (0); small less than a third of the distance from proximal end (1); small c. one third distance from proximal end (2); small, more than a third distance from proximal end (3); large c. one third distance from proximal end (4). Primitive state based on Vincelestes, Henkelotherium and stem cladotherians NHMUK.PV.OR48250, M13126. Modified from Wible et al. (2009) character 376. STEPMATRIX.

\begin{tabular}{cccccc} 
& 0 & 1 & 2 & 3 & 4 \\
\hline 0 & - & 1 & 2 & 3 & 3 \\
1 & 1 & - & 1 & 2 & 2 \\
2 & 2 & 1 & - & 1 & 1 \\
3 & 3 & 2 & 1 & - & 2 \\
4 & 3 & 2 & 1 & 2 & -
\end{tabular}

250. Trochanteric fossa deep (0); shallow (1); essentially absent (2). Primitive state based on stem cladotherian M13126.

251. Intertrochanteric crest restricted to lateral position (0); reaches or nearly reaches the base of the lesser trochanter (1). Primitive state based on stem cladotherian M13126.

252. Shaft essentially round in cross section (0); anteroposteriorly compressed (1). Primitive state based on Henkelotherium and stem cladotherian M13126.
253. Distal femur similar in size in anteroposterior and mediolateral dimensions (0); longer anteroposteriorly (1). Primitive state based on Vincelestes. Wible et al. (2009) character 378.

254. Patellar groove broad and shallow (0); narrow and elevated (1). Primitive state based on Vincelestes. Wible et al. (2009) character 379.

255. Articulation between femur and fibula (0); no articulation (1). Primitive state based on Eomaia. Wible et al. (2009) character 381 , but polarity coding reversed.

\section{Tibia}

256. Tibia separate from fibula distally (0); in contact along part of the shaft (1); co-ossified distally (2); co-ossified along much of the distal half (3). Primitive state based on Vincelestes. STEPMATRIX

\begin{tabular}{ccccc} 
& 0 & 1 & 2 & 3 \\
\hline 0 & - & 1 & 1 & 2 \\
1 & 1 & - & 2 & 1 \\
2 & 1 & 2 & - & 1 \\
3 & 2 & 1 & 1 & -
\end{tabular}

257. Shaft smooth (0); with groove distally for flexor digitorum fibularis tendon (1); with groove distally for flexor digitorum tibialis and tibialis posterior tendons (2); with grooves for flexor digitorum fibularis tendon and for flexor digitorum tibialis and tibialis posterior tendons (3). UNORDERED. Primitive state based on Vincelestes.

258. Medial malleolus distally long (i.e., more than half as long as the distal width of the tibia) with articular surface for sustentaculum of calcaneum (0); Medial malleolus distally long (i.e., more than half as long as the distal width of the tibia) without articular surface (1) PRIMITIVE; length about one third of the distal width of the tibia (2); short (3); absent (4). Primitive state based on Vincelestes.

259. Posterior process absent (0); present (1). Primitive state based on Vincelestes.

260. No tibia-fibula fusion proximally (0); fusion (1). Primitive state based on Vincelestes. Wible et al. (2009) character 382.

\section{Astragalus}

261. Body broader (measured proximally) than long (measured laterally) (0); approximately equidimensional (1); longer than broad (2). Primitive state based on Ukhaatherium, which, although belonging to the ingroup, is broadly primitive. Hooker (2001) character 1.

262. Lateral trochlear ridge taller than medial one (0); trochlear ridges of approximately equal height (1); medial trochlear ridge taller than lateral one (2). Primitive state based on Ukhaatherium. Hooker (2001) character 2. 
263. Neck not distinct from body medially as navicular facet extends as far as body medially (0); free neck, navicular facet extending $c$. half way up medial side (1); free neck, navicular facet extending less than half way up medial side (2). Part of Hooker 2001, character 15. Polarity based on Vincelestes, which lacks a neck, so the more metatherian-like pattern in zalambdalestids (Szalay and Sargis, 2006) is likely to be primitive.

264. Medial and lateral walls of body (i.e., for articulation with the fibula and the medial malleolus of the tibia) converge dorsally at more than 60 degrees (0); at 60 degrees (1); essentially parallel (2). From Horovitz 2000, character 14 and description of Vincelestes.

265. Lateral tibial facet not excavated (0); gently excavated (1); deeply excavated, U-shaped (2); deeply excavated, V-shaped (3). Primitive state (0) as 'ancestral therian', Horovitz (2000). N.B., the deep $\mathrm{V}$-shape of zalambdalestids separates two dorsally-facing facets. These were labelled 'medial and lateral tibial facets by Szalay and Sargis (2006, figures $16-17$ ), presumably as there is no medially facing facet on the body. However, it seems more likely that a medial tibial facet is missing, along with the medial malleolus of the tibia and that the 'medial' and 'lateral' facets are together homologous with the lateral facet of other therians. Modified from Horovitz (2000) character 11 and Hooker (2001) character 16.

266. Lateral tibial facet follows the curvature of the trochlear ridges (0); gently indented distally, into which cavity, convexity of tibial facet or anterior process of tibia fits (1); deeply indented distally for anterior process of tibia (2). Primitive state based on Ukhaatherium.

267. No extension of trochlea onto neck (0); extension of medial ridge (1); extension between ridges (2). UNORDERED. Primitive state based on Ukhaatherium. Modified from Hooker (2001) character 3.

268. Proximal foramen of astragalar canal present (0); absent (1). Primitive state based on Vincelestes. Horovitz (2000) character 17; Hooker (2001) character 4 . This structure labelled as present in the dermopteran Galeopterus variegatus by Smith et al. (2010, figure $1 \mathrm{~h})$ is in fact the dorsal edge of the groove for the flexor digitorum fibularis tendon (personal obs.; Beard, 1993, figure 10.12).

269. Ventral limit of trochlea on proximal surface of body at midpoint (0); more ventral (1). Primitive state based on Vincelestes. Hooker (2001) character 5.

270. Groove for flexor digitorum fibularis tendon shallow (0); deep (1). Primitive state based on ingroup commonality. Hooker (2001) character 6.

271. Medial plantar tuberosity large (0); medium (1) PRIMITIVE; small (2). Modified from Horovitz
2000, character 15; Hooker 2001, character 7. Primitive state based on Eomaia (Luo et al., 2003, figure 3D). Deccanolestes scored incorrectly by Horovitz 2000 as having large state, probably because of distorted cast figured by Prasad and Godinot (1994), see Hooker (2001).

272. Attachment area on lateral body wall for fibuloastragalar ligament proximal (0); central (1). Primitive state based on ingroup commonality. Hooker (2001) character 8.

273. Sustentacular facet extensive, confluent with navicular facet (0); restricted distally to lateral of astragalocalcaneal ligament area, confluent with navicular facet (1); restricted distally to medial of astragalocalcaneal ligament area, confluent with navicular facet (2); extensive mediolaterally, restricted to proximal of astragalocalcaneal ligament area, not confluent with navicular facet (3); subcircular, isolated (4). Primitive state based on Eomaia (Luo et al., 2003, figure 3D). Modified from Hooker (2001) characters 9 (in part) and 10. STEPMATRIX.

\begin{tabular}{cccccc} 
& 0 & 1 & 2 & 3 & 4 \\
\hline 0 & - & 1 & 1 & 2 & 2 \\
1 & 1 & - & 2 & 2 & 1 \\
2 & 1 & 2 & - & 1 & 2 \\
3 & 2 & 2 & 1 & - & 1 \\
4 & 2 & 1 & 2 & 1 & -
\end{tabular}

274. Sustentacular facet strongly convex (0); flat or nearly so (1). Polarity based on Ukhaatherium being primitive. Modified from Hooker (2001) character 9 (in part).

275. Navicular facet not projecting over lateral side of neck (0); projecting over lateral side of neck (1). Primitive state based on Eomaia (Luo et al., 2003, figure 3D).

276. Head irregular or rounded in only one plane (0); evenly convex (1). Primitive state based on Vincelestes. Hooker (2001) character 11.

277. Navicular facet in distal view: nearly circular, equidimensional (0); elongate oval, long axis 1.4-1.5 times short axis, horizontally aligned (1); elongate oval, long axis 1.6 times short axis or more, horizontally aligned (2); elongate oval, long axis 1.41.5 times short axis, dipping medially (3); elongate oval, long axis 1.6 times short axis or more, dipping medially (4). Primitive state based on Ukhaatherium. Modified from Hooker (2001) characters 12, 13, 14. STEPMATRIX.

\begin{tabular}{cccccc} 
& 0 & 1 & 2 & 3 & 4 \\
\hline 0 & - & 1 & 2 & 1 & 2 \\
1 & 1 & - & 1 & 1 & 2 \\
2 & 2 & 1 & - & 2 & 1
\end{tabular}




$$
\begin{array}{llllll}
3 & 1 & 1 & 2 & - & 1 \\
4 & 2 & 2 & 1 & 1 & -
\end{array}
$$

278. Cotylar fossa absent (0); present (1). Primitive state based on Vincelestes. Wible et al. (2009) character 388.

279. Head lacks cuboid facet (0); bears cuboid facet (1). Primitive state based on Vincelestes. Wible et al. (2009) character 394.

\section{Calcaneum}

280. Tuber curved/twisted ventromedially and dorsoventrally compressed (0); straight, cylindrical to 1.25 times higher dorsoventrally than wide mediolaterally (1); straight, 1.3-1.6 times higher than wide (2); 1.7 or more times higher than wide (3). Primitive state based on Vincelestes and supported by more primitive mammals, fide Horovitz (2000), although Vincelestes is only medially deflected and not dorsoventrally compressed (Rougier, 1993). Modified from Horovitz (2000) characters 2 and 3; Hooker (2001) character 18.

281. Lateral edge of tuber continuous with peroneal process (0); no lateral edge (1). Polarity based on Vincelestes. Modified from Horovitz (2000) character 10.

282. Groove on lateral surface of tuber for peroneus brevis tendon absent (0); present (1). Primitive state based on ingroup commonality. Hooker (2001) character 24, from Szalay and Lucas (1996).

283. Ectal facet medial of midline passing through tuber (0); essentially median or more lateral (1). Primitive state based on Vincelestes.

284. Ectal facet orientation: distal end more medial than proximal end (0); proximodistal (1); proximomedial-distolateral 5-15 degrees (2); proximomedial-distolateral 25-30 degrees (3); proximomedial-distolateral 40-60 degrees (4); mediolateral with or without wrap around (5). Primitive state based on Vincelestes, backed up by Morganucodon, but no eutherian has primitive state. Modified from Horovitz (2000) character 7; Hooker (2001) character 20.

285. Ectal facet strongly evenly convex (0); gently evenly convex (1); helical (2); unevenly convex (3); sigmoidal (4). UNORDERED. Primitive state based on Vincelestes. Modified from Hooker (2001) character 19.

286. Ectal facet nearer to distal than proximal end (i.e. tuber relatively long) (0); at about midpoint along length (1) PRIMITIVE; nearer to proximal than distal end (i.e., tuber short) (2). Primitive state based on Vincelestes. Polarity changed from Hooker (2001) character 17.

287. Fibular facet present (0); absent (1). Primitive state based on Vincelestes. Horovitz (2000) character 4; Hooker (2001) character 21.
288. Peroneal process fully distal, its distal edge reaching level of cuboid facet (0); apex of peroneal process positioned at $10-15 \%$ of calcaneal length from the distal extremity (1); $17-25 \%$ from distal extremity (2); 35-55\% from distal extremity (3). Primitive state based on Vincelestes. Horovitz (2000) character 5; modified from Hooker (2001) character 26.

289. Peroneal process lateral projection as percentage of calcaneal length: $15-30 \%$ (0); $9-13 \%(1) ; 5-7 \%$ (2); no lateral projection (3). Primitive state based on Vincelestes. Polarity reversed from Hooker (2001) character 27.

290. Peroneal process restricted distally (0); extending for $15-20 \%$ of calcaneal length (1); $21-27 \%$ (2); $32-46 \%$ (3) PRIMITIVE. Primitive state based on Eomaia. Hooker (2001) character 28.

291. Ectal and sustentacular facets do not overlap on long axis (0); do overlap (1) PRIMITIVE. Primitive state based on Vincelestes. Polarity changed from Hooker (2001) character 22; Wible et al. (2009) character 399.

292. Sustentacular facet reaches edge of cuboid facet (0); divided into a sustentacular facet sensu stricto and a distal sustentacular facet (1); single, but distinctly separated from edge of cuboid facet (2). UNORDERED. Primitive state based on Vincelestes. Modified from Hooker (2001) character 23, see Horovitz (2000). N.B. the 0 state is often treated as derived and an archontan synapomorphy, e.g., Hooker (2001). This change in polarity has important implications for phylogeny. The character is represented (and is interdependent) in the astragalus by a level of connection between the sustentacular facet and the navicular facet and is not treated as a separate character. However, the exact nature of this connection is a distinct character (q.v.).

293. Navicular facet absent (0); present (1). Primitive state based on Vincelestes. Hooker (2001) character 25.

294. Cuboid facet faces distoventrally (0); faces distomedially at c.55-60 degrees to long axis of calcaneum (1); at c.70-75 degrees to long axis of calcaneum (2); faces essentially distally (3). STEPMATRIX. Primitive state based on Vincelestes. Horovitz (2000) character 8; modified from Hooker (2001) character 31.

\begin{tabular}{ccccc} 
& 0 & 1 & 2 & 3 \\
\hline 0 & - & 1 & 1 & 1 \\
1 & 1 & - & 1 & 2 \\
2 & 1 & 1 & - & 1 \\
3 & 1 & 2 & 1 & -
\end{tabular}

295. Cuboid facet dorsoventrally concave (0); shallowly evenly concave (1); deeply evenly concave (2) PRIMITIVE; sellar (3). UNORDERED. Primi- 
tive state based on Vincelestes. Polarity and ordering changed from Hooker (2001) character 29.

296. Cuboid facet deeper dorsoventrally than wide mediolaterally (0); subequal (1) PRIMITIVE; wider mediolaterally than deep dorsoventrally (2). Primitive state based on Vincelestes. Wible et al. (2009) character 407.

297. Cuboid facet without plantar pit (0); with plantar pit allowing rotation (1); with grooved plantar pit inhibiting rotation (2). UNORDERED. Primitive state based on Vincelestes. Hooker (2001) character 30 .

298. Plantar groove present (0); absent (1). Primitive state based on Vincelestes and Eomaia (Luo et al. 2003, figure 3J). Modified from Horovitz (2000) character 6.

299. Distal plantar tubercle absent (0); present distal, medial (1); present distal central (2); proximal of distal edge, medial (3); proximal of distal edge, central (4). UNORDERED. Primitive state based on Vincelestes. Modified from Hooker (2001) characters 33-34.

300. Groove for tendon of flexor digitorum fibularis absent (0); shallow (1); deep (2). Primitive state based on Vincelestes. Modified from Wible et al. (2009) character 408.

301. Calcar absent (0); present (1). Primitive state based on ingroup commonality.

\section{Navicular}

302. Ectocuneiform and mesocuneiform facets not distinguished (0); the two facets of equal length (1); ectocuneiform facet longer dorsoventrally than mesocuneiform facet (2); mesocuneiform facet longer dorsoventrally than ectocuneiform facet (3). STEPMATRIX. Primitive state based on simplest form and 0 state in Zalambdalestidae).

\begin{tabular}{lllll} 
& 0 & 1 & 2 & 3 \\
\hline 0 & - & 1 & 2 & 2
\end{tabular}

$\begin{array}{rrrrr}1 & 1 & - & 1 & 1 \\ 2 & 2 & 1 & - & 2 \\ 3 & 2 & 1 & 2 & -\end{array}$

303. Plantar process scarcely or not projecting distally (0); projecting distinctly distally (1). Primitive state based on Eomaia (Luo et al., 2003).

304. Tuber tibialis absent (0); short (1); long (2). Primitive state based on Eomaia (Luo et al., 2003).

\section{Cuboid}

305. Edge of calcaneal facet overhangs dorsal wall, making it concave (0); not overhanging, dorsal wall essentially straight (1). Primitive state based on Asioryctes.

306. Plantar process strong (Kielan-Jaworowska, 1979, plate 9, figures 1a,1b) (0); weak (1). Primitive state based on Asioryctes (Kielan-Jaworowska, 1977, plate 18, figure $2 b$ ).

\section{Metapodials}

307. Tubercles for insertion of $m$. extensor carpi radialis on metacarpals absent (0); present on M/C III (1); present on M/C II-III (2). UNORDERED. Primitive state based on Henkelotherium. See Rose (1999), Rose and Lucas (2000), Rose and Koenigswald (2005).

\section{Phalanges}

308. Attachment on phalanx 1 for annular ligament absent or weak (0); present as tubercles (1) PRIMITIVE; present as long ridges (2). Primitive state based on Henkelotherium and Eomaia.

309. Manual phalanges relatively short (0); those of digits II-V greatly elongate (1). Primitive state based on ingroup commonality.

310. Unguals well developed (0); reduced to absent on manual digits III-V (1). Primitive state based on ingroup commonality. 


\section{APPENDIX 2.}

\section{CHARACTER-TAXON MATRIX}

Note that characters of the astragalus and navicular of Fordonia are from as yet undescribed material. Some characters unknown for Palaeosinopa and Cryptotopos have been substituted from Pantolestes and Scraeva respectively.

\section{Outgroup}

$\begin{array}{llllllllllll}00000 & 00000 & 10000 & 00100 & 00000 & 00000 & 10110 & 00000 & 00100 & 10100 & 00011 & 10110 \\ 00010 & 00010 & 01000 & 30000 & 00000 & 01010 & 00000 & 00000 & 10001 & 00000 & 01000 & 00000 \\ 00020 & 00011 & 00000 & 00001 & 00000 & 00300 & 00000 & 10010 & 00100 & 00110 & 10000 & 00000 \\ 00000 & 00100 & 00000 & 00000 & 00000 & 00000 & 00010 & 00000 & 01011 & 10000 & 10110 & 00000 \\ 00000 & 00000 & 00000 & 00100 & 00000 & 00000 & 10000 & 00000 & 00000 & 10003 & 10002 & 10000 \\ 00000 & 00100 & & & & & & & & & & \end{array}$

\section{Ukhaatherium}

$\begin{array}{llllllllllll}00001 & 11000 & 20100 & 00100 & 00000 & 00110 & 20120 & 00000 & 00130 & 20000 & 01122 & 10110 \\ 00011 & 10010 & 0100 ? & ? 02 ? 1 & 0 ? ? 00 & 110 ? 0 & 000 ? 0 & 11010 & 100 ? 1 & 10200 & 11 ? 01 & ? 0 ? ? 0 \\ ? ? 000 & 10 ? 2 ? & 0001 ? & 00000 & ? ? 000 & 10112 & 10200 & 10210 & ? 1000 & 0 ? ? 0 ? & 1 ? 001 & 00211 \\ ? 0001 & 00110 & ? 0011 & ? ? 31 ? & ? ? ? ? ? & ? ? 000 & 01010 & 01020 & 010 ? ? & ? 1 ? ? ? & ? 01 ? ? & 0 ? 001 \\ ? 11 ? ? & 0 ? ? 01 & 100 ? 0 & 0 ? ? ? 0 & 00210 & 00000 & 0 ? 000 & 10000 & 00010 & 10203 & 1 ? 002 & 10000 \\ ? ? ? ? ? & ? 0100 & & & & & & & & & & \end{array}$

\section{Maelestes}

$\begin{array}{lllllllllllll}\text { ??201 } & 10110 & 20000 & 00001 & 00110 & 00000 & 20000 & 10011 & 01021 & 12100 & 01022 & 10110 \\ 00112 & 11010 & 01101 & 31210 & 00201 & ? 101 ? & ? ? 0 ? ? & ? ? 000 & ? ? 112 & 10200 & 31101 & 10000 \\ 01 ? 0 ? & ? ? 020 & ? ? ? 1 ? & 00110 & ? ? ? 10 & ? 0010 & 00200 & 10010 & 30100 & 00000 & ? ? 001 & 00011 \\ \text { 20021 } & 00 ? 0 ? & 00 ? 11 & 12210 & 0012 ? & ? ? 000 & ? 1111 & 11020 & 01100 & 11001 & 0 ? 01 ? & \text { ????? } \\ \text { ????? } & \text { ????? } & \text { ????? } & \text { ????? } & \text { ????? } & \text { ????? } & \text { ????? } & \text { ????? } & \text { ????? } & \text { ????? } & \text { ????? } & \text { ????? } \\ \text { ????? } & \text { ???? } & & & & & & & & & & \end{array}$

\section{Asioryctes}

$\begin{array}{lllllllllllll}00000 & 01000 & 20100 & 00100 & 00000 & 00100 & 20110 & 10000 & 00030 & 20000 & 01122 & 10110 \\ 00011 & 10010 & 01001 & 31111 & 10000 & 11010 & ? 0000 & 01010 & 100 ? 1 & 10200 & 110 ? 1 & 00000 \\ 0 ? ? 00 & 10021 & 0001 ? & 00000 & 12000 & 10112 & 1 ? 200 & 10210 & 01000 & 00 ? 01 & ? ? 001 & 00211 \\ 10011 & 001 ? 0 & 000 ? ? & ? ? 311 & 00110 & ? ? ? ? ? & ? ? ? ? ? & ? ? ? ? ? & ? ? ? ? ? & ? ? ? ? ? & ? ? ? ? 0 & 00 ? ? ? \\ ? ? ? ? ? & ? ? ? ? ? & ? ? ? ? ? & 0010 ? & ? ? 2 ? 0 & ? ? ? ? ? & 0 ? ? ? ? & ? ? 010 & 0 ? 010 & 10002 & 1 ? 002 & ? 0120 \\ ? ? ? ? 0 & 00 ? 00 & & & & & & & & & & \end{array}$

\section{Zhelestidae}

$\begin{array}{lllllllllllll}4 ? 001 & 10100 & 100 ? 1 & 10031 & 00100 & 00000 & 20121 & 10021 & 01121 & 21201 & 10121 & 10110 \\ 01122 & 01011 & 12102 & 40000 & 10000 & 11010 & ? 0 ? 00 & 1 ? ? ? ? & ? ? ? ? ? & 1 ? 2 ? 0 & \text { ?0??? } & \text { ????? } \\ \text { ?100? } & ? ? ? 10 & \text { ????? } & \text { ????? } & \text { ????? } & ? ? ? ? ? & \text { ????? } & 10 ? 1 ? & 00000 & 00 ? ? ? & \text { ?0?00 } & 00 ? 00 \\ \text { 0???? } & ? ? ? ? ? & \text { ??0?1 } & 022 ? ? & \text { ????? } & \text { ????? } & \text { ????? } & \text { ??001 } & 10100 & 100 ? ? & \text { ????? } & \text { ????2 } \\ 11121 & 11000 & 1000 ? & \text { ????? } & \text { ????? } & \text { ????? } & \text { ????? } & \text { ????1 } & 10043 & 01013 & 10021 & 20100 \\ \text { ????? } & \text { ????? } & & & & & & & & & & \end{array}$




\section{Zalambdalestidae}

$\begin{array}{llllllllllll}411 ? 0 & 01100 & 20100 & 00030 & 00000 & 00000 & 11122 & 00111 & 01120 & 20200 & 01131 & 10100 \\ 00114 & 01011 & 01102 & 20001 & 41101 & 11010 & 00000 & 00000 & 00021 & 10100 & 01101 & 20010 \\ 10020 & 20010 & 00010 & 00010 & 12000 & ? 0112 & 10200 & 10210 & 11000 & 00000 & 1 ? 001 & 00211 \\ 20000 & 00110 & 200 ? 1 & ? ? 111 & 00021 & ? 011 ? & ? 0111 & 11001 & 11100 & 2000 ? & 0 ? ? 20 & 10002 \\ 01022 & 01010 & 00001 & 30400 & 00023 & 00110 & 21200 & 01002 & 10153 & 01030 & 10021 & 10100 \\ ? 0021 & 00 ? 00 & & & & & & & & & & \end{array}$

\section{Cimolestes magnus}

$\begin{array}{lllllllllllll}\text { ???01 } & 11,0 ? & 20000 & 10200 & 00011 & 10000 & 21000 & 10001 & 00121 & 21200 & 01121 & 10210 \\ 00002 & 11000 & 02002 & 300 ? 1 & 10 ? 01 & 2 ? ? ? ? & \text { ????? } & \text { ????? } & \text { ????? } & \text { ????? } & \text { ????? } & \text { ????? } \\ \text { ????? } & \text { ????? } & \text { ????? } & \text { ????? } & \text { ????? } & \text { ????? } & \text { ????? } & \text { ????? } & \text { ????? } & \text { ????? } & \text { ????? } & \text { ????? } \\ \text { ????? } & \text { ????? } & \text { ????? } & \text { ????? } & \text { ????? } & \text { ????? } & \text { ????? } & \text { ????? } & \text { ????? } & \text { ????? } & \text { ????? } & \text { ????? } \\ \text { ????? } & \text { ????? } & \text { ????? } & \text { ????? } & \text { ????? } & \text { ????? } & \text { ????? } & \text { ????? } & \text { ????? } & \text { ????? } & \text { ????? } & \text { ????? } \\ \text { ????? } & \text { ????? } & & & & & & & & & & & \end{array}$

\section{Batodon}

$\begin{array}{lllllllllllll}\text { ????? } & 11,10 & \text { ?0110 } & 10000 & 00011 & 01000 & 11001 & 10011 & 01121 & 22200 & 11111 & 10110 \\ 00012 & 11010 & 01000 & 4 ? ? ? ? & \text { ????? } & \text { ????? } & \text { ????? } & \text { ????? } & \text { ????? } & \text { ????? } & \text { ????? } & \text { ????? } \\ \text { ????? } & \text { ????? } & \text { ????? } & \text { ????? } & \text { ????? } & \text { ????? } & \text { ????? } & \text { ????? } & \text { ????? } & \text { ????? } & \text { ????? } & \text { ????? } \\ \text { ????? } & \text { ????? } & \text { ????? } & \text { ????? } & \text { ????? } & \text { ????? } & \text { ????? } & \text { ????? } & \text { ????? } & \text { ????? } & \text { ????? } & \text { ????? } \\ \text { ????? } & \text { ????? } & \text { ????? } & \text { ????? } & \text { ????? } & \text { ????? } & \text { ????? } & \text { ????? } & \text { ????? } & \text { ????? } & \text { ????? } & \text { ????? } \\ \text { ????? } & \text { ????? } & & & & & & & & & & & \end{array}$

\section{Gypsonictops}

$\begin{array}{lllllllllllll}\text { ???0? } & 10000 & 21202 & 00022 & 00110 & 00010 & 41123 & 30111 & 01221 & 22201 & 11122 & 10100 \\ 00113 & 11010 & 11102 & 401 ? 1 & 1010 ? & 2 ? 0 ? ? & \text { ????? } & \text { ????? } & \text { ????? } & \text { ????? } & \text { ????? } & \text { ????? } \\ \text { ????? } & \text { ????? } & \text { ????? } & \text { ????? } & \text { ????? } & \text { ????? } & \text { ????? } & \text { ????? } & \text { ????? } & \text { ????? } & \text { ????? } & \text { ????? } \\ \text { ????? } & \text { ????? } & \text { ????? } & \text { ????? } & \text { ????? } & \text { ????? } & \text { ????? } & \text { ????? } & \text { ????? } & \text { ????? } & \text { ????? } & \text { ????? } \\ \text { ????? } & \text { ????? } & \text { ????? } & \text { ????? } & \text { ????? } & \text { ????? } & \text { ????? } & \text { ????? } & \text { ????? } & \text { ????? } & \text { ????? } & \text { ????? } \\ \text { ????? } & \text { ????? } & & & & & & & & & & & \end{array}$

\section{Deccanolestes}

$\begin{array}{lllllllllllll}\text { ????? } & 11,0 ? & 2010 ? & \text { ????? } & \text { ????? } & \text { ?0??? } & 1000 ? & 10101 & 01110 & 20200 & 01110 & 20110 \\ 00012 & 11010 & 0100 ? & \text { ????? } & \text { ????? } & \text { ????? } & \text { ????? } & \text { ????? } & \text { ????? } & \text { ????? } & \text { ????? } & \text { ????? } \\ \text { ????? } & \text { ????? } & \text { ????? } & \text { ????? } & \text { ????? } & \text { ????? } & \text { ????? } & \text { ????? } & \text { ????? } & \text { ????? } & \text { ????? } & \text { ????? } \\ \text { ????? } & \text { ????? } & \text { ????? } & \text { ????? } & \text { ????? } & \text { ????? } & \text { ????? } & \text { ??0?0 } & 12012 & 110 ? ? & \text { ????? } & \text { ????? } \\ \text { ????? } & \text { ????? } & \text { ????? } & \text { ????? } & 00211 & 00000 & 10101 & 11002 & 10120 & 11003 & 10001 & 10120 \\ \text { ????? } & \text { ????? } & & & & & & & & & & & \end{array}$

\section{Afrodon/Bustylus}

$\begin{array}{lllllllllllll}\text { ????? } & \text { ?1?1? } & \text { ????0 } & 20013 & 00010 & 00000 & 10211 & 40101 & 01110 & 20200 & 00111 & 20110 \\ 00012 & 11010 & 01010 & 5 ? ? ? 1 & \text { ???0? } & \text { ????? } & \text { ????? } & \text { ????? } & \text { ????? } & \text { ????? } & \text { ????? } & \text { ????? } \\ \text { ????? } & \text { ????? } & \text { ????? } & \text { ????? } & \text { ????? } & \text { ????? } & \text { ????? } & \text { ????? } & \text { ????? } & \text { ????? } & \text { ????? } & \text { ????? } \\ \text { ????? } & \text { ????? } & \text { ????? } & \text { ????? } & \text { ????? } & \text { ????? } & \text { ??010 } & 00020 & 12012 & 1,0 ? ? & \text { ????? } & \text { ????? } \\ \text { ??0?1 } & 10110 & 00 ? ? ? & \text { ????? } & 00211 & 00000 & 10101 & 1300 ? & 10120 & 11003 & 10001 & \text { ?0120 } \\ \text { ????? } & \text { ????? } & & & & & & & & & & & \end{array}$




\section{Fordonia}

\begin{tabular}{|c|c|c|c|c|c|c|c|c|c|c|c|}
\hline ????? & ?1??? & ?1??2 & $1 ? 022$ & 10110 & 00110 & 31122 & 40011 & 01221 & 22201 & 21121 & 10000 \\
\hline 00013 & 00010 & $0110 ?$ & ????? & ????? & ????? & ????? & ????? & ????? & ????? & ????? & ????? \\
\hline ????? & ????? & ????? & ????? & ????? & ????? & ????? & ????? & ????? & ????? & ????? & ????? \\
\hline ????? & ????? & ????? & ????? & ????? & ????? & ????? & ????? & ????? & ????? & ????? & ????? \\
\hline ????? & ????? & ????? & ????? & ????? & 11123 & 00110 & ?0110 & 041?? & ????? & ????? & ????? \\
\hline ?01? & ????? & & & & & & & & & & \\
\hline
\end{tabular}

\section{Leptictidium}

$\begin{array}{llllllllllll}30300 & 21000 & 20 ? ? 2 & 10022 & 00110 & 01010 & 01112 & 30111 & 21211 & 23211 & 21120 & 20100 \\ 01023 & 11010 & 03014 & 52021 & 40101 & 2112 ? & 0 ? ? ? 1 & ? 1 ? ? ? & \text { ????? } & \text { ???00 } & \text { ?1??? } & \text { ????? } \\ \text { ???2? } & \text { ????? } & \text { ??1?? } & \text { ????? } & \text { ????0 } & \text { ????? } & \text { ????? } & \text { ????? } & \text { ????? } & \text { ????? } & \text { ????? } & \text { ????? } \\ \text { ????? } & \text { ????? } & \text { ????? } & \text { ????? } & \text { ??1?? } & 01 ? 1 ? & \text { ?011? } & 11,3 ? & 1 ? ? ? ? & \text { ????? } & \text { ????? } & \text { ??01? } \\ \text { ?0?2 } & 01020 & 001 ? 1 & 11210 & \text { ????? } & \text { ????? } & \text { ????? } & \text { ????2 } & 101 ? ? & 01021 & \text { ???10 } & \text { ?0111 } \\ \text { 0???1 } & 00100 & & & & & & & & & & \end{array}$

\section{Prodiacodon/Palaeictops}

$\begin{array}{llllllllllll}31301 & 21110 & 22302 & 20002 & 10110 & 00113 & 21222 & 31101 & 01121 & 12201 & 11122 & 10100 \\ 01113 & 11010 & 01102 & 41111 & 00101 & 21220 & 010 ? 1 & ? 1 ? ? ? & ? ? ? ? 1 & 0 ? ? 00 & ? 1 ? ? ? & \text { ????? } \\ \text { ???0? } & ? ? ? ? ? & 00 ? 1 ? & ? ? ? 0 ? & ? ? ? 0 ? & ? ? ? ? ? & ? ? ? ? ? & ? ? ? 1 ? & ? ? ? ? ? & ? 0 ? ? ? & \text { ????? } & \text { ????? } \\ \text { ????? } & ? ? ? ? ? & \text { ????? } & \text { ????? } & \text { ????? } & ? 210 ? & ? 0010 & 01030 & 02000 & 1 ? 00 ? & 02 ? 11 & 0 ? ? ? 1 \\ 01002 & 01040 & 10111 & 23310 & 00123 & 00110 & 21410 & 03003 & 10153 & 010 ? 1 & 12021 & 00111 \\ ? 1101 & 12 ? 00 & & & & & & & & & & \end{array}$

\section{Leptictis}

$\begin{array}{llllllllllll}31301 & 21010 & 21102 & 10002 & 00110 & 00003 & 11322 & 20022 & 01321 & 15001 & 21112 & 10100 \\ 00113 & 11010 & 02101 & 21111 & 40201 & 21221 & 01011 & 10010 & 10001 & 11100 & 11110 & 00000 \\ 01001 & 01011 & 10011 & 11101 & 21110 & 20011 & 00110 & 10010 & 11000 & 00 ? 00 & ? 1001 & 00210 \\ 01110 & 00010 & 21011 & 113 ? 1 & 11 ? ? ? & 02111 & 10021 & 1103 ? & ? 11 ? ? & ? ? ? ? ? & ? 2020 & 11012 \\ 10012 & 01110 & 10111 & 33310 & ? 0221 & ? ? 11 ? & ? ? ? ? ? & ? ? 00 ? & 10 ? ? ? & 110 ? 2 & ? ? ? ? ? & 1 ? ? 20 \\ ? ? 1 ? 1 & 12 ? 0 ? & & & & & & & & & & \end{array}$

\section{Aphronorus}

$\begin{array}{lllllllllllll}\text { ??201 } & 11220 & 20111 & 22002 & 10110 & 01000 & 01001 & 30012 & 01101 & 23200 & 21122 & 10111 \\ 01203 & 01012 & 01010 & 50011 & 30101 & \text { ??01? } & 01011 & \text { ????? } & \text { ??0?0 } & 10 ? 00 & \text { ????? } & \text { ????? } \\ \text { ????? } & \text { ????? } & 0 ? 01 ? & \text { ????? } & \text { ???0? } & \text { ?00?? } & \text { ????? } & \text { ??01? } & \text { ????? } & \text { ????? } & \text { ????? } & \text { ????? } \\ \text { ????? } & \text { ????? } & \text { ?1??? } & \text { ????? } & \text { ????? } & \text { ????? } & \text { ???2? } & 0 ? ? 0 ? & \text { ????? } & \text { ????? } & \text { ?0??? } & \text { ????? } \\ \text { ????? } & \text { ????? } & \text { ????? } & \text { 2?3?? } & \text { ????3 } & \text { ??1?? } & \text { ??4?? } & \text { ????? } & \text { ????? } & \text { ????? } & \text { ????? } & \text { ????? } \\ \text { ????? } & \text { ????? } & & & & & & & & & & & \end{array}$

\section{Coriphagus}

$\begin{array}{lllllllllllll}\text { ???0? } & 11,10 & 20010 & 12 ? 02 & 00011 & 00000 & 11100 & 40010 & 01111 & 23200 & 11130 & 20120 \\ \text { 00?13 } & 00011 & 02022 & 40 ? ? 1 & 00001 & 1 ? ? ? ? & \text { ????? } & \text { ????? } & \text { ????? } & \text { ????? } & \text { ????? } & \text { ????? } \\ \text { ????? } & \text { ????? } & \text { ????? } & \text { ????? } & \text { ????? } & \text { ????? } & \text { ????? } & \text { ????? } & \text { ????? } & \text { ????? } & \text { ????? } & \text { ????? } \\ \text { ????? } & \text { ????? } & \text { ????? } & \text { ????? } & \text { ????? } & \text { ????? } & \text { ????? } & \text { ????? } & \text { ????? } & \text { ????? } & \text { ????? } & \text { ????? } \\ \text { ????? } & \text { ????? } & \text { ????? } & \text { ????? } & \text { ????? } & \text { ????? } & \text { ????? } & \text { ????? } & \text { ????? } & \text { ????? } & \text { ????? } & \text { ????? } \\ \text { ????? } & \text { ????? } & & & & & & & & & & & \end{array}$




\section{Palaeosinopa}

$\begin{array}{llllllllllll}1 ? 301 & 11110 & 10110 & 00000 & 00010 & 00010 & 11010 & 00021 & 01111 & 23201 & 11231 & 20210 \\ 00113 & 11011 & 02002 & 51111 & 40201 & 22221 & 01001 & 10010 & ? ? ? ? ? & ? ? ? 00 & ? 0 ? ? ? & 0 ? ? ? 0 \\ 1 ? ? 00 & ? ? ? 22 & 010 ? ? & ? 1 ? ? ? & ? ? ? ? 1 & ? 00 ? 1 & ? 02 ? ? & 100 ? 0 & ? ? ? ? 1 & 00011 & 1 ? 0 ? ? & 0 ? ? 1 ? \\ ? 1010 & ? ? ? ? ? & ? ? ? 0 ? & ? ? ? 01 & 1 ? 1 ? 0 & 01110 & 11020 & 00030 & 1 ? 000 & 0 ? 0 ? ? & 10 ? 2 ? & 00 ? 11 \\ 100 ? 0 & 01140 & 01011 & 03310 & 00121 & 00010 & 11310 & 030 ? 2 & 10143 & 00012 & 10 ? 21 & 20110 \\ ? ? 10 ? & 12000 & & & & & & & & & & \end{array}$

\section{Escavadodon}

\begin{tabular}{|c|c|c|c|c|c|c|c|c|c|c|c|}
\hline ????1 & $11 ? 1 ?$ & 22202 & 00000 & 00010 & 00110 & 21222 & $30 ? ? 1$ & 01300 & 20201 & 31021 & 10110 \\
\hline 00013 & 10011 & 01002 & 3???1 & ?0??? & ????? & ????? & ????? & ????? & ????? & ????? & ????? \\
\hline ????? & ????? & 0?0?? & ????? & ????? & ????? & ????? & ????? & ????? & ????? & ????? & ????? \\
\hline ????? & ????? & ????? & ????? & ????? & ????? & $? 1121$ & 00030 & 02011 & $0000 ?$ & $02 ? 21$ & ????1 \\
\hline 1??10 & $0 ? 120$ & $11 ? 11$ & $23 ? 10$ & 00221 & 00110 & $2 ? 410$ & $0301 ?$ & ????? & ??0?? & ?2021 & $2012 ?$ \\
\hline ?1001 & $12 ? 00$ & & & & & & & & & & \\
\hline
\end{tabular}

\section{Miacis/Vulpavus}

$\begin{array}{llllllllllll}10201 & 11110 & 20010 & 00300 & 00011 & 10010 & 11010 & 00001 & 00111 & 11100 & 01111 & 20210 \\ 00002 & 10000 & 02001 & 21011 & 30101 & 11111 & 01001 & 11010 & 10012 & 00301 & 100 ? 1 & 00000 \\ 11030 & ? 0110 & 00111 & 11002 & 21200 & ? 0000 & 11200 & 00000 & ? 1200 & 10100 & 0 ? 000 & 00010 \\ 01000 & 2 ? ? ? 0 & 2 ? 0 ? ? & ? ? ? ? ? & ? ? ? ? ? & ? 11 ? 0 & 01111 & 01031 & 12011 & 1110 ? & 01401 & 00 ? ? 1 \\ 00001 & 11020 & 00001 & 03200 & 10221 & 00001 & 20300 & 12003 & 10130 & 01213 & 12021 & 10110 \\ ? 1001 & 10 ? 00 & & & & & & & & & & \end{array}$

\section{Viverravus}

\begin{tabular}{|c|c|c|c|c|c|c|c|c|c|c|c|}
\hline ???01 & 11000 & 10010 & 00300 & 00011 & 11003 & 00010 & 20001 & 00131 & 16000 & 01110 & 20220 \\
\hline 00013 & 00000 & 24201 & 20??1 & ?0?01 & ??00? & ????? & ??01? & ??01? & ???01 & ?1??? & ????? \\
\hline ???1? & ????? & $0 ? 01 ?$ & ????? & ??100 & ?00?? & 11??? & $0 ? 012$ & ????? & 00??? & ????? & $00 ? ? 0$ \\
\hline ?1110 & $2 ? 2 ? 0$ & ????? & ???01 & 1???? & ?111? & ?1011 & 11020 & 02000 & $1110 ?$ & $0041 ?$ & ??011 \\
\hline 00011 & 11110 & $100 ? 1$ & ????0 & 11122 & 00001 & 20411 & $130 ? ?$ & ????? & ????? & ????? & ????? \\
\hline ??0? & ???? & & & & & & & & & & \\
\hline
\end{tabular}

\section{Protungulatum}

$\begin{array}{lllllllllllll}\text { ???01 } & 11,1 ? & 20100 & 10001 & 00100 & 00110 & 10221 & 00101 & 01301 & 24201 & 11230 & 10110 \\ 01012 & 02011 & 22121 & 32211 & 30201 & 2 ? ? ? ? & \text { ????? } & \text { ????0 } & \text { ????? } & \text { ????? } & \text { ????? } & \text { ????? } \\ \text { ????? } & \text { ????? } & \text { ????? } & \text { ????? } & \text { ????? } & \text { ????? } & \text { ????? } & 00010 & 010 ? ? & 0 ? 201 & \text { ??001 } & 00210 \\ \text { 1???? } & \text { ????? } & 2 ? 0 ? 1 & 023 ? ? & \text { ????? } & \text { ????? } & \text { ????? } & \text { ??010 } & 01010 & 010 ? ? & \text { ????? } & \text { ????? } \\ \text { ????? } & \text { ????? } & \text { ????? } & \text { ????? } & 00121 & 00000 & 20311 & 03001 & 10140 & 00013 & 11(10 & 20120 \\ \text { ????? } & \text { ????? } & & & & & & & & & & \end{array}$

\section{Loxolophus}

\begin{tabular}{|c|c|c|c|c|c|c|c|c|c|c|c|}
\hline 1??01 & 11110 & 20100 & 00001 & 00110 & 00000 & 10110 & 11111 & 01322 & 17101 & 21121 & 10010 \\
\hline 02213 & 02011 & 12022 & 10021 & 30101 & ?1020 & ?1011 & 11??? & ??0?1 & 0??10 & 01??? & ????? \\
\hline ??01? & ???20 & $0 ? 11 ?$ & ????? & ???00 & $200 ? ?$ & ????? & ???1? & ????? & ????? & ????? & ????? \\
\hline ????? & ????? & ????? & ????? & ????? & ????? & ???10 & $0 ? 000$ & $1 ? 000$ & 0?0?? & ????? & ???10 \\
\hline $000 ? ?$ & $1 ? 14 ?$ & ?0??? & $0 ? 10 ?$ & $0 ? 121$ & ??000 & ????1 & ??0?1 & $1014 ?$ & 00111 & ???20 & ?00?? \\
\hline ?300? & ?0?00 & & & & & & & & & & \\
\hline
\end{tabular}




\section{Arctocyon}

$\begin{array}{llllllllllll}10201 & 11110 & 20100 & 01001 & 00000 & 00000 & 10010 & 00132 & 01321 & 17201 & 31230 & 20111 \\ 12213 & 02011 & 32121 & 30101 & 30201 & 10010 & 01011 & 10010 & 20010 & 10310 & 00 ? ? ? & 0 ? ? 00 \\ 1 ? 01 ? & 0 ? 020 & 0011 ? & ? ? ? ? 2 & ? 1200 & 2000 ? & ? 1 ? ? ? & ? ? 010 & 1 ? ? ? ? & ? 0 ? ? ? & ? ? 0 ? ? & 00 ? ? 0 \\ ? 111 ? & 1 ? ? ? ? & 2 ? ? ? ? & ? ? ? 01 & 11100 & ? ? 111 & 01121 & 01030 & 11000 & 10000 & 12110 & 01 ? 11 \\ 00010 & 11110 & 10001 & 02200 & 01121 & 01001 & 20411 & 13011 & 10133 & 00111 & 10020 & 10130 \\ ? 1011 & 0 ? 000 & & & & & & & & & & \end{array}$

Pseudictops

$\begin{array}{lllllllllllll}81701 & 11100 & 21301 & 10046 & 00100 & 00202 & 30303 & 30031 & 023 ? 2 & 06002 & 41122 & 00001 \\ 00113 & 00120 & 02102 & 1 ? ? ? 1 & ? 0 ? ? ? & ? ? 0 ? ? & ? ? ? ? ? & \text { ????? } & \text { ??0?? } & \text { ??000 } & \text { ????? } & \text { ????? } \\ \text { ????? } & \text { ????? } & \text { ????? } & \text { ????? } & \text { ????? } & \text { ????? } & \text { ????? } & \text { ????? } & \text { ????? } & \text { ????? } & \text { ????? } & \text { ????? } \\ \text { ????? } & \text { ????? } & \text { ????? } & \text { ????? } & \text { ????? } & \text { ????? } & \text { ????? } & \text { ????? } & \text { ????? } & \text { ????? } & \text { ????? } & \text { ???1? } \\ \text { ????2 } & \text { ????0 } & 1 ? 111 & 03200 & 00122 & 20010 & 20110 & 02002 & 10131 & 00030 & 11023 & 20140 \\ \text { ??001 } & 1 ? ? 00 & & & & & & & & & & \end{array}$

\section{Gomphos}

$\begin{array}{lllllllllllll}90814 & 51223 & 21310 & 21107 & 00010 & 00002 & 51002 & 30132 & 02410 & 17102 & 31221 & 00000 \\ 11212 & 11122 & 02113 & 42021 & 30200 & 21001 & 0000 ? & ? 1011 & ? 10 ? 2 & 00301 & 401 ? 0 & 10 ? ? 0 \\ ? ? 00 ? & ? 0 ? 1 ? & ? ? 01 ? & 11001 & ? 1 ? 01 & 11100 & 0210 ? & 003 ? ? & ? ? ? ? ? & ? 0 ? ? ? & ? ? ? ? ? & \text { ????? } \\ ? 1 ? ? 0 & ? 0210 & 200 ? ? & ? ? ? ? 1 & 11 ? ? ? & ? 0110 & ? 0 ? ? ? & ? ? 0 ? ? & ? ? 1 ? ? & ? ? ? ? ? & ? ? ? 2 ? & ? ? ? 11 \\ ? 0 ? ? 2 & 01130 & ? ? 111 & 03210 & 02122 & 00110 & 2 ? 411 & 03012 & 10123 & 11121 & 12023 & 20131 \\ ? 0101 & 1 ? 00 ? & & & & & & & & & & \end{array}$

\section{Rhombomylus}

$\begin{array}{llllllllllll}90814 & 51224 & 21311 & 22147 & 00010 & 00111 & 51213 & 30032 & 013 ? 0 & 07022 & 41131 & 00001 \\ 11103 & 10122 & 02115 & 42211 & 30200 & 21002 & 00001 & 11011 & 11002 & 00301 & 40110 & 10110 \\ 10030 & 10122 & 00011 & 10100 & 21101 & 21100 & 02200 & 10311 & 11210 & 10120 & 32 ? 01 & 00200 \\ 01020 & 20211 & 20001 & 013 ? ? & ? 1 ? ? 1 & ? 11 ? 0 & 10011 & 00011 & 11100 & 01010 & 1111 ? & ? ? ? 10 \\ 10012 & 01120 & 10111 & 03210 & 12122 & 00110 & 1 ? 411 & 14012 & 10121 & 00111 & 12013 & 20121 \\ ? 0101 & 1 ? ? 00 & & & & & & & & & & \end{array}$

\section{Macrocranion}

$\begin{array}{lllllllllllll}31301 & 21112 & 00000 & 21003 & 00110 & 01000 & 01101 & 01111 & 01111 & 23201 & 21200 & 01111 \\ 01213 & 02011 & 01011 & 42211 & 30201 & 12011 & ? ? ? 01 & 100 ? ? & ? ? ? ? ? & 0 ? ? 00 & 41 ? ? ? & \text { ????? } \\ \text { ??00? } & ? ? ? 1 ? & 0 ? 0 ? ? & ? ? ? ? ? & ? ? ? 0 ? & 20130 & ? ? ? ? ? & ? 101 ? & \text { ????? } & ? 0 ? ? ? & 1 ? 0 ? ? & 00 ? 1 ? \\ ? 0 ? 11 & ? 00 ? 0 & ? 0 ? ? ? & ? ? ? ? ? & ? ? ? ? ? & 01100 & 1011 ? & 0 ? 02 ? & ? ? ? ? ? & ? ? ? ? ? & \text { ??01? } & 0 ? 01 ? \\ ? ? ? ? 2 & 01 ? 4 ? & 1 ? ? 01 & 3 ? 200 & 21121 & 20110 & 20011 & 03111 & 10141 & 00112 & 10013 & 10111 \\ 0 ? 001 & ? 0100 & & & & & & & & & & & \end{array}$

\section{Apheliscus}

$\begin{array}{lllllllllllll}\text { ???0? } & \text { ?1??0 } & 100 ? 0 & 22043 & 00010 & 01000 & 21200 & 21122 & 01321 & 16102 & 31121 & 01101 \\ 01214 & 02010 & 2202 ? & 32011 & 51001 & \text { ??01? } & \text { ????? } & \text { ????? } & \text { ????? } & \text { ????0 } & \text { ????? } & \text { ????? } \\ \text { ???0? } & \text { ????? } & 0 ? 0 ? ? & \text { ????? } & \text { ????? } & \text { ????? } & \text { ????? } & \text { ????? } & \text { ????? } & \text { ????? } & \text { ????? } & \text { ????? } \\ \text { ????? } & \text { ????? } & \text { ????? } & \text { ????? } & \text { ????? } & \text { ????? } & \text { ????? } & \text { ??011 } & 10010 & 1 ? 01 ? & 02 ? 2 ? & \text { ????0 } \\ 10001 & 01140 & 10110 & 33300 & 01122 & 20110 & 2 ? 411 & 04112 & 10143 & 00021 & 12023 & 2012 ? \\ \text { ????0 } & 1, ? ? ? & & & & & & & & & & \end{array}$




\section{Haplomylus}

$\begin{array}{lllllllllllll}\text { ???0? } & \text { ?1??? } & \text { ????1 } & 10031 & 00110 & 00220 & 10221 & 30121 & 01321 & 28202 & 31220 & 10111 \\ \text { 02225 } & 02010 & 22013 & 4 ? ? ? 1 & \text { ????? } & \text { ????? } & \text { ????? } & \text { ????? } & \text { ????? } & \text { ????? } & \text { ????? } & \text { ????? } \\ \text { ????? } & \text { ????? } & \text { ????? } & \text { ????? } & \text { ????? } & \text { ????? } & \text { ????? } & \text { ????? } & \text { ????? } & \text { ????? } & \text { ????? } & \text { ????? } \\ \text { ????? } & \text { ????? } & \text { ????? } & \text { ????? } & \text { ????? } & \text { ????? } & ? 1100 & 11011 & 10110 & 100 ? ? & \text { ????? } & \text { ????0 } \\ 10002 & 01040 & 1011 ? & 31300 & 01222 & 20110 & 0 ? 411 & 03112 & 10153 & 00021 & 12023 & 1012 ? \\ \text { ????0 } & 1 ? ? ? ? & & & & & & & & & & \end{array}$

\section{Paschatherium}

$\begin{array}{lllllllllllll}\text { ??30? } & 21,00 & 21201 & 11012 & 00110 & 00110 & 20002 & 40121 & 01211 & 13101 & 21102 & 00011 \\ \text { 01213 } & 02010 & 02012 & 523 ? 1 & 30111 & 2 ? ? ? ? & \text { ????? } & \text { ????? } & \text { ????? } & \text { ????? } & \text { ????? } & \text { ????? } \\ \text { ????? } & \text { ????? } & \text { ????? } & \text { ????? } & \text { ????? } & \text { ????? } & \text { ????? } & \text { ????? } & \text { ????? } & \text { ????? } & \text { ????? } & \text { ????? } \\ \text { ????? } & \text { ????? } & \text { ????? } & \text { ????? } & \text { ????? } & \text { ????? } & \text { ????? } & \text { ????? } & \text { ????? } & \text { ????? } & \text { ????? } & \text { ????? } \\ \text { ????? } & \text { ????? } & \text { ????? } & \text { ????? } & 01123 & 20110 & 21410 & 14111 & 10131 & 01001 & 12021 & 20111 \\ \text { ????? } & \text { ????? } & & & & & & & & & & \end{array}$

\section{Rhynchocyon}

$\begin{array}{llllllllllll}91700 & 41000 & 21212 & 02014 & 03010 & 00003 & 10322 & 30022 & 01320 & 19221 & 41110 & 10011 \\ 02225 & 02022 & 04212 & 42001 & 41211 & 21121 & 01101 & 01010 & 20000 & 01010 & 11000 & 01000 \\ 01020 & 11101 & 00010 & 11002 & 21000 & 21201 & 01111 & ? 1100 & 21011 & 00120 & 11 ? 0 ? & ? ? 10 ? \\ 3 ? 100 & 00111 & 21111 & 12301 & 11110 & 01111 & 11111 & 11001 & 10100 & 20000 & 12021 & 00012 \\ 10002 & 01140 & 10110 & 33201 & 21223 & 20110 & 10410 & 01112 & 10153 & 00121 & 01033 & 10141 \\ 03001 & 11000 & & & & & & & & & & \end{array}$

\section{Soricidae}

$\begin{array}{llllllllllll}61602 & 51123 & 00010 & 20004 & 01010 & 01120 & 11000 & 11112 & 31120 & 19121 & 11120 & 20120 \\ 01334 & 02010 & 33115 & 51301 & 30111 & 22221 & 11011 & 1111 ? & ? 0020 & 10100 & 63 ? 00 & ? 1 ? ? ? \\ ? 1002 & ? 0021 & 00011 & 11001 & 2 ? 010 & 203 ? 1 & 11200 & 01010 & 21200 & 00100 & 01000 & 00211 \\ 31010 & 00100 & 20100 & 01301 & 11120 & ? 2100 & 11010 & 00000 & 12000 & 00011 & 00320 & 21211 \\ 00112 & 01042 & 00001 & 30300 & 02221 & 10101 & 00410 & 00002 & 10114 & 20011 & 12010 & 00120 \\ 02020 & 10000 & & & & & & & & & & \end{array}$

\section{Echinosorex}

$\begin{array}{llllllllllll}31300 & 11112 & 20210 & 11044 & 01000 & 00000 & 10001 & 01132 & 01122 & 19102 & 21120 & 20021 \\ 00324 & 02010 & 23025 & 31201 & 40211 & 23112 & 11111 & 11110 & 00020 & 10001 & 51111 & 10111 \\ 00001 & 01010 & 01011 & 11001 & 21100 & 20001 & 01111 & 02010 & 11210 & 00000 & 11001 & 00010 \\ ? 1100 & 20000 & 10011 & 02101 & 11110 & 12110 & 11110 & 11001 & 11100 & 20000 & 11020 & 11211 \\ 00012 & 01010 & 10111 & 33301 & 12123 & 21000 & 00410 & 01002 & 10114 & 10012 & 12011 & 00110 \\ 02120 & 10000 & & & & & & & & & & \end{array}$

\section{Erinaceus}

$\begin{array}{llllllllllll}41403 & 31223 & 20210 & 22104 & 00010 & 01000 & 00321 & 01132 & 001 ? 2 & 09101 & 31220 & 20121 \\ 00324 & 02010 & 24223 & 42221 & 40110 & 23112 & 11011 & 10111 & 20100 & 11101 & 51110 & 10111 \\ 00000 & 00012 & 01011 & 11001 & 21000 & 20111 & 00111 & 01010 & 11011 & 00110 & 11001 & 00011 \\ 11010 & 20000 & 10011 & 0 ? 201 & 11110 & 12110 & 11110 & 01111 & 01000 & 21010 & 12010 & 21211 \\ 10300 & 11131 & 11001 & 33401 & 22121 & 20000 & 00110 & 01012 & 10123 & 10020 & 10020 & 10110 \\ 02020 & 00000 & & & & & & & & & & \end{array}$




\section{Onychonycteris}

$\begin{array}{lllllllllllll}2,201 & 31222 & 10010 & 2000 ? & 0001 ? & 01000 & 00000 & 01101 & 110 ? ? & \text { ????1 } & 01 ? 21 & \text { ???10 } \\ \text { 00?23 } & 12010 & 3300 ? & \text { ?20?? } & 30101 & \text { ????? } & \text { ????? } & \text { ????? } & \text { ????? } & \text { ????0 } & \text { ?1??? } & \text { ????? } \\ \text { ????? } & \text { ????? } & 0 ? ? ? ? & \text { ????? } & \text { ????? } & \text { ????? } & \text { ????? } & \text { ????? } & \text { ????? } & \text { ?0??? } & \text { ????? } & \text { ????? } \\ \text { ????? } & \text { ????? } & \text { ????? } & \text { ????? } & \text { ????? } & 02 ? 1 ? & \text { ?010? } & \text { ????? } & \text { ?20?? } & \text { ????? } & \text { ????? } & \text { ???1? } \\ \text { ????? } & \text { ??00? } & \text { ?0??1 } & 1 ? ? ? 0 & \text { ????? } & \text { ????? } & \text { ????? } & \text { ????0 } & 10 ? ? ? & 1,0 ? 2 & \text { ???2? } & \text { ??1?? } \\ \text { 1???? } & \text { ???11 } & & & & & & & & & & & \end{array}$

Icaronycteris

$\begin{array}{lllllllllllll}21701 & 11222 & 10110 & 20003 & 00010 & 00000 & 00221 & 20101 & 11011 & 22200 & 01121 & 20110 \\ 01123 & 02010 & 33014 & 00201 & 20101 & 2 ? 11 ? & \text { ????? } & \text { ????? } & \text { ????? } & \text { ???00 } & \text { ?1??? } & \text { ????? } \\ \text { ????? } & \text { ????? } & \text { ????? } & \text { ???0? } & \text { ???0? } & \text { ?0??? } & \text { ????? } & \text { ???1? } & \text { ????? } & \text { ?1??? } & \text { ????? } & \text { ????? } \\ \text { ????? } & \text { ?00?? } & \text { ????? } & \text { ????? } & \text { ????? } & 0 ? ? 1 ? & \text { ?110? } & 0 ? ? 0 ? & \text { ????? } & \text { ????? } & \text { ????? } & \text { 2?21? } \\ \text { ?1??0 } & \text { ???0? } & \text { ????1 } & \text { 0???0 } & \text { ????? } & \text { ????? } & \text { ????? } & \text { ????? } & \text { ????? } & \text { ????? } & \text { ????? } & \text { ????? } \\ \text { ????? } & \text { ???11 } & & & & & & & & & & & \end{array}$

\section{Rhinolophus}

$\begin{array}{llllllllllll}21701 & 11224 & 00010 & 22003 & 00000 & 01000 & 01000 & 00102 & 21031 & 12001 & 11210 & 20120 \\ 01332 & 02011 & 33014 & 00101 & 20101 & 1422 ? & 1 ? ? ? ? & ? 101 ? & 200 ? 2 & 00000 & 51 ? ? 0 & ? 1 ? ? ? \\ ? 0001 & ? 102 ? & 0111 ? & ? 1002 & ? ? 000 & 20000 & 0 ? 2 ? 0 & 00010 & ? 1000 & 01000 & ? 2101 & 00200 \\ 01110 & 101 ? 0 & 2 ? 011 & 01 ? 01 & 11110 & 01010 & 01101 & 00100 & 02022 & 10000 & 10210 & 21211 \\ 01200 & 11002 & 10001 & 12200 & 02222 & 20110 & 20410 & 03000 & 10123 & 20033 & 11023 & 20110 \\ 11000 & 10211 & & & & & & & & & & \end{array}$

\section{Leptacodon}

$\begin{array}{lllllllllllll}\text { ????? } & \text { ?1010 } & 10011 & 10001 & 00110 & 00010 & 11121 & 31011 & 01111 & 22200 & 11110 & 10110 \\ 00122 & 12010 & 11010 & 3010 ? & 00001 & \text { ????? } & \text { ????? } & \text { ????? } & \text { ????? } & \text { ????? } & \text { ????? } & \text { ????? } \\ \text { ????? } & \text { ????? } & \text { ????? } & \text { ????? } & \text { ????? } & \text { ????? } & \text { ????? } & \text { ????? } & \text { ????? } & \text { ????? } & \text { ????? } & \text { ????? } \\ \text { ????? } & \text { ????? } & \text { ????? } & \text { ????? } & \text { ????? } & \text { ????? } & \text { ????? } & \text { ????? } & \text { ????? } & \text { ????? } & \text { ????? } & \text { ????? } \\ \text { ????? } & \text { ????? } & \text { ????? } & \text { ????? } & \text { ????? } & \text { ????? } & \text { ????? } & \text { ????? } & \text { ????? } & \text { ????? } & \text { ????? } & \text { ????? } \\ \text { ????? } & \text { ????? } & & & & & & & & & & & \end{array}$

\section{Cryptotopos}

$\begin{array}{lllllllllllll}6 ? 602 & 31110 & 20211 & 20012 & 01110 & 01010 & 11222 & 31011 & 01111 & 23211 & 11112 & 10110 \\ 00111 & 12010 & 11015 & 31100 & 00101 & 2 ? 11 ? & \text { ????? } & ? 101 ? & \text { ????? } & \text { ???00 } & \text { ?1??? } & \text { ????? } \\ \text { ????? } & \text { ????? } & \text { ????? } & \text { ????? } & \text { ????? } & \text { ????? } & \text { ????? } & \text { ????? } & \text { ????? } & \text { ????? } & \text { ????? } & \text { ????? } \\ \text { ????? } & \text { ????? } & \text { ????? } & \text { ????? } & \text { ????? } & \text { ????? } & \text { ?0010 } & 00021 & 12021 & 11101 & 1020 ? & \text { ????1 } \\ 10101 & 11041 & 10 ? ? ? & 1320 ? & 00122 & 21100 & 20301 & 12013 & 10120 & 10202 & 01021 & 10111 \\ \text { ?3001 } & 10100 & & & & & & & & & & & \end{array}$

Tupaia

$\begin{array}{llllllllllll}51502 & 11221 & 20010 & 20003 & 00010 & 00100 & 00111 & 01112 & 31000 & 13101 & 10110 & 20010 \\ 01233 & 02012 & 02010 & 21001 & 40201 & 10010 & 01011 & 00000 & 10100 & 10101 & 02101 & 01000 \\ 01140 & 10012 & 01011 & 11103 & 11100 & 20001 & 11110 & 00112 & 21211 & 00101 & 11110 & 00200 \\ 00110 & 01010 & 21011 & 12301 & 11110 & 01110 & 00110 & 01011 & 11100 & 00000 & 11210 & 20010 \\ 00102 & 11140 & 00101 & 03000 & 22221 & 11101 & 00201 & 12012 & 10130 & 21313 & 01033 & 10141 \\ 03001 & 10100 & & & & & & & & & & \end{array}$




\section{Ptilocercus}

$\begin{array}{llllllllllll}51503 & 31221 & 20010 & 20003 & 00010 & 01000 & 01211 & 30122 & 01131 & 17011 & 11121 & 20110 \\ 01224 & 12010 & 32020 & 11000 & 40201 & 13100 & 01011 & 11110 & 10001 & 10001 & 22111 & 00100 \\ 11040 & 10010 & 11001 & 11002 & 21100 & 20011 & 01110 & 00112 & 11211 & 00101 & 11100 & 00100 \\ 00110 & 01010 & 21011 & 12301 & 11110 & 01110 & 00110 & 01031 & 12042 & 10101 & 11300 & 10111 \\ 00100 & 10121 & 10001 & 02000 & 20220 & 01111 & 10201 & 11002 & 10112 & 21303 & 01022 & 20140 \\ 03000 & 10100 & & & & & & & & & & \end{array}$

\section{Mixodectes}

$\begin{array}{lllllllllllll}\text { 4?4?4 } & 51222 & \text { ?0010 } & 00001 & 00110 & 01000 & 01300 & 10121 & 21121 & 23201 & 21110 & 10010 \\ \text { 02224 } & 02011 & 01010 & 4 ? ? ? 1 & \text { ?0?0? } & \text { 2???? } & \text { ????? } & \text { ????? } & \text { ????? } & \text { ???00 } & \text { ????? } & \text { ????? } \\ \text { ????? } & \text { ????? } & \text { ????? } & \text { ????? } & \text { ????? } & \text { ????? } & \text { ????? } & \text { ????? } & \text { ????? } & \text { ????? } & \text { ????? } & \text { ????? } \\ \text { ????? } & \text { ????? } & \text { ????? } & \text { ????? } & \text { ????? } & \text { ???1? } & \text { ????? } & \text { ???0? } & \text { ?2022 } & 1 \text { 1?100 } & 0040 ? & \text { ????? } \\ \text { 1?0?1 } & 11110 & 1000 ? & \text { ????? } & 20 ? 20 & 0 ? 000 & 20 ? ? ? & \text { ??0?2 } & 11122 & 11203 & 10131 & 02140 \\ \text { ?0?0? } & \text { ????0 } & & & & & & & & & & & \end{array}$

\section{Eudaemonema}

$\begin{array}{lllllllllllll}\text { ??4?? } & 21,12 & \text { ?0111 } & 00021 & 10110 & 01000 & 11212 & 30111 & 21221 & 23202 & 21111 & 10111 \\ \text { 01222 } & 12012 & 21012 & 4 ? ? ? ? & \text { ????? } & \text { ????? } & \text { ????? } & \text { ????? } & \text { ????? } & \text { ????0 } & \text { ????? } & \text { ????? } \\ \text { ????? } & \text { ????? } & \text { ????? } & \text { ????? } & \text { ????? } & \text { ????? } & \text { ????? } & \text { ????? } & \text { ????? } & \text { ????? } & \text { ????? } & \text { ????? } \\ \text { ????? } & \text { ????? } & \text { ????? } & \text { ????? } & \text { ????? } & \text { ????? } & \text { ????? } & \text { ????? } & \text { ????? } & \text { ????? } & \text { ????? } & \text { ????? } \\ \text { ????? } & \text { ????? } & \text { ????? } & \text { ????? } & \text { ????? } & \text { ????? } & \text { ????? } & \text { ????? } & \text { ????? } & \text { ????? } & \text { ????? } & \text { ????? } \\ \text { ????? } & \text { ????? } & & & & & & & & & & & \end{array}$

\section{Elpidophorus}

$\begin{array}{lllllllllllll}80 ? ? 2 & \text { ?1110 } & 22201 & 10018 & 10110 & 01110 & 51322 & 31101 & 21112 & 26201 & 11121 & 10101 \\ \text { 01233 } & 12010 & 31010 & 4 ? 3 ? 1 & \text { ?0?0? } & 1 ? 0 ? ? & \text { ????? } & \text { ????? } & \text { ????? } & \text { ????0 } & \text { ????? } & \text { ????? } \\ \text { ????? } & \text { ????? } & \text { ????? } & \text { ????? } & \text { ????? } & \text { ????? } & \text { ????? } & \text { ????? } & \text { ????? } & \text { ????? } & \text { ????? } & \text { ????? } \\ \text { ????? } & \text { ????? } & \text { ????? } & \text { ????? } & \text { ????? } & \text { ????? } & \text { ????? } & \text { ????? } & \text { ????? } & \text { ????? } & \text { ????? } & \text { ????? } \\ \text { ????? } & \text { ????? } & \text { ????? } & \text { ????? } & \text { ????? } & \text { ????? } & \text { ????? } & \text { ????? } & \text { ????? } & \text { ????? } & \text { ????? } & \text { ????? } \\ \text { ????? } & \text { ????? } & & & & & & & & & & & \end{array}$

\section{Plagiomene}

$\begin{array}{lllllllllllll}\text { ??702 } & 31110 & 22302 & 10128 & 10110 & 00222 & 41323 & 51111 & 30112 & 16201 & 21221 & 20200 \\ 02323 & 12010 & 31011 & 22311 & \text { ?0101 } & \text { 2?01? } & \text { ????? } & \text { ????? } & \text { ????? } & \text { ????1 } & \text { ????? } & \text { ????? } \\ \text { ????? } & \text { ????? } & \text { ???1? } & \text { ??1?3 } & \text { ???0? } & \text { ????1 } & \text { ???11 } & \text { ??11? } & \text { ??101 } & \text { ?0??? } & \text { ????? } & \text { 0???? } \\ \text { ?0?10 } & \text { ?02?0 } & \text { ????? } & \text { ????? } & \text { ????? } & \text { ????? } & \text { ????? } & \text { ????? } & \text { ????? } & \text { ????? } & \text { ????? } & \text { ????? } \\ \text { ????? } & \text { ????? } & \text { ????? } & \text { ????? } & \text { ????? } & \text { ????? } & \text { ????? } & \text { ????? } & \text { ????? } & \text { ????? } & \text { ????? } & \text { ????? } \\ \text { ????? } & \text { ????? } & & & & & & & & & & \end{array}$

\section{Cynocephalus}

$\begin{array}{llllllllllll}81703 & 41224 & 22002 & 02018 & 10010 & 00122 & 40123 & 50112 & 31020 & 10102 & 11100 & 21011 \\ 02234 & 12012 & 02010 & 50301 & 50201 & 10000 & 01001 & 11010 & 20041 & 11000 & 01011 & 00000 \\ 21130 & 00110 & 11111 & 11102 & 22000 & 00400 & 01200 & 10310 & 21110 & 00200 & 11011 & 00 ? 20 \\ 01111 & 10211 & 21011 & 01301 & 11110 & 02110 & 00101 & 01031 & 10122 & 00000 & 12010 & 21111 \\ 01110 & 11112 & 00001 & 02100 & 21120 & 02111 & 10110 & 01003 & 01122 & 21212 & 00133 & 12101 \\ 03011 & 10200 & & & & & & & & & & \end{array}$




\section{Purgatorius}

\begin{tabular}{|c|c|c|c|c|c|c|c|c|c|c|c|}
\hline $705 ? ?$ & ?1?10 & ????1 & 10003 & 00011 & 00100 & 21300 & 41021 & 01111 & 22201 & 11220 & 10110 \\
\hline 01122 & 02010 & 11111 & 3???? & ????? & ????? & ????? & ????? & ????? & ????? & ????? & ????? \\
\hline ????? & ????? & ????? & ????? & ????? & ????? & ????? & ????? & ????? & ????? & ????? & ????? \\
\hline ????? & ????? & ????? & ????? & ????? & ????? & ????? & ????? & ????? & ????? & ????? & ????? \\
\hline ????? & ????? & ????? & ????? & ????? & ????? & ????? & ????? & ????? & ????? & ????? & ????? \\
\hline ???? & ???? & & & & & & & & & & \\
\hline
\end{tabular}

Micromomyidae

$\begin{array}{lllllllllllll}704 ? 3 & 31221 & 20201 & 00001 & 10110 & 01100 & 00300 & 40122 & 01221 & 24201 & 21221 & 20110 \\ 01103 & 02010 & 10010 & 41111 & 00101 & 2 ? 00 ? & \text { ????? } & \text { ????? } & \text { ????? } & \text { ????0 } & \text { ????? } & \text { ????? } \\ \text { ???0? } & \text { ????? } & \text { ????? } & \text { ????? } & \text { ????? } & \text { ????? } & \text { ????? } & \text { ??01? } & \text { ????? } & \text { ????? } & \text { ????? } & \text { ?0??? } \\ \text { ????? } & \text { ????1 } & \text { ????? } & \text { ????? } & \text { ????? } & \text { ????? } & \text { ??010 } & 00 ? 3 ? & \text { ????2 } & \text { ????? } & \text { ????0 } & 00111 \\ \text { 00111 } & 10110 & 10001 & 1,200 & \text { ????? } & \text { ????? } & \text { ????? } & \text { ????? } & \text { ????? } & \text { ????? } & \text { ????? } & \text { ????? } \\ \text { ????? } & \text { ?0100 } & & & & & & & & & & & \end{array}$

Ignacius

$\begin{array}{lllllllllllll}704 ? 2 & 51223 & 11011 & 02004 & 01010 & 01200 & 10300 & 40112 & 01221 & 28121 & 21020 & 20100 \\ 12123 & 02012 & 00023 & 51001 & 40101 & 12000 & 10001 & 1001 ? & 00000 & 10011 & 50 ? 1 ? & ? 111 ? \\ ? 100 ? & ? ? ? 22 & 00011 & ? 0000 & ? 1000 & 2001 ? & ? ? ? ? ? & ? ? 11 ? & ? ? ? ? ? & ? 0 ? ? ? & ? ? ? ? ? & ? 1 ? ? ? \\ ? 0110 & 000 ? 1 & ? 1 ? ? ? & 0 ? ? ? 1 & ? ? ? ? ? & ? 1 ? ? ? & ? 0000 & 00030 & 12022 & 10101 & 0040 ? & 00011 \\ 00011 & 10110 & 10001 & 03200 & 21221 & 01 ? 00 & 00001 & 120 ? 3 & 10132 & 11203 & 12 ? 32 & 11121 \\ 0 ? ? ? ? & ? 0200 & & & & & & & & & & & \end{array}$

\section{Plesiadapis}

$\begin{array}{llllllllllll}70404 & 51223 & 20202 & 01013 & 00110 & 00200 & 50300 & 40122 & 21221 & 28201 & 21231 & 20010 \\ 11015 & 02010 & 10120 & 51021 & 30101 & 23202 & 01001 & 01110 & 10001 & 11301 & 0010 ? & 00110 \\ 1 ? 000 & ? 0122 & 0001 ? & 101 ? 0 & 11010 & 20001 & 01100 & 02010 & 11210 & 001 ? ? & 32111 & 11200 \\ 31110 & 01001 & 200 ? ? & ? ? 311 & 1 ? ? ? 1 & ? 11 ? ? & ? 0110 & 00030 & 12032 & 1110 ? & 01400 & 00011 \\ 10011 & 10120 & 00001 & 03200 & 21221 & 01000 & 20201 & 12003 & 10130 & 10303 & 00032 & 10142 \\ ? ? ? 01 & 0 ? 200 & & & & & & & & & & \end{array}$

\section{Cantius/Notharctus}

$\begin{array}{llllllllllll}30301 & 11110 & 20210 & 02023 & 00110 & 00000 & 10212 & 10122 & 01221 & 28202 & 21220 & 20010 \\ 11105 & 02011 & 10121 & 22021 & 00201 & 22011 & 11001 & 11111 & 10001 & 01300 & 401 ? 0 & 00 ? ? 0 \\ ? ? 040 & ? 0 ? 22 & 0000 ? & 10000 & ? 1010 & ? 0000 & 01100 & 02112 & 11211 & 00101 & ? 1 ? 11 & 11200 \\ 31110 & 01001 & 200 ? ? & ? 2311 & 111 ? ? & 01 ? ? 0 & ? 0110 & 01031 & 02042 & 11101 & 00100 & 00010 \\ 00010 & 10111 & 00011 & 01200 & 21221 & 01100 & 20201 & 10003 & 10122 & 21321 & 00032 & 21142 \\ ? 1011 & 10200 & & & & & & & & & & \end{array}$




\section{APPENDIX 3.}

\section{CHARACTER STATES AT NUMBERED NODES}

The following numbered characters and their states relate to the numbered nodes in Figure 18. Bold type indicates unequivocal synapomorphy; plain type indicates homoplasy. Square brackets enclose character states found only by ACCTRAN optimization; parentheses enclose character states found only by DELTRAN optimization.

\section{Node 1}

$7.1,11.2,13.1,46.2,52.1,53.1,65.1,66.1,78.1$ $79.1,80.1,86.1,115.1,134.1,141.1,142.1$ $146.1,153.2,169.0,175.1,178.2,179.1,194.1$, 195.1, 198.3, 200.1, 203.1, 204.1, 212.1, 219.2, 227.1, 240.1, 264.1, 284.1 [5.1, 6.1, 36.1, 44.1, $54.2,75.1,77.1,96.1,97.1,99.1,104.1,106.1$, $108.2,122.1,124.0,126.1,129.2,140.0,142.2$, 148.0, 149.1, 162.1, 163.0, 180.1, 189.1, 197.2, 199.1, 217.1, 242.1, 244.1, 245.1, 248.1, 251.1, 263.2, 276.1, 298.1] (108.3, 124.1, 263.1)

\section{Node 2}

$28.1,31.2,44.3,48.0,55.2,111.1,148.1,150.2$, 151.1, 158.2, 185.1, 271.0 [170.1, 181.1, 243.1, 250.1] (54.2, 97.1, 99.1, 106.1, 108.2, 124.0, $126.1,129.2,140.0,149.1,162.1,163.0,180.1$, 199.1, 263.2)

\section{Ukhaatherium}

$29.1,34.2,78.2,288.2[36.0,77.0,298.0]$ (5.1, $6.1,96.1,189.1,217.1,242.1,243.1,250.1$, $251.1,276.1)$

\section{Asioryctes}

43.0, 81.1, 184.1, 279.1, 290.2, 299.2 [5.0, 6.0, $96.0](75.1,77.1,142.2,170.1,181.1)$

\section{Node 3}

18.0, 20.1, 24.1, 35.1, 40.1, 42.1, 48.2, 65.2, 67.1, 221.1, 246.1, 249.1, 265.1, 277.1, 281.1, 283.1, 284.2, 287.1, 295.1, [1.1, 3.2, 8.1, 9.1, $16.1,81.3,83.1,85.1,113.1,121.1,130.0,146.2$, 161.1, 191.2, 208.1, 209.1, 233.0, 255.1, 258.2, $275.1,280.2,305.1](6.1,36.1,245.1,280.1$, 298.1)

\section{Node 5}

$39.1,45.1,47.1,247.1,264.2,271.2,273.2$, 286.0, 289.1, $294.2[47.2,63.1,213.1,215.1$, 225.0, 263.1, 276.0, 284.4] (1.1, 5.1, 8.1, 83.1, $85.1,104.1,113.1,122.1,130.0,148.0,197.2$, $255.1,258.2,284.3,305.1)$

\section{Node 6}

44.2, 73.1, 139.1, 168.0, 198.2, 204.2, 216.1, $223.1,224.0,231.0[1.4,2.1,7.0,13.0,16.0$, $23.1,31.2,80.0,97.0,99.0,101.0,116.1,126.2$, 162.0, 181.2, 205.1, 230.1, 236.1, 240.2, 244.2,
248.0, 256.3, 258.4, 263.0, 265.3, 268.1, 269.1, $272.1,275.0,285.3,304.2](54.2,63.1,75.1$, 106.1, 108.2, 140.0, 149.1, 199.1, 213.1, 215.1, $217.1,225.0)$

\section{Maelestes}

$33.0,34.0,35.0,43.0,46.1,48.1,53.0,55.2$, $78.2,83.2,103,1,105.2,111.3,138.1,144.1$, $161.3,178.0,184.2,185.1,196.1,200.0,221.0$ $[81.0,121.0,163.1,189.0,191.0,208.0,209.0]$ (3.2, 7.0, 9.1, 13.0, 23.1, 31.2, 47.2, 77.1, 80.0, $116.1,124.0,129.2,180.1,181.2,230.1,233.0)$

\section{Node 7}

$19.3,24.0,34.2,66.0,70.1,75.2,78.0,79.0$, 219.0, 220.1, 227.0 [3.0, 9.0, 47.1, 77.0, 104.2, $116.2,119.2,129.1,148.1,150.2,151.1,158.2$, $203.0,212.0,234.2](1.4,163.0,240.2,242.1$, $244.2,284.4,285.3)$

\section{Zhelestidae}

$11.1,16.1,39.2,50.1,51.1,52.0,62.1,64.2$, $71.1,72.2,76.4,81.1,83.0,85.0,112.0,175.0$, 179.0, 222.0, 241.1, 243.1, 249.0, 283.0, 296.2 $[161.0,180.0,181.0,280.1](7.0,13.0,15.1,23.1$, $31.2,80.0,96.1,124.0,251.1)$

\section{Zalambdalestidae}

$3.1,5.0,6.0,20.0,32.1,35.2,36.0,38.1,45.0$, $47.0,54.3,59.0,65.4,76.2,81.4,82.1,108.1$, 122.0, 124.2, 162.1, 198.1, 229.2, 245.2, 246.0, 284.5, 289.3, 290.0 [7.1, 13.1, 23.0, 31.1, 80.1, $96.0,251.0](2.1,101.0,104.2,116.2,119.1$, $121.1,126.2,142.2,148.1,150.2,151.1,158.2$, 161.1, 180.1, 181.2, 189.1, 191.2, 203.0, 205.1, 208.1, 209.1, 212.0, 234.2, 236.1, 256.3, 258.4, 263.0, 265.3, 268.1, 269.1, 272.1, 280.2, 304.2)

\section{Node 8 - Placentalia}

51.1, 92.1, 95.1, 114.1, 135.1, 136.1, 137.1, 141.2, 152.1, 156.0, 172.1, 183.1, 184.1, 202.1, 207.1, 239.1, 257.3, 273.3, 299.1, 302.1 [50.1, 55.0, 62.1, 67.2, 71.1, 74.1, 86.2, 106.0, 108.3, $124.1,126.0,140.2,142.1,149.0,180.0,182.1$, $188.0,192.1,199.0,242.0,249.2,306.1]$ (3.2, $9.1,16.1,47.2,81.3,96.1,99.1,146.2,162.1$, 191.2, 208.1, 209.1, 251.1, 275.1) 


\section{Node 9}

$14.1,32.1,128.1,163.2,222.2,228.1,233.2$, 276.1, 280.3, 288.2 [54.1, 75.1, 129.1, 213.0, 220.1, 225.1, 234.0, 261.1, 277.2, 284.3] (97.1, 121.1, 306.1)

Node 10

$20.0,25.1,33.0$ [34.0, 44.2, 50.0, 55.1, 62.0, $63.0,67.1,71.0,74.0,77.0,78.0,90.1,105.2$, $110.1,111.1,113.0,143.1,151.1,171.0,175.0$, $178.0,186.2,188.2,231.0,233.4,235.1,270.1$, 292.2]

\section{Node 11}

26.1, 13.0, 18.2, 35.0, 39.0, 42.0, 51.0, 58.2, $69.0,72.2,75.1[9.0,47.1,64.0](78.0)$

\section{Cimolestes magnus}

14.0, 31.2, 54.2, 75.2, 81.1 (9.0, 34.0, 44.2, 47.1, $64.0,86.2)$

\section{Node 12 - Carnivora}

$16.0,18.3,46.1,48.1,56.2,67.0,76.2$ [34.1, $44.1,86.1](110.1,151.1,182.1,186.2,215.1$, $217.1,231.0,233.4,261.1,270.1)$

\section{Miacis/Vulpavus}

$29.1,36.0,77.1,88.1,112.0,124.3,133.1,143.2$, $159.0,166.1,183.0,184.0,213.1,219.3,232.1$, 251.0, 263.2, 275.0 [9.1, 244.0, 248.0] (47.1, $64.0,90.1,105.2,111.1,113.0,140.2,171.0$, $175.0,178.0,220.1,234.0,235.1,249.2,277.2$, 292.2)

\section{Viverravus}

8.0, 11.1, 27.1, 30.3, 31.0, 32.0, 36.2, 44.3, 47.6, $48.0,55.0,59.2,65.3,66.0,71.2,72.4,73.2$, $89.0,160.2,216.1,221.0,224.0,225.0,262.1$, 265.2, 273.4, 274.1, 277.3 [64.1, 220.0, 234.1, 249.1] $(9.0,143.1,188.2,244.1,248.1)$

\section{Batodon}

$27.1,76.4(34.0,44.2)$

\section{Node 13 - Euarchonta}

$1.4,5.2,15.1,33.2,64.2,212.0,224.2,267.1$, $284.2,286.1,300.1[3.4,6.3,36.3,79.0,104.0$, $106.0,108.0,140.3,150.1,153.1,158.1,164.1$, $165.1,170.1,173.1,174.1,179.0,182.0,215.0$, 217.0, 238.1, 243.1, 250.1, 268.1, 289.0, 291.0, 302.3] $(6.2,36.4,50.1,63.1,67.2,71.1,74.1)$

\section{Node 14}

1.6, 37.1 [80.0, 81.0, 88.1, 230.1, 241.1. 244.0, $248.0,249.4,256.1,261.0,265.2,266.2,279.1$, $287.0,290.2,292.1]$

\section{Node 15 - Nyctitheriidae}

$23.1,29.1,34.2[3.6,62.0](36.3,79.0,81.0)$

\section{Leptacodon}

8.0, 11.1, 13.0, 33.1, 50.0, 83.0 [77.0] (55.0)

\section{Cryptotopos}

13.2, 16.2, 19.1, 20.2, 22.1, 27.1, 35.2, 47.3, $49.1,55.2,64.1,65.1,75.5(3.6,6.3,77.1,80.0$, 86.2, 88.1, 220.1, 230.1, 234.0, 241.1, 243.1, 249.4, 250.1, 256.1, 265.2, 266.2, 268.1, 277.2, 279.1, 287.0, 289.0, 290.2, 291.0, 292.1, 302.3)

\section{Purgatorius}

$1.7,3.5,20.3,25.1,28.1,31.2,33.3,34.0,35.0$, 39.2, 53.2, 54.2, 66.0, 73.1, 75.1 [36.4] (55.0, 62.1)

\section{Node 16}

8.2, 10.1, 38.1, 41.2, 63.2, 225.2, 261.2, 273.2, 285.2, 294.3, 299.4 [9.2, 47.3, 65.3, 70.1, 76.4, 89.0, 219.3, 227.0, 249.1, 262.1, 263.2, 265.0, 297.2] $(62.1,77.1,106.1,161.1,164.1,174.1$, $179.0,248.1)$

\section{Node 17}

$46.1,56.2,87.0,124.3,132.1,213.1,217.1$, 232.1, 258.1, 270.1, 271.1, 286.2, 295.3 [2.1, 3.2, $13.0,28.1,40.2,41.3,48.1,64.3,72.2,83.2$, $86.1,123.1,131.1,138.1,154.1,161.2,222.1$, 223.1, 226.0, 228.0, 234.1, 236.2, 245.0, 251.0, 257.2, 269.1, 277.1, 289.1] (65.1, 108.0, 140.2, 189.1, 192.1, 219.3, 220.1, 227.0, 236.1, 243.1, $268.1,291.0,302.3)$

\section{Node 18 - Scandentia}

$1.5,3.5,15.0,16.2,20.3,31.0,76.2,78.0,81.4$, $94.1,110.1,112.2,124.4,126.1,128.0,143.1$, $160.2,175.0,187.1,196.1,249.2,258.0,280.2$, 288.3, 292.1 [44.0, 244.0, 297.0] (2.1, 9.2, 13.0, 40.2, 47.3, 48.1, 72.2, 79.0, 83.2, 104.0, 150.1, 153.1, 154.1, 158.1, 165.1, 170.1, 173.1, 188.0, 263.2)

\section{Tupaia}

$6.1,32.0,33.1,36.0,37.1,43.0,45.0,52.0,58.0$, $66.0,70.2,71.0,96.0,97.0,99.0,103.1,105.0$, $108.1,114.0,117.1,121.0,130.2,141.1,151.1$, $219.1,224.0,225.0,240.0,245.2,249.4,253.1$, $262.2,266.1,271.0,277.2,279.1,284.3,285.0$ $[89.1,131.0,238.0,250.0,257.3,265.1,269.0]$ (28.1, 41.3, 44.0, 64.3, 123.1, 138.1, 140.3, $161.2,222.1,223.1,226.0,228.0,236.2,251.0$ ) 


\section{Ptilocercus}

5.3, 27.1, 39.2, 41.0, 44.3, 47.7, 48.0, 49.1, 54.2, $65.4,71.3,74.2,76.1,80.0,87.3,88.1,98.1$, $111.2,118.1,134.0,149.1,174.0,178.1,224.4$, $230.1,233.3,234.0,247.0,284.1,289.0,294.2$, 295.2, 296.2, 300.0, 305.0 [28.0, 55.1, 64.2, 70.0, $123.0,138.0,140.2,161.1,222.2,223.0,226.1$, $228.1,236.1,251.1,262.0](6.3,36.3,89.0$, 131.1, 238.1, 245.0, 250.1, 257.2, 265.0, 269.1)

\section{Node 19 - Dermoptera}

$1.8,3.7,12.2,14.0,19.1,20.8,21.1,34.2,78.3$, 163.1, $188.2[15.2,29.2,30.2,31.4,35.3,36.5$, 47.2, 60.1, 62.2, 81.5, 101.2, 104.4, 107.1, 113.0, $121.2,133.1,142.2,146.0,148.4,153.2,156.1$, $168.2,170.0,173.0,179.2,186.1,197.1,207.2$, 214.0, 215.1, 222.0, 232.2, 233.0, 237.1, 242.1, 250.2, 263.1, 267.2, 273.1, 274.1, 275.0, 276.0, 281.0, 282.1, 290.2, 293.1, 299.0, 304.1, 308.2] $(28.1,29.1,31.5,35.2,36.3)$

\section{Node 20 - Plagiomenidae}

8.1, 10.0, 13.2, 23.1, 33.3, 37.1, 45.2, 47.6, 54.2, 59.0, 71.3 [2.0, 9.1, 40.1, 48.2, 55.1, 70.0, 72.1, $77.2,79.1,83.1,89.1,155.1,164.0]$

\section{Elpidophorus}

27.1, 39.0, 46.2, 56.1, [15.1, 29.1, 30.0, 31.5, $35.2,36.3,41.2,62.1](60.1,64.3,76.4)$

\section{Plagiomene}

13.3, 18.1, 19.2, 28.2, 42.0, 51.2, 53.2, 58.2, $63.3,75.1,76.2,86.2,110.1$ [60.0, 64.2] (6.3, $15.2,29.2,30.2,31.4,35.3,36.5,41.3,62.2$, 77.2, 140.3, 150.1, 154.1, 155.1, 158.1, 164.0, 165.1)

\section{Cynocephalus}

$5.3,6.4,10.4,16.0,17.2,32.0,33.1,43.0,44.2$, $45.0,47.0,50.2,54.0,57.1,58.0,65.4,70.2$, $71.0, \quad 76.5,77.0,158.3,182.1,185.1,190.1$ $[140.2,150.0,154.0,165.0](2.1,9.2,13.0,15.2$, $29.2,30.2,31.4,35.3,36.5,40.2,41.3,48.1$, $55.0,60.1,62.2,64.3,72.2,79.0,81.5,83.2$, $89.0,101.2,104.4,107.1,113.0,121.2,123.1$, $131.1,133.1,142.2,146.0,148.4,156.1,161.2$, $168.2,179.2,186.1,197.1,207.2,214.0,215.1$, $222.0,223.1,226.0,228.0,232.2,233.0,236.2$, 237.1, 238.1, 242.1, 244.1, 245.0, 250.2, 251.0, 257.2, 262.1, 265.0, 267.2, 269.1, 273.1, 274.1, $275.0,276.0,281.0,282.1,290.2$, 293.1, 297.2, 299.0, 304.1, 308.2)

\section{Node 21}

10.2, 16.0, 23.1, 27.1, 44.2, $51.2[6.2,43.2,79.1$, $87.2,91.1,111.4,112.0,115.0,118.1,119.1$, $124.0,129.2,130.2,137.0,140.0,141.1,157.2$, 171.3, 176.1, 181.3, 189.0, 190.1, 199.1, 205.1, 220.0, 231.0, 233.4, 243.0, 250.0, 268.0, 291.1, 302.1] $(3.4,70.1,76.4)$

Node 22

6.5, 33.3, 34.0, 35.0, 39.2, $66.0[31.0,36.4](9.2$, $65.3,86.2,231.0,233.4,234.0,289.0$ )

\section{Mixodectes}

$5.4,13.0,15.0,36.1,58.0,62.2,65.4,71.0$, 219.0, 241.1, 280.2, 282.1, 293.1, 296.0, 300.0, 302.0 [43.1, 262.0] (31.0, 47.3, 55.0, 265.0, 297.2)

\section{Node 23}

1.7, 28.1, 32.0, 40.2, 41.0, 47.4, 54.2, 56.2, 63.1, $72.0,247.0[13.2,53.2,64.1,230.1,265.1,284.3$, 295.2, 297.1] (43.2, 89.0, 124.0, 190.1, 219.3, 244.1)

\section{Micromomyidae}

5.3, 6.3, 10.1, 14.0, 21.1, 64.0, 70.0, 81.0, 243.1, $256.1[55.1,158.0](13.2,31.0,53.2,238.1)$

\section{Node 24}

20.3, 47.8, 61.1, 74.2, 78.0, 177.1, 308.2 [10.3, $17.2,28.2,31.1,76.5,110.1,238.0](17.1,87.2$, $104.0,112.0,118.1,119.1,129.2,130.2,137.0$, 140.0, 188.0, 230.1, 262.1, 263.2, 295.2)

\section{Ignacius}

$11.1,12.1,13.0,20.4,22.1,23.0,39.1,48.1$, $49.2,53.0,59.0,62.2,70.2,71.0,75.3,79.0$, 81.4, 86.1, 92.0, 97.0, 101.0, 105.0, 109.1, 111.5, $117.1,149.1,214.0,271.0,273.0,292.2,299.2$ [64.2] $(10.3,17.2,28.2,55.0,76.5,91.1,108.0$, $110.1,158.1,192.1,227.0,277.2,284.3,297.1)$

\section{Node 25}

$19.1,27.0,58.0,65.5,73.1,79.2,90.1,98.1$, 107.1, 144.1, 182.1, 187.1, 213.1, 224.3, 251.0, $288.3,291.0,300.2$ [108.3, 114.0, 192.0, 227.1] (13.2, 53.2, 64.1, 153.1, 157.2, 176.1, 181.3, 199.1)

\section{Plesiadapis}

5.4, 14.0, 15.2, 31.5, 41.2, 54.3, 63.0, 70.0, 87.3, $88.2,90.2,96.0,138.1,172.2,232.1,241.1$, $249.2,285.0,287.0,306.0$ [17.1, 55.1, 91.0, $111.0,158.0,165.0,297.0](10.3,28.2,76.5$, $110.1,114.0,141.1,150.1,171.3,173.1,205.1$, $277.2,284.3)$ 


\section{Cantius/Notharctus}

1.3, 3.3, 5.1, 6.1, 8.1, 9.1, 10.0, 15.0, 19.2, 28.0, $33.2,34.1,35.2,36.1,50.2,64.0,75.1,76.2$, $77.2,81.0,83.2,89.1,100.1,106.0,124.4,134.0$, 160.2, 217.1, 220.1, 221.0, 224.4, 233.1, 240.0, 245.0, 250.1, 254.1, 257.1, 268.1, 277.0, 286.2, $289.2,290.1,296.2,304.1[110.0,150.0,284.2]$ $(17.2, \quad 55.0,91.1,111.4,115.0,158.1,165.1$, 170.1, 297.1)

\section{Eudaemonema}

$19.2,21.1,35.2,50.2,60.1,70.2,71.2,75.2$ [9.1, $55.1,65.2](36.3,43.2,47.3)$

\section{Node 26}

38.1, 66.0, 70.1, 72.2, 274.1, 277.3, 287.0 [36.0, 43.3, 47.4, 74.2, 94.1, 101.2, 115.0, 127.1, 154.1, $219.0,226.0,237.1,245.0,280.1,295.0,308.0]$ $(50.1,54.2,62.1,67.2,74.1,75.1,163.0,225.0$, 284.4)

Node 27

$63.2,65.3,224.0,227.0,273.4,279.1,285.3$, 290.2 [35.0, 47.5, 51.2, 86.1, 197.1, 262.1] (47.3, $161.1,182.1,213.1,244.1)$

\section{Node 29}

2.1, 76.4, 90.1, 108.0, 124.0, 130.1, 211.1, 246.0, 256.2, 268.1, 269.1 [14.1, 32.1, 34.0, 43.1, 47.3, $71.0,74.1,87.2,121.0,132.1,140.1,217.0$, 222.2, 275.0, 295.1] (115.0, 197.1, 233.0, 249.2, 306.1)

\section{Node 36}

$67.1,214.2,258.3[36.4,38.0,55.1,62.0,75.2$, $101.1,104.0,111.1,143.1,150.1,152.0,156.1$, 169.1, 196.1, 234.2, 235.1, 237.0, 241.1, 252.1, $254.1,259.1,262.0,272.1,280.2,296.2,307.2]$ $(32.1,192.1)$

\section{Node 38}

$3.3,29.1,63.1,66.1,74.0,86.2,89.2,219.3$ $[16.0,20.0,34.1,88.2,94.0,107.1](62.0,75.2$, $77.1,150.1,156.1,234.2,241.1,248.1,254.1$, $259.1,275.0,280.2,296.2,307.2)$

\section{Node 39}

$12.1,13.2,15.2,31.2,34.2,35.2,36.3,43.2$, 232.2, $292.2[1.3,8.0,14.0,28.1,33.2,38.1$, $47.2,72.1,87.1,129.1,132.0,153.1,210.1$, 221.0, 231.0, 253.1, 287.1, 289.2, 290.1, 300.1] $(51.2,215.1,235.1)$

\section{Node 40}

$20.2,23.1,59.0,70.0,212.0,217.1,245.2[6.2$, $16.1,44.2,73.1,214.1,216.1,222.1,223.1$, 226.1, 252.0, 256.3, 265.2] (1.3, 104.0, 153.1, 189.1, 253.1, 287.1)

Node 42

$9.0,266.1,278.1[5.0,19.2,33.1,88.0,124.2$, $126.1,128.1,147.1,148.1,152.1,164.1,169.2$, 179.0, 184.0, 188.1, 190.1, 220.1, 221.1, 229.1, 231.1, 240.0, 256.1, 258.2, 262.1, 266.1, 272.0, $284.3,285.1,307.0](8.0,19.1)$

\section{Node 43}

$31.3[6.1,77.0,81.1,267.1,269.2,270.3,271.0$, 273.1, 277.0, 280.0, 281.0, 282.4, 304.1] (19.2, $44.2,47.2,72.1,73.1)$

\section{Gypsonictops}

7.0, 16.0, 31.4, 35.3, 51.1, 55.2, 71.1 [28.0] (77.0, 81.1)

\section{Fordonia}

21.1, 36.4, 38.0, 58.0, 63.0, 66.0, 67.0 (28.1, $267.1,269.2,270.3,271.0,273.1,277.0,280.0$, $281.0,282.4,304.1)$

\section{Node 44}

34.1, 62.1, 74.1, 77.2, [44.1, 47.3, 72.2, 73.0, 76.5, 78.0, 266.2, 277.4] (6.2, 97.1, 214.1, 290.1, $300.1)$

\section{Leptictidium}

2.0, 12.0, 27.1, 31.0, 41.2, 49.1, 55.0, 56.2, 63.0, $64.2,72.3,75.4,79.2,81.4,88.1,133.1,248.0$, $251.0,257.1,294.1,295.0,306.0$ [28.0, 308.1] $(5.0,19.2,76.5,78.0,124.2,216.1,256.1,258.2$, $289.2,307.0)$

Node 45

$15.1,17.1,34.0,39.2,46.1,48.1,56.0,60.1,66.0$ $[1.9,19.1,32.0,58.0,63.2,67.2,89.1,219.1$, $259.0,307.1](262.1,265.2,266.2,277.4)$

\section{Node 46}

29.0, 33.2, 43.3, 50.2, 51.3, 287.0, 295.3, 299.2 $[3.7,14.1,19.4,23.0,40.2,47.6,76.4,83.2$, 275.1] $(1.9,3.8,19.0,47.7,126.1,128.1,147.1$, $164.1,169.2,179.0,219.1,220.1,289.2,308.0)$

\section{Node 47 - Anagalida}

8.1, 13.3, 20.6, 39.3, 68.1, 69.2, 73.1, 256.0, $278.0[5.1,30.2,35.3,38.0,42.2,46.0,48.0$, 51.4, 63.1, 67.0, 85.0, 89.0, 92.0, 100.1, 102.1, $105.2,107.0,111.4,112.0,116.1,118.1,119.1$, $121.1,122.0,127.0,130.2,145.1,150.0,152.2$, 
$154.0,158.3,160.1,163.2,166.1,171.3,172.2$, $183.0,164.2,186.2,188.2,192.0,194.0,196.0$, 205.1, 210.0, 213.0, 216.0, 217.0, 226.0, 227.1, $232.1,233.1,302.0](30.1,58.0,258.2,284.3)$

\section{Pseudictops}

$1.8,6.1,17.0,24.0,28.2,31.3,33.3,45.2,55.2$, $62.0,74.0,76.1,262.0,268.0,273.1,277.2$, $279.0,289.3,290.0,292.1,299.4,300.0$ [14.0, $23.1,40.1,275.0](3.7,19.4,30.2,32.0,35.3$, $38.0,42.2$, 46.0, 47.6, 48.0, 51.4, 67.0, 259.0, 285.1)

\section{Node 48 - Glires}

2.0, 4.1, 5.4, 6.5, 8.2, 9.2, 10.3, 16.2, 18.1, 20.7, $31.5,45.0,61.1,66.1,70.2,75.5,108.3,110.1$, 262.2, 266.0, 284.2, 288.1, 303.1 [3.8, 32.1, 47.7, 259.1] (14.1, 23.0, 40.2, 83.2, 85.0, 89.0, 92.0, $100.1,102.1,105.2,111.4,112.0,116.1,145.1$, $148.1,150.0,152.2,158.3,188.2,192.0,223.1$, $275.1,302.0)$

\section{Gomphos}

$15.0,33.0,43.4,53.2,60.0,63.2,65.2,75.3$, 79.2, 146.1, 156.0, 207.0, 249.3, 277.3, 286.1, 287.1299 .3 [19.0, 28.0, 35.2, 38.1, 46.1, 48.1, $51.3,67.1,124.0,190.0,240.1,285.3]$ (30.2, $42.2,78.0$ )

\section{Rhombomylus}

$10.4,17.2,29.1,34.1,49.2,54.3,64.0,78.2$, $90.2,124.3,129.2,137.0,138.1,140.0,153.2$, 234.1, 261.1, 271.1, 276.1, 289.1, 294.1 [30.1, 42.1] $(19.4,28.1,35.3,38.0,46.0,48.0,51.4$, $67.0,118.1,119.1,121.1,122.0,130.2,143.1$, $160.1,163.2,166.1,171.3,172.2,183.0,184.2$, 186.2, 190.1, 194.0, 205.1, 213.0, 217.0, 226.0, $227.1,229.1,232.1,233.1,240.0,285.1)$

\section{Node 49 - Macroscelidea}

$44.2,65.4,82.1,222.0,244.0,249.4,255.0$, $256.3[6.4,17.2,20.3,28.0,35.1,58.1,71.2$, $93.1,96.0,101.2,105.0,109.1,113.0,114.0$, $117.1,129.0,135.0,140.2,143.0,148.2,155.1$, $157.1,158.1,159.0,161.2,165.1,178.1,181.3$, 193.1, 197.2, 212.1, 224.1, 258.3, 284.4, 285.3, $302.3,305.0](20.1,63.2,67.2,78.0,259.0)$

\section{Apheliscus}

$11.1,12.0,13.0,15.0,16.2,27.1,35.0,36.2$, $37.1,57.1,74.2,76.3,81.5,83.0,231.0,245.1$ $[32.1,124.0,223.0](17.2,19.4,20.3,23.0,40.2$, $47.6,71.2,89.1,224.1,229.1,240.0,275.1$, 305.0)

\section{Node 50}

$31.1,34.2,48.2,55.0,56.1,59.1,62.2,64.2$, 65.5, 263.2, 271.1, 277.3, 284.5, 296.1 [19.0, $79.0,81.4,84.1,88.1,89.2,229.0](32.0)$

\section{Haplomylus}

$17.0,19.3,28.2,29.2,46.2,47.8,53.2,75.3$, 214.0, 215.0, 248.0, 257.1, 271.0 [20.1, 23.1, 40.1] $(35.1,71.2,224.1,240.0,275.1,305.0)$

\section{Rhynchocyon}

$15.2,16.0,19.1,20.4,22.3,30.3,33.3,38.0$, $45.0,47.9,49.2,50.1,51.4,54.1,58.0,69.2$, $70.2,72.4,73.2,219.0,226.2,240.2,258.2$, 260.1, 261.2, 265.3, 277.1, 288.1, 291.0, 292.1, $294.3,299.4$ [35.2, 71.0, 224.0, 275.0, 305.1] $(3.7,5.0,6.4,14.1,17.2,23.0,40.2,79.0,81.4$, 83.2, 84.1, 88.1, 93.1, 96.0, 101.2, 105.0, 107.1, $109.1,111.1,113.0,114.0,117.1,124.2,127.1$, $129.0,135.0,140.2,148.2,154.1,155.1,157.1$, 158.1, 159.0, 161.2, 165.1, 178.1, 181.3, 184.0, $190.1,193.1,196.1,197.2,210.1,302.3,307.1)$

\section{Paschatherium}

33.0, 36.4, 54.0, 55.2, 58.0, 59.1, 78.3, 84.1, 265.3, 272.1, 276.1, 280.1, 289.0 (28.1, 32.0, $63.2,67.2,76.5,284.3,285.1)$

\section{Node 41 - Leptictidae}

$30.3,46.1,55.2,207.2,213.0,279.0,296.1$, 303.1 [94.1, 108.1, 125.1, 138.1, 149.1, 169.0, $237.1,280.3,284.5](6.2,33.2,44.2,73.1,88.2)$

\section{Prodiacodon/Palaeictops}

12.2, 13.3, 16.2, 21.1, 37.1, 39.0, 43.1, 51.1, $62.1,81.0,90.0,209.0,215.0,222.2,234.1$, 241.0, 242.1, 244.0, 248.0, 249.4, 265.3, 296.0 $[8.1,216.0,223.0,256.2](28.1,47.2,72.1,97.1$, 214.1, 221.0, 231.0, 272.1, 289.3, 284.5, 290.1, 300.1)

\section{Leptictis}

$13.1,29.0,31.1,33.3,36.2,38.0,39.2,40.2$, $43.3,47.5,48.0,54.1,75.1,76.2,81.4,83.2$, $106.1,131.1,144.1,235.0,236.1,240.2,249.1$, 263.2, 286.1, 299.2 [28.0, 72.2, 97.0, 214.2, 265.1, 290.2, 300.0] (8.0, 94.1, 107.1, 108.1, $111.1,125.1,127.1,138.1,143.1,149.1,152.0$, 154.1, 188.0, 196.1, 210.1, 216.1, 223.1, 237.1, 256.3)

\section{Escavadodon}

$12.2,43.3,44.0,45.0,47.0,51.3,53.0,63.0$, 67.0, 76.3, 224.1, 225.1, 263.2, $299.2(16.0,20.0$, $28.1,33.2,72.1,221.0,222.2,226.0,231.0$, 245.0, 252.1) 


\section{Palaeosinopa}

$11.1,33.0,36.0,39.2,53.2,54.3,56.2,58.2$, $76.5,81.4,83.2,112.0,121.1,130.2,145.1$, $165.1,168.0,170.1,183.0,194.0,213.0,249.4$, 251.0, 256.0, 268.0, 271.1, 273.3, 303.1 [51.1, $97.0,215.0](14.1,16.0,20.0,35.0,38.0,87.2$, $88.2,129.2,132.1,152.0,169.1,226.0,245.0$, $252.1,272.1,308.0)$

\section{Node 37 - Pentacodontidae}

$17.2,20.2,50.0[8.2,77.0,78.0,105.0,106.1$, 265.3] $(14.1,34.0,36.4,38.0)$

\section{Aphronorus}

$9.2,15.1,16.2,21.1,23.1,27.1,31.0,33.0,36.3$, $40.2,44.0,55.2,60.1,64.0,70.2,72.1,75.0,76.5$ $[35.1,62.1](8.2,51.2,78.0,94.1,105.0,106.1$, 219.0, 265.3)

\section{Coriphagus}

13.0, 25.1, 40.0, 54.3, 55.0, 56.2, 59.2, 67.0, $74.2,81.0,83.0$ [51.1] $(35.0,62.0,75.2)$

\section{Node 30}

$6.2,10.2,11.1,13.0,16.2,20.3,27.1,37.1,111.4$, 256.3, 266.2, 295.3 [31.0, 78.2, 91.1, 104.2, $116.1,117.1,118.1,119.1,120.1,122.0,125.1$, 157.1, 189.0, 192.0, 226.1, 245.2, 248.0, 250.2, 294.1, 308.1] (34.0, 36.0, 77.1, 87.2, 262.1)

\section{Macrocranion}

$1.3,3.3,11.0,17.1,23.1,53.2,54.0,56.0,57.1$, $60.1,72.1,77.2,83.2,148.1,182.0,185.1,209.0$, 212.0, 249.4, 261.2, 273.0, 278.1, 285.1, 288.1, 300.1 [14.0, 35.1, 94.0, 97.0, 129.1, 219.2, 275.1] (31.0, 32.1, 51.2, 55.0, 78.2, 157.1, 188.0, 245.2, 294.1)

\section{Node 31}

9.2, 33.0, 56.2, 64.2, 70.0, 72.3, 75.5, 79.0, 88.1, 111.5, 236.2, 238.2, 262.2, 279.0, 284.2, 286.1, 305.0 [32.0, 41.1, 46.1, 48.1, 51.1, 63.3, 71.3, 86.2, 207.2, 263.2, 292.1] (14.1, 71.1, 91.1, 97.1, 219.0, 237.1, 250.1, 275.0)

\section{Node 32 - Lipotyphla}

20.4, 40.2, 44.2, 47.9, 59.2, 65.4, 84.1, 98.1, 105.0, 106.1, 150.1, 181.1, 258.3, 269.0, 271.0, 280.2, 295.0, 302.2, 304.2, 308.0 [1.4, 3.4, 5.2, 10.3, 22.1, 31.1, 73.1, 108.1, 127.0, 163.2, 180.1, 183.0, 206.1, 215.0, 229.1, 234.2, 277.0, 284.1, 285.4, 290.1, 292.2, 296.0] (46.1, 48.1, 55.0, $63.3,78.2,86.2,94.1,157.1,207.2)$

\section{Soricidae}

$1.6,3.6,6.5,11.0,28.1,29.2,32.1,36.1,41.3$, $45.0,49.2,64.3,76.5,78.3,88.2,89.2,111.6$, $112.3,114.0,125.2,144.1,148.3,151.1,161.2$, 171.0, 175.0, 181.3, 193.1, 194.0, 195.0, 204.2, 209.0, 213.0, 226.0, 230.1, 231.0, 233.3, 243.1, 249.4, 251.0, 257.0, 266.1, 270.1, 286.2, 299.2 [122.1, 132.0, 154.0, 188.1] $(5.2,10.3,22.1,35.0$, 71.3, 73.1, 104.2, 108.1, 117.1, 129.2, 163.2, 180.1 , 183.0, 222.2, 229.1, 234.2, 245.2, 250.2, 263.2, 277.0, 284.1, 285.4, 290.1, 292.2, 294.1, 296.0)

\section{Node 33 - Erinaceidae}

$11.2,13.2,17.1,39.3,45.2,51.2,60.1,62.0$, $71.2,74.2,81.4,87.3,90.2,110.1,153.1,155.1$, 164.1, 178.0, 186.2, 191.1, 217.1, 220.1, 226.2, 232.1, 260.1, 261.1, 268.0, 277.1 [5.3, 35.1, 41.0, $117.0,129.1,197.2,198.1,222.1,250.1,263.1]$ (5.0, 116.1, 118.1, 119.1, 120.1, 122.0, 132.1, 154.1, 188.0, 206.1)

\section{Echinosorex}

$1.3,3.3,6.1,9.1,16.1,19.4,24.0,27.0,50.2$, 58.0, 76.3, 83.2, 93.1, 101.0, 115.1, 127.1, 130.0, 143.1, 157.2, 168.0, 184.0, 216.1, 223.1, 236.1, 249.1, 250.0, 253.1, 254.1, 265.3, 267.1, 295.1, 303.1 [5.0, 10.2, 73.0, 108.0, 180.0, 183.1, 229.0, 290.2] (22.1, 104.2, 125.1, 163.2, 197.2, 198.1, 234.2, 245.2, 284.1, 285.4, 292.2, 294.1, 296.0)

\section{Erinaceus}

$6.3,8.2,17.2,18.1,31.0,33.3,34.2,42.0,46.0$, $51.3,53.2,72.4,73.2,75.3,77.2,79.2,85.0$, $97.0,100.1,103.1,104.0,107.1,130.2,148.1$, $149.1,152.0,165.1,169.1,198.2,218.1,219.1$, 221.0, 227.1, 232.2, 241.1, 243.3, 244.0, 245.0, $246.1,248.1,249.3,252.1,258.4,261.2,273.1$, $279.1,289.2,290.0,306.0$ [22.0, 125.0, 163.0, 234.1, 284.2, 285.3, 292.0, 294.2, 296.1] (1.4, $3.4,5.3,10.3,101.2,108.1,180.1,183.0,229.1)$

\section{Node 34 - Chiroptera}

$1.2,8.2,39.0,43.0,214.0,249.0,256.1,280.0$, $301.1,309.1,310.1[47.2,51.0,55.1,75.4$, 76.0, 78.1, 87.4, 105.2, 133.1, 140.2, 157.0, $168.0,172.2,173.1,179.0,186.1,208.0,211.0$, 218.1, 221.0, 224.2, 225.2, 233.2, 242.1, 243.2, 244.0, 245.0, 246.1, 257.2, 265.2, 289.3, 294.2, 296.2, 308.2] $(31.0,41.1,71.3,222.2)$

\section{Onychonycteris}

$6.3,62.0,66.1,74.0,77.2,78.0,212.0$ (35.0, $51.0,207.2)$ 
Node 35

3.7, 6.1, 37.0, 77.0, 81.2, 167.1 [207.1, 286.2, 290.3] $(47.2,75.4,76.0,242.1,245.0)$

\section{Icaronycteris}

$13.1,27.0,33.2,34.2,36.2,50.0,63.1,78.2$, $256.0[35.1,46.2,48.2](51.0,86.2,188.0)$

\section{Rhinolophus}

$10.4,11.0,17.2,24.0,32.1,40.2,41.2,44.3$, $48.0,53.2,54.1,55.0,59.2,64.3,65.2,70.1$, 88.2, 89.2 [51.1, 86.1, 188.1] $(35.0,46.1,63.3$, $87.4,101.2,105.2,117.1,122.0,125.1,127.1$, $129.2,132.1,133.1,140.2,168.0,172.2,173.1$, 179.0, 186.1, 208.0, 211.0, 215.1, 218.1, 221.0, 224.2, 225.2, 233.2, 243.2, 244.0, 246.1, 250.2, 257.2, 263.2, 265.2, 286.2, 289.3, 290.3, 292.1, $296.2,308.2)$

\section{Node 28}

16.0, 44.2, 46.1, 47.7, 62.2, 109.1, 133.1, 288.1, 290.1 [77.0, 143.2, 186.1, 204.0, 210.1, 232.2, 233.1, 257.2, 267.1, 276.1, 299.3, 306.0] (35.0, $43.3,51.2,71.1,74.2,94.1,129.2,248.1,295.0)$

\section{Loxolophus}

$23.1,37.1,45.2,48.1,58.0,75.2,76.1,78.0$, 79.2, 89.2, 240.0, 249.4, 258.1, 298.0, 302.3 $[36.1,55.1,215.0](97.1,219.0,226.0)$

\section{Arctocyon}

$17.1,24.0,33.0,39.3,40.2,51.3,53.2,54.3$, $56.2,60.1,61.1,71.3,73.1,79.0,83.2,87.0$, 105.0, 106.1, 112.0, 214.2, 219.3, 270.1, 284.3, 304.1 [97.0, 226.1, 249.1] (36.0, 55.0, 101.2, 121.1, 140.2, 143.2, 186.1, 204.0, 210.1, 215.1, 217.1, 232.2, 237.1, 245.0, 257.2, 262.1, 267.1, $276.1,299.3,308.0)$

\section{Protungulatum}

$23.1,24.0,28.1,29.1,33.2,34.2,39.0,44.0$, 53.2, 54.3, 71.2, 73.1, 77.2, 78.2, 83.2, 168.2, $170.1,181.1,219.1,221.0,292.1,294.1,296.2$, 299.2 [63.0, 161.0] (36.0, 43.3, 47.4, 55.0, 74.2, $86.2,226.0,295.0)$

\section{Node 4 - Adapisoriculidae}

$38.1,56.2,222.2,225.2,273.1,299.2$ [16.2, 19.1, 20.3, 54.1, 75.0, 76.5, 217.0, 251.0] (263.2, $275.1,276.1)$

\section{Deccanolestes}

$33.0,34.0,55.0$ [9.0] (280.2)

\section{Afrodon/Bustylus}

33.2, 36.4, 52.0, $74.1(9.1,16.2,19.1,20.3,76.5$, 248.1) 